\title{
Análise e restauração de vídeos de Microscopia Eletrônica de Baixa Energia
}

\author{
Welinton Andrey Contato
}



Data de Depósito:

Assinatura:

Welinton Andrey Contato

\title{
Análise e restauração de vídeos de Microscopia Eletrônica de Baixa Energia
}

\author{
Dissertação apresentada ao Instituto de Ciências \\ Matemáticas e de Computação - ICMC-USP, \\ como parte dos requisitos para obtenção do título \\ de Mestre em Ciências - Ciências de Computação e \\ Matemática Computacional. VERSÃO REVISADA \\ Área de Concentração: Ciências de Computação e \\ Matemática Computacional \\ Orientador: Prof. Dr. João do Espírito Santo \\ Batista Neto \\ Coorientador: Prof. Dr. Moacir Antonelli Ponti
}




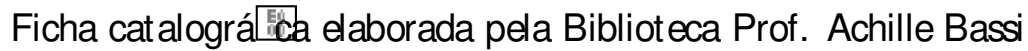
e Seção Técnica de Informática, ICMC/ USP, com os dados fornecidos pelo(a) autor(a)

Contato, Welinton Andrey
Análise e restauração de vídeos de Microscopia
Eletrônica de Baixa Energia / Welinton
Andrey Contato; orientador João do Espírito Santo
Batista Neto; coorientador Moacir Antonelli Ponti. -
São Carlos - SP, 2016.
105 p.
Dissertação (Mestrado - Programa de Pós-Graduação
em Ciências de Computação e Matemática Computacional)
- Instituto de Ciências Matemáticas e de Computação,
Universidade de São Paulo, 2016.
1. Microscopia Eletrônica de Baixa Energia.
2. Remoção de ruídos em vídeos. 3. Redução
de borramento em vídeos. 4. Non-Local Means.
5. Filtragem não local. I. Neto, João do Espírito
Santo Batista, orient. II. Ponti, Moacir Antonelli,
coorient. III. Título.


Welinton Andrey Contato

\title{
Analysis and video restoration of Low Energy Electron Microscopy
}

\author{
Master dissertation submitted to the Instituto de \\ Ciências Matemáticas e de Computação - ICMC- \\ USP, in partial fulfillment of the requirements for the \\ degree of the Master Program in Computer Science \\ and Computational Mathematics. FINAL VERSION \\ Concentration Area: Computer Science and \\ Computational Mathematics
}

Advisor: Prof. Dr. João do Espírito Santo Batista Neto Co-advisor: Prof. Dr. Moacir Antonelli Ponti

USP - São Carlos

November 2016 

Este trabalho é dedicado aos meu pais. 

Em primeiro lugar agradeço ao professor Dr. João do Espírito Santo Batista Neto, pela oportunidade e por todo o apoio e orientação, não somente no projeto como nas di sciplinas e na amizade. Agradeço também ao professor Dr. Moacir Antonelli Ponti, pela co-orientação, por todas discussões e aj uda na disciplina de Processamento de Imagens e em meu trabalho.

Obrigado a toda mi nha família e amigos que sempre me incentivaram a buscar novos desafios. Aos meus pais, pelo amor incondicional e que sempre fizeram de tudo por mim e por meu irmão.

A minha noiva e amiga, Bianca Dawis Vinaud, por todo amor e toda compreensão nos momentos mais complicados.

A todos os mestrandos e doutorandos do VICG. Por todas as conversas, discussões e pelo café. Agradeço a amizade do Fábio, Gabriel, Gabriel a e Tiago. Muito obrigado pelas ajudas nos trabal hos e principalmente nos momentos de descontração. A amizade de vocês jamais será esquecida.

Agradeço, também, àqueles que me deram uma base para poder chegar aqui. Aos meus prof essores do ensino médio, principal mente a Rita Parzewski e a Rose Parzewski. Aos meus mestres da graduação: Ana Cláudia Nery Salomão, André Curvello, Cacildo José Devós, Claudia Vicci Amadeu, Ely Prado, Fabiano Magrin da Costa Vieira, Fernando Orsi, Heitor Cunha e Jovander Silva Freitas. O conhecimento que vocês me passaram foi essencial para chegar aqui.

Agradeço a Deus, por todas oportunidades dada em minha vida e por col ocar em meu caminho todos acima citados.

Final mente, agradeço à FAPESP pelo auxílio financeiro concedido através do processo $n^{0} 2014 / 21888-2$. 

" The cave you fear to enter, holds the treasure you sedk." (Joseph Campbell)

"Humanity's deepest desire for knowledge is justification enough for our continuing quest."

(Stephen Hawking) 



\section{RESUMO}

CONTATO, W. A.. Análise e restaur ação de vídeos de Microscopia Eletrônica de Baixa Energia. 2016. 105 f. Dissertação (Mestrado em Ciências - Ciências de Computação e Matemática Computacional) - Insti tuto de Ciências Matemáticas e de Computação (ICMC/USP), São Carlos-SP.

A Microscopia Eletrônica de Baixa Energia (LEEM) é uma recente e poderosa modalidade para o estudo de superfície passível de uma grande quantidade de degradações, como ruídos e borramento. Ainda incipiente na literatura, este trabal ho visou a análise e identificação das fontes de degradações presentes em vídeos, a lém da utilização de um conjunto de técnicas de remoção de ruído e borramento para a restauração de dados LEEM. Além disso, foram desenvolvidas duas novas técnicas de filtragem de vídeo com o intuito de preservar detal hes pequenos e texturas presentes. Na etapa de análise foi constatado que as imagens LEEM possuem uma grande quanti dade e variedade de ruídos, sendo o Gaussiano o mais preponderante. Foi também estimada a Função de Espal hamento de Ponto (PSF) do microscópio utilizado, visando o emprego de técni cas de redução de borramento. Este trabal ho também analisou a combi nação de técnicas de redução de borramento com as técnicas de filtragem do ruído Gaussiano existente. Foi constatado que as técnicas não locais, como Non-Local Means (NLM) e Block-Matching 3-D (BM3D), proveem uma mai or capacidade de filtragem das imagens $L E E M$, preservando descontinuidades. Ainda nesta análise, identificou-se que algumas técnicas de redução de borramento não são efetivas em imagens LEEM, exceto a técnica Richardson-Lucy $(R L)$ que suprimi u grande parte do borramento sem adicionar mais degradação. A indesejável remoção de pequenas estruturas e texturas pelas técnicas de filtragem existentes motivou o desenvolvimento de duas novas técnicas de filtragem de ruído Gaussiano (NLM3D-LBP-MSB e NLM3D-LBP-Adaptive) que mostraram resultados superiores para filtragem de imagens com grande quantidade de textura. Porém, em imagens com muitas regiões homogêneas o BM3D foi superior. Avaliações quantitativas foram realizadas sobre imagens artificiais. Em imagens LEEM reais, realizou-se um experimento qual itativo em que observadores aval iaram visual mente o resultado de restaurações por diversas técnicas existentes e as propostas neste trabalho. O experimento comprovou que os métodos de filtragem não locais foram superiores, principal mente quando combinados com o método RL. Os métodos propostos produzi ram bons resultados, entretanto, inferiores aos exibidos pelas técni cas NLM eBM3D. Este trabal ho demonstrou que as técnicas de filtragem não locais são as mais adequadas para dados $L E E M$. Além disso, a técnica $R L$ mostrou-se eficaz na redução de borramento.

Palavr as-chave: Microscopia Eletrônica de Baixa Energia, Remoção de ruídos em vídeos, Redução de borramento em vídeos, Non-Local Means, Filtragem não local . 



\section{ABSTRACT}

CONTATO, W. A.. Análise e restaur ação de vídeos de Microscopia Eletrônica de Baixa Energia. 2016. 105 f. Dissertação (Mestrado em Ciências - Ciências de Computação e Matemática Computacional) - Instituto de Ciências Matemáticas e de Computação (ICMC/USP), São Carlos-SP.

Low Energy Electronic Microscopy (LEEM) is a recent and powerful surface science image modal ity prone to considerable amounts of degradations, such as noise and blurring. Still not fully addressed in the literature, this worked ai med at analysing and identifying the sources of degradation in LEEM videos, as well as the adequacy of existing noise reduction and deblurring techniques for LEEM data. This work also presented two new noise reduction techniques ai med at preserving texture and small details. Our analysis has reveal ed that LEEM images exhibit a large amount and variety of noises, with Gaussian noise being the most frequent. To handle the deblurring issue, the Point Spread Function (PSF) for the microscope used in the experiments has al so been estimated. This work has al so studied the combination of deblurring and denoising techniques for Gaussian noise. Results have shown that non-local techniques such as Non-Local Means (NLM) and Block-Matching 3-D (BM3D) are more adequate for filtering LEEM images, while preserving discontinuities. We have also shown that some deblurring techniques are not suitable for LEEM images, except the Richardson-Lucy (RL) approach which coped with most of the blur without the addition of extra degradation. The undesirable removal of small structures and texture by the existing denoising techniques encouraged the development of two novel Gaussian denoising techniques (NLM3D-LBP-MSB and NLM3D-LBP-Adaptive) which exhibited good results for images with a large amount of texture. However, BM3D was superior for images with large homogeneous regions. Quantitative experiments have been carried out for synthetic images. For real LEEM images, a qualitative analysis has been conducted in which observers visually assessed restoration results for existing techniques and al so the two proposed ones. This experiment has shown that non-local denoising methods were superior, especially when combined with the $R L$ method. The proposed methods produced good results, but were outperformed by NLM and BM3D. This work has shown that non-local denoising techniques are more adequate for LEEM data. Also, the RL technique is very efficient for deblurring purposes.

Key-words: Low Energy Electron Microscopy, Video denoise, Video deblur, Non-Local Means, Non-local denoising. 



\section{LISTA DE ILUSTRAÇÕES}

Figura 1 - Imagens de estruturas de superfícies de vídeos . . . . . . . . . . . . . 3

Figura 2 - Microscópio El etrônico de Varredura . . . . . . . . . . . . . . . . 7

Figura 3 - Esquema típico do aparato experimental LEED. . . . . . . . . . . . . . . . 9

Figura 4 - Padrão LEED . . . . . . . . . . . . . . . . . . . . . . . . . . . 11

Figura 5 - Microscópio LEEM e suas partes constituintes . . . . . . . . . . . . . . . . 12

Figura 6 - Diagrama do microscópio LEEM . . . . . . . . . . . . . . . . . . . . 12

Figura 7 - Gotículas de Gálio em movimento . . . . . . . . . . . . . . . . . . . . 14

Figura 8 - Exemplo de imagens PEEM . . . . . . . . . . . . . . . . . . . . 15

Figura 9 - Exemplo de imagens SPLEEM . . . . . . . . . . . . . . . . . 16

Figura 10 - Processo de aqui sição e restauração de imagem . . . . . . . . . . . . . . . 19

Figura 11 - Exemplo filtragem bilateral . . . . . . . . . . . . . . . . . . . . . . 24

Figura 12 - Esquema do NL-M eans. . . . . . . . . . . . . . . . . . . . . . . . . . . 27

Figura 13 - Exemplo da janel a de busca e dos patches da vizinhança. . . . . . . . . . . 27

Figura 14 - Diagrama BM3D. . . . . . . . . . . . . . . . . . . . . . . . . . 29

Figura 15 - Diferentes tipos de vizinhanças para raio $\mathrm{R}=1$ e $\mathrm{P}=8 \ldots \ldots$. . . . . . . 37

Figura 16 - Todos os possíveis padrões uniformes para um bai rro circular de $R=1$ e $P=8.39$

Figura 17 - Principais passos do descritor LBP-TOP. . . . . . . . . . . . . . . . . . . . 40

Figura 18 - Diagrama NLM3D-LBP-MSB . . . . . . . . . . . . . . . . . . . 42

Figura 19 - Etapas do trabal ho . . . . . . . . . . . . . . . . . . . . . . . 46

Figura 20 - Histograma de um frame do vídeo moview60fps.avi . . . . . . . . . . . . . 48

Figura 21 - Estimativa da PSF . . . . . . . . . . . . . . . . . . . . . . . . . . . . . 49

Figura 22 - Histograma de um frame do vídeo GaAsFringe.avi . . . . . . . . . . . . . . 54

Figura 23 - Histograma de um frame do vídeo ncomms7880-s2.mov . . . . . . . . . . . 54

Figura 24 - Histograma de um frame dos vídeos NiAl04.avi e NiAl04.avi . . . . . . . . 55

Figura 25 - Exemplo visual do fitting . . . . . . . . . . . . . . . . . . 56

Figura 26 - Estimativa das PSF pelo Fast Motion Deblurring . . . . . . . . . . . . . . . 57

Figura 27 - Imagens sintéticas somente com ruído. . . . . . . . . . . . . . . . . . . . . 59

Figura 28 - Imagens sintéticas com ruído e borramento. . . . . . . . . . . . . . . . . 60

Figura 29 - Imagens sintéticas somente com ruído. . . . . . . . . . . . . . . . . . . . . 61

Figura 30 - Variação do parâmetro s do al goritmo BM3D. . . . . . . . . . . . . . . . . 63

Figura 31 - Combinação do Wiener com os al goritmos TV, BF, NLM e BM3D. . . . . . 65

Figura 32 - Combinação do RL com os al goritmos TV, BF, NLM e BM3D. . . . . . . . 66

Figura 33 - Variação do parâmetro s do al goritmo BM3D. . . . . . . . . . . . . . . . . 67 
Figura 34 - Quadros centrais de cada sequência: quadros de (a) a (f) referem-se às sequências 1 a 6 , respectivamente. . . . . . . . . . . . . . . 68

Figura 35 - Diferentes níveis de ruído aplicados na sequência $4 \ldots \ldots$. . . . . . 68

Figura 36 - Resultados para diferentes valores de s para a sequência 4 com $s=20 \ldots 69$

Figura 37 - Resultados para diferentes val ores de s para a sequência 4 com $s=25 . \ldots 70$

Figura 38 - Análise qualitativa do resultado da filtragem das imagens com textura. . . . 72

Figura 39 - Aplicação da combinação do método RL com os filtros de ruído na imagem LEEM GaAsFringe. . . . . . . . . . . . . . . . . . . . . . . 74

Figura 40 - A plicação da combinação do método $R L$ com os filtros de ruído na imagem LEEM MoviewGa. . . . . . . . . . . . . . . . . . . . . . . 75

Figura 41 - Aplicação da combinação do método RL com os filtros de ruído na imagem

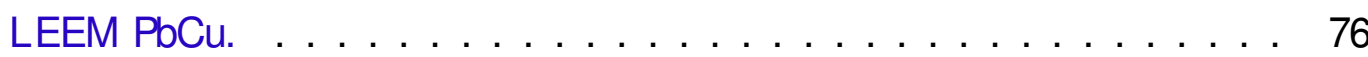

Figura 42 - Aplicação da combinação do método $R \mathrm{~L}$ com os filtros de ruído na imagem LEEM Graphene. . . . . . . . . . . . . . . . . . . . . . . . 77

Figura 43 - Aplicação da combinação do método $R \mathrm{~L}$ com os filtros de ruído na imagem LEEM NiAl2.

Figura 44 - Aplicação da combinação do método $\mathrm{RL}$ com os filtros de ruído na imagem LEEM Nell_Z. . . . . . . . . . . . . . . . . . . . . . . . . . . . 79

Figura 45 - Exemplo imagens LEEM. . . . . . . . . . . . . . . . . . . . . . 82

Figura 46 - Aplicação da combinação do método Wiener com os filtros de ruído na imagem LEEM GaAsFringe. . . . . . . . . . . . . . . . . . .

Figura 47 - Aplicação da combinação do método CLSF com osfiltros de ruído na imagem LEEM GaAsFringe. . . . . . . . . . . . . . . . . . . . . . . . . 95

Figura 48 - Aplicação da combinação do método Wiener com os filtros de ruído na imagem LEEM MoviewGa. . . . . . . . . . . . . . . . . . . . .

Figura 49 - Aplicação da combinação do método CLSF com os filtros de ruído na imagem LEEM MoviewGa. . . . . . . . . . . . . . . . . . . . . . . . 97

Figura 50 - Aplicação da combinação do método Wiener com os filtros de ruído na imagem LEEM PbCu. . . . . . . . . . . . . . . . . . . . . .

Figura 51 - Aplicação da combinação do método CLSF com os filtros de ruído na imagem LEEM PbCu. . . . . . . . . . . . . . . .

Figura 52 - Aplicação da combinação do método Wiener com os filtros de ruído na imagem LEEM Graphene. . . . . . . . . . . . . . . . . . . . . 100

Figura 53 - Aplicação da combinação do método CLSF com os filtros de ruído na imagem LEEM Graphene. . . . . . . . . . . . . . . . . . . . . . . . . . . 101

Figura 54 - Aplicação da combinação do método Wiener com os filtros de ruído na imagem LEEM NiAl2. . . . . . . . . . . . . . . . . . . . . 102

Figura 55 - A plicação da combinação do método CLSF com os filtros de ruído na imagem LEEM NiAl2. . . . . . . . . . . . . . . . . . . . . . . . . 103 
Figura 56 - Aplicação da combinação do método Wiener com os filtros de ruído na imagem LEEM Neel_Z. . . . . . . . . . . . . . . . . . . . . . . . . 104

Figura 57 - A plicação da combinação do método CLSF com os filtros de ruído nai magem LEEM Neel_Z. . . . . . . . . . . . . . . . . . . . . . . . . 105 



\section{LISTA DE TABELAS}

Tabela 1 - Fitting dos histogramas dos vídeos LEEM . . . . . . . . . . . . 56

Tabela 2 - Val ores de PSNR (dB) após a aplicação dos métodos de filtragem nas imagens sintéticas (Somente Ruído). . . . . . . . . . . . . . . . . . . . 61

Tabela 3 - Melhores parâmetros de filtragem. . . . . . . . . . . . . . . . . . 62

Tabela 4 - SSIM das imagens degradadas. . . . . . . . . . . . . . . . . . . . 64

Tabela 5 - Análise da combinação de métodos de redução de borramento e ruído. .. 64

Tabela 6 - Análise da combinação de métodos de redução de borramento e ruído (Parâmetros) . . . . . . . . . . . . . . . . . . 67

Tabela 7 - Ganho relativo a utilização do MSB. . . . . . . . . . . . . . . . 70

Tabela 8 - Resultados quantitativos dos métodos de filtragem de ruído em imagens com

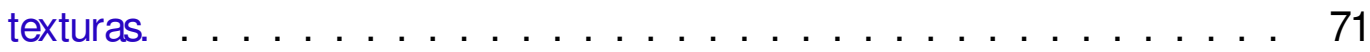

Tabela 9 - Teste de usuário - utilização dos métodos de remoção de ruídos . . . . . . 80

Tabela 10 - Teste de usuário detal hado . . . . . . . . . . . . . . . . 81 



\section{LISTA DE ABREVIATURAS E SIGLAS}

ABF ..... Adaptive Bilateral Filter

AIC ...... Akaike Information Criterion

BF ....... Bilateral Filter

BIC ...... Bayesian Information Criterion

BIQI ..... Blind Image Quality Index

BM3D ... Block-Matching and 3-D Filtering

BRISQUE Blind/Referenceless Image Spatial QUal ity Eval uator

CLSF .... Constrained Least Squares Filtering

GOF ..... Goodness-of-Fit

LBP ...... Local Binary Patterns

LBP-TOP . (Local Binary Patterns on Three Orthogonal Planes

LEED .... Low Energy Electron Diffraction

LEEM .... Low Energy Electron Microscopy

MEM .... Mirror Electron Microscopy

MSB ..... Most Significant Bits

MSE ..... Mean Squared Error

MSSIM .. Mean Structural Similarity Index

NIQE .... Natural Image Quality Eval uator

NLM ..... Non-Local Means

NR-IQA .. No-Reference Image Quality Assessment

PDF ...... Probability Density Function

PEEM .... Photoemission Electron Microscopy

PSF ...... Point Spread Funcion

PSNR .... Peak Signal-to-Noise Ratio

$\mathrm{RL}$....... Richardson-Lucy

SEM ..... Scanning Electron Microscopy

SNR ..... Signal-to-Noise Ratio

SPLEEM . Spin-Polarized Low Energy Electron Microscopy

SSIM ..... Structural Similarity Index

TV ....... Total Variation

UIQI ..... Universal Image Quality Index 

INTRODUÇÃO . . . . . . . . . . . . . . . . . . . . . 1

Contexto e Motivação . . . . . . . . . . . . . . . . . . . . . . . . 1

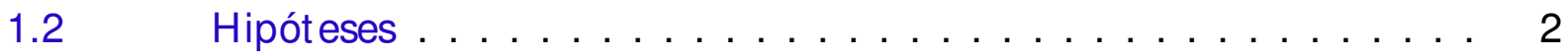

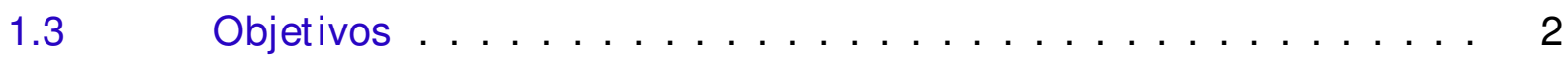

$1.4 \quad$ Contribuições . . . . . . . . . . . . . . . . 3

1.4.1 Contribuição Geral . . . . . . . . . . . . . . . . . 3

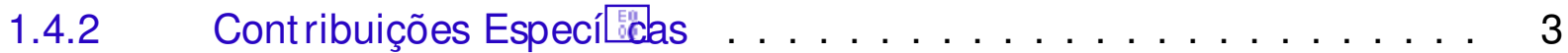

1.4.3 Reprodutibilidade . . . . . . . . . . . . . . . . . 4

1.5 Organização da Dissertação . . . . . . . . . . . . . . . . 4

2 INTRODUÇÃO À MICROSCOPIA ELETRÔNICA PARA ANÁLISE DE SUPERFÍCIES . . . . . . . . . . . . . . . . . 5

$2.1 \quad$ Microscopia Ótica . . . . . . . . . . . . . . . 5

2.2 Microscopia Eletrônica de Varredura . . . . . . . . . . . . . . . 6

2.3 Difração de Elétrons de Baixa Energia . . . . . . . . . . . . . . . . 8

$2.4 \quad$ Microscopia Eletrônica de Baixa Energia . . . . . . . . . . . . . . . 10

2.4.1 Estrutura do microscópio . . . . . . . . . . . . . . . . . 11

$2.4 .2 \quad$ Processo de imageamento . . . . . . . . . . . . . . . . 13

2.4.3 Outras técnicas de análise de superfícies . . . . . . . . . . . . . . . 14

3 TÉCNICAS DE PROCESSAM ENTO DE IM AGENS PARA MICROSCOPIA . . . . . . . . . . . . . . . . 17

3.1 Processo de degradação e restauração de imagens digit ais . . . . . 18

$3.2 \quad$ Análise das imagens LEEM . . . . . . . . . . . . . . . . 20

3.2.1 Ruídos . . . . . . . . . . . . . . . . . . . . . . . . 20

3.2.2 Função de Espalhamento de Ponto . . . . . . . . . . . . . . . . . . . . 20

3.3 Remoção de ruídos em imagens . . . . . . . . . . . . . . . . . 21

3.3.1 Filtragem clássica . . . . . . . . . . . . . . . . . . 22

3.3.2 Total Variation . . . . . . . . . . . . . . . . . . 22

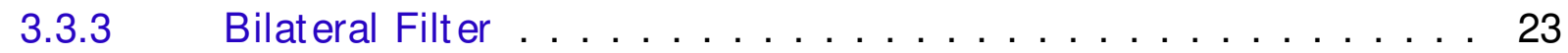

3.3.4 Adaptive Bilateral Filter . . . . . . . . . . . . . . . 25

3.3.5 Non-Local Means . . . . . . . . . . . . . . . . . . . 26

3.3.6 Block-Matching and $3-\mathrm{D}$ Filtering . . . . . . . . . . 28 
3.4 Redução de borramento em imagens . . . . . . . . . . . 31

3.4.1 Filtro de Wiener . . . . . . . . . . . . . . . . . 31

3.4.2 Filtro mínimos quadráticos com restrição . . . . . . . . . . . 32

3.4.3 Richardson-Lucy . . . . . . . . . . . . . . . . . 33

4 MÉTODO PROPOSTO . . . . . . . . . . . . . . . . . 35

$4.1 \quad$ Embasamento Teórico . . . . . . . . . . . . . . . . . 35

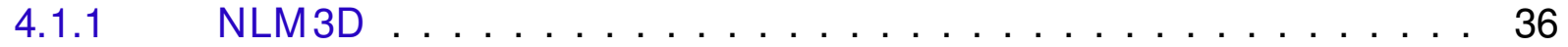

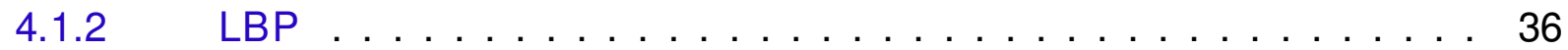

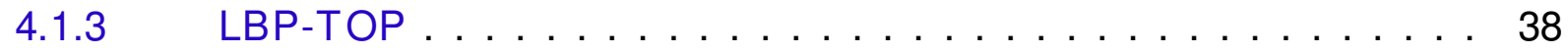

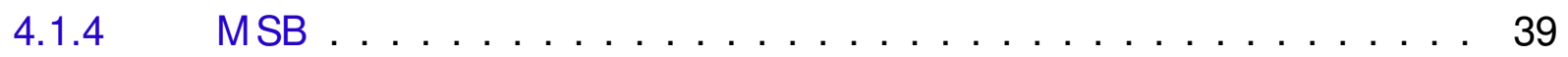

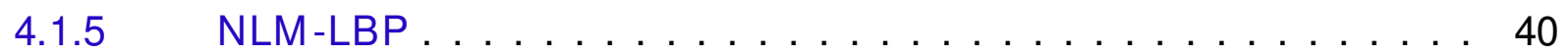

$4.2 \quad$ Técnicas Propostas $\ldots \ldots \ldots \ldots \ldots \ldots \ldots \ldots \ldots \ldots$

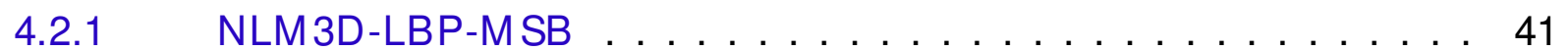

$4.2 .2 \quad$ NLM 3D-LBP-Adaptive . . . . . . . . . . . . . . 43

5 METODOLOGIA ................. . 45

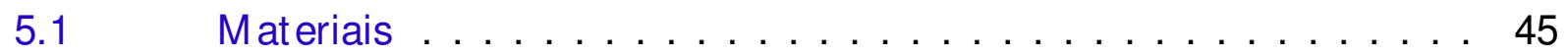

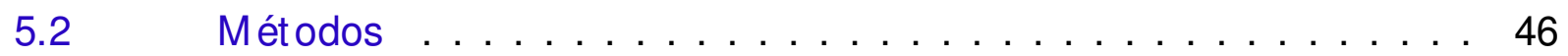

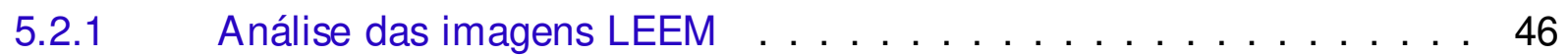

5.2.1.1 Análise histograma . . . . . . . . . . . . . . . . . . . . . 47

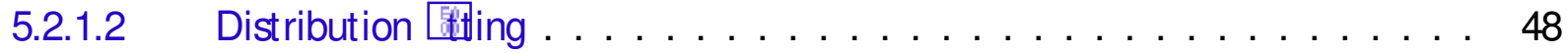

5.2 .1 .3 Estimativa do PSF . . . . . . . . . . . . . . . . . . . . 48

5.2.2 Combinações - métodos de 5 [ittragem e redução de borramento . . 49

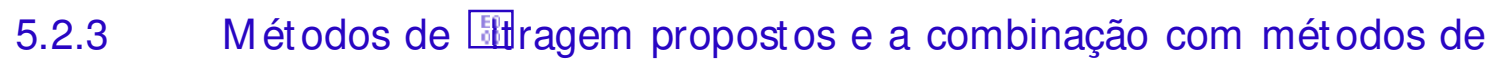
redução de borramento . . . . . . . . . . . . . . . . . . 50

$5.3 \quad$ Forma de Avaliação . . . . . . . . . . . . . . . . . . . . . 50

5.3.1 Peak Signal-to-Noise Ratio . . . . . . . . . . . . . . 50

$5.3 .2 \quad$ Structural Similarity . . . . . . . . . . . . . . . . . . . . 51

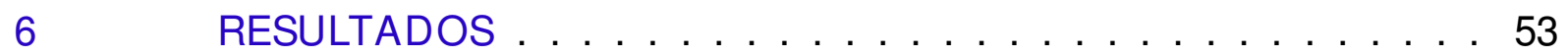

6.1 Experimento 1 - Análise das características dos vídeos LEEM . . . 53

$6.1 .1 \quad$ Análise de Histograma . . . . . . . . . . . . . . . . . 54

6.1 .2 Distribution 国ing . . . . . . . . . . . . . . . 55

6.1.3 Função de Espalhamento de Ponto . . . . . . . . . . . . . . . . . . 55

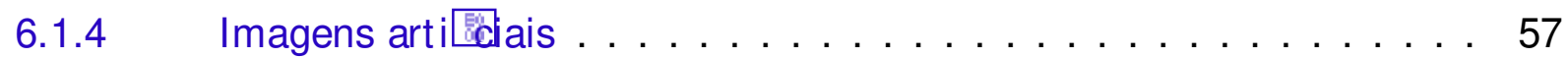

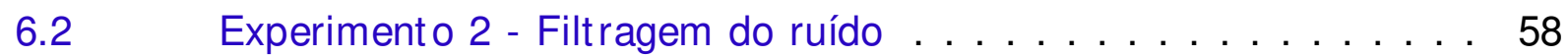

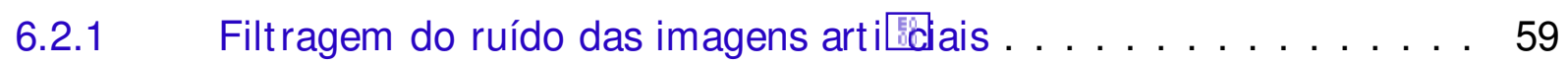

6.2.2 Análise dos melhores parâmetros . . . . . . . . . . . . . 62 
6.3 Experimento 3 - Redução de borramento e 59 tragem das imagens sintéticas . . . . . . . . . . . . . . . . . 66 63

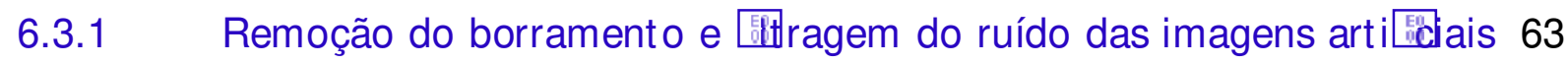

6.3.2 Análise dos melhores parâmetros . . . . . . . . . . . . . . . 64

6.4 Experimento 4 - Testes de ${ }^{0}$ titragem de imagens com texturas e pequenos detalhes . . . . . . . . . . . . . . . . 66 66

6.4.1 Imagens sintéticas . . . . . . . . . . . . . . . . 67

$6.4 .2 \quad$ Análise de parâmetros . . . . . . . . . . . . . . 68

6.4.3 Impacto da utilização do MSB . . . . . . . . . . . . . . . 69

$6.4 .4 \quad$ Avaliação quantitativa . . . . . . . . . . . . . . . . 70

6.4.5 Avaliação Qualitativa . . . . . . . . . . . . . . . . . 72

6.5 Experimento 5 - Aplicação das melhores combinações de algoritmos em imagens LEEM . . . . . . . . . . . . . . . . . . 73

$6.6 \quad$ Experimento 6 - Análise qualitativa . . . . . . . . 80

$7 \quad$ CONCLUSÃO $\ldots \ldots \ldots \ldots$

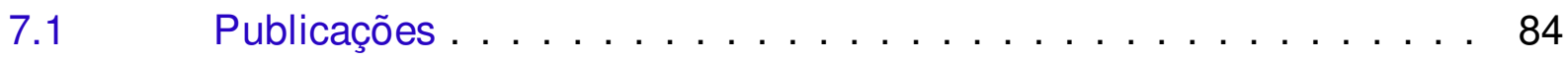

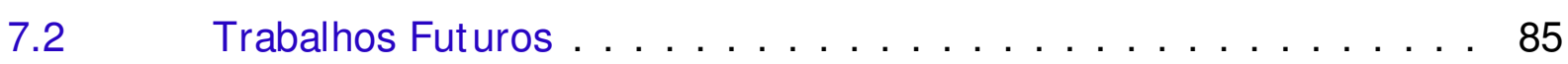

REFERÊNCIAS . . . . . . . . . . . . . . . . 87

APÊNDICE A COMBINAÇÃO DOS MÉTODOS WIENER E CLSF COM OS MÉTODOS DE REMOÇÃO DE RUÍDO . . 93 

CAPÍTULO

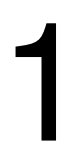

1

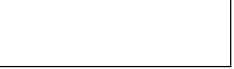

INTRODUÇÃO

\subsection{Cont exto e Motivação}

Ciência de superfícies é uma área importante da física de matéria condensada. O seu foco é o estudo de fenômenos físicos que ocorrem na interface entre duas fases, incluindo interfaces sólido-líquido, sólido-gás, sólido-vácuo e líquido-gás. É também uma área estreitamente relacionada a temas como metal urgia, ciência de materiais, física de semi condutores, catal isadores e física de vácuos, de grande relevância econômica

A Microscopia Eletrônica de Baixa Energia, do inglês Low Energy Electron Microscopy (LEEM), é uma poderosa modalidade de microscopia para estudo de superfícies. LEEM tem um papel destacado na área em função de sua capacidade única em revelar fenômenos de superfície no formato de vídeos em tempo real, com grande precisão espacial do fenômeno sob observação (ALTMAN, 2010; BAUER, 1994). O conhecimento obtido da LEEM é essencial para o entendimento da física, química e fricção das superfícies, que são propriedades críticas dos dispositivos de armazenamento de alta densidade e vel ocidade, comumente usados no dia a dia e também em ambientes mais áridos, como satélites e naves espaciais.

Porém, a investigação e visual ização das estruturas em vídeos geradas pela técnica LEEM requer uma segmentação precisa, não apenas de um único quadro, mas de sequência de imagens presentes em um vídeo gerados pela técnica. E para obter-se uma segmentação precisa é necessário o préprocessamento para eliminar fontes de ruído, al gumas desconhecidas, presentes nos vídeos.

As tentativas de uso de software ou aplicativos genéricos de processamento de imagens para este fim revelaram-se um fracasso. Em muitos casos, devido à generalidade das sol uções existentes. Até o presente momento, nenhuma pesquisa no campo de restauração ou segmentação de imagens LEEM é conhecida e, em sua mai oria, pesqui sadores da área apelam para soluções codificadas por eles próprios. Muitas destas iniciativas são pouco satisfatórias e incapazes de 
prover alguma melhora significativa

O microscópio LEEM é fabricado comercial mente por poucas empresas, além de ser customizado pel os próprios pesquisadores que o util izam. Mui tas vezes, tais equi pamentos são desenvolvidos inteiramente por eles. A inserção de novos tipos de lentes, autilização de diferentes tipos de elétrons, a utilização de novos sensores de captura, entre outros fatores, dificultam a utilização e criação de al goritmos de restauração. Por exemplo, mudanças de componentes do equipamento podem influenciar no nível, ou mesmo alterar o tipo de degradação encontrada e, consequentemente, prejudicar o processo de restauração.

\subsection{Hipóteses}

Conforme citado, imagens LEEM possuem diversas peculiaridades devido ao processo de imageamento. Além disso, devido a customizações realizadas pelos especialistas, novos ruídos ou diferentes degradações podem surgir. Devido a dificul dade de criação de técnicas de restauração específicas para cada equipamento este trabal ho de mestrado levanta duas hipóteses:

A combinação de técnicas de filtragem e redução de borramento existentes e não específicas a nenhum equi pamento, podem ser utilizadas para real çar detal hes importantes enquanto ao mesmo tempo em que elimina ruídos das imagens. A través disso, a análise das imagens pel os especial istas pode ser real izada com menos dificul dades;

Devido a possi bil lidade de imagear estruturas pequenas, a utilização de técnicas de filtragem clássicas podem remover estruturas importantes. Técnicas de filtragem não locais mostraram-se efetivas ao manter estruturas importantes, como bordas. Porém, removem texturas e estruturas pequenas demasiadamente. Acredita-se que a união de técnicas de filtragens não locais com descritores de texturas pode mel horar significativamente o resultado da filtragem, ao mesmo tempo em que preserva detal hes importantes. Como resultado, tem-se uma contribuição para o campo de filtragem de imagens de microscopia el etrônica.

\subsection{Objetivos}

Este trabal ho de mestrado teve dois objetivos específicos:

1. Anal isar as características das degradações presentes nas imagens geradas pela técnica LEEM em diferentes equi pamentos e anal isar a qual idade de restauração de métodos já existentes através da combinação de métodos de filtragem e redução de borramento;

2. Desenvolver novas técnicas de filtragem que possam ao mesmo tempo manter estruturas pequenas e remover ruído. 


\subsection{Contribuições}

Acreditamos que este trabal ho traz contribuições não apenas para a comuni dade LEEM, bem como colabora para a área de processamento de sinais, ao propor uma nova abordagem para a filtragem de vídeos e imagens.

\subsubsection{Contribuição Geral}

As imagens geradas por LEEM são suscetíveis a ruídos e outros fatores proveni entes do processo físico de aqui sição. Tai s fatores podem af etar diretamente as análi ses realizadas pelos especial istas da área. A Figura 1 il ustra al gumas imagens extraídas dos vídeos utilizados neste trabal ho, onde é possível observar o al to nível de ruido presente. Entender como estas imagens são obti das e, consequentemente, como estes problemas acontecem foi um passo importante para definir as estratégias e técnicas de visão computacional mais adequadas (eliminação de ruido com preservação de contorno, deconvolução, segmentação, etc). Fez-se necessário entender os fundamentos do processo de microscopia el etrônica de baixa energia e al guns concei tos da física de superfícies. A partir destes conceitos foi possível identificar as diversas formas de degradação e propor conjuntos de combi nações de al goritmos de filtragem e redução de borramento.

Figura 1 - Imagens de estruturas de superfícies de vídeos: (a) ondul ações se propagando ao redor das gotículas de Gálio; (b) Gotículas de Gálio em deslocamento; (c) e (d) exempl os diversos ilustrando o nível de ruído nas imagens a serem tratadas neste projeto.

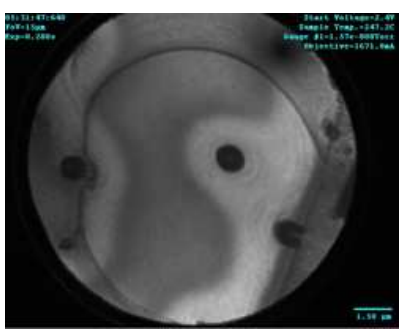

(a)

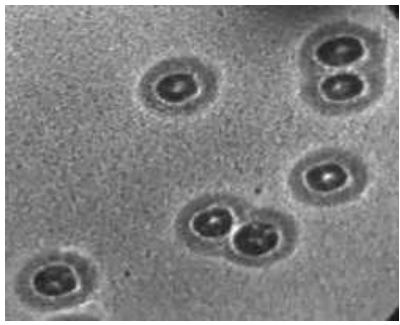

(c)

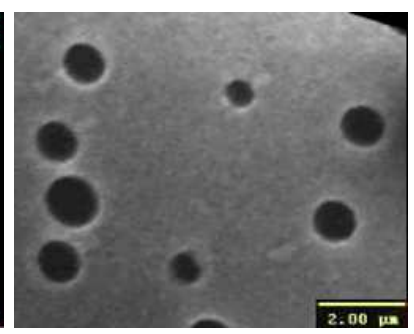

(b)

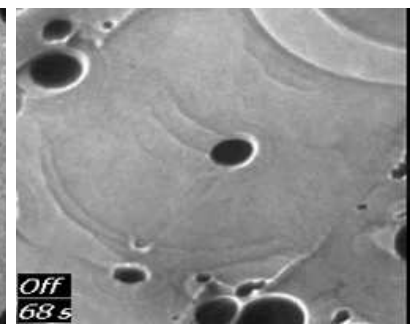

(d)

Fonte: Imagens cedidas pelo professor Dr. Wen-Xin Tang.

\subsubsection{Cont ribuições Especí Eclas}

Pelo seu carácter interdi sci plinar, as contribuições deste trabal ho de mestrado podem ser dividas em: 
- Micr oscopia LEEM: Criar e analisar diferentes combinações de técnicas existentes de filtragem e redução de borramento, a fim de melhorar a qual idade das imagens/vídeos LEEM. Portanto, com vídeos de mel hor quali dade, os especialistas daárea podem, então, fazer uma análise com uma maior precisão. Além disso, futuras aplicações de técnicas de segmentação podem ser beneficiadas com imagens de mel hor qual idade.

- Computação: Os al goritmos não locais possuem bons resul tados para filtragens de ruídos em imagens. Porém, estruturas pequenas e texturas são removidas. Outra contribuição deste trabal ho foi desenvolver uma nova técnica de filtragem de vídeos e imagens 3D que possuam estruturas pequenas e texturas, modificando o algoritmo Non-Local Means através do descritor de texturas LBP-TOP.

\subsubsection{Reprodutibilidade}

Os testes de análise de ruído, comparações e combinações dos métodos, entre outros testes foram realizados com MATLAB. Para fim de reprodutibilidade, as scripts e códigos utilizados estão disponíveis em um repositório Git pelo link <https://github.com/welintonandrey/ leem_image_restoration-MSc-scr>. A técnica proposta de filtragem está disponível em outro repositório Git disponível pelo link <https://github.com/welintonandrey/3d_denoising>.

\subsection{Organização da Dissert ação}

O restante desta dissertação está estruturado da segui nte maneira:

- No Capítulo 2 serão apresentados os conceitos teóricos básicos sobre as técnicas de microscopia eletrônica para o estudo de superfícies, com ênfase em LEEM.

- No Capítulo 3 será apresentada a revisão bibliográfica das técnicas de remoção de ruído e borramento de imagens.

- No Capítulo 4 será apresentado o método de filtragem proposto.

- O Capítulo 5 descreve a metodol ogia adotada neste trabal ho e como foram real izadas as análises quantitativas e qual itativas neste trabal ho.

- No Capítulo 6 são apresentados os resultados do trabal ho.

- Finalmente, no Capítulo 7 são apresentados as conclusões, assim como os trabalhos futuros. 
CAPÍTULO

\section{2}

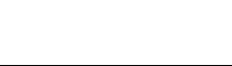

\section{INTRODUÇÃO À MICROSCOPIA ELETRÔNICA PARA ANÁLISE DE SUPERFÍCIES}

Este capítul o visa introduzir o conceito da microscopia tradicional citando o seu funcionamento e suas limitações, assi $m$ como os microscópicos el etrônicos que evoluíram a partir deste, cada qual com sua especificidade. Por fim, serão introduzidas as principais técnicas de microscopia eletrônica atual mente utilizadas para anál ise de superfícies e suas interfaces, em especial a Microscopia Eletrônica de Baixa Energia, cujas imagens/videos resul tantes são principal foco deste trabalho.

\subsection{Microscopia Ótica}

A microscopia é uma técnica que tem como objetivo tornar visível o que para o ol ho humano é muito pequeno, permitindo um estudo mais detal hado daquilo que é observado. $A$ ideia básica é utilizar um conjunto de lentes onde se passa a luz proveniente da amostra ou objeto a ser observado, criando uma representação ampliada dos mesmos e possi bilitando sua análise (PONTI, 2008). O primeiro uso de um microscópico foi real izado em meados de 1660 d.C. (BIGNAMI, 2000). Posteriormente, diversas evoluções e aprimoramentos foram sendo desenvolvidos, desde o estudo de diversos tipos de lentes até o desenvolvimento de outras categorias de microscopia

O microscópio ótico conta com um sistema de ilumi nação que incide sobre a amostra ou objeto de interesse, sendo que este objeto em questão é col ocado sobre uma superfície de vidro, apropriada para este fim, posicionando-o sobre uma plataforma (PONTI, 2008). A luz então passa através do material e atinge um si stema de lentes denominadas de objetivas, que é um conjunto de lentes que apresenta pequena di stância focal e que fornece uma imagem real e 
aumentada do objeto que é observado. A pós passar pela lente objetiva, a luz então passa através da lente ocular, que funciona como uma lupa e nos dá uma imagem virtual e aumentada da imagem real que se formou em pela objetiva. As lentes objetiva e a ocular são dispostas nas extremidades de um cilindro oco, constituindo a coluna do microscópio, sendo que esta coluna possui a capacidade de se aproximar ou af astar da amostra para que que seja possível um aj uste na focal ização do objeto.

Os microscópios ópticos são limitados a um aumento máximo de 2000 vezes, neste tipo de equi pamento detal hes menores são imperceptíveis. Como tentativa para aumentar a resolução pode-se então utilizar diferentes tipos de radiações com comprimentos de onda menores que a luz visível como fonte de iluminação (DEDAVID; GOMES; MACHADO, 2007). Diversas outras técnicas de microscopias foram desenvolvidas para variados propósi tos, como a microscopia de fluorescência, que utiliza diversos tipos de materiais fluorescentes para destacar em uma amostra determinados elementos, tais como proteínas, lipídios, etc.

Devido a limitação da taxa de aumento dos microscópios óticos surgiu-se a necessidade de encontrar novas formas de imageamento para el ementos ainda não visíveis. A utilização de elétrons no lugar dos fótons foi capaz de superar esse limite de resolução, surgindo assim os microscópios el etrônicos de varredura, cujos model os existentes atual mente são capazes de aumentar uma imagem em até 300.000 vezes.

\subsection{Microscopia Eletrônica de Varredura}

A técnica de Microscopia El etrônica de Varredura, do inglês Scanning Electron Microscopy (SEM) utiliza um feixe de elétrons no lugar dos fótons utilizados no microscópico óptico convencional. Isso permite solucionar o problema de resolução relacionado com a fonte de luz branca Sob uma tensão grande (50kV), são emitidos elétrons de comprimento de onda extremamente curto $\left(0,005 \AA^{1}\right)$, sendo assim, possuem poder de resolução potencial mente al to. Além disto, através de campos el etromagnéticos e eletrostáticos, os elétrons podem ser focalizados, 0 que é uma característica essencial a um microscópico de alta resol ução (DEDAVID; GOMES; MACHADO, 2007).

O SEM é considerado um dos equi pamentos mais versáteis disponíveis para observação das características de obj etos sólidos, em função de sua al ta resolução. Esta pode variar entre 2 a 5 nanômetros, para microscópios comerciais, podendo atingir 1 nanômetro para microscópios de pesquisa avançada (NAGATANI; SAITO, 1987 apud DEDAVID; GOMES; MACHADO, 2007).

A geração do feixe de elétrons utilizado no microscópio é realizada, normal mente, por um filamento de tungstênio aquecido (aproximadamente $2500^{\circ}$ ), operando um uma faixa de tensão de 1 a 50kV. Este aquecimento produz elétrons que, tipicamente, tem uma energia que varia de $0,2 \mathrm{keV}$ a $40 \mathrm{keV}$. A emissão do feixe é realizada ponto a ponto na amostra, em linhas sucessivas,

$11 \AA=0: 1 \mathrm{~nm}$. 
seguindo uma mal ha retangular, sendo focal izado por uma série de três lentes el etromagnéticas. O esquema de um SEM pode ser visto na Figura 2.

Figura 2-Microscópio Eletrônico de Varredura

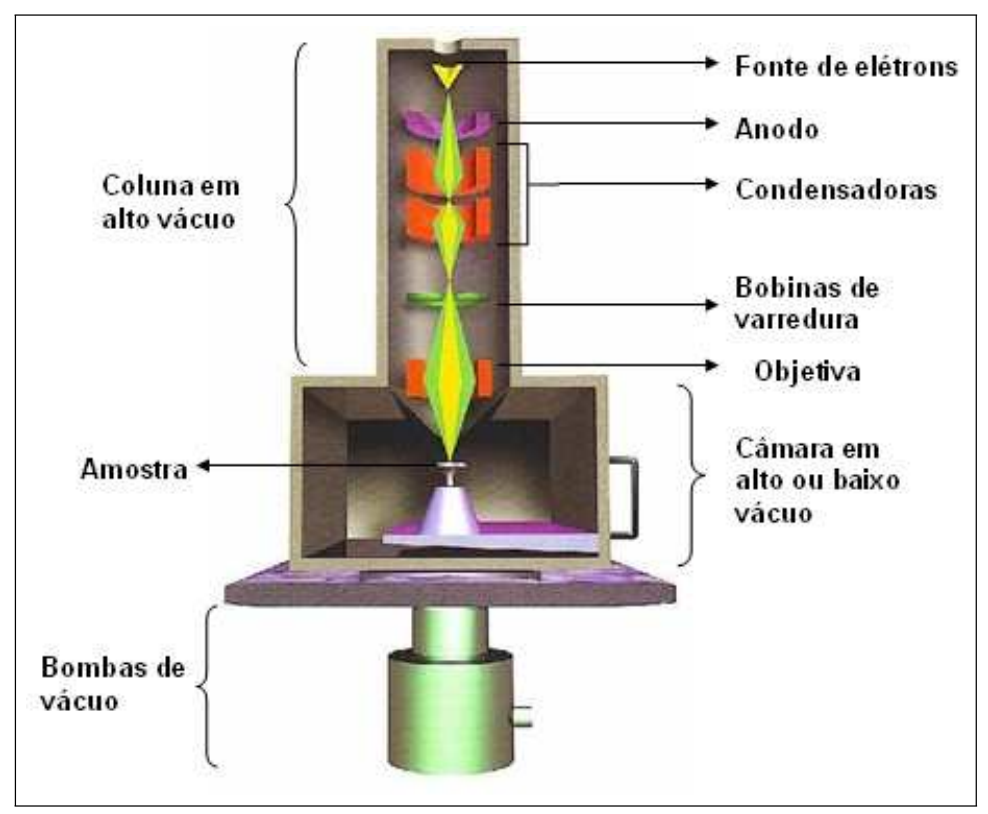

Fonte: LFF-IF-USP (2013).

A interação do feixe de elétrons na amostra provém diferentes si nais que apresentam características individuais. Dente os sinais emitidos pela amostra, os mais utilizados são os elétrons secundários e os elétrons retro-espal hados.

Os elétrons secundários são resul tantes da interação do feixe eletrônico com o material da amostra. Estes el étrons possuem baixa energia, abaixo de $50 \mathrm{eV}$, e através deles é possível formar imagens com alta resol ução. Devido a estes elétrons emergirem das proximidades da superfície da amostra, el es possi bi litam uma visual ização da topografia da amostra, com el evada profundidade.

Os elétrons retro-espel hados possuem energia que pode variar de $50 \mathrm{eV}$ até o mesmo potencial dos elétrons primários. Os elétrons que possuem energia próxima aos el étrons primários são aquel es que sof reram espal hamento elástico e, portanto, provêm informações superficiais da amostra

Há outros si nai s que são gerados pela interação do feixe de el étrons e a amostra: el étrons transmitidos, absorvidos e Auger. Além destes, em determinados materiais da amostra, como isolantes e semicondutores bombardeados pelo feixe, geram fótons de grande comprimento de onda (ultraviol eta e luz visível).

Resolução

A tensão de acel eração dos elétrons, a corrente da sonda (quanto mai or a corrente, mai or o diâmetro do feixe) e a distância de trabal ho (distância entre a amostra e a lente objetiva) são 
parâmetros decisivos para a resol ução das imagens geradas.

A distância do trabal ho é o parâmetro que mais influencia na resol ução: quanto menor a distância de trabal ho, mai or será a resol ução das imagens. Porém, quanto maior a distância, maior será a profundidade de campo obtida

O feixe de elétrons possui um diâmetro de poucos nanômetros. Porém, mesmo sendo pequeno não evita que o feixe se espalhe dentro da amostra. Sendo assim, o sinal recebido pode vir de diferentes áreas al ém do diâmetro do feixe. Portanto, não será possível observar detal hes da amostra menores que o diâmetro do feixe emitido.

Como citado anteriormente, os elétrons secundários e os retro-espal hados são responsáveis pel as princi pais informações sobre a amostra Os elétrons secundários são mais difíceis de serem capturados e são os que geram mel hor resolução. Já os elétrons retro-espal hados possuem informações da superfície da amostra A energia destes elétrons são próximas ao feixe incidente, fazendo com que a resolução seja mai or à medida que a tensão enf raquece. Porém, a quantidade de elétrons retro-espal hados será menor conforme a tensão di mi nui (DEDAVID; GOMES; MACHADO, 2007).

O peso atômico influencia a penetração dos elétrons do feixe primário: quanto mai or o peso atômico, menor o poder de penetração. Sendo assim, Dedavid, Gomes e Machado (2007) concluem que a mel hor configuração para se obter uma boa resolução é através dos dados oriundos dos elétrons secundários em materiais com pesos atômicos elevados.

Tanto a microscopia ótica quanto a microscopia eletrônica de varredura foram, e ainda são, de grande importância para diversas áreas como biologia, odontologia, farmácia, engenharia, química, metalurgia, física, medicina e geologia (DEDAVID; GOMES; MACHADO, 2007). Devido a diversas particularidades, outras técnicas de microscopia foram sendo desenvolvidas. Neste trabal ho o foco principal é a análise e tratamento das imagens geradas pel a microscopia el etrônica de baixa energia, técnica essa desenvolvida para análise de superfícies. Esta teve sua origem a partir do potencial de imageamento da técnica de Difração de Elétrons de Baixa Energia, descrito na seção seguinte.

\subsection{Difração de Elétrons de Baixa Energia}

Dentre as diversas técnicas de análise de superfícies a Difração de Elétrons de Baixa Energia, do inglês Low Energy Electron Diffraction (LEED) é a técnica mais utilizada na determinação estrutural, em escal a atômica, de superfícies (CASTILHO et al., 2005).

$\mathrm{O}$ processo consiste em emitir elétrons na faixa de 20 a $1000 \mathrm{eV}$ sobre a amostra, que penetram cerca de 5 a $10 \AA$. Assim, como na SEM, estes elétrons sofrem espal hamento e são refletidos. Por meio destes é possível obter informações da superfícies da amostra (CASTILHO et al., 2005). 
Através da emissão dos el étrons na fai xa de energia anteriormente citada, o seu comprimento de onda fica na ordem de $0.1 \mathrm{~nm}$, mesma ordem de grandeza do espaçamento inter-atômico (HELD, 2010). Com esse comprimento de onda, é possível atingir, em condições ideais, uma resolução próxima a $0.01 \AA ̊$ (CASTILHO et al., 2005).

O feixe de elétrons deve ser emitido em uma câmara, mantendo um vácuo na faixa de 10-10 Torr, direcionando-o para incidir sobre a superfície da amostra Os elétrons então sofrem espal hamento, sendo que os el étrons utilizados nesta técnica são os retro-espelhados, ou seja, aquel es que após o espal hamento possuem energia igual àquela dos elétrons do feixe incidente.

Castilho et al. (2005) cita que em uma amostra, os elétrons retro-espal hados pelas primeiras camadas da amostra se agrupam em conjuntos de feixes difratados, formando um padrão de difração, padrão esse que ao colidir com uma tel a fluorecente pode ser analisado. A Figura 3 contém um exemplo simplificado do funcionamento deste equipamento.

Figura 3 - Esquema típico do aparato experimental LEED.

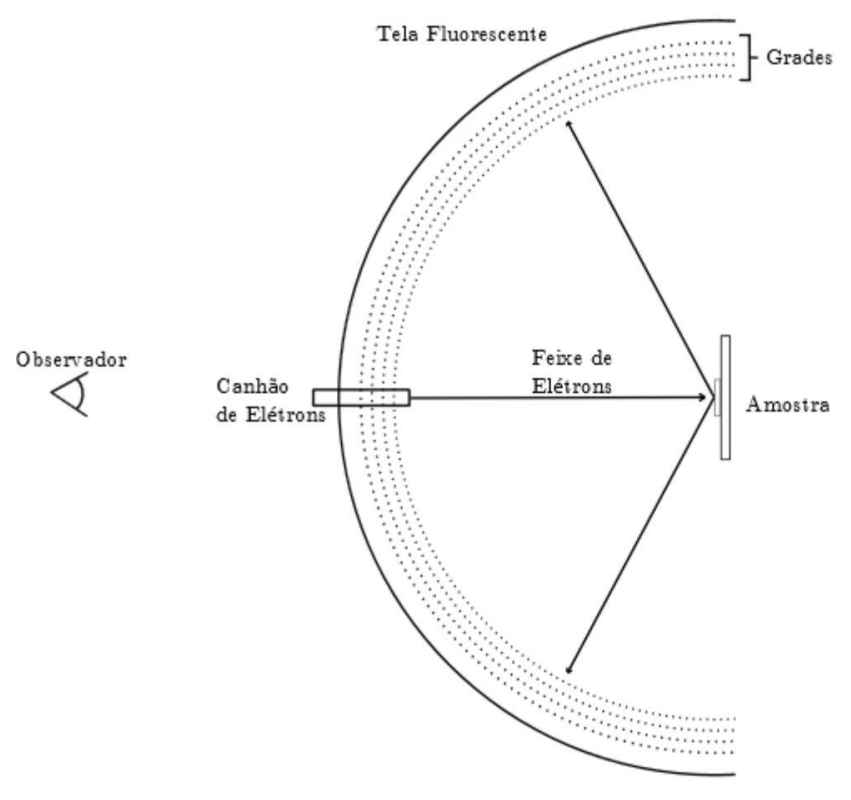

Fonte: Elaborada pelo autor.

Pode-se dividir o aparato experimental em quatro componentes: canhão de elétrons, goniômetro, detector e a câmara de ultra-alto-vácuo.

O canhão de elétrons é formado por um filamento de tungstênio aquecido, acel erando os elétrons por um diferencial de potencial entre o canhão e a amostra $O$ feixe de elétrons gerado possui energia entre 0 e $1000 \mathrm{eV}$, sendo que seu diâmetro é da ordem de 1 a 3 mm (CASTILHO et al., 2005).

O goniômetro é responsável pela sustentação e pela manipul ação da amostra. Por trabal har em condições de ul tra-al to-vácuo, sua compl exidade el etrônica e mecânica é al ta. Outro 
ponto importante acoplado a este componente é um si stema que possui a capacidade de aquecer e resfriar uma amostra, essencial para análise das amostras em diferentes condições (CASTILHO et al., 2005).

O detector é o dispositivo de col eta dos elétrons retro-espal hados, constituído por uma tel a fluorescente e por um conjunto de quatro grades hemisféricas e concêntricas, normal mente contendo um furo no centro, onde o canhão de elétrons é inserido, que pode ser observado na Figura 3. A primeira grade (mais próxima da amostra) é aterrada a fim de permitir uma região livre de campo elétrico entre a amostra e a grade. Um potencial negativo é apl icado à segunda eà terceira grade, chamadas redes supressoras que possuem a função de repel ir todos os elétrons que não sofreram retro-espal hamento. Isso significa que passam por estas grades somente os elétrons que possuírem o mesmo potencial do feixe primário. A quarta grade é aterrada para reduzir os efeitos de penetração do campo el étrico das grades supressoras sobre a região seguinte. A última região é composta por uma tel a fluorescente, aplicando um potencial de aproximadamente 6kV, com o intuito de acelerar os elétrons que passaram pelas grades supressoras, permitindo uma visual ização mais nítida (HELD, 2010).

Todos os componentes citados anteriormente são di spostos em uma câmera de ul tra-al továcuo, que opera em pressões da ordem de $10^{-10}$ a $10^{-11}$ Torr. Baseado na di stribuição espacial dos feixes difratados e a variação de duas intensidades e a energia do feixe incidente, é possível obter informações sobre o arranjo estrutural dos átomos na superfície da amostra. Um observador verá um conjunto de pontos brilhantes, sendo que a este conjunto de pontos dá-se o nome de padrão de difração LEED.

Castil ho et al. (2005) cita que em LEED não é possível, a partir de um padrão como a Figura 4, determi nar as posições atômicas na cela unitárias e nem obter as distâncias interplanares entre os planos da amostra. Estas, e outras informações podem ser obtidas através de análi ses de variação das intensidades do feixe incidente juntamente com um especial ista da área

Ao contrário da técnica LEED, que descreve a estrutura atômica de superfícies, a Microscopia Eletrônica de Baixa Energia objetiva o imageamento das iterações que acontecem na superfície de uma amostra entre interfaces. Esta técnica, que é o principal foco deste trabal ho, será descrita na próxima seção.

\subsection{Microscopia Eletrônica de Baixa Energia}

A Microscopia Eletrônica de Baixa Energia, do inglês Low Energy Electron Microscopy (LEEM), é uma técnica analítica da ciência de superfícies inventada por Ernst Bauer em 1962, embora, não total mente estabelecida até o ano de 1985 (BAUER, 2014). LEEM é uma técnica empregada por cientistas de superfície para imagear anatomicamente superfícies, interações superfícieátomo e filmes bastante finos de cristais (BAUER, 1998; ALTMAN, 2010). 
Figura 4 - Padrão LEED para um filme de óxido de estanho crescido sobre $\mathrm{Ag}(100)$ após aquecimento a $850 \mathrm{~K}$.

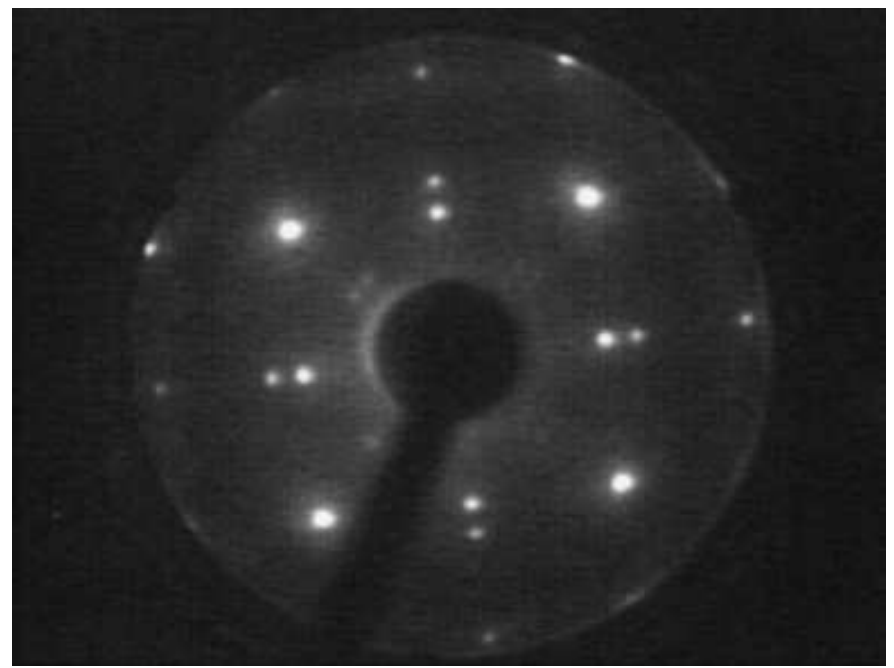

Fonte: Castilho et al. (2005).

LEEM tem a capacidade de gerar imagens de um grande campo de visão em formato de vídeos, tornando-se uma técnica ideal para o estudo da di nâmica de superfícies e de interfaces. A técnica é facilmente combi nada in situ com o aqueci mento da amostra, doseadores de gás, e fontes de evaporação, de modo que o crescimento e formação de interface pode ser seguido em tempo real (TROMP, 1994). Além disso, esta técnica é considerada mais complexa devido a necessi dade de um separador magnético, cujo objetivo é separar o feixe de el étrons emi tido em direção a amostra e o feixe refletido (BAUER, 2014).

A Figura 5 ilustra o microscópio LEEM desenvolvido pelo pesquisador Dr. Wen-Xin Tang, da Universidade de Monash (Austrália), e colaborador neste projeto cedendo grande parte das imagens utilizadas. Para mel hor se compreender o processo de formação de uma imagem LEEM, apresenta-se na Figura 6 o esquema da seção transversal deste.

\subsubsection{Estrutura do microscópio}

A configuração típica de um LEEM consiste em:

- Canhão de elétrons: usado para gerar el étrons por meio de reação térmica (normalmente de um filamento de tungstênio). Na reação térmica, elétrons são emiti dos por aquecimento resi stivo e por uma apl icação de um campo el étrico. Assim, atinge a energia necessária para que os elétrons escapem da superfície. Uma vez atingida a energia necessária, os elétrons então podem viajar (no vácuo) em di reção as lentes que são aterradas e com isso são di recionados para a amostra.

- Lentes do condensador : usada para concentrar os el étrons que saem do canhão de el étrons e mani pular o feixe. Normal mente é utilizado um conjunto de quatro lentes magnéticas, 
Figura 5 - Microscópio LEEM e suas partes constituintes, incluindo as fontes de Gálio, di spositivos de geração de imagem e mecanismo de refrigeração.

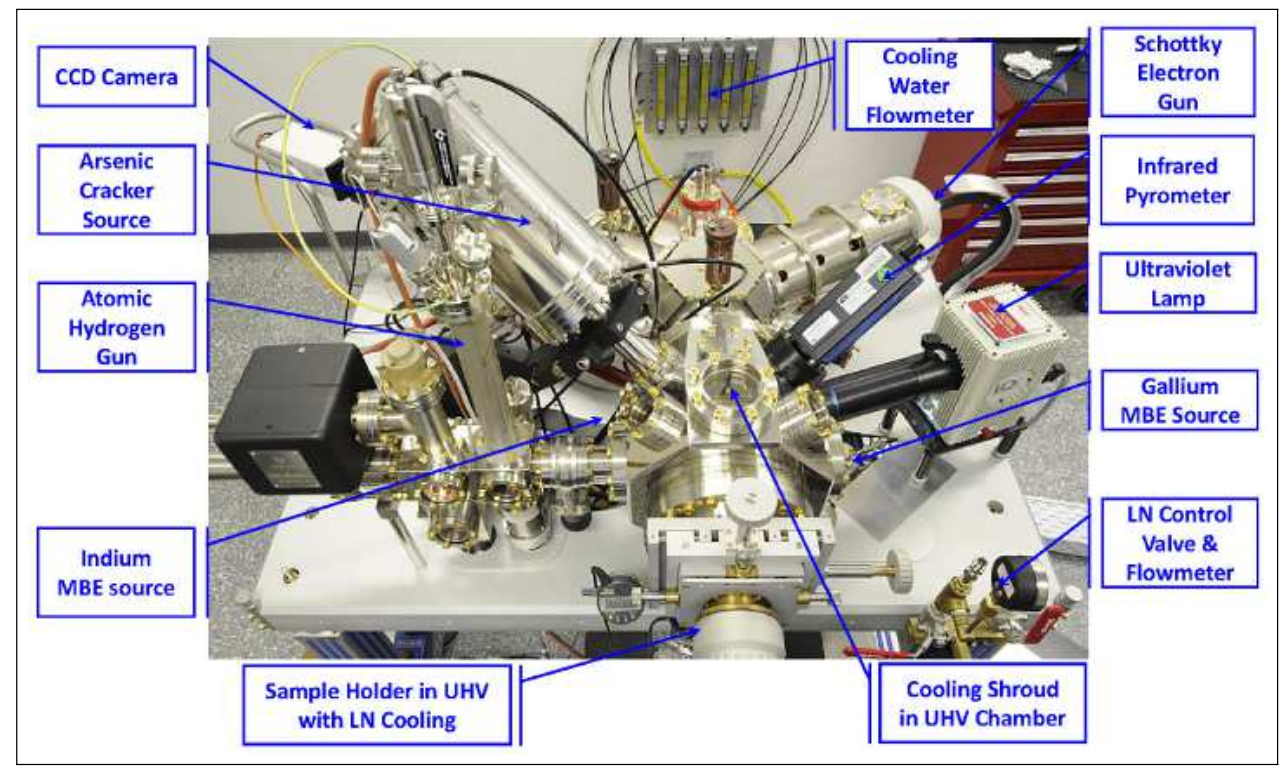

Fonte: Jesson e Tang (2010).

Figura 6 - Diagrama do microscópio LEEM: a imagem é produzi da a partir de uma amostra depositada em um cartucho Cartridge, amostra esta atingida por el étrons desacel erados (bai xa energia). A geração se dá a partir de um canhão de el étrons (Electron Gun) de alta energia. A imagem representa um padrão de difração no plano da imagem, relacionado ao plano focal das lentes objetivas (Objetive Lens)). $O$ caminho do feixe de elétrons a partir do canhão, passando pela amostra até atingir a câmera CCD, é determinado por um prisma como defletor magnético, representado por um hexágono no centro da figura.

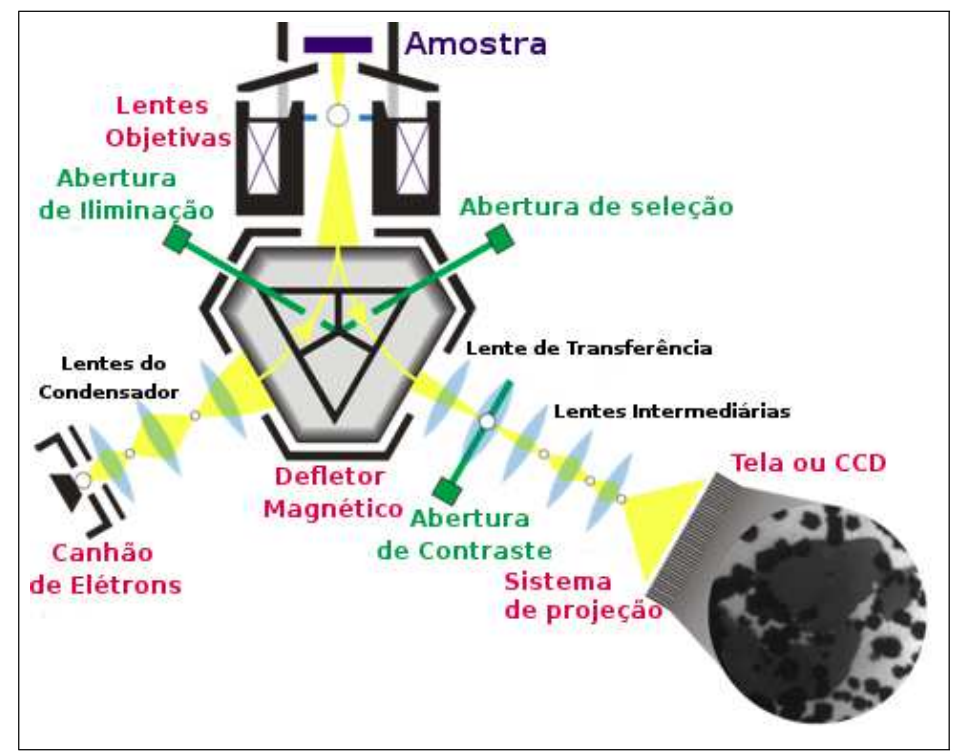

Fonte: Adaptada de Flege (2013).

mas este número depende da quantidade de resolução desejada. No entanto, a resol ução final de LEEM é geral mente determinada pela lente objetiva.

- Aber tur a de iluminação: permite aos investigadores controlar a área do espécime que é iluminada/atingida Situa-se no separador de feixe magnético do lado da iluminação. 
- Defletor magnético ou separ ador de feixe magnético: Necessário para direcionar o feixe de elétrons, direcionando-o para a amostra, caso o feixe venha do canhão; ou direcionando-o para a captura, caso os elétrons sejam refletidos.

- Lente obj etiva: utilizada para formar uma imagem "real" da amostra por meio de uma imagem virtual.

- Aber tur a de contr aste: utilizada pel os investigadores para ajustar o feixe oriundo da lente objetiva, de modo a produzir uma imagem do padrão de difração e escolher a intensidade local desejada para a imagem. Esta abertura permite aos cientistas anal isar diferentes intensidades dos padrões de difração a fim de que possam visual izar as estruturas desejadas.

- Lentes de tr ansfer ência e lentes inter mediár ias: utilizadas para ampliar o padrão de imagem ou difração e projetá-lo sobre o sensor CCD ou sobre a tel a fluorescente.

- Tela fluorescente ou sensor CCD: quando o equipamento é preparado para a técnica de Difração de Elétrons de Baixa Energia (LEED) utilizase uma tel a fluorescente para visualizar os elétrons refletidos. O sensor CCD é utilizado para armazenar a imagem resul tante do LEEM a modo de utilizar posteriormente.

\subsubsection{Processo de imageamento}

O processo de imageamento desta técnica ini cia com elétrons de al ta energia (15-10 keV) que são emitidos de um canhão de elétrons (electron gun), cujo foco é dado por um conjunto de condensadores óticos, e enviados através de fecho defletor magnético (normal mente posicionado a $60^{\circ}$ ou $90^{\circ}$ ). Estes elétrons viajam através de um conjunto de lentes objetivas e iniciam um processo de desaceleração até atingirem baixa energia (1-100 eV) próximos à superfície da amostra, uma vez que a amostra é mantida com o mesmo potencial do canhão de elétrons. Tais elétrons de baixa energia passam a ser denominados sensíveis-a-superfície, e a prof undidade rel ativa à superfície pode ser variada ao ajustar-se a energia dos elétrons incidentes, a ém de ser dependente do peso atômico do material, assim como os SEM. Os elétrons de baixa energia refletidos elasticamente (retro-espal hados) "viajam" novamente através das Ientes do condensador, adquirindo a tensão elétrica que possuía no canhão, passando novamente pelo fecho defletor magnético (TROMP, 1994).

No entanto, neste momento os elétrons viajam na direção oposta ao condensador ótico e em direção às lentes do projetor. O imageamento do plano focal das lentes objetivas no plano do objeto das lentes do projetor produz um padrão de difração no plano da imagem (padrão semel hante ao LEED) (TROMP, 1994). Este padrão no pl ano da imagem pode, então, ser gravado de várias maneiras (sensor CCD, por exemplo). 
Diversos fenômenos podem ser imageados em tempo real com os equipamentos LEEM. Tais fenômenos incluem (mas não estão limitados) a: tomografia, transi ções de fase, reação, o crescimento de película fina, gravura, alívio de tensão, sublimação, e microestrutura magnética Estas investigações só são possíveis por causa da acessi bilidade da amostra, permitindo uma grande variedade de estudos in situ através de uma vasta gama de temperaturas.

\subsubsection{Outras técnicas de análise de superfícies}

Além das técnicas SEM, LEED e LEEM, existem diversas outras técnicas utilizadas para o imageamento e anál ise de superfícies. Dentre estas técnicas destacam-se: Photoemission Electron Microscopy (PEEM), Mirror Electron Microscopy (MEM) e Spin-Polarized Low Energy Electron Microscopy (SPLEEM).

- Mirror Electron Microscopy: Durante a emissão dos el étrons, caso a energia do feixe seja reduzida aos poucos, em al gum momento a energia da amostra estará a uma tensão ligeiramente mais negativa do que a do feixe de elétrons. Assim, o feixe não terá energia suficiente para encontrar ou até mesmo penetrar na amostra. Com isso, todo o feixe é refl etido antes da superfícies da amostra. Este modo de imageamento é denomi nado MEM (FIGUERA; MCCARTY, 2013). A importância desta técnica pode ser vista no trabal ho do Dr. Wen-Xin Tang, que através dela descobriu um comportamento inédi to de gotícul as de Gál io durante a evaporação do Arseneto de Gálio, sendo o principal o movimento destas gotículas em somente uma di reção. Al gumas amostras dessa modalidade são ilustradas na Figura 7 (TERSOFF; JESSON; TANG, 2009).

Figura 7 - Gotículas de Gálio em movimento durante a evaporação do Arseneto de Gálio.

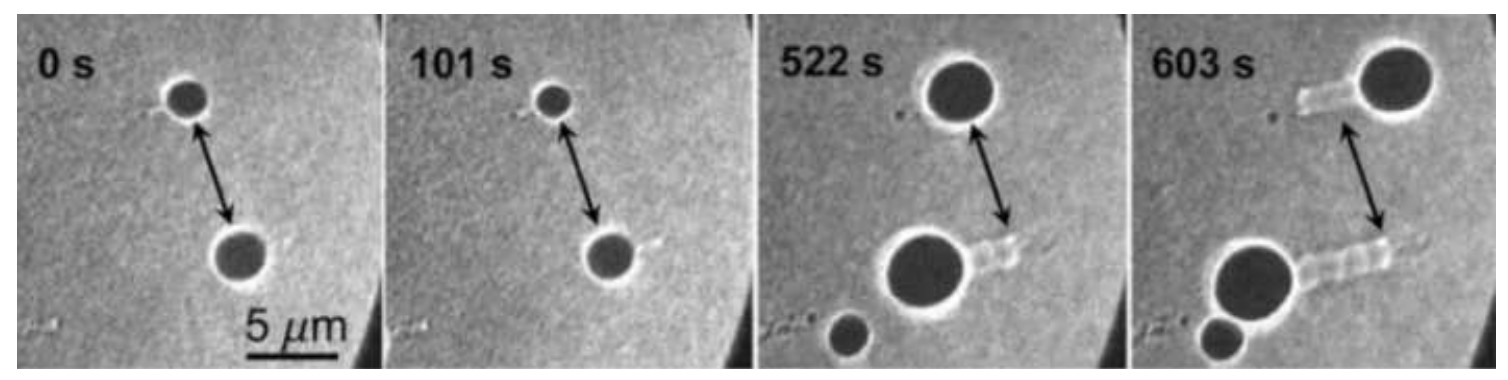

Fonte: Tersoff, Jesson e Tang (2009).

- Photoemission Electron Microscopy: Conforme Anders et al. (1999), em PEEM, após a exposição a radiação el etromagnética (fótons), os elétrons secundários são animados a partir da superfície e então fotografados. A modalidade PEEM foi desenvolvida pela primeira vez no início dos anos 1930, usando radiação ultravioleta (UV) para induzir fotoemi ssão de elétrons (secundários). Desde então, esta técnica tem evoluído substancial mente, sendo um de seus desdobramentos mais importantes a radi ação de rai os-x de bai xa energia. Essa aplicação permite a cientistas recuperar o contraste magnético de superfícies topográficas. 
Nos estudos real izados por Anders et al. (1999), a resolução máxima atingida foi de $1 \mathrm{~nm}$. Porém, se for considerada a média das resoluções de vários experimentos a resol ução desta modal idade pode ser considerada de 20nm. A Figura 8 mostra um exemplo de imagens PEEM.

Figura 8 - Exemplo de imagens PEEM.

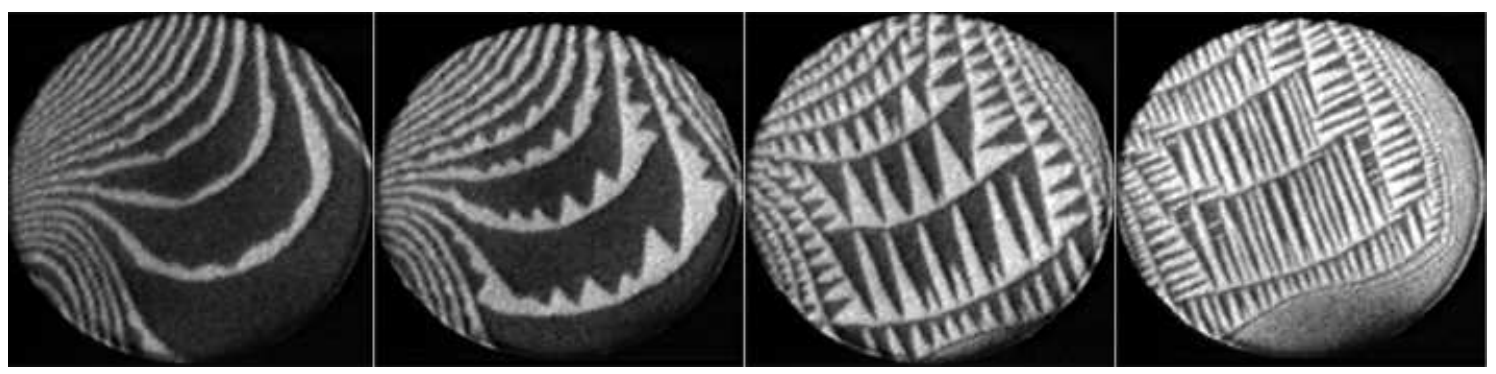

Fonte: Adaptado do vídeo cedido pelo professor Dr. Wen-Xin Tang.

- Spin-Polarized Low Energy Electron Microscopy: É uma variação da técnica LEEM que faz uso de elétrons com pol arização rotacionada ${ }^{2}$ para gerar uma imagem real da estrutura em superfícies no domínio magnético. Ao invés de uma fonte de elétrons não polarizados, em SPLEEM utiliza-se uma fonte de elétrons com pol arização rotaci onada, além dos mecanismos de contraste de imagem que estão disponíveis no LEEM. As interações são dependentes da rotação do canhão de el étrons com os elétrons presentes na amostra, gerando assi m um mecanismo de contraste que permite imagens de propriedades magnéticas e outros fenômenos como LEEM (N'DIAYE; QUESADA, 2012). Em termos de desempenho, as limitações de resolução espacial de SPLEEM são comparáveis aos de LEEM onde rotinei ramente obtém-se uma resol ução da ordem de 10nm. As imagens SPLEEM são derivadas de duas imagens LEEM adquiridas com polarizações opostas do canhão de imageamento. Para cada pixel $\psi_{i}$ da imagem SPLEEM, imageado através do canhão de elétrons com energia $E$, cal cula-se a assi metria $A$ a partir das intensi dades $I_{\uparrow}\left(E ; \psi_{i}\right)$ e $I_{\downarrow}\left(E ; \uparrow_{i}\right)$ capturadas através das imagens LEEM de acordo com a equação 2.1. A assimetria do sinal, pixel-a-pixel, é representada como uma imagem em nível de cinza (N'DIAYE; QUESADA, 2012). A Figura 9 ilustra exemplos de imagens SPLEEM, sendo as duas primeiras capturadas com a técnica LEEM utilizando elétrons spin-up e spindown, respectivamente. A terceira imagem é a combi nação das duas primeiras e resul ta da aplicação da Equação 2.1.

$$
A\left(E ; \nvdash_{i}\right)=\frac{I_{\uparrow}\left(E ; \psi_{i}\right)-I_{\downarrow}\left(E ; \psi_{i}\right)}{I_{\uparrow}\left(E ; \psi_{i}\right)+I_{\downarrow}\left(E ; \psi_{i}\right)}:
$$

Neste trabal ho todas as imagens utilizadas serão baseadas em LEEM e em suas variações (MEM, PEEM e SPLEEM). Normalmente, um único equipamento desenvolvido pode gerar

2 Tradução literal de spin-polarized electrons. É o grau em que a rotação, isto é, o momento angular intrínseco de partículas el ementares que está al inhada em uma dada di reção. 
Figura 9 - Exemplo de imagens SPLEEM.

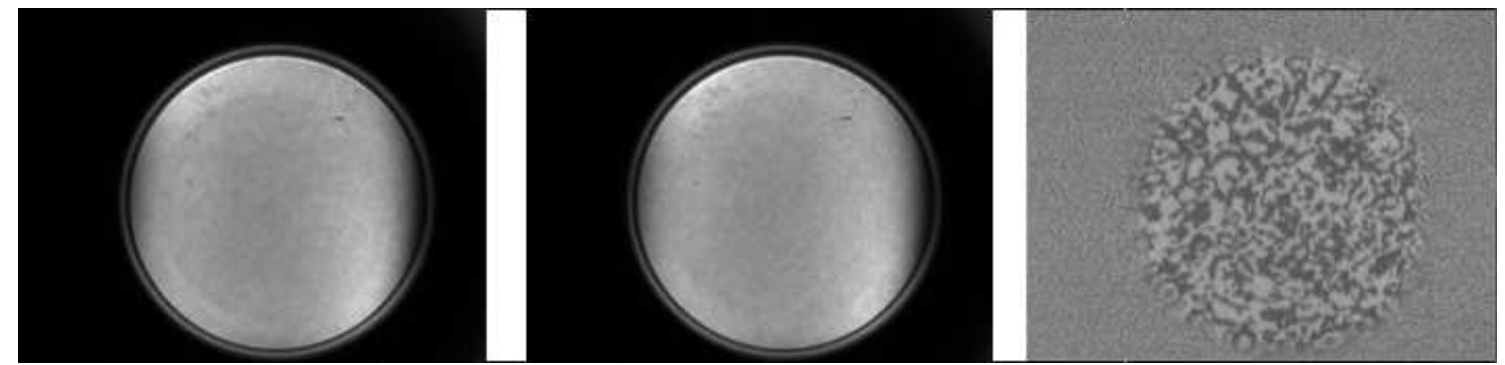

Fonte: Adaptado do vídeo cedido pelo professor Dr. Gong Chen.

imagens de todas essas modal idades, apenas al terando a forma de emissão dos elétrons ou a forma final de captura. Doravante, neste texto, qual quer citação à “imagem LEEM”, poderá designar qual quer uma das modal idades variantes acima citadas. 
CAPÍTULO

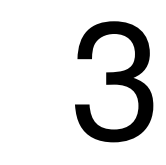

.

\section{TÉCNICAS DE PROCESSAMENTO DE IMAGENS PARA MICROSCOPIA}

Genericamente, o termo processamento de imagens refere-se a uma forma de processamento de si nais em que a entrada corresponde a uma imagem, sendo a saída ou uma imagem modificada ou ainda um conjunto de características ou parâmetros dela extraído (GONZALEZ; WOODS, 2006). Por se tratar de um tema bastante amplo, com vasta quantidade de rotinas, o processamento de imagens é normal mente dividi do em etapas, cada qual dedicada à manipul ação da imagem de acordo com o nível de compl exidade envolvido, segundo a introdução de "agentes inteligentes" no processo. Portanto, uma taxonomia bastante utilizada nesta área das ciências é a divisão dos métodos de processamento em níveis: baixo, médio e al to.

Baixo nível: Tarefas de baixo nível dizem normal mente respeito ao pré-processamento. Esta etapa é composta de métodos capazes de mel horar a qual idade das imagens, suprimindo distorções indesejadas e/ou real çando características importantes para o processamento posterior. Tarefas de baixo nível em imagens são (a) transformações geométricas; (b) transformações de brilho ou histograma; (c) métodos que utilizam a vizinhança local de um dado pixel para filtrar, suavizar ou real çar certos detal hes de uma imagem e (d) restauração.

Médio nível: Operações de nível médi o são normal mente associadas à segmentação e representação. Existem na literatura inúmeros métodos para segmentação de imagens sendo os princi pais baseados na anál ise de hi stograma, forma, cor e textura. Não obstante, exi stem outras categorias de métodos de segmentação baseados, por exemplo, em model os originados da física como os Campos Aleatórios de Markov (ROCHE et al., 2011). Já a representação relaciona-se às características ou parâmetros que podem ser computados a partir de uma imagem e que, na forma de um vetor de características ou descritores, podem ser utilizados como el ementos para discriminar uma imagem ou um conjunto delas.

Alto nível: As operações de al to nível, por outro lado, utilizam os descritores de imagem para 
fins de classificação e/ ou agrupamento, o que normal mente envolve al guma forma de treinamento ou processos de aprendizagem (BRUNO et al., 2008; SANTOS; NETO, 2007).

A grande quantidade de ruído existente nas imagens LEEM são provenientes de diversas fontes. Com base nas imagens coletadas, é possível perceber que, quanto menor o diâmetro do feixe de elétrons (emitido pel o canhão de elétrons) maior será o nível de ruído. Além disso, se o diâmetro do feixe for muito grande, estruturas pequenas deixam de ser capturadas e o nível de borramento das estruturas visíveis aumenta. As lentes magnéticas tendem a corrigir fal has de nitidez. Porém, é difícil ajustar perfeitamente todas el as. Consequentemente, al gum desfoque, por menor que seja sempre estará presente. Como qual quer sensor de captura de imagens, após um grande tempo de utilização, elétrons são acumulados neste, provocando o ruído térmico. Devido a todos estes fatores, além de outros não citados, a utilização de métodos de restauração de imagens pode ajudar a melhorar a qual idade das imagens sem que haj a a necessidade de se fazer modificações no equipamento manualmente.

No caso específico das imagens LEEM, há um grande número de tarefas a serem real izadas em baixo nível, visto que há ruídos e artefatos a serem eliminados. Ao mesmo tempo, há estruturas de baixo contraste a serem realçadas. Esse é um problema de difícil solução, pois a redução de ruídos e artefatos tende a di minuir a variância da imagem. Essa alteração na variância pode também remover estruturas importantes de baixo contraste, impedindo a identificação de objetos relevantes nos vídeos. Assim, uma filtragem espacial simples, como por exemplo um filtro Gaussiano, pode não ser suficiente e nem adequado para resolver o problema A suavização com preservação de bordas (GOYAL; BIJALWAN; CHOWDHURY, 2012) é importante para permitir uma posterior segmentação dos objetos desejados precisa das estruturas LEEM estudadas (automaticamente elou manual mente através de especialistas). Portanto, é importante a utilização de al goritmos que tenham como principal característica a preservação de borda e de obj etos pequenos. Além disso, quanto mel hor o pré-processamento, mel hor serão os resultados dos al goritmos subsequentes de mai or nível (PONTI, 2010) e, também, em análises manuais.

As seções subsequentes descrevem o processo de degradação das imagens digitais e as técnicas de processamento de imagens utilizadas neste trabal ho.

\subsection{Processo de degradação e restauração de imagens digitais}

Diversos processos visam melhorar a qual idade de uma imagem como transformações de intensidades e aguçamentos. Porém estes processos são subjetivos, ou seja, são aplicados sem o conhecimento acerca das fontes responsáveis pel a degradação da imagem. Já o processo de restauração busca mel horar a qual idade de uma imagem de forma objetiva. A restauração busca recuperar a imagem com base no conhecimento a priori do fenômeno de degradação, ou 
seja, busca se orientar na definição da degradação e com isto real izar o processo inversos para reconstruir a imagem original, ou a que seja mais próxima desta.

O processo de degradação em geral é definido como uma função de degradação $h(x ; y)$ que juntamente com um ruído aditivo $h(x ; y)$ atua sobre a imagem de entrada e produz uma imagem degradada $\mathrm{g}(\mathrm{x} ; \mathrm{y})$. Em restauração, através de al gum conheci mento sobre a função de degradação h e sobre o ruído adi tivo $\mathrm{h}$, pretende-se obter uma estimativa da imagem original , dada como $\hat{f}(x ; y)$. Em geral, quanto mais se sabe de $h$ e de $h$, mais próxima a imagem estimada será da original (GONZALEZ; WOODS, 2006). A Figura 10 exemplifica este processo.

Figura 10 - Processo de aquisição e restauração de imagem

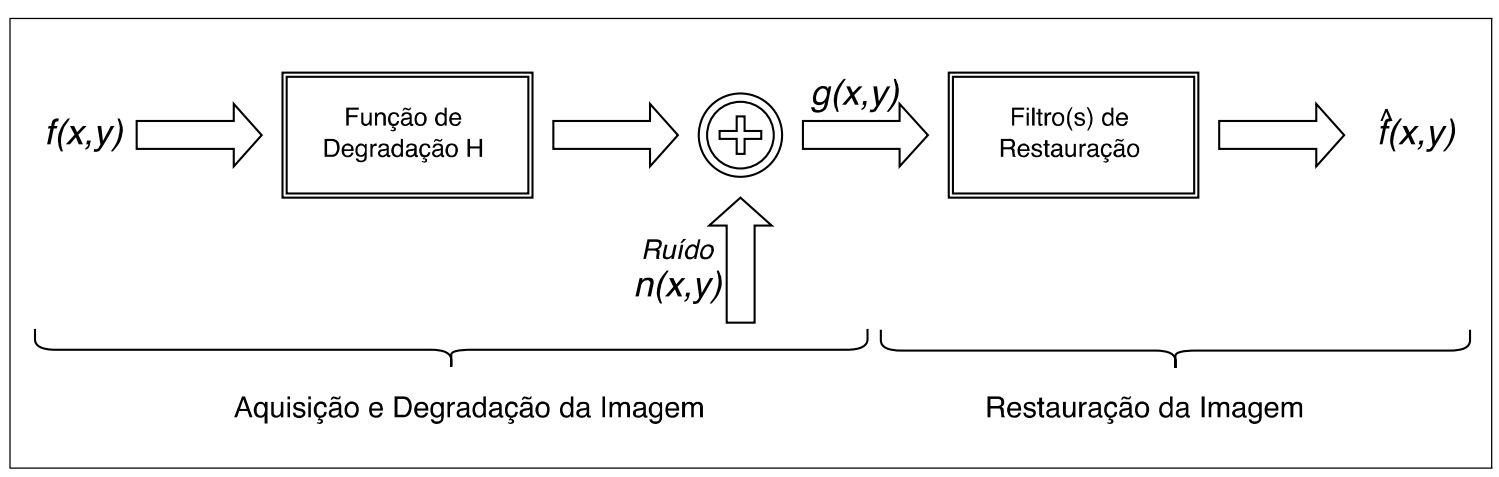

Fonte: Elaborada pelo autor.

O modelo de degradação da imagem no domínio espacial é definido como:

$$
g(x ; y)=h(x ; y) * f(x ; y)+h(x ; y)
$$

onde * indica convolução.

Como a convolução no domínio espacial é análoga à multiplicação no domínio da frequência, a Equação 3.1 pode ser escrita da seguinte maneira:

$$
\mathrm{G}(u ; v)=H(u ; v) F(u ; v)+N(u ; v)
$$

onde as letras mai úsculas representam as transformadas de Fourier dos termos correspondentes.

Como citado anteriormente, o processo de restauração de uma imagem é real izado através do conhecimento da função de degradação e do ruído presente na imagem. Como estes processos são normal mente independentes, el es são tratados separadamente. Porém, antes da escol ha dos métodos a serem utilizados, faz-se necessário a estimativa do modelo de ruído e da função de degradação. 


\subsection{Análise das imagens LEEM}

Antes de qual quer aplicação de técnicas de filtragem ou deconvolução é preciso conhecer o(s) tipo(s) de ruído(s) presente(s) na imagem e também sua função de degradação, ou função de espal hamento de ponto, do inglês Point Spread Funcion (PSF). Como na literatura não foi encontrada nenhuma forma de análise si milar para imagens LEEM, nas subseções seguintes serão descritos os experimentos real izados para estimar/detectar o tipo de ruído presente nas imagens LEEM e também a PSF proveniente do microscópio utilizado para a aquisição.

\subsubsection{Ruídos}

Os ruídos em imagens normal mente são processos aditivos e al eatórios que ocorrem devidos a diversas fontes. A principal fonte de ruídos é proveniente da aquisição e/ou transmissão das imagens (GONZALEZ; WOODS, 2006). Na aquisição, são dois os fenômenos físicos responsáveis pela geração de ruídos al eatórios durante o processo: a natureza discreta da luz (que está rel acionada à contagem dos fótons) e agitação térmica (geração al eatória dos elétrons dentro do sensor quando a temperatura aumenta) responsável pelo ruído térmico (AGUERREBERE et al., 2012). Além destes dois fenômenos físicos, tem-se o ruído de quantização, o ruído de transmissão, entre outros.

Antes de realizar a filtragem de uma imagem é necessário saber qual (is) o(s) tipo(s) de ruído(s) presente(s). Para isto existem diversas maneiras de identificar qual a di stribuição estatística mel hor define o ruído. A forma mais utilizada e também a mais si mplesé a análise de histograma. Através de uma pequena região homogênea da imagem é possível analisar o comportamento dos val ores de intensi dade no componente do ruído. Estatisticamente, estas intensidades podem ser consideradas variáveis al eatórias, caracterizadas por uma função densidade de probabilidade, do inglês Probability Density Function (PDF) (GONZALEZ; WOODS, 2006). Diversas PDFs são conhecidas, por exemplo: Gaussiana, Rayleigh, Erlang, Impul siva ou Bipolar, entre outras. Nas Seção 6.1.1 são apresentados a anál ise dos histogramas das imagens LEEM.

Uma forma estatística, e complementar à análise de histograma, para descobrir qual o tipo de ruído af eta a imagem é por meio da extração de pixels de regiões homogêneas e apl icação métodos de Goodness-of-Fit (GOF). Através de métodos GOF é possivel verificar, a partir de uma lista de distribuições conhecidas, qual del as mel hor representam os dados anal isados. A Seção 6.1.2 apresenta os métodos de GOF util izados nesse trabal ho e os resultados obtidos.

\subsubsection{Função de Espalhamento de Ponto}

O fenômeno de degradação $\mathrm{h}$, também conhecido como função de espal hamento de ponto (PSF), é uma das formas mais comuns de degradação. Este tipo de espal hamento é produzido de diversas formas: vibração da câmera durante a captação da imagem, movimento da câmera ou do alvo durante a captação, problemas no foco, entre outros. O termo espal hamento deve-se ao 
fato de o si stema de captação provocar um espal hamento em cada ponto de luz que o atravessa (GONZALEZ; WOODS, 2006), sendo o grau de espal hamento determi nado pel a qual idade do sensor ótico.

Algumas PSFs são conhecidas como, por exempl o, o Motion Blur, que borra a imagem em uma única direção devido ao movimento da câmera ou do objeto e o Atmospheric Turbul ence Blur, que é causado pela turbul ência na atmosfera al terando o índice de refração do ar e, com isto, prejudicando a captação da imagem (WEN; LEE, 2002). Porém, neste trabal ho a PSF não é conheci da, e estimá-la foi necessário. Existem três modos de estimar uma PSF: Estimativa por observação, estimativa por experi mentação e estimativa por modelamento (GONZALEZ; WOODS, 2006). Na Seção 6.1.3 será apresentado como a PSF foi estimada neste trabal ho.

A partir do conhecimento do modelo de ruído, pode-se real izar a eliminação dos mesmos. As principais técnicas de supressão de ruídos Gaussiano/Normal serão apresentadas nas subseções a seguir. Devido a pequena taxa da PSF estimada e do baixo nível de borramento visível observado nas imagens, métodos clássi cos de deconvolução foram escol hidos para compor o pipeline de técnicas, em função da fácil impl ementação e seu baixo custo computacional.

\subsection{Remoção de ruídos em imagens}

As técnicas de filtragem são, normal mente, desenvolvidas ignorando outros meios de degradação em uma imagem. Sendo assim, grande partes destas técnicas partem do princípio de que uma imagem degradada contém somente o sinal original e o ruído, representado pelas equações 3.3 e 3.4 .

$$
g(x ; y)=f(x ; y)+h(x ; y)
$$

no domínio da frequência pode ser reescrita como:

$$
G(u ; v)=F(u ; v)+N(u ; v):
$$

Como os termos de ruídos são desconhecidos, não é possível subtrai $\mathrm{h}$ de g. Em ruídos periódicos, é possível fazer uma estimativa de $\mathrm{N}$ através do espectro de $\mathrm{G}$, e então subtraí-lo. Porém, esta estratégi a funciona somente neste tipo de ruído (GONZALEZ; WOODS, 2006).

A escol ha correta dos métodos de filtragem de ruídos, com base no conhecimento da di stribuição deste, leva a uma mel hor qual idade no resultado final. Neste trabal ho, baseado nas anál i ses da Seção 6.1.2, tem-se o conhecimento que as imagens LEEM são af etadas principalmente por ruídos Normais (Gaussi anos). Portanto as técnicas posteriores de filtragem de ruídos são limitadas a este tipo de ruído. 


\subsubsection{Filtragem clássica}

Dentre os filtros clássicos existentes destacam-se: Gaussiano, Média, Média Geométrica, Média Harmônica e Média Contra Harmônica. Estes filtros suavizam umaimagem reduzindo sua variância Porém, tendem, ao suavizar, eliminar muitas informações importantes, principalmente bordas.

Outros filtros muito utilizados são os filtros não-lineares ou de estatísticas de ordem, cuja filtragem é obtida ordenando um certo conjunto de pixels presentes em uma janela, substituindo o val or do pixel central da janela por um determinado resul tado da classi ficação. Dentre os mais conhecidos estão: o filtro de Mínimo (utiliza o menor valor coberto pelo filtro), Máximo (utiliza o maior val or coberto pelo filtro), Ponto Médio (utiliza a média do menor e do mai or valor coberto pel o filtro) e o da Mediana (como o próprio nome diz utiliza o val or mediano dos pixels cobertos pelo filtro), sendo este último capaz de reduzir o ruído impul sivo enquanto mantém informações de bordas.

\subsubsection{Total Variation}

A técnica de Total Variation (TV) é uma abordagem para a redução de ruídos desenvolvida de forma a preservar as bordas presentes na imagem. Esta técnica foi idealizada por Rudin, Osher e Fatemi (1992), e baseia-se no princípio de que os si nais com detal hes excessivos possivel mente tem al ta variação total, isto é, a integral do gradiente absol uto do sinal é al ta. De acordo com este princípio, reduzindo a variação total do sinal, o sinal estimado será semel hante ao original, além de remover detal hes indesejados e preservar detal hes importantes, tais como bordas.

Esta técnica de remoção de ruído tem vantagens sobre as técnicas si mples, tais como as técnica clássicas de filtragem lineares ou as técnicas de filtragem de estatísticas de ordem, que reduzem o ruído mas ao mesmo tempo suavizam as bordas. Por outro lado, TV é eficaz em preservar si multaneamente bordas enquanto real iza a suavização do ruído em regiões planas, mesmo em baixos val ores de relação sinal-ruído (do inglês, Signal-to-Noise Ratio (SNR)).

Ao contrário de um filtro passa-baixa convencional, TV é definido em termos de um problema de otimização onde a filtragem é obtida através da mi ni mização (por exemplo PrimalDual) de uma função de custo em particular. Rudin, Osher e Fatemi (1992) utilizam um termo de regul arização do al goritmo baseado na norma $L 1$ ao invés da norma $L 2$ que fora utilizada no al goritmo Tikhonov-Miller, sendo a função de mini mização resumida da seguinte forma:

$$
\min _{x}\|-H+I\| x-f \|
$$

onde x é a imagem filtrada, f éa imagem observada el é o coeficiente de regularização.

O parâmetro de regul arização (l ) desempenha um papel crítico no processo de redução 
do ruído. Quando I = 0, não há suavização e a imagem de saída é idêntica a imagem de entrada Com I $\rightarrow \bullet$, entretanto, o termo desempenha um papel cada vez mais forte, fazendo com que a variação total seja cada vez menor, a ponto da imagem perder detal hes importantes e distanciar-se da imagem original. Portanto, a escol ha correta do parâmetro é fundamental para al cançar a quantidade certa de remoção do ruído sem perder detal hes importantes.

A variação total é usada não apenas para a filtragem, mas para outros problemas de restauração de sinal, incluindo: deconvolução, interpolação, inpainting, entre outros. Em microscopia, esta técnica é amplamente utilizada em restauração de imagens médicas, microscopia ótica e microscopia el etrônica de varredura (OUARTI; SAUVET; RÉGNIER, 2012; GOLDSTEIN; OSHER, 2009; LI; QUE, 2011). Pela qual idade observada de restauração sobre outras modal idades de imagens e, dada a necessidade de preservação de preservação de bordas, esta técnica mostra-se um poderoso filtro para imagens LEEM.

Detal hes de como é real izada a mi ni mização ou quais os parâmetros corretos a serem utilizados não serão explorados neste trabal ho. Para mai ores detal hes recomenda-se a leitura do trabal ho original e a leitura do trabal ho de Agarwal (2003), que descreve a técnica, bem como o processo de estimação do val or del .

\subsubsection{Bilateral Filter}

Bilateral Filter (BF) ou filtro bilateral é uma técnica para suavizar imagens preservando bordas. Essa técnica teve origem em 1995, com o trabalho de Aurich e Weule em filtros gaussianos não-lineares. Posteriormente, foi "redescoberto" por Smith e Brady, como parte do framework SUSAN, e somente no trabal ho de Tomasi e Manduchi (1998) consagrou-se o nome atual (PARIS et al., 2009). Esta técnica tem sido utilizado em vários contextos, tais como a suavização, edição de textura, estimativa de fluxo ótico, entre outros (PARIS et al., 2009). O filtro bilateral tem várias qual idades que justificam o seu sucesso:

Sua formulação é simples: cada pixel é substituído por uma média ponderada de seus vizinhos. Este é um importante aspecto que confere si mplicidade de implementação, além de permitir fácil adaptação às necessidades específicas da aplicação. Além disso, torna mais previsível o seu comportamento.

- Ele depende apenas dois parâmetros: o tamanho do filtro e o contraste que pondera o quanto uma imagem seráfiltrada

O filtro bilateral também é definido como uma média ponderada de pixels vizinhos, de uma maneira muito semel hante à convol ução Gaussiana $A$ diferença é que o filtro bilateral leva em conta a diferença de val or com os vizinhos para preservar bordas durante a filtragem. A ideia-chave do filtro bilateral é que, para um pixel influenciar outro pixel, ambos devem não só ocupar um local na vizinhança, mas também ter um valor semel hante. 
Paris et al . (2009) descreve o filtro bilateral pela seguinte equação:

$$
B F[I] p=\frac{1}{W_{p}} \hat{A}_{q \in S} G_{S_{s}}(|| p-q||) G_{s_{r}}(|| p-|q|) I_{q} ;
$$

onde $W_{p}$ é um fator de normalização que garante que a soma dos pesos seja igual a 1.0:

$$
W_{p}=\hat{A}_{q \in S} G_{S_{s}}(\|p-q\|) G_{S_{r}}\left(\left|l p-I_{q}\right|\right) ;
$$

onde || : || é a norma $L_{2}$ (distância euclidiana) e | : é o val or absoluto.

A equação 3.6 é uma média ponderada normal izada onde $\mathrm{G}_{\mathrm{S}_{\mathrm{s}}}$ é uma ponderação gaussi ana espacial , que diminui a influência de pixels distantes e $G_{\mathrm{S}_{\mathrm{r}}}$ é uma gaussiana que dimi nui a influência de pixels $I_{q}$ quando seus valores de intensidade diferem de $l_{p}$. A Figura 11 ilustra a utilização do filtro bilateral. É possível observar uma grande quantidade de textura é filtrada, porém há grande preservação das bordas.

Figura 11 - O filtro bilateral converte qual quer imagem de entrada (a) para uma versão suavizada (b). Ele remove texturas, ruídos e detal hes finos, mas preserva grandes quantidades de bordas sem af etar o foco
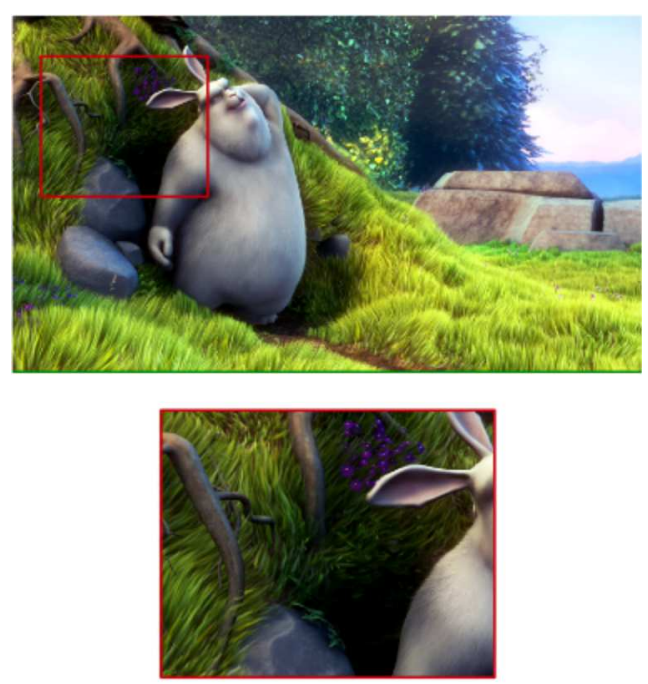

(a) Imagem de entrada
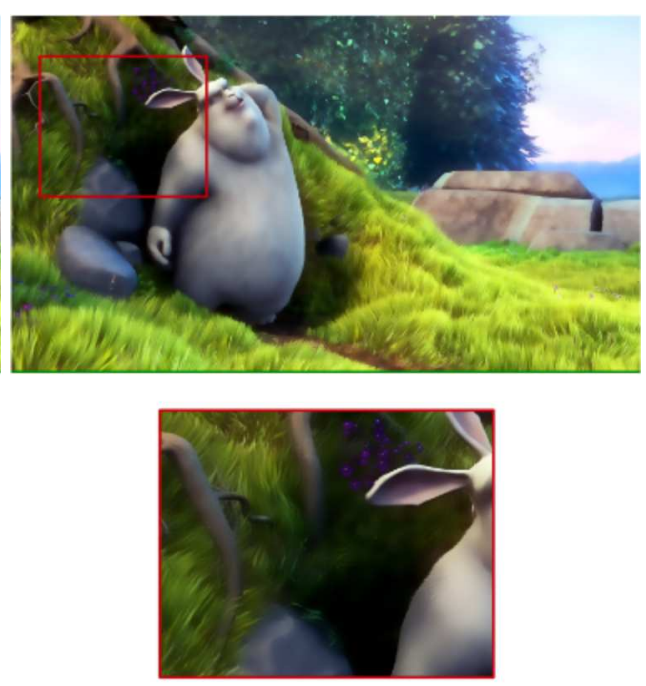

(b) Imagem de saída

Fonte: Elaborada pelo autor.

O filtro bilateral é controlado por dois parâmetros: $s_{r}$ e $s_{s}$. Conforme o val or de $s_{r}$ aumenta, o filtro bilateral gradual mente se aproxima da convolução Gaussiana-2D. Isto porque a curva da função gaussi ana "al arga-se e achata-se", ou seja, é praticamente constante ao longo do interval o da intensi dade da imagem. O parâmetro $s_{\mathrm{s}}$ indica o val or da filtragem, ou tamanho do filtro. Quanto maior o val or de $s_{\mathrm{s}}$, maior seráa filtragem.

Em imagens de microscopia el etrônica, o filtro bilateral foi utilizado por Jiang et al. (2003) para filtrar e reconstruir imagens bi ológicas capturadas por um microscópio el etrônico de varredura. Devido aos bons resul tados e sua capacidade de preservação de bordas, este filtro mostra-se uma promissora técnica para a filtragem das i magens LEEM. 


\subsubsection{Adaptive Bilateral Filter}

A técnica Adaptive Bilateral Filter (ABF) retém a forma geral de um filtro bilateral, mas contém duas modi ficações importantes. Em primeiro lugar, introduz um deslocamento para a faixa do filtro denominado z (ver equação 3.9). Em segundo lugar, ambos z e a largura da faixa de filtro $s_{r}$, são local mente adaptativos. Se $z=0$ e $s_{r}$ forem val ores fixos, o filtro ABF funcionará como um filtro bilateral convencional. Além disso, para o filtro de domínio, o filtro ABF utiliza uma função gaussiana com o val or de $s_{d}=1: 0$ fixo, ao contrário do filtro bilateral tradicional. A combinação de uma adaptação local por meio de $z$ e $s_{r}$ confere ao filtro bilateral a habi lidade de suavizar, ao mesmo tempo em que aumenta a nitidez, aguçando uma imagem através do aumento da inclinação das arestas (ZHANG; ALLEBACH, 2008).

Segundo Zhang e Allebach (2008) a operação de filtragem é dada por:

$$
\hat{f}(m ; n)=\hat{A}_{k} \hat{A} h(m ; n ; k ; l) g(k ; l) ;
$$

onde $\hat{f}(m ; n)$ é a imagem restaurada, $g(m ; n)$ é a imagem degradada e $h(m ; n ; k ; l)$ é a resposta em $(m ; n)$ para um impulso em $(k ; l)$.

E o filtro ABF é definido pela equação abaixo:

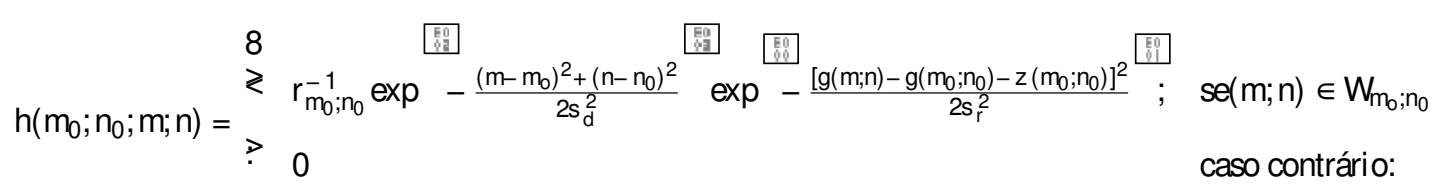

onde $\left(m_{0} ; n_{0}\right)$ éo centro dajanela, $W_{m_{0} ; n_{0}}$ éajanela $(2 N+1) \times(2 X+1)$ centrada no pixel $\left(m_{0} ; n_{0}\right)$, e $r_{m_{0} ; n_{0}}$ é definido como:

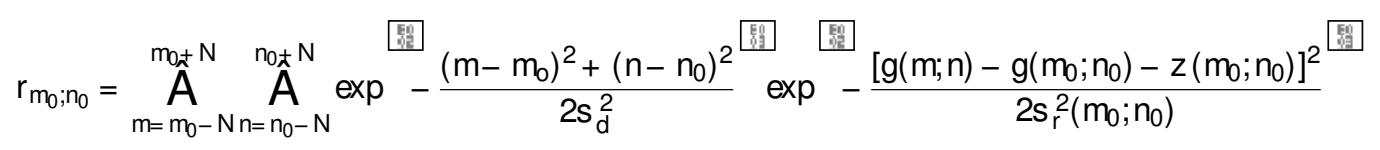

Como citado anteriormente, o deslocamento entre os valores possíveis do filtro (z) influencia di retamente na qual idade de fil tragem e aguçamento. Zhang e Allebach (2008) realizaram um estudo variando os val ores de z para identificar sua influencia tanto na suavização quanto no aguçamento. Neste estudo os val ores de $z$ eram variados através de um delta (D) definido pelo valor do pixel a ser filtrado e a média da janela centrada neste pixel, sendo $D_{m_{0} ; n_{O}}=g\left(m_{0} ; n_{O}\right)-\bar{W}_{m_{0} ; n_{O}}$, onde $\overline{W_{m_{0} ; n_{O}}}$ é a média dos val ores da janela

Através do valor do delta, é possível definir quatro estados para o val or de z. São eles:

1. $z\left(m_{0} ; n_{0}\right)=0$ : o filtro ABF tem comportamento igual ao filtro bilateral.

2. $z\left(m_{0} ; n_{0}\right)=-D_{m_{0} ; n_{0}}$ : os val ores do histograma tendem a se aproximar da média $O$ filtro ABF neste caso é um filtro de suavização. 
3. $z\left(m_{0} ; n_{0}\right)=D_{m_{0}} ; n_{0}$ : os val ores do histograma se distanciam da média. O filtro neste caso é utilizado para aguçamento.

4. Na equação 3.11, os valores do hi stograma também se distanciam da média. Porém, tendem aos val ores máximo e mínimo da janela Com isto o aguçamento é "extremo", gerando visíveis serrilhados nas bordas da imagem.

$$
\begin{aligned}
& 8 \\
& \gtrless \operatorname{MAX}\left(\mathrm{W}_{\mathrm{m}_{0} ; \mathrm{n}_{0}}\right)-\mathrm{g}\left(\mathrm{m}_{\mathrm{o}} ; \mathrm{n}_{0}\right) ; \text { se } \mathrm{D}_{\mathrm{m}_{0} ; \mathrm{n}_{0}}>0 \\
& z\left(m_{0} ; n_{0}\right)=\begin{array}{ll}
\operatorname{MIN}\left(W_{m_{0} ; n_{0}}\right)-g\left(m_{0} ; n_{0}\right) ; & \text { se } D_{m_{0} ; n_{0}}<0 \\
0 & \text { se } D_{m_{0} ; n_{0}}=0
\end{array}
\end{aligned}
$$

Através dos desl ocamento em direções diferentes de $z$, a técni ca pode ser adaptada para o objetivo desejado (suavização ou aguçamento). Porém Zhang e Allebach (2008) cita que se o interval o do fil tro é desl ocado na direção errada, grandes erros irão ocorrer. São indicadas formas

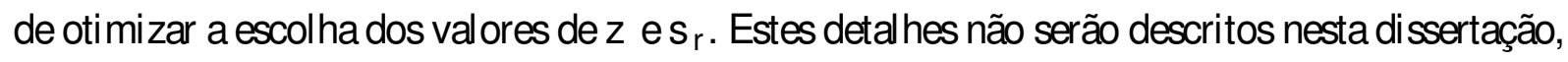
levando em consi deração que o filtro ABF neste contexto somente será utilizado para suavização. Este fil tro será utilizado neste trabal ho devido a sua capaci dade de não criar artefatos nas bordas, mel horando assim a qual idade de nitidez das mesmas em comparação ao filtro Bilateral .

\subsubsection{Non-Local Means}

O al goritmo Non-Local Means (NLM) baseia-se na ideia de que as imagens possuem características espacial mente recorrentes, ou que se repetem em várias partes, sendo possível utilizar essa informação para realizar a filtragem, extrapolando os limites locais. O algoritmo basi camente real iza um médi a ponderada de todos os pixels da imagem, ou de uma janela em questão, para estimar o valor de um pixel i (BUADES; COLL; MOREL, 2005).

A Figura 12 representa o esquema de funcionamento do algoritmo Non-Local Means. Nesta imagem é possível verificar que a região (patch) centrada no pixel p possui grande semel hança com as regi ões centradas nos pixels q1 e q2. Esta semel hança é dada de acordo com a distância entre os patches em questão com os demais pixels da janela limitante. Porém, ele não possui semel hança com a região centrada no pixel q3. Sendo assim, o peso será maior nos pixels em que a vizinhança é semel hante, e menor nos pixel s que contiverem uma vizinhança diferente.

Para a execução do al goritmo al guns parâmetros são necessários, sendo eles: tamanho da janela, tamanho do patch ou vizinhança e val or do parâmetro de filtragem ou fator de decai mento h. O tamanho da janel a representa o limite de busca por pixels com vizinhança si milares ao pixel em questão. Buades, Coll e Morel (2005) sugerem que o val or dajanela seja $21 \times 21$. O tamanho do patch representa a vizinhança do pixel em análise, sendo que o tamanho de sua vizinhança é igual ao dos outros pixels dentro da janela de busca. $O$ tamanho da vizinhança sugerido é $7 \times 7$. O fator de decaimento $\mathrm{h}$ representa o quanto uma imagem será filtrada, sendo que quanto menor 
Figura 12 - Esquema do NL-Means.

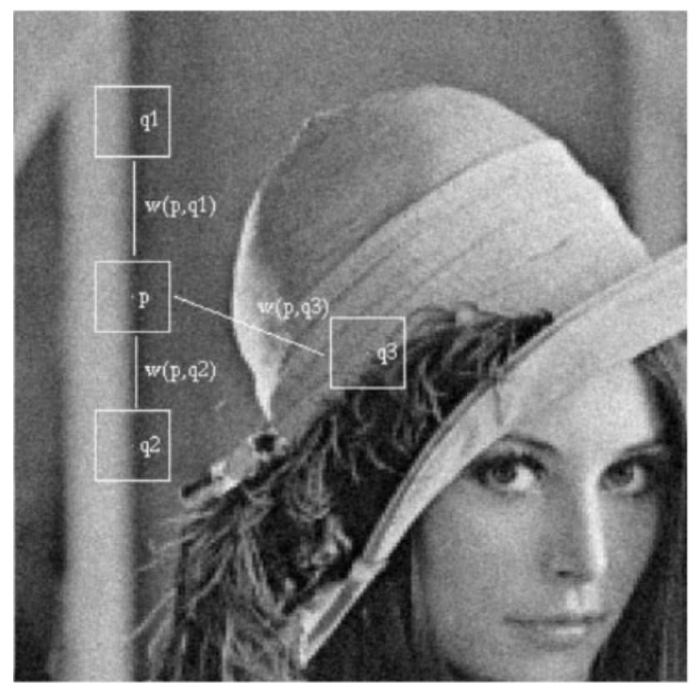

Fonte: Buades, Coll e Morel (2005) $\propto 2005$ IEEE.

o val or de h, menor a filtragem. No entanto, quanto mai or o valor, maior será a filtragem do ruído e também a perda de detal hes, como texturas.

Figura 13 - Exemplo da janela de busca e dos patches da vizinhança.

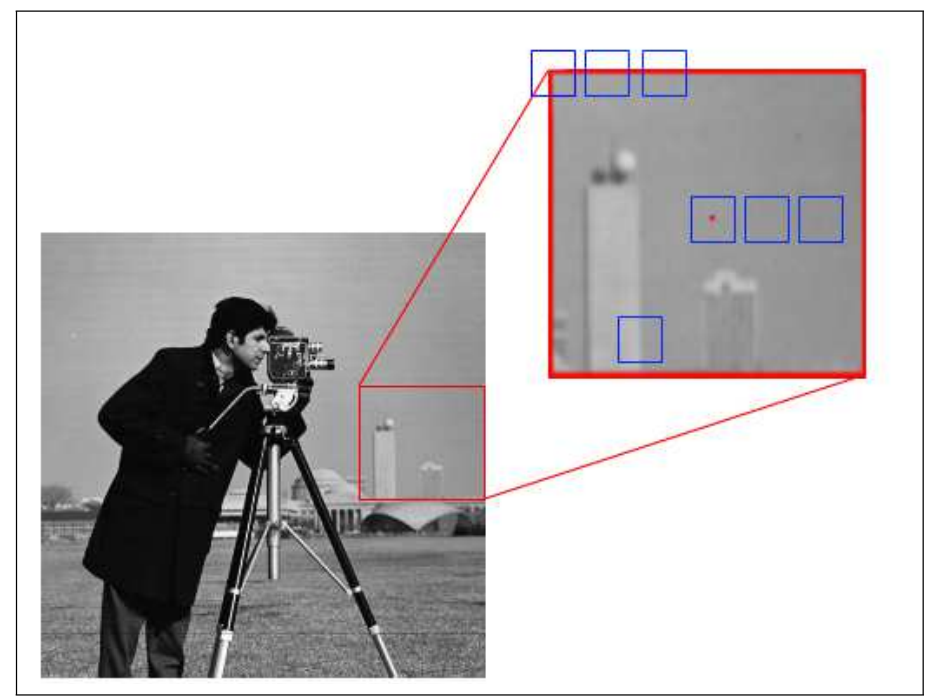

Fonte: Elaborada pelo autor.

A Figura 13 ilustra o uso da janel a de busca e das vizinhanças. Em vermel ho é destacada uma janela, com o pixel em questão central izado. Nesta janela é feito o cál cul o dos pesos de todos os pixels baseado na di stância entre a vizinhança do pixel (retângulo em azul) em questão, com todas as vizinhanças de todos os outros pixels da janela, com vizinhanças do mesmo tamanho do pixel em questão. 
O novo val or do pixel é cal culado a partir da seguinte equação:

$$
N L[v](i)=\hat{A}_{j \in S} w(i ; j) v(j) ;
$$

onde $\mathrm{NL}[\mathrm{v}](\mathrm{i})$ representa o novo val or do pixel $\mathrm{i}, \mathrm{w}(\mathrm{i} ; \mathrm{j})$ representa os pesos relativos ao pixel $v(j)$, peso este definido pela semel hança das vizinhanças entre os pixels i e j. Os val ores dos pesos são cal culados a partir da seguinte equação:

$$
w(i ; j)=\frac{1}{Z(i)} e^{(-1) \frac{\left\|v\left(N_{i}\right)-v\left(N_{j}\right)\right\|_{2 ; a}^{2}}{n^{2}}} ;
$$

onde h é um fator de decaimento, $v\left(N_{i}\right)$ e $v\left(N_{j}\right)$ representam os vetores (patch) centrados nos pixels i e j. Z(i) é um fator de normalização, definido pela equação:

$$
Z(i ; j)=\hat{A}_{j \in S} e^{(-1) \frac{\left\|v\left(N_{i}\right)-v\left(N_{j}\right)\right\|_{2 ; a}^{2}}{n^{2}}} ;
$$

sendo que o termo $\left\|v\left(N_{i}\right)-v\left(N_{j}\right)\right\|_{2 ; a}^{2}$ é denominado distância Euclidiana quadrática ponderada, definida pela seguinte equação:

$$
\left\|v\left(N_{i}\right)-v\left(N_{j}\right)\right\|_{2 ; a}^{2}={\underset{j=1}{\mathrm{~A}}}_{\mathrm{k}}^{\mathrm{k}} a_{j}\left(x_{j} ; y_{j}\right)^{2}
$$

onde $a_{\mathrm{j}}$ é estimado usando um kernel Gaussiano bidimensional.

Um problema conhecido na equação 3.13 é que o pixel i tende a ter um peso excessivo quando o cál culo é feito com ele próprio (BUADES; COLL; MOREL, 2011). Para resolver esse problema, o peso é definido como o val or máximo da matriz de pesos cal culada, excluindo a posição central (o pixel a ser filtrado), seguindo a seguinte equação:

$$
w(i ; i)=\max _{j \in S ; j=i}[w(i ; j)]:
$$

Buades, Coll e Morel (2005) citam que o Non-Local Means é superior aos filtros Gaussiano-2D, Ani sotropic e Total Variation através de testes que foram real izados utilizando ruídos aditivos brancos (Gaussi ano com média zero). É importante sal ientar que a técnica Total Variation é amplamente utilizada para real izar filtragem em imagens de microscopia e imagens médicas. A expectativa é que as técnicas de filtragem não locais apresentem também um bom desempenho na filtragem de imagens LEEM.

\subsubsection{Block-M atching and 3-D Filtering}

O al goritmo Block-Matching and 3-D Filtering (BM3D) foi inspirado no mesmo princípio do NLM, que expl ora pequenos blocos da imagem com uma al ta si milaridade para real izar a 
filtragem do ruído. Esta técnica, desenvolvida por Dabov et al. (2007) deu origem a um novo processo de filtragem denominado filtragem col aborativa.

O BM3D é resumido em duas etapas: estimativa básica e estimativa final. A primeira etapa é consi derada um estágio de estimativa da imagem sem ruído através do hard thresholding. Já a segunda etapa, emprega a imagem resul tante da estimativa inicial para realizar, com uma mai or eficiência, o agrupamento dos patches. Além disso, utiliza também a estimativa inicial como entrada para o filtro de Wiener, que requer um sinal livre de ruído. O diagrama do processo éilustrado na Figura 14.

Figura 14 - Diagrama BM3D.

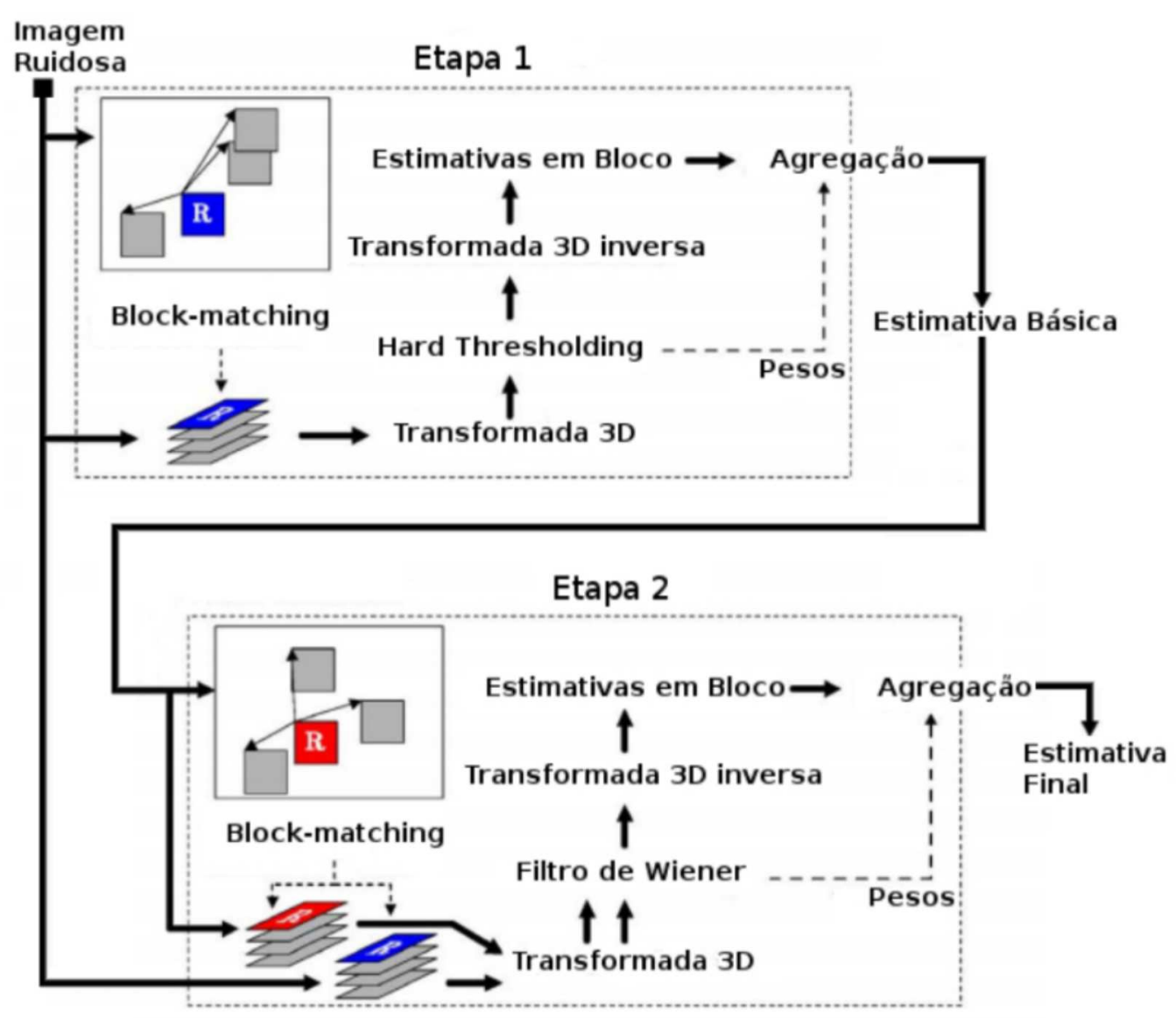

Fonte: Adaptada de Dabov et al. (2007) ๔ 2007 IEEE.

Nas duas etapas do al goritmo é real izada afil tragem colaborativa. Esteéum procedimento de agrupamento e de filtragem, sendo real izado em quatro etapas: 1) encontrar os patches ou bl ocos similares em uma determinada janel a da imagem e agrupá-los em um bloco 3D; 2) aplicar uma transformada linear 3D no grupo de patches; 3) aplicar o hard threshold (etapa 1) ou filtragem de Wiener (etapa 2); 4) aplicar a transformada 3D inversa no bloco 3D e real izar a agregação dos patches que se sobrepõem (LEBRUN, 2012).

No início da primei ra etapa é real izado o block-matching. A busca é um processo anál ogo ao do algoritmo NLM: é definida uma janela de busca e o tamanho do patch ao redor do pixel de 
referência $\left(\mathrm{X}_{\mathrm{R}}\right)$ e o pixel de análise $(\mathrm{x})$, seguida da procura por bl ocos semel hantes. Ao encontrar um bloco semel hante este é inserido em uma pilha (3D) de blocos que possuem uma semel hança limitada por um limiar $\left(\mathrm{t}^{\mathrm{ht}}\right.$ ) que determina o limite para que os patches sejam considerados semel hantes, conforme a equação abaixo:

$$
S_{X_{R}}^{\text {ht }}=\left\{x \in X: d\left(Z_{x_{R}} ; Z_{x}\right) \leq t^{h t}\right\} ;
$$

onde $S_{x_{R}}^{\text {ht }}$ o grupo de patches empilhados em ordem decrescente de si milaridade do topo em direção aos demais el ementos da pilha A similaridade é medida através da distância euclidiana quadrada, como mostra a equação abaixo:

$$
\mathrm{d}\left(\mathrm{Z}_{\mathrm{X}} ; \mathrm{Z}_{\mathrm{x}}\right)=\frac{\left\|^{\circ}\left(\mathrm{T}_{2 \mathrm{D}}^{\mathrm{ht}}\left(\mathrm{Z}_{\mathrm{x}_{\mathrm{R}}}\right)\right)-\circ^{\circ}\left(\mathrm{T}_{2 \mathrm{D}}^{\mathrm{ht}}\left(\mathrm{Z}_{\mathrm{x}}\right)\right)\right\|_{2}^{2}}{\left(\mathrm{~N}_{1}^{\mathrm{ht}}\right)^{2}}
$$

onde $T_{2 \mathrm{D}}^{\text {ht }}$ é uma transformação linear $2 \mathrm{D}$, sendo sugerida pel os autores a transformada wavelet biortogonal 1.5 (Bior1.5), aplicada a cada patch. ${ }^{\circ}$ é definido como o hard thresholding, sendo aplicado nos coeficientes wavelets. $N_{1}^{\text {ht }}$ é o tamanho do bloco utilizado. Os autores não aplicam a distância euclidi ana quadrada di retamente nos patches anal isados, pois verificaram que quando os patches possuem sobreposição estes são inseridos erroneamente no grupo de patches si milares (DABOV et al., 2007).

A pós o empi Ihamento dos patches, real iza-se a filtragem colaborativa. Esta filtragem se resume em aplicar uma transformadalinear $3 \mathrm{D}$ no grupo $\left(Z_{\mathrm{Sh}_{\mathrm{R}}}\right)$ e apósisso real izar a transformada inversa Por questão de praticidade, a transformada 3D é substituída por uma transformada wavel et 2D (Bior1.5) em cada patch do grupo e após isso é aplicada uma transformada 1D na terceira dimensão do grupo. Real izada a transf ormação linear, aplica-se o hard thresholding para atenuar o ruído. Por fim, uma transformada inversa é aplicada e os patches do grupo são então reposicionados na imagem. Por existir patches com sobreposição, a estimativa dos pixels é real izada pel a médi a ponderada das estimativas (LEBRUN, 2012).

Na segunda etapa, a técnica de block-matching é utilizada novamente para agrupar os patches. Entretanto, o agrupamento é real izado a partir da estimativa básica gerada a partir da primeira etapa. Nesta etapa de agrupamento, são geradas duas pil has de patches. A primeira pilha é gerada pelo bl ock-matching da imagem resultante da estimativa básica e a segunda pil ha pelo o agrupamento dos patches correspondentes na imagem ruidosa.

Assim como na primeira etapa, uma transformada 3D é aplicada aos grupos. Porém, a estimativa final é real izada aplicando o filtro de Wiener aos grupos de patches ruidosos. Como o filtro de Wiener visa mi nimizar o erro médio quadrático entre duas imagens, o grupo gerado pela primeira etapa é usado no processo de filtragem (DABOV et al., 2007).

Por fim, assim como na primeira etapa, após a filtragem é real izada uma transformada 3D inversa e os patches são reposicionados em seus locais de origem, aplicando a agregação para 
estimar os val ores dos pixels devido a sobreposi ção. Diversos testes com diferentes transformadas foram real izados pel os autores que não serão citados neste trabal ho. Para mais detal hes consultar a referência original do método.

Este filtro possui resultados de filtragem surpreendentes para ruídos do tipo Gaussiano, al ém de bons resul tados em diversas apl icações. Uma evol ução desse filtro, o BM3D-SAPCA (DABOV et al., 2009) é consi derado o estado da arte para a filtragem de imagens em escal a de cinza Porém, podem produzir artefatos oscilatórios " ringing artifacts" (KNAUS; ZWICKER, 2013) em al gumas regi ões de bordas da imagem, o que inviabiliza sua utilização neste trabal ho. O filtro "original" (BM3D) proveu mel hores resultados de filtragem das imagens LEEM.

\subsection{Redução de borramento em imagens}

Do mesmo modo que as técnicas de remoção de ruído ou filtragem tratam a imagem levando em consideração que a degradação presente é somente o ruído, as técnicas de remoção do borramento normal mente não consideram que a imagem possui ruído ou consideram que o nível do ruído é pequeno. Porém, quando a presença do ruído é alta, as técnicas de redução de borramento podem amplificar o ruído, uma explicação mais detal hada pode ser visto no trabal ho de Ponti (2008, p. 25-31). Entretanto, as técnicas de redução de borramento podem realçar detal hes não antes visíveis, além de mel horar a nitidez de detal hes já antes visíveis como bordas, texturas e pequenos objetos.

Conhecendo a função de degradação ou tendo uma estimativa da mesma, é possível utilizar al gumas técnicas de filtragem que buscam restaurar as imagens degradadas. A mais simples e pouco utilizada é a filtragem inversa, que busca dividir a imagem degrada pela PSF. Porém, devido a diversos fatores, como a presença de ruídos, esta fil tragem mui to frequentemente produz resultados insatisfatórios. Um dos filtros mais utilizados é o filtro de Wiener, que será explicado a seguir.

\subsubsection{Filtro de Wiener}

Ao contrário do filtro inverso, a filtragem de Wiener trabal ha na restauração tanto com a função de degradação quanto com o ruído. Este filtro tem como objetivo encontrar uma estimativa $\hat{f}$ daimagem não corrompi da $f$, de forma que o erro médio quadrático entre el as seja mi nimizado segundo a equação:

$$
e^{2}=E\left\{(f-\hat{f})^{2}\right\}
$$

onde $E\{:\}$ é o valor esperado do argumento. Presumindo que a imagem e o ruído não são correl acionados, que um deles tenha médi a zero (GONZALEZ; WOODS, 2006), esta equação 
pode ser escrita no domínio da frequência da seguinte forma:

$$
\hat{\mathrm{F}}(\mathrm{u} ; \mathrm{v})=\frac{1}{\mathrm{H}(\mathrm{u} ; \mathrm{v})} \frac{|\mathrm{H}(\mathrm{u} ; \mathrm{v})|^{2}}{|\mathrm{H}(\mathrm{u} ; \mathrm{v})|^{2}+\mathrm{S}_{\mathrm{h}}(\mathrm{u} ; \mathrm{v})=\mathrm{S}_{\mathrm{f}}(\mathrm{u} ; \mathrm{v})} \mathrm{G}(\mathrm{u} ; \mathrm{v})
$$

onde $|\mathrm{H}(\mathrm{u} ; \mathrm{v})|^{2}$ é a multiplicação de $\mathrm{H}^{*}(\mathrm{u} ; \mathrm{v})$ por $\mathrm{H}(\mathrm{u} ; \mathrm{v}), \mathrm{H}^{*}(\mathrm{u} ; \mathrm{v})$ é o complexo conjugado de $H(u ; v), S_{h}(u ; v)$ éo espectro de potência do ruído $\left(|N(u ; v)|^{2}\right)$ e $S_{f}(u ; v)$ éo espectro de potência da imagem não degradada $\left(|F(u ; v)|^{2}\right)$. Caso o ruído seja zero, o filtro de Wiener passa a ser o filtro Inverso.

Como na maioria das vezes não se conhece o espectro de potência da imagem não degradada, frequentemente é utilizada uma aproximação da Equação 3.20 na expressão:

$$
\hat{F}(u ; v)=\frac{1}{H(u ; v)} \frac{|H(u ; v)|^{2}}{|H(u ; v)|^{2}+K} G(u ; v)
$$

sendo $\mathrm{K}$ uma constante que é adicionada a todos os termos de $|\mathrm{H}(\mathrm{u} ; \mathrm{v})|^{2}$. Esta aproximação somente é possível se o ruído presente for branco, situação em que o seu espectro é uma constante. Este processo deve ser feito iterativamente até encontrar um valor de $\mathrm{K}$ que leve a um bom resultado.

Como iterar o val or de $K$ até encontrar um val or ótimo é um processo nem sempre viável, outra maneira de estimar os val ores de $S_{h}(u ; v)$ e $S_{f}(u ; v)$ é utilizar a variância do ruído na imagem:

$\cdot \hat{S}_{h}(u ; v)=s_{h}^{2}$.

. $\hat{S}_{f}(u ; v)=1=N^{2}\left[G(u ; v) G^{*}(u ; v)\right]-s_{h}^{2}$.

O filtro de Wiener é um filtro clássico, com resultados satisf atórios em diversas áreas. Como neste trabal ho o borramento da imagem é pequeno, tanto a utilização deste filtro quanto o filtro de Mínimos Quadráticos com Restrição, que será explicado na próxima seção, foram satisfatórios.

\subsubsection{Filtro mínimos quadráticos com restrição}

Em praticamente todos o filtros que removem o borramento, é necessário o conhecimento da PSF que af eta a imagem, com exceção do método de deconvol ução cega. Este procura estimar a PSF com base na imagem, e não será di scutido neste trabal ho. Porém, além da PSF o filtro de Wiener necessita de dados adi cionais que são difíceis de estimar: o espectro de potência do ruído e o espectro da imagem sem ruído.

O filtro de mínimos quadráticos com restrição (do inglês Constrained Least Squares Filtering (CLSF)) necessita apenas do conhecimento da PSF, da média e da variância da imagem. 
Além de requerer menor conhecimento a priori da função de degracação, este filtro apresenta, para cada imagem que lhe é apresentado, o resultado ótimo (GONZALEZ; WOODS, 2006).

Um problema encontrado no filtro inverso é a sensibilidade da PSF com o ruído. No filtro CLSF é empregada a segunda derivada de uma imagem, utilizando assim um filtro laplaciano. A equação deste filtro pode ser escrita da seguinte forma:

$$
\hat{F}(u ; v)=\frac{H^{*}(u ; v)}{|H(u ; v)|^{2}+I|P(u ; v)|^{2}} G(u ; v) \text {; }
$$

onde l éum parâmetro de regularização e $\mathrm{P}(\mathrm{u} ; \mathrm{x})$ éa transf ormação para o domínio da frequência do Iaplaciano:

$$
P(u ; v)=\begin{array}{ccccc}
2 & 0 & -1 & 0 & 3 \\
4 & -1 & 4 & -15 \\
0 & -1 & 0
\end{array}
$$

Além do filtro de Wiener e do filtro CLSF, existem diversos outros métodos utilizados para realizar a deconvolução das imagens a partir da PSF. Pode-se citar os métodos Blind Deconvolution, que al tera a PSF a cada iteração a fim de estimar a imagem deconvol ui da e a PSF ideal ao final do processo. Além deste método, outro muito utilizado é o Richardson-Lucy, que será explicado abaixo.

\subsubsection{Richardson-Lucy}

De acordo com Biggs e Andrews (1997) Richardson-Lucy (RL) é um al goritmo de de convolução não linear e iterativo. Algoritmos iterativos são comuns na restauração/deconvolução de imagens de telescópios (como o Telescópio Espacial Hubble), tomografia médica e sensores de satélite. Por não ser linear, o método oferece uma restauração mais eficaz do que técni cas mais simples, tais como a filtragem inversa, e que muitas vezes fal ha na restauração com a presença de ruídos. Técni cas não lineares são úteis quando os dados são ruidosos ou incompl etos, o que geral mente é o caso em aplicações práticas.

Por operarem sobre o resultado da iteração anterior, técnicas iterativas são normal mente lentas para convergir ao resul tado final. Contudo apresentam melhores resultados em comparação com métodos lineares, exigindo maior complexidade computacional (BIGGS; ANDREWS, 1997). Richardson-Lucy não é uma exceção e é consideravel mente mais lento que os filtros de Wiener e CLSF citados anteriormente. Além disso, o al goritmo requer uma boa esti mativa do processo através do qual a imagem é degradada. Portanto, o conhecimento da PSF é necessário para que a restauração seja real izada. 
O algoritmo RL pode ser descrito sucintamente pela Equação 3.24.

$$
\hat{f}(x ; y)_{k+1}=\hat{f}(x ; y)_{k} \quad h(x ; y) ? \frac{g(x ; y)}{h(x ; y)^{*} \hat{f}(x ; y)_{k}}, y\left(\hat{f}(x ; y)_{k}\right)
$$

onde $\hat{f}(x ; y)_{k}$ é a estimativa de $f(x ; y)$ após $k$ iterações, ? indica o operador de correlação, * indica o operador de convolução, e y (:::) é a função de RL.

O procedimento descrito pela Equação 3.24 é inicialmente ajustado com $\hat{f}(x ; y)_{0}=$ $g(x ; y)$. Em outras palavras, o algoritmo é semeado utilizando como primeira estimativa a distribuição de entrada para que a saída seja cal cul ada. $A$ menos que aimagem esteja severamente degradada, a saída não é muito diferente em comparação a distribuição de entrada, contudo este simples procedimento converge bem (SOLOMON; BRECKON, 2011).

$\mathrm{O}$ algoritmo RL mantém duas propriedades entre a imagem distorcida e a imagem restaurada: conservação de energia e não negatividade. Manter a energia total é importante para diversas aplicações, tais como a astronomia e a mi croscopia eletrônica, onde a di storção não altera o número total de fótons ou elétrons detectados. Não negatividade é importante, pois a contagem de fótons ou de elétrons em qualquer pixel não pode ser negativo (BIGGS; ANDREWS, 1997). 
CAPÍTULO

\section{4}

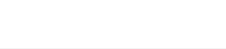

\section{MÉTODO PROPOSTO}

Apesar dos grande avanços das técnicas de filtragem de ruídos através do surgimento das técnicas não locais, um dos maiores problemas ainda encontrados é a remoção de pequenas estruturas e texturas durante o processo de filtragem. Na área de filtragem de imagens, poucas técnicas existem, com destaque para o filtro NLM-LBP desenvolvido por Khellah (2013). Esta técnica utiliza o filtro Non-Local Means e modifica sua função de ponderação inserindo um parâmetro de ponderação proveniente do descritor de textura Local Binary Patterns (LBP) (OJALA; PIETIKAINEN; HARWOOD, 1994). Todavia, a aplicação deste filtro em vídeos e imagens 3D mostrou-se insati ffatório quanto existe a presença de grandes níveis de ruído. Este trabal ho de mestrado propõe uma nova técnica de filtragem que utiliza a essência do método NLM-LBP, modificando a função de ponderação da versão 3D do al goritmo NLM. Além disso, propõe também uma versão adaptativa que apresentou bons resultados em imagens que possuem predominância de regiões homogêneas (pouca textura).

Para entender o funcionamento do al goritmo é necessári a a compreensão das técnicas NLM3D, LBP, (Local Binary Patterns on Three Orthogonal Planes (LBP-TOP) (ZHAO; PIETIKAINEN, 2007), Most Significant Bits (MSB) e NLM-LBP. Estas são descritas na seção 4.1. Os métodos propostos são apresentados na seção 4.2.

\subsection{Embasamento Teórico}

Val e recapitul ar que muitos dos dados LEEM são disponibilizados no formato de vídeo, o que estimul ou o desenvolvimento de métodos de elimi nação de ruído que pudessem explorar um conjunto de quadros, ao invés de tratar quadros individual mente. Primeiramente, é apresentada uma variação para vídeos do al goritmo NLM chamado NLM3D. Em seguida, apresenta-se o descritor de texturas LBP para imagens e uma de suas variantes para descrição de vídeos (LPB-TOP). A técnica de quantização Most Significant Bits (MSB) é também apresentada e foi utilizada para mel horar robustez do LBP-TOP ao ruído. Final mente, é apresentado o filtro 
NLM-LBP, uma variante do NLM, que utiliza o descritor LBP para mel horar a filtragem de imagens com textura, sendo esta a técnica base dos métodos propostos.

\subsubsection{NLM 3D}

O método NLM foi estendido para processar dados em 3D, mais precisamente vídeos, tendo em conta dois recursos extras (BUADES; COLL; MOREL, 2005). Em primeiro lugar, o pixel a ser suavizado, denotada por i naformul ação 2D do NLM, contém uma terceira coordenada (temporal, no caso de vídeos). Em segundo lugar, a janel a de pesquisa S tem um comprimento temporal definida por um parâmetro $\left(\mathrm{s}_{\mathrm{t}}\right)$. Com isso em mente, a compreensão e implementação do método NLM para vídeos é bastante simples.

Neste trabalho - com o objetivo de aproveitar a informação espaço-temporal — é utilizada uma versão ligei ramente diferente do al goritmo NLM3D. Esta versão consi dera não só uma janel a de pesqui sa 3D, mas também uma vizinhança 3D ao cal cular a semelhança entre dois pixels. Consequentemente, podemos adicionar um parâmetro extra $p_{t}$, que define a duração temporal (número de quadros) sobre a qual a vizinhança será expandida $\mathrm{N}_{\mathrm{i}} \mathrm{e} \mathrm{N} \mathrm{J}$, nos métodos propostos este parâmetro é do mesmo tamanho da janela de buscas. Entretanto, no método NLM3D, este parâmetro indica a quantidade de quadros que será utilizada temporal mente. A introdução de tais modificações requer uma máscara Gaussiana 3D para cal cular a distância Euclidiana ponderada.

\subsubsection{LBP}

Local Binary Patterns (LBP) (OJALA; PIETIKAINEN; HARWOOD, 1994) é uma das abordagens mais bem sucedi das para descrever texturas. Dado o bom desempenho da proposta original, surgiram diversas variantes e mel horias do LBP (NANNI; LUMINI; BRAHNAM, 2012; OJALA; PIETIKäl NEN; MäENPää, 2002). Esta seção apresenta a versão LBP de Ojala, Pietikäinen e Mäenpää (2002) utilizado em (KHELLAH, 2013) e nos al goritmos propostos. Ela consi dera os padrões uniformes e é invariante a mudanças na intensidade dos pixels, escal a e rotação.

Na formul ação do LBP, uma textura $T^{1}$ para um pixel $g_{c}$ é a distribuição conjunta de $g_{c}$ e uma vizinhança de tamanho $P$, dada pela equação abai xo:

$$
\mathrm{T}=\mathrm{t}\left(g_{c} ; g_{0} ; \ldots ; g_{P-1}\right)
$$

onde $g_{0} ;: \ldots ; g_{P-1}$ são o $P$ vizinhos de $g_{c}$. Além disso, o arranjo espacial desta vizinhança é geral mente circular ou quadrada. Uma vizinhança circular é defini da por amostragem de pontos $\mathrm{P}$, igual mente espaçados em um círculo de raio $\mathrm{R}$, que é centrada em $g_{c}$. Um exemplo dessa

1 Conforme definido por Ojala, Pietikäinen e Mäenpää (2002). Em processamento de imagem tradicional não há nenhuma definição universal de textura 
vizinhança é ilustrado na Figura 15a. Os pontos não localizados no centro de um pixel precisam ter seus val ores interpolados (por exemplo, por uma interpolação bi-linear). Uma vizinhança quadrado é obtido de forma semel hante, onde os vizinhos $P$ são igual mente espaçados ao longo de um quadrado de lado $\mathrm{R}$, ilustrado na Figura $15 \mathrm{~b}$.

Figura 15 - Diferentes tipos de vizinhanças para raio $R=1$ e $P=8$.

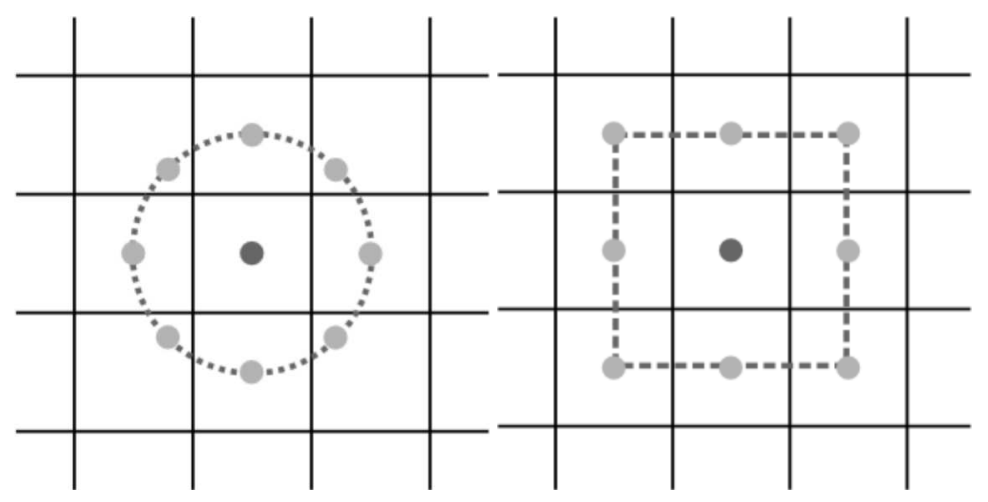

(a) Vizinhança circular

(b) Vizinhança quadrada

Fonte: Elaborada pelo autor.

Para al cançar invariância às mudanças de tons de cinza, o val or de $g_{c}$ é subtraído de todos os seus vizinhos, segundo a equação:

$$
T=t\left(g_{c} ; g_{0}-g_{c} ; \cdots ; g_{P-1}-g_{c}\right):
$$

Esta mudança não causa perda de inf ormações. Além disso, $g_{p}-g_{c}(p=0 ; 1 ; \ldots ; P-1)$ são invariáveis a mudanças nos tons de cinza. No entanto, $g_{c}$ e, consequentemente, a equação $g_{p}-g_{c}(p=0 ; 1 ; \ldots ;: ;-1)$ não são invariáveis a mudanças em tons de cinza. Visando superar este problema, duas aproximações (que implicam na perda de informações) são feitas. Em primeiro lugar, $g_{c}$ e $g_{p}-g_{c}(p=0 ; 1 ; \ldots ; P-1)$ são considerados termos independentes. Em segundo lugar, o termo $t\left(g_{c}\right)$ é removido das definições de $T$ por descrever a di stribui ção em tons de cinza dentro da imagem e não fornecer inf ormação estrutural relevante. Estas aproximações são apresentados na equação abaixo:

$$
\begin{aligned}
T & \approx t\left(g_{c}\right) t\left(g_{0}-g_{c} ; \cdots ; g_{P-1}-g_{c}\right) \\
& \approx t\left(g_{0}-g_{c} ; \ldots ; g_{P-1}-g_{c}\right):
\end{aligned}
$$

Embora o operador de textura apresentado na equação 4.3 seja invariante a mudanças dos tons de cinza, ele não é invariante a escal a. Para que isso ocorra, basta considerar os si nais das diferenças:

$$
T \approx t\left(s\left(g_{0}-g_{c}\right) ;: ; ; s\left(g_{P-1}-g_{c}\right)\right)
$$


onde a função sinal sé dada por:

$$
s(x)=\begin{aligned}
& <_{1}^{<}, \quad \text { if } x \geq 0 \\
& : 0 ; \quad \text { if } x<0 .
\end{aligned}
$$

Com a distribuição T definida por zeros e uns, é possível gerar a primeira versão do operador LBP segundo a equação:

$$
L_{B P}, R=\stackrel{P}{A}=0_{p=0}^{1} s\left(g_{p}-g_{c}\right) 2^{p}:
$$

Para tornar o operador invariante a rotação, um novo operador ( $\left(\mathrm{BPP}_{\mathrm{P}, \mathrm{R}}^{\mathrm{r}}\right)$ é definido através da real ização de oper ações de desl ocamentos circulares de bits em LBP,R. O novo operador é então definido como:

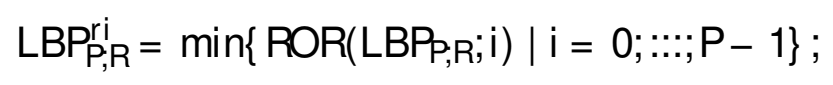

onde $\mathrm{ROR}(I ; \mathrm{m})$ é uma função que realizal deslocamentos circulares de bits em $\mathrm{m}$.

O operador $L B P P_{P, R}^{r i}$ é invariante a mudanças em tons de cinza, mudanças na escala e rotação. No entanto, observou-se que a mai or parte das possíveis transições $L B P P_{P, R}^{r i}$ ocorrem muito esporadicamente. Destas, apenas oito transições são responsáveis por mais de $90 \%$ das observações (PIETIKälNEN; OJALA; XU, 2000). No entanto, os padrões mais comuns foram as que, quando considerados circularmente, exibiram duas transições de bit ou menos ( $0-1$ ou 1-0). Estes padrões foram nomeados uniformes. Este conceito éilustrado na Figura 16, onde os 8 possíveis padrões uniformes para uma vizinhança circular $(P=8 \mathrm{e} R=1)$ são apresentados.

Com o código LBP computado para cada pixel, podemos final mente cal cular o descritor de textura LBP: um hi stograma em que cada padrão uniforme tem o seu próprio bin e os padrões não uniformes são todos mapeados para um único bin extra. O histograma pode ser cal culado para toda a imagem, ou para as célu las da imagem. Neste último, histogramas de todas as células são concatenados para gerar o vetor de característica final.

\subsubsection{LBP-TOP}

O descritor de texturas LBP-TOP (ZHAO; PIETIKAINEN, 2007) é uma extensão do descritor LBP para a representação de vídeos. Ao considerar o vídeo como uma função $f(x ; y ; t)$ - com $x$ e y representando uma posição espacial $2 \mathrm{D}$ et a coordenada temporal - um descritor $2 \mathrm{D}$ LBP é cal cul ado para cada plano XY, XT eYT dentro do vídeo. Em segui da, três histogramas são computados, uma para cada conjunto de planos (XY, XT eYT). O descritor final é obtido pel a concatenação dos três histogramas. Este processo é mostrado na Figura 17. Assim como na versão 2D LBP, os hi stogramas não são computados para todo o vídeo. Nos métodos propostos, 
Figura 16 - Todos os possíveis padrões uniformes para um bai rro circular de $\mathrm{R}=1$ eP $=8$. Os padrões 0 e 8 não tem nenhuma transição, enquanto o resto dos padrões possuem duas transições.

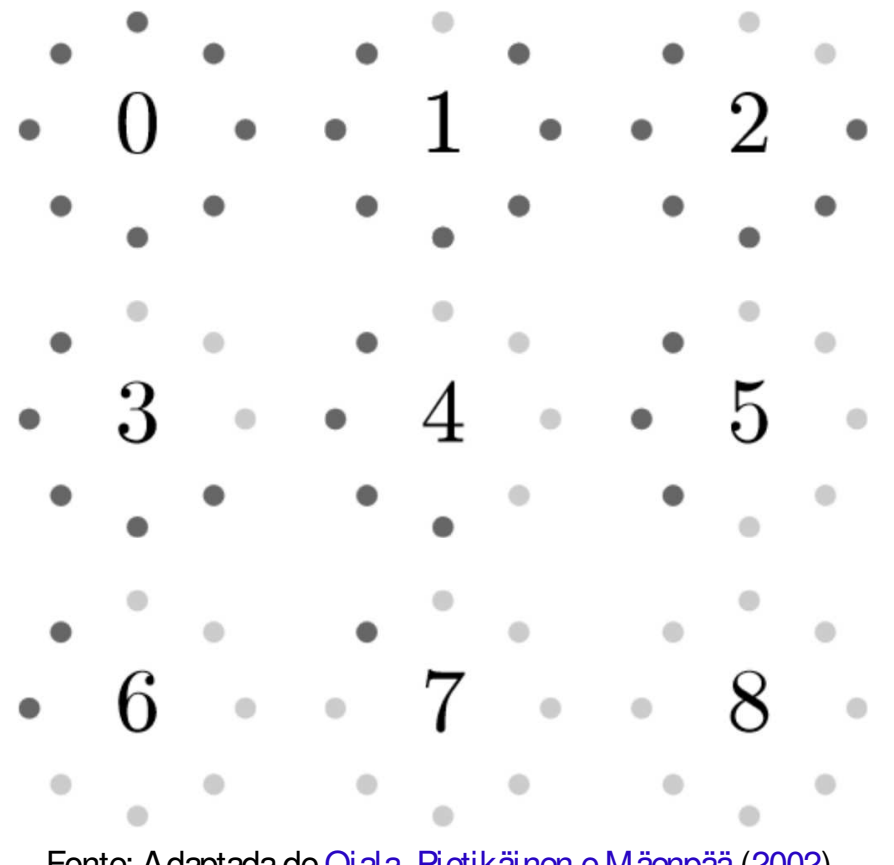

Fonte: Adaptada de Ojala, Pietikäinen e Mäenpää (2002).

durante o processo de filtragem é definida uma vizinhança entorno do pixel a ser filtrado. Utilizase esta mesma janela para cal cular o hi stograma do vídeo LBP a ser utilizado, portanto a cada pixels a ser filtrado será gerado um histograma relativo a sua vizinhança e comparado aos histogramas de todos os pixels presentes na janela de busca do NLM. Uma explicação mais detal hada será apresentada na Seção 4.2.1.

\subsubsection{MSB}

A quantização por bits mais significativos - Most Significant Bits (MSB) - tem várias aplicações em processamento de imagem e vídeo. Por exemplo, Ponti, Nazaré e Thumé (2016) empregam MSB para reduzir a quantidade de cores em imagens coloridas e, como consequência, reduzir a dimensional idade dos recursos extraídos. Neste trabal ho, usa-se a anál ise de imagem MSB para descartar os bits menos significativos de uma imagem, pois el es possuem uma maior probabilidade de serem af etados por ruídos.

A quantização MSB de um pixel com 8 bits pode ser definido como:

$$
\hat{p}=p \wedge \neg\left(2^{8-n}-1\right) ;
$$

onde pe é a saída (imagem quantizada), p é a imagem de entrada e n é o número dos bi ts de mai or significância de p que estarão contidos em p̂.

Como um exemplo, considere $\mathrm{p}=221$ (val or bi nário $=11011101$ ) e $\mathrm{n}=5$. Computando $2^{8-n}-1$ resulta em 7 (val or binário $=00000111$ ). Então, com a inversão $(\neg)$ de 7 é obtido o valor 248 (val or binário $=11111000$ ). Final mente, através da operação $A N D(\wedge)$ tem-se $\hat{p}=216$ 
Figura 17 - Principais passos do descritor LBP-TOP.

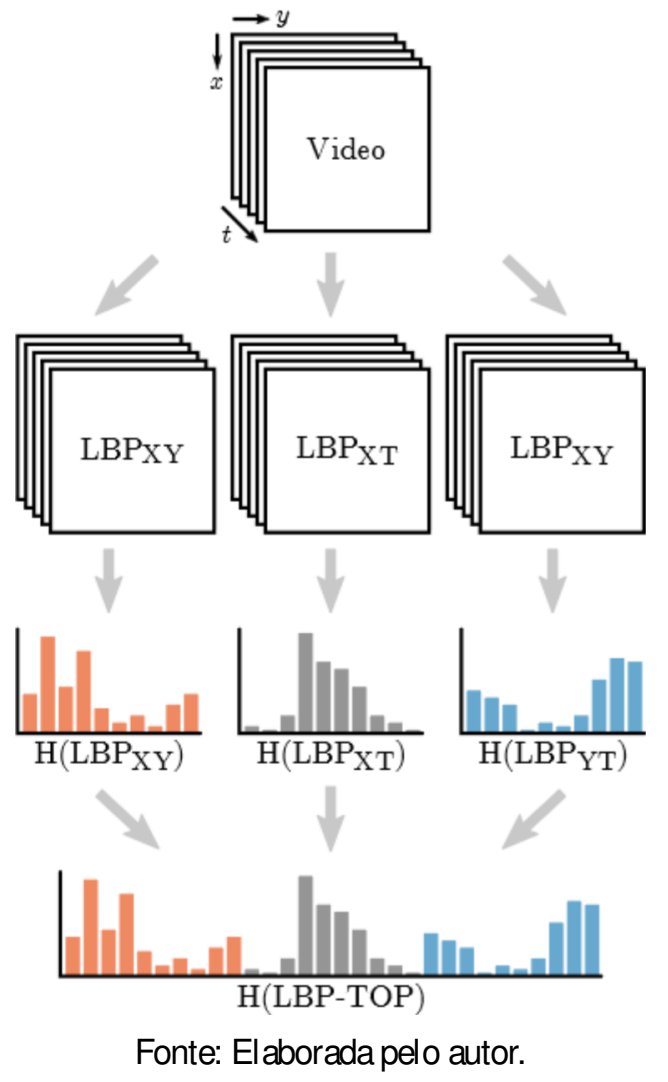

(valor bi nário $=11011000$ ). Neste exemplo, os 5 bits mais significativos de $p$ são armazenados em p̂, enquanto os 3 bits menos significativos tornam-se zero.

\subsubsection{NLM-LBP}

Khellah (2013) desenvolveu uma variante do NLM denomi nada NLM-LBP. Esta técnicas visa preservar texturas durante o processo de filtragem das imagens. Para real izar tal tarefa, este algoritmo utiliza o descritor de texturas LBP para al terar a função de pesos do NLM, segundo a equação:

$$
w_{m}(i ; j)=w_{N L M}(i ; j) \times w_{L B P}(i ; j) ;
$$

onde $w_{N L M}(i ; j)$ é a função de pesos original do NLM (equação 3.13) e wLBP(i; j) é a ponderação por ele realizada com base no descritor LBP na vizinhança do pixel a ser filtrado $N_{i}$ e $N_{j}$. A nova matriz de pesos (w(i; j) LBP) é, então, definida por:

$$
\mathrm{WLBP}_{\mathrm{LB}}(\mathrm{i} ; \mathrm{j})=\frac{1}{\mathrm{Z}(\mathrm{i})} \mathrm{e}^{-\frac{\mathrm{D}\left(\mathrm{H}\left(\mathrm{L}_{\mathrm{i}}\right) ; \mathrm{H}\left(\mathrm{L}_{\mathrm{j}}\right)\right)}{\mathrm{h}(\mathrm{S})}} ;
$$

ondeh(S) éo desvio padrão relativo aos pixels dajanela de busca $S ; L_{i}$ e $L_{j}$ são, respectivamente, os códigos LBP das vizinhanças $\mathrm{N}_{i}$ e $\mathrm{N}_{j} ; \mathrm{H}\left(\mathrm{L}_{\mathrm{i}}\right)$ e H( $\left.\mathrm{L}_{\mathrm{j}}\right)$ são os descritores LBP (hi stogramas) 
de $\mathrm{N}_{\text {i }}$ e N j; Z(i) é o fator de normalização e D éa distância Chi-square computada pela equação:

$$
\mathrm{D}\left(\mathrm{H}\left(\mathrm{L}_{\mathrm{i}}\right) ; \mathrm{H}\left(\mathrm{L}_{\mathrm{j}}\right)\right)=\AA_{\mathrm{n}=1}^{\mathrm{R}} \frac{\left(\mathrm{H}\left(\mathrm{L}_{\mathrm{i}}\right)_{n}-\mathrm{H}\left(\mathrm{L}_{\mathrm{j}}\right)_{n}\right)^{2}}{\mathrm{H}\left(\mathrm{L}_{\mathrm{i}}\right)_{n}+\mathrm{H}\left(\mathrm{L}_{\mathrm{j}}\right)_{\mathrm{n}}} ;
$$

onde $\mathrm{n}$ representa o índice do bin do histograma e B é o tamanho do histograma.

Final mente, é importante salientar que: a) $w_{m}(i ; i)$ deve ser ajustada para evitar um peso excessivo, assim como na definição do NLM original (equação 3.16) e b) a matriz de pesos $w_{m}(i ; j)$ deve ser normalizada, a fim de garantir que a soma de seus elementos seja 1 (um).

A qual idade de filtragem é af etada quando o nível de ruído na imagem éal to. Por isso, neste trabal ho são propostas duas novas técnicas de filtragem que, a lém de utilizar o LBP, também empregam o MSB como um artifício para tornar o LBP mais robusto a ruídos.

\subsection{Técnicas Propostas}

Esta seção apresenta os dois métodos propostos: NLM3D-LBP-MSB e NLM3D-LBPAdaptive (CONTATO et al., 2016). NLM3D-LBP-MSB estende NLM-LPB e é adequado para o processamento de vídeos. Além disso, ao contrário NLM-LBP, este método emprega um passo de quantização MSB para minimizar a influência de ruído na sua função de ponderação, mais especificamente no processo de cál culo do LBP. O segundo método, NLM3D-LBP-Adaptive, rotula cada pixel como sendo parte de uma região uniforme ou não uniforme baseado na quantidade de val ores contidos no último bin do histograma LBP e a filtragem do pixel é finalmente real izada levando em conta o tipo de região que este se encontra. Para ambas as técnicas, foi utilizado o descritor LBP-TOP.

\subsubsection{NLM 3D-LBP-M SB}

O al goritmo proposto, NLM3D-LBP-MSB, é dividido em duas fases: pré-processamento e filtragem do pixel. Pré-processamento começa com uma quantização MSB de cada quadro do vídeo. Esta quantização preserva os $m$ bits mais significativos, onde $m$ é um parâmetro do al goritmo. O vídeo MSB é, então, utilizado para computar o LBP-TOP nos planos ortogonais (XY, XT eYT), produzindo três novos vídeos: LBP $P_{X Y}, L B P_{X T}$ e LBP $P_{Y T}$. Como será exibido na seção de resultados 6.4.3, realizar o cál culo do LBP sobre vídeos MSB, ao invés de fazêlo sobre o vídeo original, produz mel hores resultados de filtragem. O estágio de filtragem utiliza os três vídeos LBP-TOP gerados durante o pré-processamento para cal cul ar a segui nte função de ponderação:

$$
w_{M}(i ; j)=w_{N L M 3 D}(i ; j) \times w_{T O P}(i ; j) ;
$$


onde $W_{N L M 3 D}(i ; j)$ é a matriz de pesos original do NLM3D e $w_{T O P}(i ; j)$ é a função para calcular a matriz de pesos estendida da equação 4.10 para vídeos, definida por:

$$
w_{T O P}(i ; j)=\frac{1}{Z(i)} e^{-\frac{D\left(H\left(L_{i}^{T O P}\right) ; H\left(L_{j}^{T O P}\right)\right)}{h(q)}} ;
$$

onde $h(\mathrm{~S})$ é o desvio padrão relativo aos pixels da janela de busca $S$ (no vídeo MSB); $\mathrm{L}_{i}^{\text {TOP }}$ eL $L_{j}^{T O P}$ são, respectivamente, os códigos $L B P-T O P$ das vizinhanças dos pixels i e j; $H\left(L_{i}^{T O P}\right)$ e $H\left(L_{j}^{T O P}\right)$ são os descritores LBP-TOP (histogramas) de $L_{i}^{T O P}$ e $L_{j}^{T O P}$; $Z(i)$ é o fator de normal ização e $D$ é a di stância Chi-square, dada pela equação 4.11. Como citado anteriormente, para o cál culo da di stância $D$ são utilizados hi stogramas cal cul ados através dos vídeos LBP-TOP. Para cada pixel a ser filtrado é gerado um hi stograma, computado através da vizinhança cúbica do mesmo. A distância Chi-square é cal cul ada entre este histograma e o histograma de todos os pixels presentes na janela de busca do NLM3D.

Deste ponto em diante, o al goritmo proposto é similar ao NLM3D: emprega $w_{M}$ como a matriz de pesos para a filtragem dos val ores de pixels do vídeo original, e não o vídeo MSB. O diagrama da Figura 18 ilustra o processo de filtragem:

Figura 18-Diagrama NLM3D-LBP-MSB

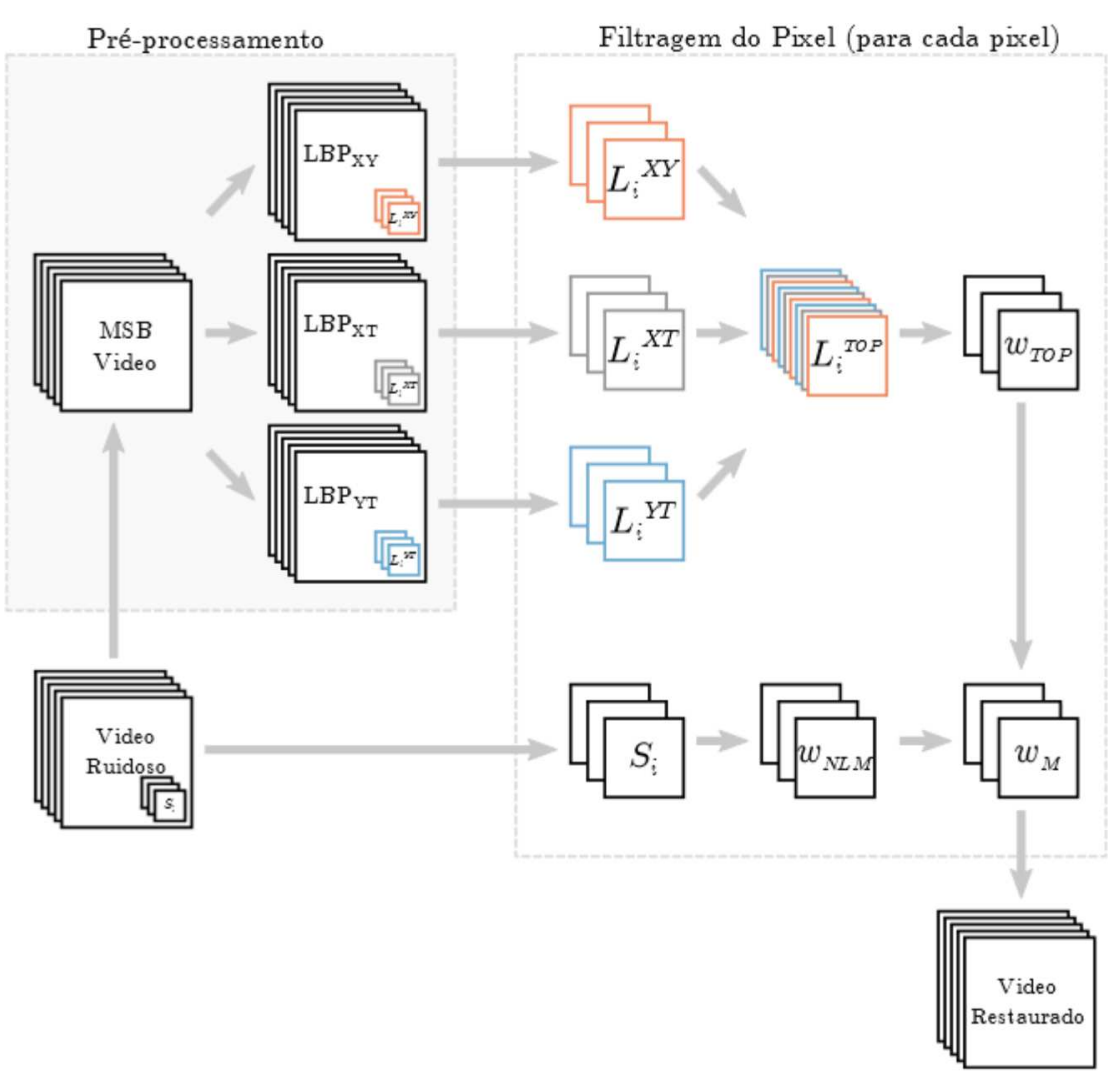

Fonte: Elaborada pelo autor. 


\subsubsection{NLM 3D-LBP-Adaptive}

O método NLM3D-LBP-MSB emprega um descritor LBP-TOP para cal cular a matriz de pesos NLM3D. No entanto, para regiões sem textura ou regiões homogêneas e com al tos níveis de ruído branco Gaussiano, o descritor LBP tende a interpretar o ruído como textura. Como consequência, o al goritmo irá preservar essas regiões ruidosas. Para superar essa limitação, foi proposta uma versão adaptativa do método apresentado na seção anterior, nomeado NLM3DLBP-Adaptive.

Estaversão adaptativa anal isa a soma do último bin dos hi stogramas ger ados pelo LBP em cada pl ano, que representa os padrões não-uniformes. Esta inf ormação é usada para discriminar textura de ruído. Para isso, é introduzido um limiar t . Se a soma destes bins não-uniformes é mai or que o limiar, os pixels são filtrados com a matriz de pesos geradas pelo NLM3D, sem qual quer modificação. Caso contrário, a matriz de pesos cal culada com métodos LBP-TOP e NML3D (equação 4.12) será empregado. Neste segundo caso, a região é interpretada como uma textura e o seu conteúdo será consequentemente preservado. Em outras palavras, esta versão adaptativa é capaz de filtrar regiões homogêneas com altos níveis de ruído Gaussiano, preservando a textura. 



\section{METODOLOGIA}

Este trabal ho de mestrado teve como objetivo analisar técnicas de filtragem, técnicas de redução de borramento e a combinação entre elas, a fim de encontrar a mel hor combi nação destas para a real ização da restauração dos vídeos LEEM, podendo assim suavizar o ruído presente nos vídeos e/ou revelar pequenas estruturas antes não visualizadas. Como objetivo secundário, porém não menos importante, foi desenvolver uma nova técnica de filtragem de vídeos a fim de preservar pequenos detal hes como pequenas estruturas (comumente presentes em imagens de microscopia) e texturas.

Neste capítulo será apresentada a metodologia adotada, descrevendo os materiais e métodos utilizados no seu desenvolvimento. Por fim, são apresentadas as técnicas quantitativas utilizadas para aval iar os experimentos realizados.

\subsection{Materiais}

Como mencionado na introdução, este trabal ho foi conduzido em parceria com o professor Dr. Wen-Xin Tang, da Universidade de Cardiff (UK) e também da Universidade de Monash (Autrália). Parte dos vídeos são provenientes de um equipamento LEEM (Figura 5), projetado por ele. Outros vídeos utilizados nas etapas de restauração são provenientes dos trabal hos de Rogge et al. (2015) e Qin et al. (2015). Além disso, o professor Dr. Gong Chen, colaborador do Dr. Wen-Xin Tang, disponi bilizou diversos vídeos da técnica SPLEEM.

Os testes de análise de ruído, comparações e combi nações dos métodos, foram escritos em MATLAB. Para fim de reproduti bilidade, os scripts e códigos utilizados estão disponíveis em um repositório Git acessivel no endereço <https://github.com/welintonandrey/leem_image_ restoration-MSc-scr>. As novas técnicas de filtragem resultantes deste trabal ho, codificadas em Python, estão disponíveis em outro, e único, repositório Git no endereço <https://github.com/ welintonandrey/3d_denoising>. 


\subsection{Métodos}

O processo de filtragem e análi se dos dados LEEM foi dividido em três etapas e pode ser resumido no diagrama da Figura 19.

Figura 19 - Etapas do trabal ho.
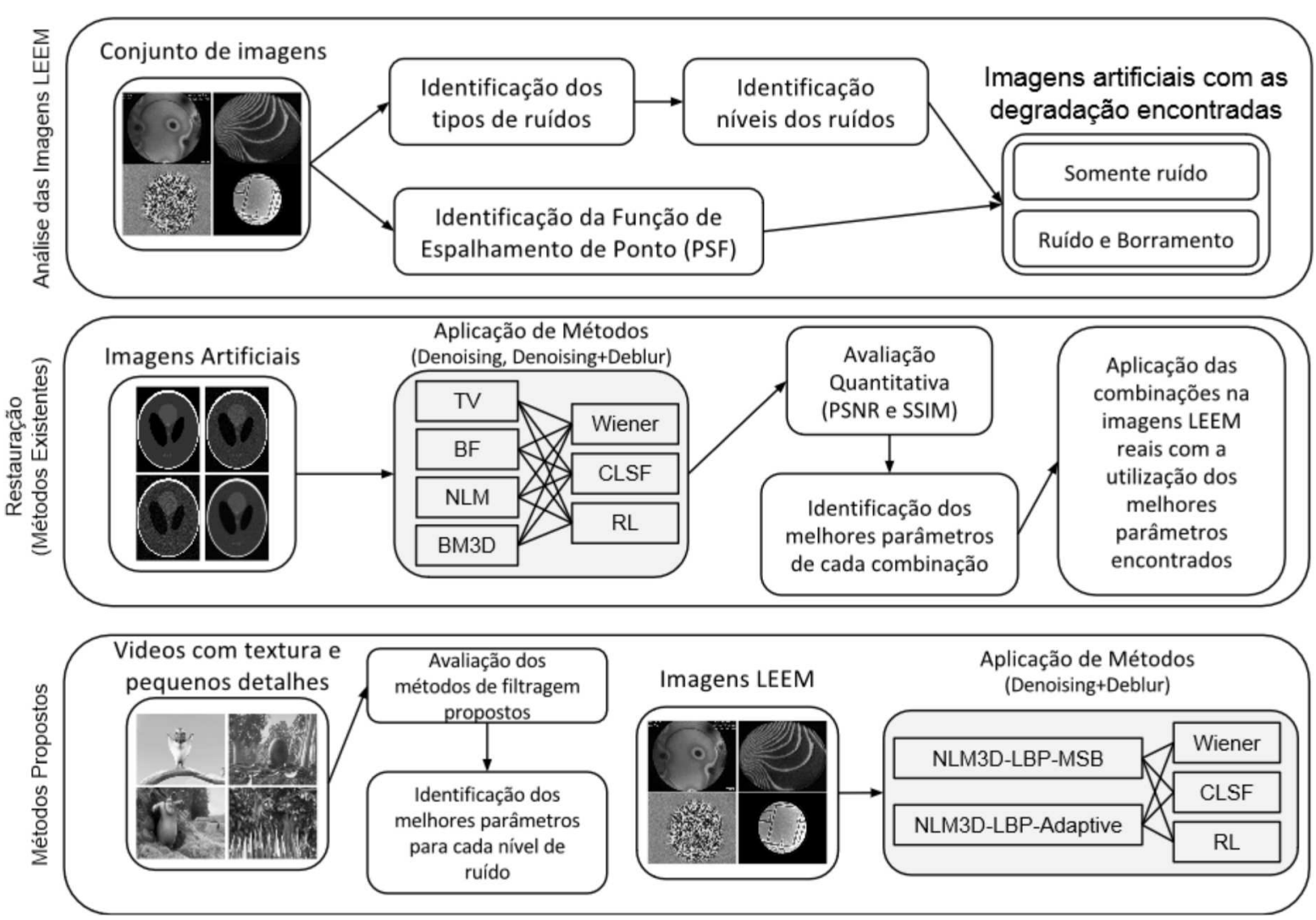

Fonte: Elaborada pelo autor.

\subsubsection{Análise das imagens LEEM}

A primeira etapa do pi peline consiste da identificação da natureza das fontes de ruído presente nos vídeos, da identificação e modelagem da função de espal hamento de ponto, e da escol ha do conjunto de métodos para real izar a remoção do borramento e da filtragem do ruído. Para definir qual a família mais adequada de filtros a ser utilizada, foi necessário modelar matematicamente as diversas fontes de ruído presentes no sinal.

Por meio de contatos recentes com o professor Dr. Wen-Xin Tang e de estudos mais aprofundados sobre os mecanismos envolvidos na formação de imagens, pôde-se observar que os vídeo de LEEM contém ruídos provenientes de 3 fontes distintas:

1. Hardware: ruído proveniente da lente magnética, vibração e ruído eletrônico dos cartões de controle; 
2. Interação el etrônica: o rearranjo de átomos nos passos de imageamento, provoca flutuações no sinal. Esse efeito não é real mente ruído, mas advém do processo físico de imageamento, estando correl acionado com o sinal;

3. Captura Digital: a baixa intensidade de el étrons, provoca um ruído de contagem, al ém de ruído escuro aditivo do sensor CCD.

A formação da imagem pode ser model ada pela seguinte equação:

$$
g(x ; y)=N \quad\left(f(x ; y){ }^{*} h(x ; y)+n_{0}(x ; y)\right)+n_{1}(x ; y)
$$

onde $f(x ; y)$ e $g(x ; y)$ representam, respectivamente, as imagens ideal (real) e observada. A primeira fonte de ruído se dá pela passagem da imagem pelo sistema de lentes. Devido ao suporte finito do si stema de lentes a imagem sofre um corte de frequências, geral mente perdendo frequências al tas. Esse ef eito é representado pel a convol ução da imagem real com uma função de espal hamento de ponto $\mathrm{h}(\mathrm{x} ; \mathrm{y})$. Por consequência do ruído proveni ente da lente magnética, vibração e ruído el etrônico dos cartões de controle, há ai nda a introdução de um ruído aditivo, representado pela função $n_{0}(x ; y)$. A interação el etrônica e a geração do sinal após a passagem pel o si stema de lentes leva a geração de um ruído dependente do si nal, o que é representado pelo processo al eatório $\mathrm{N}(\cdot)$. Final mente, a captura eletrônica gera outra fonte de ruído, comumente modelado por um ruído aditivo $\mathrm{n}_{1}(\mathrm{x} ; \mathrm{y})$.

Como o ruído teórico possui diversas fontes, é difícil obter um método capaz de abranger caso a caso. Por isso, foi feita anál ise experimental de regiões planas com diferentes intensi dades nas imagens.

Uma anál ise inicial pode ser feita através do histograma dos pixels de uma região homogênea da imagem, usando estimadores de parâmetros como forma de verificar se determinadas distribuições são suficientes para representar a distribuição real gerada pel o sistema. Por meio de testes de hipótese, pode-se verificar a função de distribuição de probabilidade que mel hor modela o ruído. A fase de identificação do modelo do ruído é importante para a escol ha dos métodos de filtragem. O processo de análise do histograma é descrito abaixo.

\subsubsection{Análise histograma}

Como citado anteriormente, através de uma pequena região homogênea da imagem é possível identificar visual mente (através do histograma desta região) o tipo de ruído presente. A Figura 20 ilustra o processo de extração de uma região em uma imagem.

Através deste histograma, e de outros que podem ser visual izados na seção 5.2.1.3, é possível descartar al guns ruídos conhecidos, como o Rayleigh e o Impul sivo devido a característica da distribuição. Porém, não é possível discernir entre o ruído Gaussiano, o Gama(Erlang) e o 
Figura 20 - Histograma de um frame do vídeo moview60fps.avi

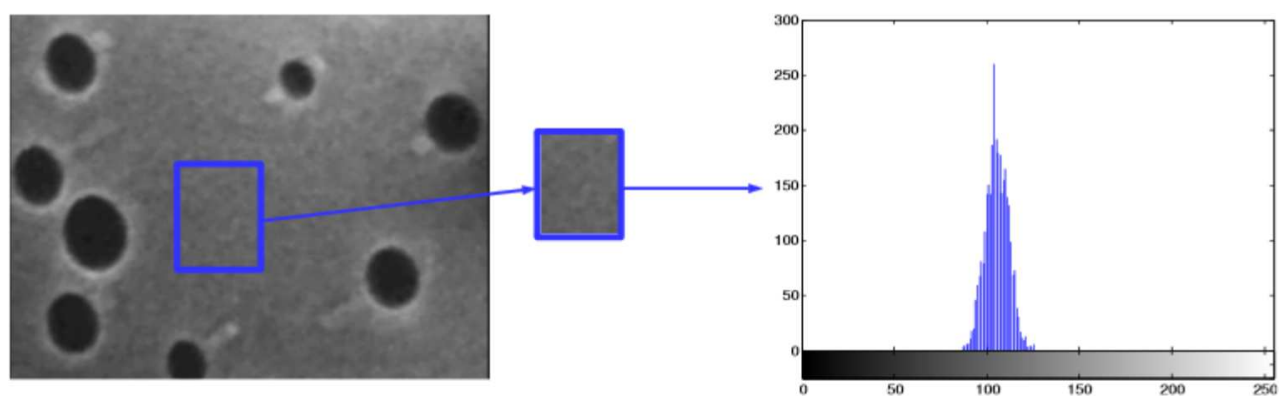

Fonte: Elaborada pelo autor.

ruído Poisson (muito encontrado em imagens de microscopia em geral). Portanto, é necessária a utilização de outras técnicas para analisar a di stribuição, sendo uma del as o fitting.

\subsubsection{Distribution 罪ing}

O Distribution Fitting, também conhecido como Goodness-of-Fit (GOF), descreve o quão bem um modelo estatístico se encaixa em um conjunto de observações. Índices GOF resumem a discrepância entre os valores observados e os val ores esperados sob um modelo estatístico, baseados em distribuições de amostragem conhecidos (MAYDEU-OLIVARES; GARCIA-FORERO, 2010). Dentre os mais conhecidos estão o Akaike Information Criterion (AIC) e o Bayesian Information Criterion (BIC).

O AIC e BIC não são utilizados para testar o modelo no sentido de testes de hipóteses, mas para sel eção de modelos. Dado um conjunto de dados, optase por AIC ou BIC, e real izase o cál culo para todos os modelos desejados. Em seguida, o modelo com o menor índice é sel ecionado. Destal hes sobre o AIC e sobre o BIC não fazem parte do escopo do trabal ho. Para maiores detal hes sobre estes métodos consultar o trabal ho de Maydeu-Olivares e Garcia-Forero (2010).

Os resultados obtidos na seção 6.1 .1 em conjunto com os resultados da seção 6.1.2, definem qual é o ruído predominante nas imagens LEEM. O capítulo de revisão bibliográfica, em particul ar a seção de filtragem de imagens, leva em consideração estes resultados para a escol ha dos métodos de filtragem.

\subsubsection{Estimativa do PSF}

A estimativa da PSF foi inicialmente realizada através de um módulo da técnica Fast Motion Deblurring do trabal ho de Cho e Le (2009). Este módulo estima a PSF com base na técnica de Blind Deconvolution, ou deconvolução cega. Ao final do processo, é gerada a PSF da imagem de entrada. A Figura 21 mostra a PSF esti mada para o vídeo GaAsFringe utilizado neste trabal ho. 
Figura 21 - Estimativa da PSF

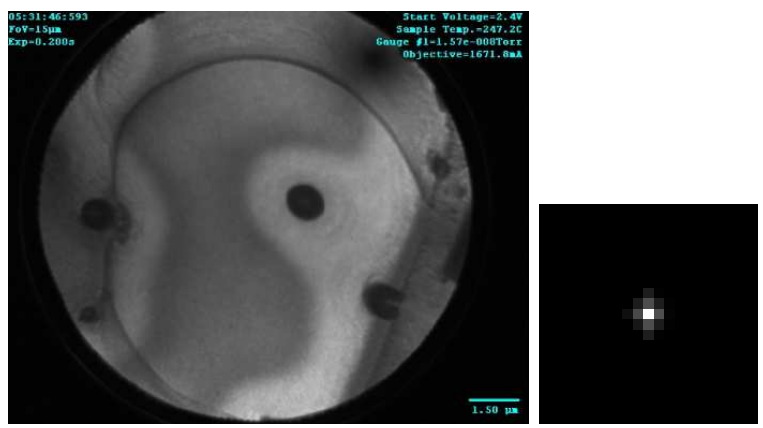

Fonte: Elaborada pelo autor.

Outra forma de estimar a PSF á através de experimentação. Se o equipamento estiver presente, pode-se obter a função de degradação a partir do imageamento de um impul so (pequeno ponto de luz, ou Beads) que representaria um pixel na imagem. Porém, através da captura, esse ponto sofrerá um espal hamento devido ao conjunto do mecani smo de imageamento, exibindo com uma mel hor precisão a PSF do equipamento. Na seção 6.1.3 são apresentados resul tados sobre a esti mativa da PSF pela técnica Fast Motion Deblurring. Será também explicado o motivo pelo qual não foi realizada a estimativa por experimentação.

\subsubsection{Combinações - mét odos de 馬tragem e redução de borramento}

Nesta etapa foram real izados diversos experimentos combinando as técnicas de filtragem e redução de borramento citadas no Capítulo 3. A combinação foi real izada da seguinte maneira:

1. Inicial mente foram identificados os níveis de ruído presente nos vídeos;

2. Foram então criadas imagens si ntéticas aplicando o ruído Gaussiano com os diferentes níveis encontrados;

3. Para cadaimagem com ruído, foram aplicadas todas as técnicas de filtragem com diferentes parâmetros, a fim de encontrar o melhor resultado de filtragem para cada técnica. Esta estratégia permite uma comparação justa;

4. Para cada imagem ruidosa, foi aplicado o borramento cal culado, gerando assim imagens sintéticas com o processo completo de degradação;

5. Para cada imagem degradada, foram aplicadas as combi nações das técnicas de redução de borramento e filtragem. Como feito anteriormente, foram anal i sados diversos parâmetros das técnicas de filtragem.

Ao final dos itens 3 e 5 foi ef etuada uma aval iação quantitativa com PSNR e do SSIM, descritos na Seção 5.3. Por fim, em posse dos mel hores parâmetros encontrados, foram aplicadas a filtragem e a restauração das imagens LEEM, que podem ser vistas na Seção 6.5. 
5.2.3 Métodos de 5 G de redução de borramento

Nesta etapa foi inicial mente aval iada a capaci dade de filtragem dos métodos propostos NLM3D-LBP-MSB e NLM3D-LBP-A daptive. Foram utilizadas imagens garantidamente livres de qual quer degradação. A avaliação foi planejada da seguinte maneira:

1. Foram extraídas 6 sequências ${ }^{1}$ do vídeo;

2. Foram adicionados ruídos Gaussianos em vários níveis, em cada sequência;

3. Os vídeos foram filtrados com métodos de filtragem existentes e com os propostos;

4. Os mel hores resultados de cada métodos de filtragem foram comparados;

5. Os mel hores parâmetros encontrados dos métodos propostos para cada nível de ruído foram armazenados.

Ao final desta etapa, os mel hores parâmetros foram encontrados. Com eles, foi possível aplicar a filtragem di retamente nas imagens LEEM para ambos métodos propostos. Além da aplicação da filtragem direta, os métodos foram combinados com os métodos de redução de borramento, assim como a etapa 5.2.2. Os resultado da filtragem e da combinação dos métodos na imagens LEEM podem ser vistos na Seção 6.5.

\subsection{Forma de Avaliação}

Foram utilizadas duas formas de aval iação quantitativas, sendo el as: Peak Signal-to-Noise Ratio (PSNR) e Structural Similarity Index (SSIM).

\subsubsection{Peak Signal-to-Noise Ratio}

Esta medida de rel ação sinal-ruído rel aciona a potência do sinal (imagem original), com a potência do ruído. Imagem com baixo nível de ruído tendem a apresentar um PSNR alto. Em contrapartida, imagens com al to nível de ruído tendem a apresentar um PSNR baixo. Tendo uma imagem de referência $\hat{f}$ e uma imagem de teste sem ruído $f$, o PSNR pode ser cal cul ado pela equação abai xo (HORÉ; ZIOU, 2010):

$$
\operatorname{PSNR}(f ; \hat{f})=10 \log _{10}\left(255^{2}=\operatorname{MSE}(f ; \hat{f})\right)
$$

1 Conjunto de quadros removidos do vídeo. Para os testes foram extraídas 6 sequências de aproximadamente 50 quadros cada, onde todas elas não possuem mudanças de cena. 
onde o val or do Mean Squared Error (MSE) é cal cul ado pela seguinte equação:

$$
\operatorname{MSE}(f ; \hat{f})=\frac{1}{\operatorname{MN}} \widehat{A}_{i=1}^{M} \underset{j=1}{N}(f(i ; j)-\hat{f}(i ; j))^{2}
$$

onde $\mathrm{M}$ e $\mathrm{N}$ são as dimensões das imagens. Quanto mais próximos forem $f$ de $\hat{f}$, maior será o valor do PSNR, ou seja, quanto mais eficaz a restauração, maior será o valor do PSNR (GONZALEZ; WOODS, 2006).

\subsubsection{Structural Similarity}

Wang et al. (2004) propuseram o índice de similaridade estrutural, do inglês Structural Similarity (SSIM), como uma mel horia para o Índice Universal de Qualidade de Imagem ou, do inglês, Universal Image Quality Index (UIQI) (WANG; BOVIK, 2002). Primeiramente, as imagens originais e modificada são divididas em blocos de tamanho $8 \times 8$ e, posteriormente, os blocos são convertidos em vetores. A seguir, duas médias, duas variâncias e um valor de covariância são cal culados para ambas imagens. Estes são representados, respectivamente, pelas equações 5.4, 5.5 e 5.6 .

$$
\begin{aligned}
& \mathrm{m}_{\mathrm{k}}=\frac{1}{\mathrm{~N}} \hat{\mathrm{A}}_{\mathrm{i}=1}^{\mathrm{N}} \mathrm{x}_{\mathrm{i}} ; \quad \mathrm{m}=\frac{1}{\mathrm{~N}} \underset{\mathrm{i}=1}{\mathrm{~A}} \mathrm{y}_{\mathrm{i}} \\
& s_{x}^{2}=\frac{1}{N-1} \hat{A}_{i=1}^{N}\left(x_{i}-m_{x}\right)^{2} ; \quad s_{y}^{2}=\frac{1}{N-1}{\underset{i=1}{N}}_{\hat{N}}^{N}\left(y_{i}-m_{y}\right)^{2} \\
& s_{x y}^{2}=\frac{1}{N-1} \hat{A}_{i=1}^{N}\left(x_{i}-m_{x}\right)\left(y_{i}-m_{y}\right)
\end{aligned}
$$

As comparações de lumi nância, contraste e estrutura são cal cul ados de forma semel hante ao UIQI, sendo que a medida do índice é dada pela seguinte equação:

$$
\operatorname{SSIM}(x ; y)=\frac{\left(2 m_{x} m_{y}+C 1\right)\left(2 s_{x y}+C 2\right)}{\left(m_{x}^{2}+m_{y}^{2}+C 1\right)\left(s_{x}^{2}+s_{y}^{2}+C 2\right)}
$$

onde $\mathrm{C} 1$ e $\mathrm{C} 2$ são constantes que quando seus valores são iguais a zero, o cál culo do SSIM é idêntico ao UIQI.

SSIM é aplicado localmente utilizando uma janela, com deslocamento pixel-a-pixel, cobrindo todas as linhas e col unas, a partir do canto superior esquerdo da imagem. O val or global do SSIM em uma imagem é denominado Mean Structural Similarity Index (MSSIM), e é obtido cal culando a média dos val ores SSIM sobre todas as janelas, representado pela equação abai xo:

$$
\operatorname{MSSIM}=\frac{1}{\mathrm{~W}} \underset{\mathrm{j}=1}{\mathrm{~A}} \mathrm{SSIM}_{\mathrm{j}}
$$


ondeW é o número de janel as que foram utilizadas.

As métricas citadas dependem de imagens "alvo", que não sejam degradadas e não apresentem ruído. Neste trabal ho, somente são conhecidas imagens já degradadas. Portanto, foram real izados testes com imagens sintéticas como base de comparação dos al goritmos de supressão de ruído, de redução de borramento e da combinação de ambos, que podem ser vistos nas seções 6.2 e 6.3.

Existem diversos métodos que quantificam a qual idade de uma imagem, sem a necessidade de uma imagem al vo ideal, classificados como No-Reference Image Qual ity Assessment (NR-IQA). Pode-se citar os métodos Blind/Referenceless Image Spatial QUality Eval uator (BRISQUE) (MITTAL; MOORTHY; BOVIK, 2012), Natural Image Qual ity Eval uator (NIQE) (MITTAL; SOUNDARARAJAN; BOVIK, 2013) e Blind Image Quality Index (BIQI) (MOORTHY; BOVIK, 2010). Estes métodos utilizam técnicas de aprendizado de máquina para "aprender" diversas características das imagens, como estrutura e luminosidade. Por serem treinamentos real izados em bases de dados "naturais", como a COREL, que possuem características diferentes das imagem microscópicas, estes métodos não mostraram resul tados signi ficativos no contexto deste trabal ho. Estas técnicas permi tem a real ização do treinamento segundo o interesse do usuário. Porém devido a inexistência de uma base de dados "ideal/alvo" de imagens LEEM, estes métodos não foram utilizados.

Entretanto, por mais conveniente que seja a utilização de critérios objetivos para se avaliar a qual idade em restauração, o sistema visual humano possui características peculiares, a ponto de duas imagens com val ores iguais, segundo al guma medida quantitativa de qual idade, parecerem completamente distintas sob análise visual por um observador humano (FILHO; NETO, 1999). Portanto, uma avaliação qualitativa, por observação visual, também foi empregada neste trabal ho, onde especial istas da área aval iaram visual mente a qual idade das imagens. Estes resultados podem ser vistos na seção 6.6 . 


\section{6}

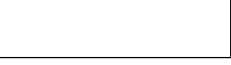

RESULTADOS

Os resul tados da pesqui sa são apresentados por meio de 5 experimentos. Sabemos que a restauração visa mel horar a qual idade visual dos vídeos LEEM. Porém, pela complexidade e o pouco conhecimento acerca destas imagens, foi inicial mente necessário identificar o modelo de ruído e a função de espal hamento de ponto presentes nesta modal idade de microscopia Os resultados de tais análises são apresentados nas seções 6.1.1 e 6.1.2. Já a seção 6.1.3 exibe como foi analisada e model ada a PSF para sua utilização nos métodos de deblur. Todo este estudo compõem o experimento 1.

O experimento 2 (Seção 6.2) mostra o desempenho dos métodos de filtragem para imagens LEEM e realiza um estudo sobre os mel hores parâmetros para diferentes níveis de ruído. O experimento 3 (Seção 6.3) mostra o resultado da realização da composição das técnicas de redução de borramento e filtragem nas imagens artificiais geradas a partir das análises realizadas nas imagens LEEM, além da análise dos mel hores parâmetros. No experimento 4 (Seção 6.4), foram realizados testes dos métodos propostos de filtragem utilizando imagens predomi nantemente texturizadas e com objetos pequenos. Já no experimento 5 (Seção 6.5), são aplicadas as técni cas de filtragem e, também, a combi nação destas com as técnicas de redução de borramento nas imagens LEEM reais. Final mente, na Seção 6.6 uma análise qual itativa foi realizada com especial istas da área de processamento de imagem e de mi croscopia aval iando, sob o ponto de vista humano, qual a melhor combinação de técnicas para a restauração das imagens LEEM.

\subsection{Experimento 1 - Análise das características dos ví- deos LEEM}

Este experimento tem como objetivo identificar as características das degradações presentes nas imagens LEEM (ruído e borramento). Inicial mente foi realizada a anál ise do histograma 
das imagens, a fim de identificar os possíveis ruídos. A etapa de Distribution fitting utiliza técnicas de fitting de distribuições para encontrar qual a distribuição estatística mel hor modela o ruído encontrado. A etapa seguinte visa estimar a função de espal hamento de ponto, com o intuito de gerar a PSF que será utilizada posteriormente no processo de deconvolução. Por fim, são exibidas as imagens sintéticas utilizadas nos experimentos.

\subsubsection{Análise de Histograma}

A análise de histograma é extremamente útil como uma etapa inicial no processo de restauração. Nela, foi possível excluir al guns modelos de ruídos baseado somente na informação visual. As Figuras 22 - 24 mostram os histogramas de regiões uniformes extraídas de al gumas imagens.

Figura 22 - Histograma de um frame do vídeo GaAsFringe.avi

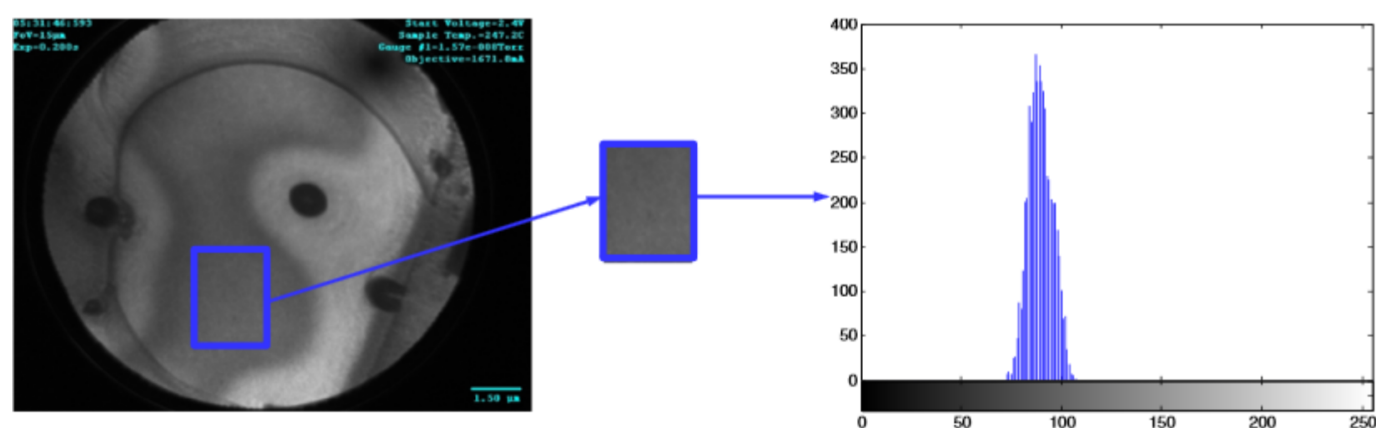

Fonte: Adaptado do vídeo cedido pelo professor Dr. Wen-Xin Tang.

Figura 23 - Histograma de um frame do vídeo ncomms7880-s2.mov
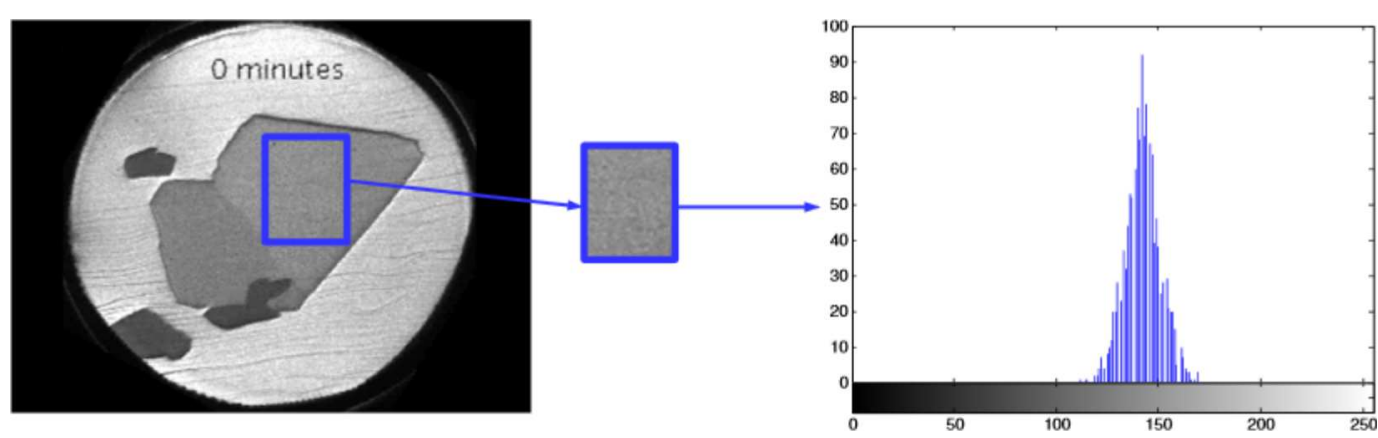

Fonte: Adaptada de Rogge et al. (2015).

É possível descartar al guns ruídos conhecidos, como Rayleigh, Uniforme e ruído Impulsivo pela si mples anál ise visual da distribuição do histograma. Porém, não é possível visual mente discernir entre ruído Gaussiano, Gama (Erlang) e ruído Poisson. Para este fim é necessária uma anál ise estatística, descrita a seguir. 
Figura 24 - Histograma de um frame dos vídeos NiAl04.avi e NiAI04.avi

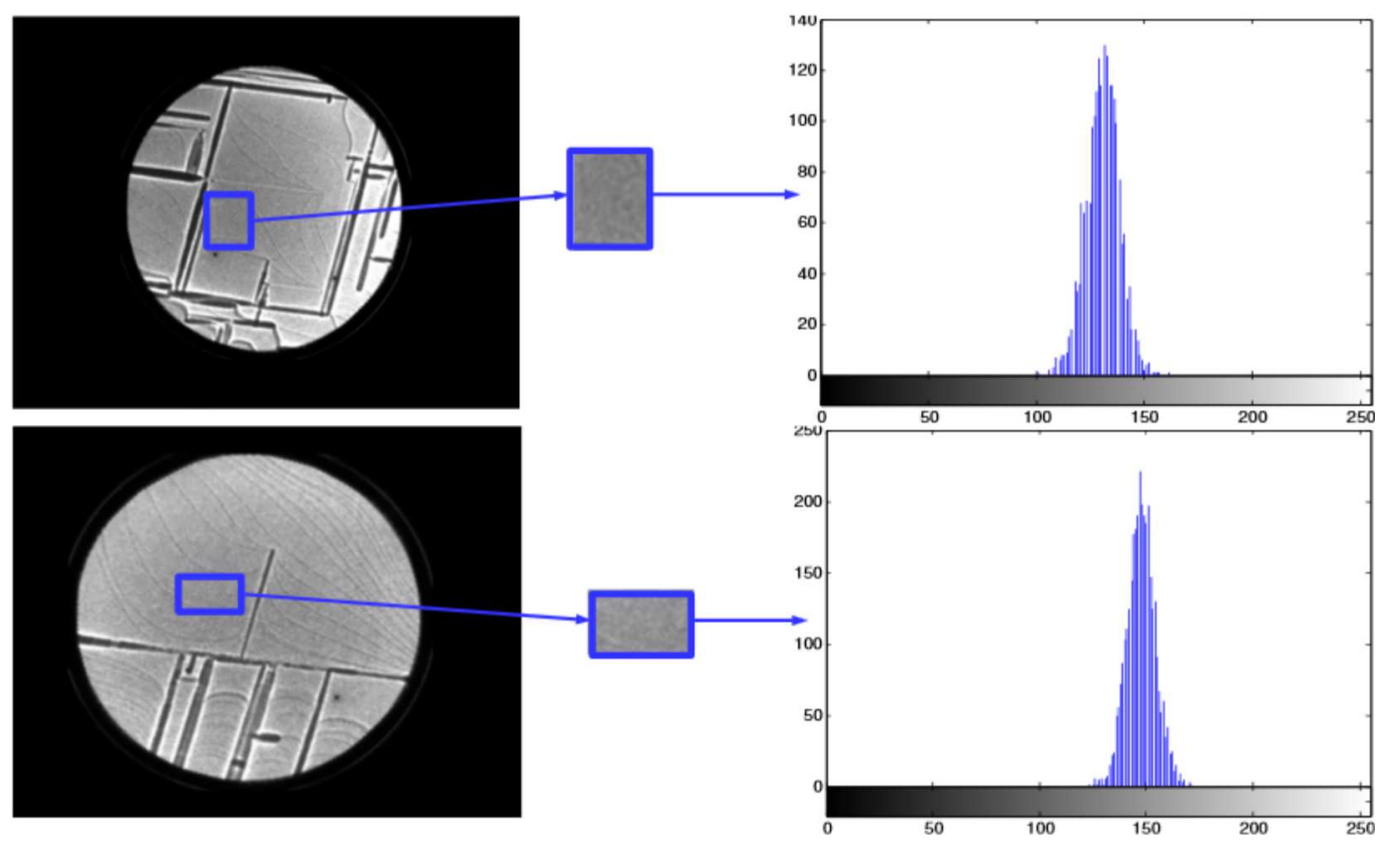

Fonte: Adaptada de Qin et al. (2015).

\subsubsection{Distribution 鳥ing}

Através da utilização dos métodos de Goodness-of-Fit (GOF) foi possível determinar, dentre os ruídos possíveis encontrados na análise visual do histograma (Gama, Gaussiano e Poisson), qual a distribuição mel hor descreve o ruído nos dados. A Tabela 1 exibe o resultado do fitting real izado com os vídeos, comparando as distribuições Gaussiana, Gama e Poisson.

É possível verificar que o ruído presente nos vídeos pode ser modelado, com menor taxa de erro, através da distribuição Normal/Gaussiana, com exceção de um único vídeo, onde o resultado encontrado foi a di stribuição Gama. Contudo, a diferença entre a distribuição Gama e Gaussiana para este vídeo foi pequena. Este fato ocorre devido a uma característica da di stribuição Gama, onde através de parâmetros específicos, é possível modelar uma distribuição Normal. Por mais simples que possa parecer, esta etapa é muito importante, pois a partir dela foi real izada a revisão bibliográfica dos métodos de supressão de ruídos Gaussiano.

Algumas ferramentas auxiliam neste processo, como por exemplo o método al lfitdist disponível no MATLAB. Funções como esta tem por objetivo exibir visual mente o quão próximo os dados se aproximam de uma determinada di stribuição. A Figura 25 ilustra o fitting de uma imagem LEEM. Neste caso especificamente, assim como na grande mai oria, foi verificado que a distribui ção que mais se aproxima dos dados é a Gaussiana.

\subsubsection{Função de Espalhamento de Ponto}

A estimação da PSF é essencial para a remoção do borramento contido nas imagens LEEM. Este processo pode ser ideal izado de duas manei ras: a) pelo imageamento da imagem 
Tabela 1 - Fitting dos histogramas dos vídeos LEEM

\begin{tabular}{|c|c|c|c|}
\hline Vídeo & Distribuição Testada & $\mathrm{AIC}$ & $\mathrm{BIC}$ \\
\hline \multirow[t]{3}{*}{ moview60fps } & Normal/Gaussiana & $1: 9875 e^{04}$ & $1: 9887 e^{04}$ \\
\hline & Gama & $1: 9879 e^{04}$ & $1: 9891 e^{04}$ \\
\hline & Poisson & $2: 1003 e^{04}$ & $2: 1009 e^{04}$ \\
\hline \multirow[t]{3}{*}{ GaAsFringe } & Normal/Gaussiana & $5: 3503 e^{03}$ & $5: 3598 e^{03}$ \\
\hline & Gama & $5: 3515 e^{03}$ & $5: 3610 e^{03}$ \\
\hline & Poisson & $5: 9511 e^{03}$ & $5: 9559 e^{03}$ \\
\hline \multirow[t]{3}{*}{ Boron_Si } & Normal/Gaussiana & $6: 7450 e^{03}$ & $6: 7545 e^{03}$ \\
\hline & Gama & $6: 7555 e^{03}$ & $6: 7651 e^{03}$ \\
\hline & Poisson & $6: 7705 \mathrm{e}^{03}$ & $6: 7753 e^{03}$ \\
\hline \multirow[t]{3}{*}{$\mathrm{Pb} \_\mathrm{Cu}$} & Normal/Gaussiana & $3: 5841 e^{04}$ & $3: 5854 e^{04}$ \\
\hline & Gama & $3: 5948 e^{04}$ & $3: 5960 e^{04}$ \\
\hline & Poisson & $5: 2517 \mathrm{e}^{04}$ & $5: 2523 e^{04}$ \\
\hline \multirow[t]{3}{*}{ NiAl01 } & Normal/Gaussiana & $6: 9987 \mathrm{e}^{03}$ & $7: 0086 e^{03}$ \\
\hline & Gama & $7: 0000 e^{03}$ & $7: 0099 e^{03}$ \\
\hline & Poisson & $7: 4790 e^{03}$ & $7: 4840 e^{03}$ \\
\hline \multirow[t]{3}{*}{ NiAl02 } & Normal/Gaussiana & $2: 7607 e^{03}$ & $2: 7688 e^{03}$ \\
\hline & Gama & $2: 7657 e^{03}$ & $2: 7738 e^{03}$ \\
\hline & Poisson & $2: 9675 \mathrm{e}^{03}$ & $2: 9715 \mathrm{e}^{03}$ \\
\hline \multirow[t]{3}{*}{$\mathrm{NiAl03}$} & Normal/Gaussiana & $4: 9455 \mathrm{e}^{03}$ & $4: 9546 e^{03}$ \\
\hline & Gama & $4: 9477 e^{03}$ & $4: 9568 e^{03}$ \\
\hline & Poisson & $5: 1122 e^{03}$ & $5: 1167 e^{03}$ \\
\hline \multirow[t]{3}{*}{$\mathrm{NiAl04}$} & Normal/Gaussiana & $1: 1625 \mathrm{e}^{04}$ & $1: 1636 e^{04}$ \\
\hline & Gama & $1: 1591 e^{04}$ & $1: 1602 e^{04}$ \\
\hline & Poisson & $1: 1820 e^{04}$ & $1: 1825 e^{04}$ \\
\hline \multirow[t]{3}{*}{ Graphene_Ir } & Normal/Gaussiana & $7: 5808 \mathrm{e}^{03}$ & $7: 5906 e^{03}$ \\
\hline & Gama & $7: 5890 e^{03}$ & $7: 5988 e^{03}$ \\
\hline & Poisson & $8: 3413 e^{03}$ & $8: 3463 e^{03}$ \\
\hline
\end{tabular}

Fonte: Elaborada pelo autor.

Figura 25 - Exemplo visual do fitting

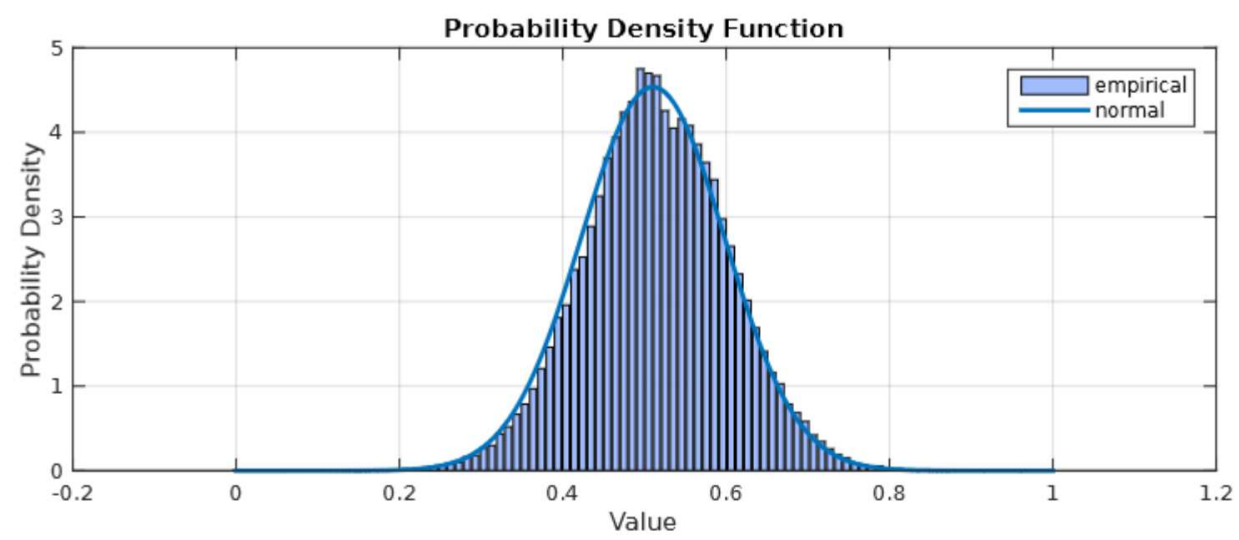

Fonte: Elaborada pelo autor. 
Bead e b) pela utilização da ferramenta Fast Motion Deblurring.

É possível estimar a função de degradação a partir do imageamento de um impulso (pequeno ponto de luz, ou Beads), cuja dimensão deve corresponder a um pixel na imagem produzida Se o equipamento fosse perfeito, a imagem resul tante constaria de apenas um pixel iluminado. Porém, no processo de captura, esse ponto sofrerá um espalhamento devido ao conjunto do mecanismo de imageamento, resultando em uma imagem cuja área ocupada pelo bead é mai or que apenas um pixel. Isso possi bi lita estimar, com uma mel hor precisão, a PSF do equipamento. Devido a problemas no equipamento esta etapa foi inicialmente descartada. Após ser consertado, constatou-se que não existe uma estrutura simi lar a um Bead suficientemente pequeno para o imageamento em um equipamento LEEM.

Alternativamente, foi realizado o imageamento variando-se o diâmetro do feixe de el étrons do equipamento. Porém, feixes com diâmetros pequenos geraram imagens com grande nível de ruído. I magens produzidas com feixes de diâmetros grandes foram demasiadamente corrompidas ao aplicarmos as técnicas de redução de borramento citadas.

Devidos a estes fatores, a estimativa da PSF adotada neste trabal ho foi realizada por meio de um módulo da técnica Fast Motion Deblurring, como descrito no trabalho de Cho e Lee (2009). Este módulo estima a PSF com base na técnica de Blind Deconvolution, ou deconvolução cega. Ao final do processo, é gerada a PSF com base na imagem de entrada. Na Figura 26 é possível verificar a PSF gerada pela técnica para diferentes vídeos, todos gerados pelo mesmo equipamento. A imagem exibida é uma média de todas as PSFs geradas: para cada vídeo foi extraído um frame e empregada a técnica Fast Motion Deblurring para computálas. Por serem produzidas pelo mesmo equi pamento, el as apresentam poucas diferenças. Ao final do processo, foi computado o valor médio para a utilização em futuros processamentos.

Figura 26 - Estimativa das PSF pelo Fast Motion Deblurring

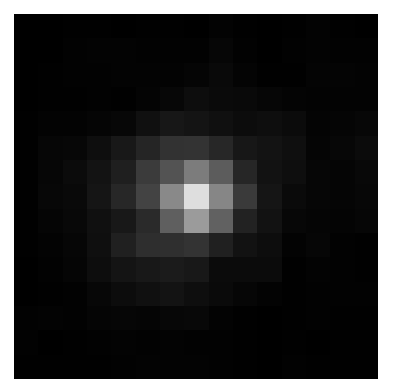

Fonte: Elaborada pelo autor.

\subsubsection{Imagens arti 臨iais}

Uma forma de aval iar a qual idade da restauração de imagens é através da utilização de critérios de qual idade como Peak Signal-to-Noise Ratio (PSNR) e Structural Similarity (SSIM) 
(WANG et al., 2004). Porém, estes métodos requerem uma imagem alvo, sem nenhum tipo de degradação, para a aval iação da similaridade da imagem restaurada com a imagem "ideal”.

Como parte deste trabal ho visa a análise dos atuais métodos de restauração, fez-se necessária a utilização de imagens sintéticas. A partir de onze vídeos LEEM, foi cal culado o nível do ruído Gaussiano em cada um deles. Foram então criadas onze imagens sintéticas sobre as quais foi adicionado o ruído Gaussiano com média zero, sendo a variância os níveis de ruídos encontrados. As Figuras 27a, 27b e 27c il ustram, respectivamente a imagem sintética gerada, a imagem si ntética após a aplicação do menor nível de ruído encontrado e a imagem sintética após a aplicação do maior nível de ruído.

Além de gerar imagens artificiai s somente com os níveis de ruídos cal culados, também foi aplicado o borramento através da PSF estimada na Seção 6.1.3. A plicando-se a PSF e os diferentes níveis de ruídos, foram obti das onze novas imagens. Porém, agora estas imagens possuem duas degradações: borramento e ruído em diferentes níveis. As Figuras 28a, 28b e 28c ilustram, respectivamente, a imagem si ntética, a imagem com menor nível de ruído a imagem com maior nível ruído, sendo as duas últimas com o mesmo nível de borramento.

Para evitar o uso de imagens si ntéticas, também foi realizado o estudo de outras formas de aval iação que quantificam a qual idade de uma imagem, sem a necessi dade de uma imagem alvo ideal, classificados como No-Reference Image Quality Assessment (NR-IQA). Pode-se citar os métodos Blind/Referenceless Image Spatial Quality Evaluator (BRISQUE) (MITTAL; MOORTHY; BOVIK, 2012), Natural Image Qual ity Evaluator (NIQE) (MITTAL; SOUNDARARAJAN; BOVIK, 2013) eBlind Image Qual ity Index (BIQI) (MOORTHY; BOVIK, 2010). Estes métodos utilizam técnicas de aprendizado de máqui na para " aprender" diversas características das imagens, como estrutura e luminosidade. Testes prel iminares foram conduzi dos com o banco de imagens COREL, mas os resultados não foram relevantes, provavelmente em função da natureza distinta que estas apresentam (cenas naturais) com rel ação às imagens de mi croscopia Devido à inexistência de um banco de imagens LEEM com amostras "i deal/al vo" foi necessário manter o uso de imagens artificias.

\subsection{Experimento 2 - Filtragem do ruído}

Este experimento visa encontrar, dentre os métodos de filtragem anal isados, o que produz o melhor resul tado (mai or PSNR) nas imagens si ntéticas geradas a partir dos níveis de ruídos encontrados. Além disso, para garantir uma comparação não enviesada entre todos os métodos, foi real izada uma anál ise dos melhores parâmetros de cada al goritmo, para os diferentes níveis de ruído. 
Figura 27 - Imagens sintéticas somente com ruído.

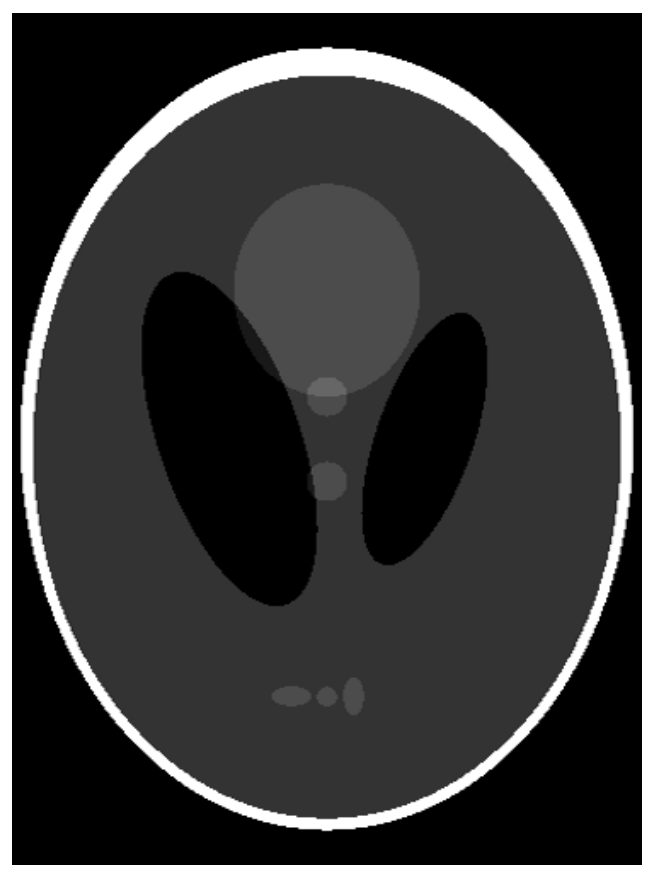

(a) Imagem Sintética

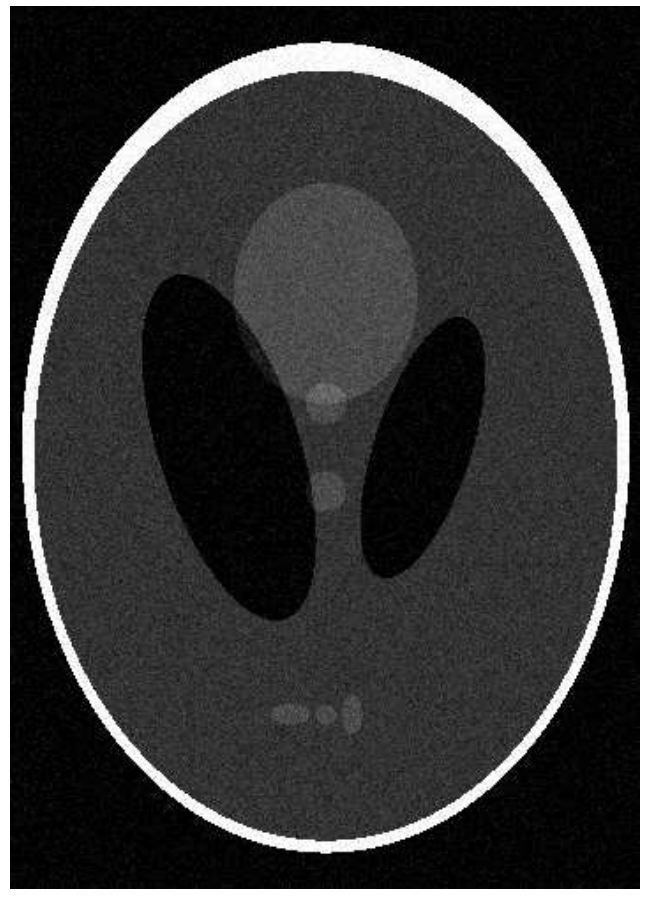

(b) Imagem (a) com baixo nível de ruído

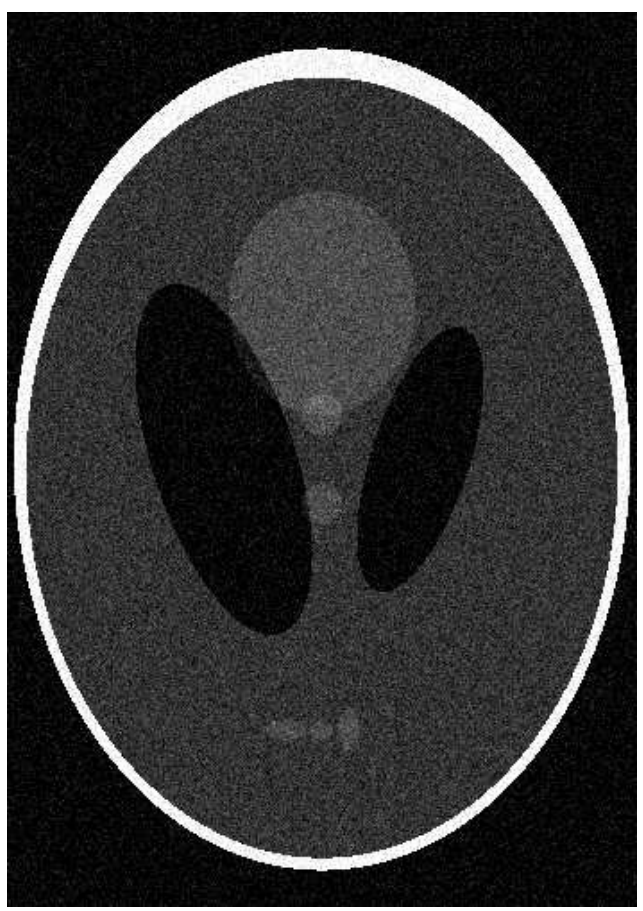

(c) Imagem (a) com al to nível de ruído

Fonte: Elaborada pelo autor.

\subsubsection{Filtragem do ruído das imagens arti Eciais}

Nesta etapa foram real izados os testes dos al goritmos de filtragem das imagens sintéticas anteriormente criadas. A Tabela 2 mostra val ores de PSNR para cada um dos métodos de denoising analisados. Val e lembrar que estes val ores são os mel hores encontrados para cada 
Figura 28 - Imagens sintéticas com ruído e borramento.

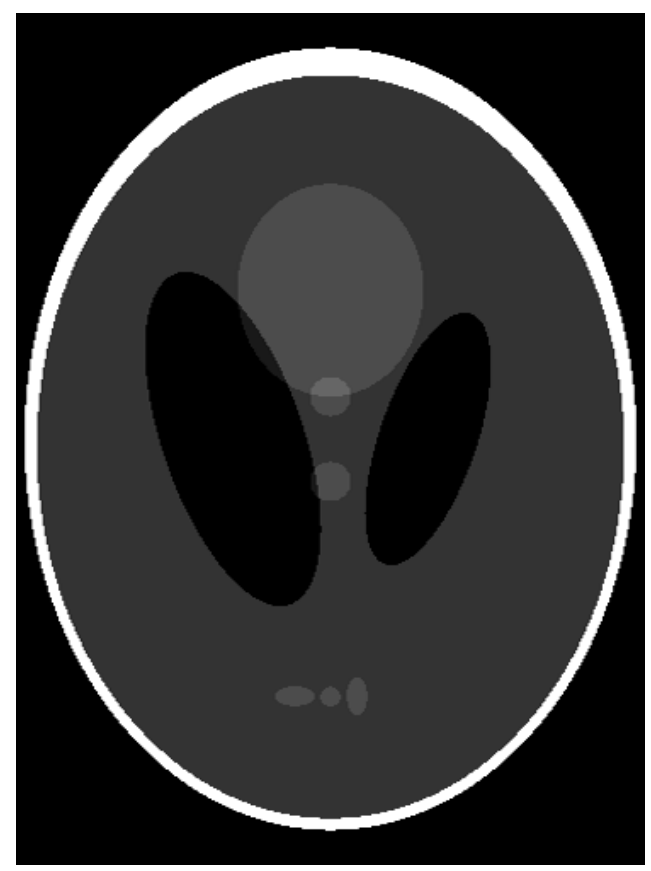

(a) Imagem Sintética

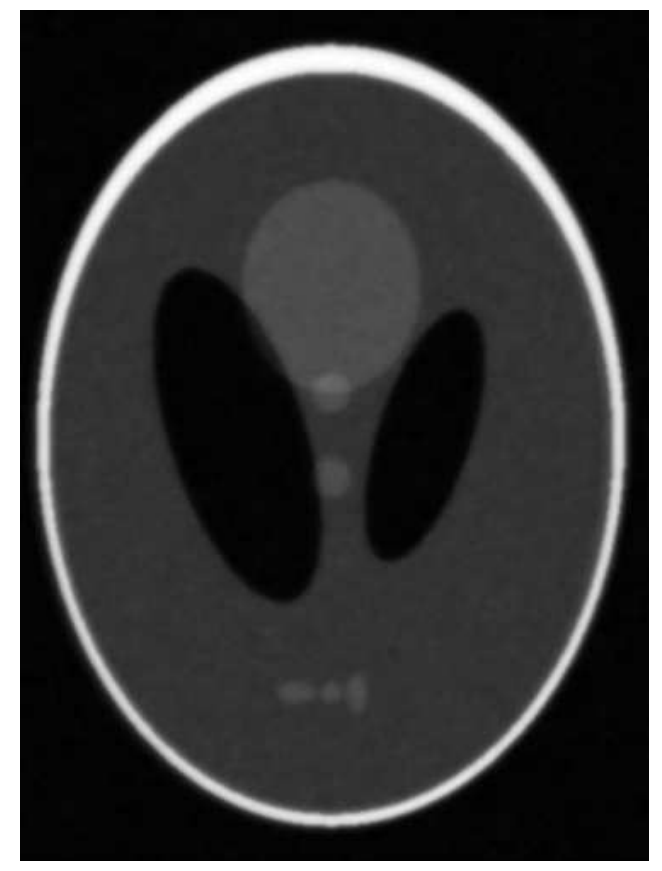

(b) Imagem (a) com baixo nível de ruído

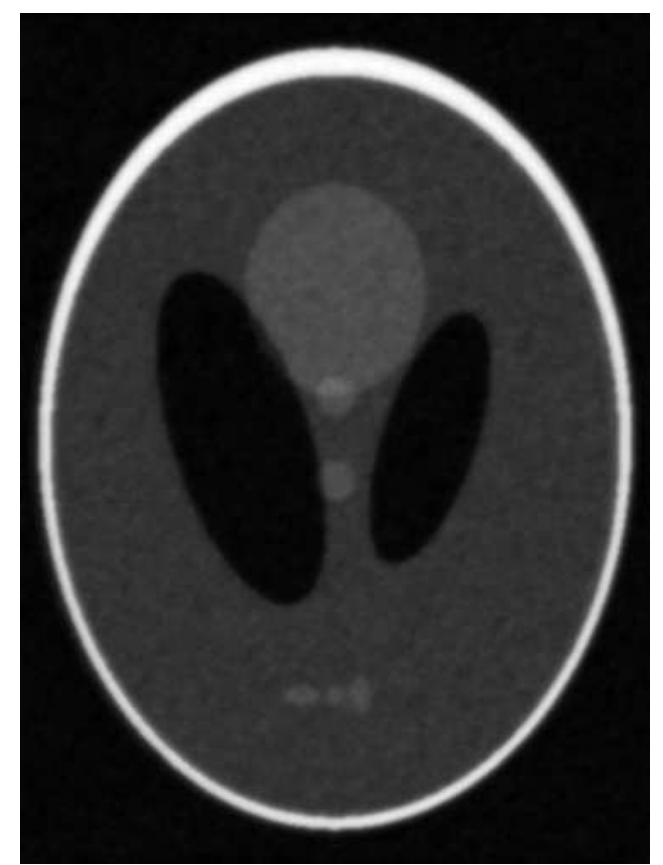

(c) Imagem (a) com alto nível de ruído

Fonte: Elaborada pelo autor.

método, ou seja, para cada nível de ruído foi feito uma variação dos parâmetros de cada um dos métodos de forma a encontrar o mel hor val or de filtragem. Ainda nesta tabela, é possível verificar que o método de filtragem BM3D foi o que produziu o mel hor desempenho em maior parte dos níveis de ruído. Porém, o método TV surprendentemente apresentou mel hores resultados quantitativos em níveis de ruídos mai ores, e os métodos BL e NLM também mostraram bons 
resultados.

Tabela 2 - Valores de PSNR (dB) após a aplicação dos métodos de filtragem nas imagens sintéticas (Somente Ruído).

\begin{tabular}{c|c|ccccc}
\hline Nível do Ruído (s ) & PSNR & TV & BF & ABF & NLM & BM3D \\
\hline 0.0176 & 30.1839 & 37.2024 & 37.7738 & 36.0276 & 37.9237 & 38.4817 \\
0.0189 & 29.8482 & 37.0758 & 37.4133 & 35.6274 & 37.5787 & 38.0912 \\
0.0189 & 29.8518 & 37.0878 & 37.4129 & 35.6454 & 37.5455 & 38.1223 \\
0.0200 & 29.6192 & 36.9476 & 37.1869 & 35.3789 & 37.3679 & 37.9191 \\
0.0256 & 28.5386 & 36.4552 & 36.0671 & 34.0873 & 36.2687 & 36.8046 \\
0.0263 & 28.4337 & 36.4656 & 35.9967 & 33.9489 & 36.1973 & 36.7704 \\
0.0286 & 28.0689 & 36.2801 & 35.6010 & 33.5121 & 35.7759 & 36.3399 \\
0.0305 & 27.7714 & 36.1753 & 35.3291 & 33.1380 & 35.5272 & 36.0591 \\
0.0340 & 27.3453 & 35.9721 & 34.9359 & 32.6002 & 35.1306 & 35.6734 \\
0.0347 & 27.2320 & 35.9328 & 34.7790 & 32.4374 & 34.9841 & 35.4594 \\
0.0523 & 25.4717 & 34.9937 & 33.1018 & 30.0563 & 33.2533 & 33.7667 \\
\hline \multicolumn{5}{|c}{ Fonte: Elaborada pelo autor. }
\end{tabular}

Embora quantitativamente tenha-se verificado um mel hor desempenho do método TV na presença de níveis de ruídos al tos, visual mente é possível verificar que isso não é total mente verdadeiro. As Figuras 29a e 29b ilustram, respectivamente, o resultado da filtragem pelos métodos TV e BM3D com o nível de ruído mais alto. É evidente que uma maior qual idade de filtragem foi obtida pelo BM3D, contrariando os resul tados baseados em análises quantitativas (PSNR eSSIM).

Figura 29 - Imagens sintéticas somente com ruído.

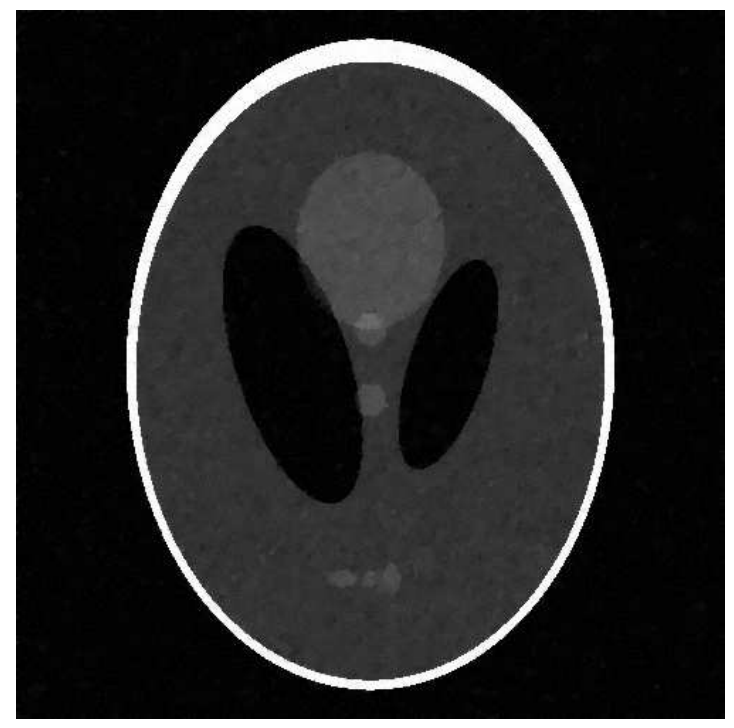

(a) TV - PSNR: 34.9937, SSIM: 0.6290

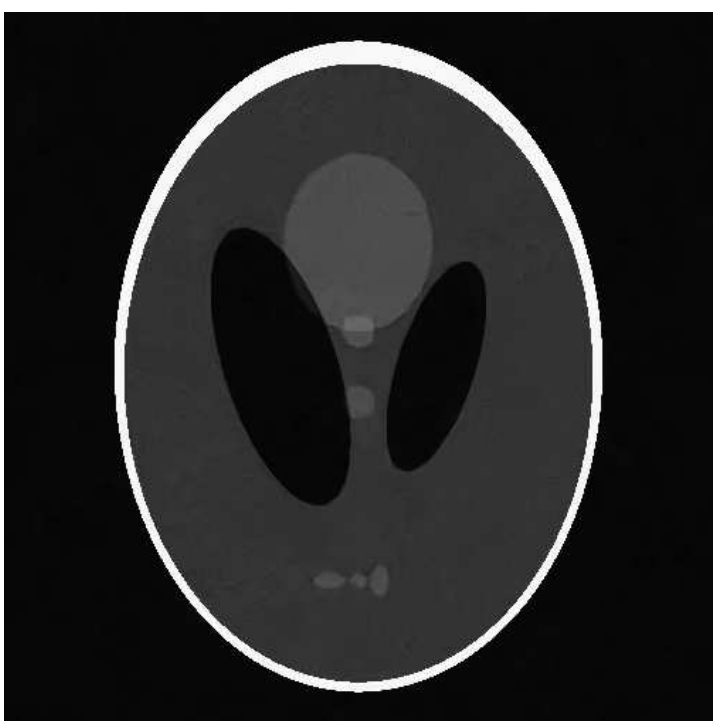

(b) BM3D - PSNR: 33.7667, SSIM: 0.5131

Fonte: Elaborada pelo autor.

Filho e Neto (1999) cita que por mais conveniente que sejam a utilização de critérios quantitativos para se aval iar a qualidade em restauração, o sistema visual humano possui caracte- 
rísticas peculiares, a ponto de duas imagens com val ores iguais em al guma medida de qualidade, serem completamente distintas visual mente. Portanto, uma aval iação qual itativa, por observação visual, foi empregada e avaliada por especial istas da área de processamento e de microscopia eletrônica. Estes resultados podem ser vistos na Seção 6.6

\subsubsection{Análise dos melhores parâmetros}

Os al goritmos anal isados foram executados com um extenso número de parâmetros, para diferentes níveis de ruído. Pôde-se, portanto, verificar o mel hor parâmetro de cada al goritmo, para cada nível de ruído. A Tabela 3 mostra os mel hores parâmetros utilizados para obtenção dos val ores de PSNR na Tabela 2. Os dados mostram que os parâmetros dos al goritmos, com exceção ao BF, não variam muito. Isto é interessante em diversos aspectos como, por exemplo, limitar para o usuário final de uma possível ferramenta que utilize somente parâmetros do al goritmo dentro de uma faixa predeterminada, evitando assim uma filtragem excessiva ou até mesmo a utilização de parâmetros muito baixos.

Esperava-se que o filtro ABF gerasse resultados melhores que o filtro BF. Porém, de todos os testados este foi de pior desempenho. Verificando os parâmetros foi possível analisar que não importava o quão fossem variados, o resultado da filtragem permanecia semel hante. Este filtro foi retirado dos próximos testes devido aos resultados ruins obtidos nesta seção.

Tabela 3 - Melhores parâmetros de filtragem.

\begin{tabular}{c|ccccc}
\hline Nível do Ruído (s ) & TV $(\mathrm{I})$ & $\mathrm{BF}\left(\mathrm{s}_{\mathrm{s}}\right)$ & $\mathrm{ABF}\left(\mathrm{s}_{\mathrm{r}}\right)$ & $\mathrm{NLM}(\mathrm{H})$ & $\mathrm{BM} 3 \mathrm{D}(\mathrm{s})$ \\
\hline 0.0176 & 1.4 & 24 & 50 & 0.04 & 10 \\
0.0189 & 1.3 & 25 & 50 & 0.04 & 10 \\
0.0189 & 1.3 & 25 & 45 & 0.04 & 10 \\
0.0200 & 1.4 & 26 & 50 & 0.05 & 10 \\
0.0256 & 1.3 & 30 & 49 & 0.05 & 12 \\
0.0263 & 1.3 & 30 & 50 & 0.05 & 12 \\
0.0286 & 1.3 & 32 & 49 & 0.05 & 12 \\
0.0305 & 1.3 & 33 & 50 & 0.06 & 13 \\
0.0340 & 1.3 & 35 & 50 & 0.06 & 13 \\
0.0347 & 1.3 & 36 & 49 & 0.06 & 13 \\
0.0523 & 1.3 & 46 & 50 & 0.07 & 16 \\
\hline
\end{tabular}

Fonte: Elaborada pelo autor.

Na Figura 30 é possível verificar a variação do PSNR por meio do filtro BM3D. A utilização de parâmetros mui to baixos levam a uma filtragem mínima, preval ecendo o ruído. Jáa util ização de parâmetros muito al tos acarretam na perda de muitas estruturas. Esta anál ise dos parâmetros foi importante para descartar a utilização de parâmetros inadequados ao problema 
Figura 30 - Variação do parâmetro s do al goritmo BM3D.

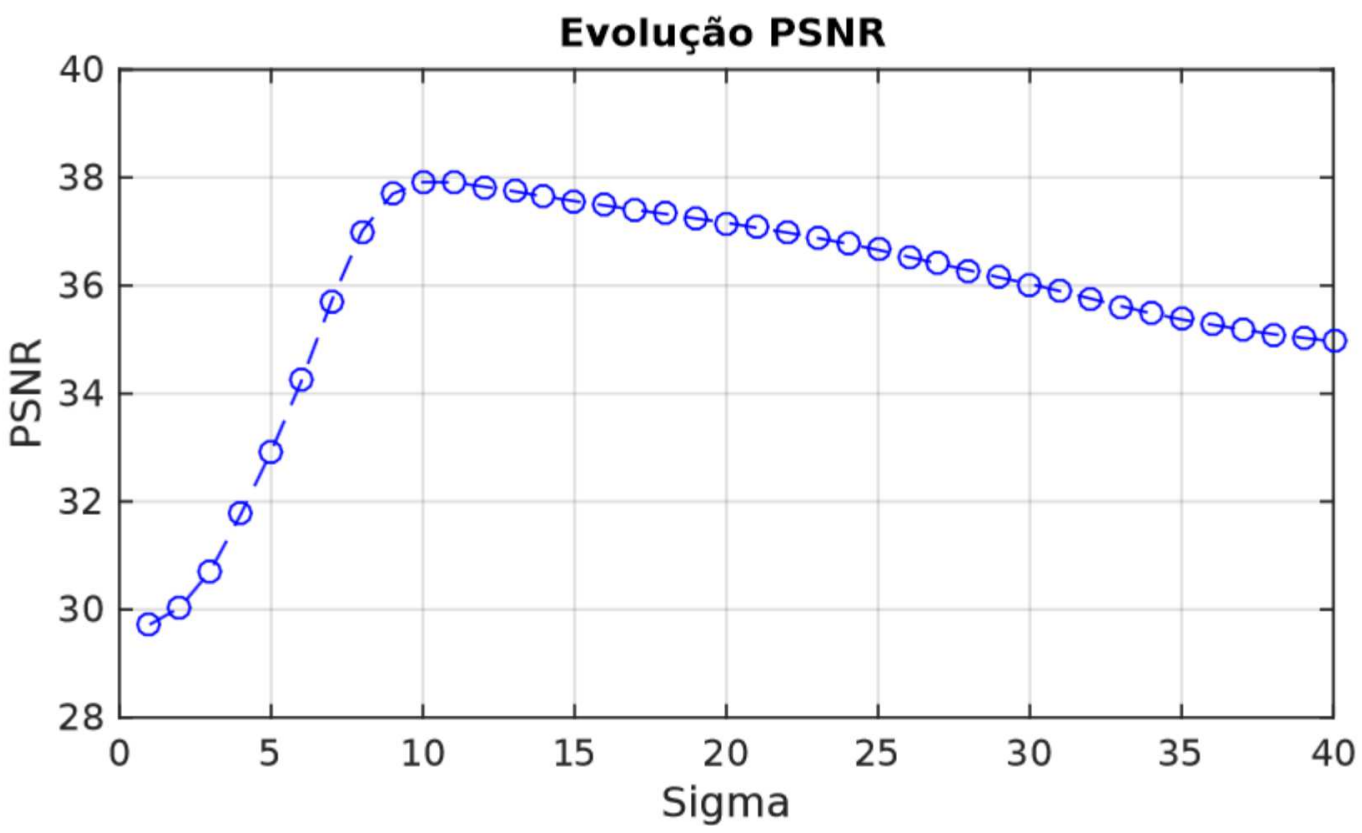

Fonte: Elaborada pelo autor.

\subsection{Experimento 3 - Redução de borramento e 国 ragem das imagens sintéticas}

Este experimento visa encontrar a melhor combinação de técnicas de filtragem com as técnicas de redução de borramento aplicadas nas imagens sintéticas degradadas (ruído + borramento). Visa também encontrar o melhor parâmetro de cada técnica de filtragem que obtenha o melhor resultado, tornando a comparação justa.

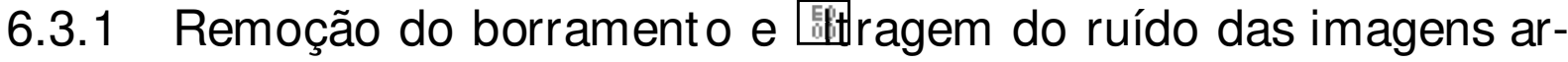 $\mathrm{ti}$ 監iais}

Nesta seção o objetivo foi investigar a qual idade da restauração (redução de borramento e ruído) combinando os diferentes al goritmos citados neste trabal ho. Foi utilizado o SSIM como métrica quanti tativa $\mathrm{O}$ al goritmo $\mathrm{ABF}$ foi descartado devido aos resul tados insatisfatório exibi dos na Seção 6.2.1. Os resultados são reportados na Tabela 5. Quantitativamente, a combinação do algoritmo Wiener com BM3D produziu os melhores resultados, exceto para os níveis de ruído mais altos. Neste caso, a combinação do CLSF com o BM3D foi ligeiramente superior. Contrariando os resultados obti dos na Seção 6.2.1, o al goritmo TV não produziu bons resultados quando combinado a todos os métodos de deconvol ução. As combinações dos al goritmos Wiener e CLSF com o filtro NLM também mostraram resultados expressivos. Este comportamento indi cou a necessi dade de uma anál ise qual itativa.

A Figura 31 ilustra a aplicação dos métodos de remoção de ruído após a utilização 
Tabela 4 - SSIM das imagens degradadas.

\begin{tabular}{c|c|c}
\cline { 2 - 3 } \multicolumn{1}{c|}{} & Nivel do Ruído & SSIM \\
\hline I & 0.0176 & 0.5859 \\
II & 0.0189 & 0.5635 \\
III & 0.0189 & 0.5638 \\
IV & 0.0200 & 0.5535 \\
V & 0.0256 & 0.5378 \\
VI & 0.0263 & 0.5375 \\
VII & 0.0286 & 0.5323 \\
VIII & 0.0305 & 0.5263 \\
IX & 0.0340 & 0.5100 \\
X & 0.0347 & 0.5199 \\
XI & 0.0523 & 0.4745 \\
\hline \multicolumn{2}{|c}{ Fonte: Elaborada pelo autor }
\end{tabular}

Fonte: Elaborada pelo autor.

Tabela 5 - Anál ise da combinação de métodos de redução de borramento e ruído.

\begin{tabular}{|c|c|c|c|c|c|c|c|c|c|c|c|c|}
\hline & \multicolumn{3}{|c|}{ TV } & \multicolumn{3}{|c|}{$\mathrm{BF}$} & \multicolumn{3}{|c|}{ NLM } & \multicolumn{3}{|c|}{ BM3D } \\
\hline & Wiener & CLSF & $R L$ & Wiener & CLSF & $\mathrm{RL}$ & Wiener & CLSF & $\mathrm{RL}$ & Wiener & CLSF & $\mathrm{RL}$ \\
\hline $\mathrm{I}$ & 0.6119 & 0.6173 & 0.6659 & 0.9005 & 0.9001 & 0.8389 & 0.8868 & 0.8872 & 0.8469 & 0.9072 & 0.9066 & 0.8691 \\
\hline II & 0.5870 & 0.5913 & 0.7247 & 0.8672 & 0.8680 & 0.8121 & 0.8814 & 0.8818 & 0.8417 & 0.9045 & 0.9037 & 0.8759 \\
\hline III & 0.5892 & 0.5931 & 0.7268 & 0.8668 & 0.8680 & 0.8121 & 0.8773 & 0.8782 & 0.8377 & 0.9054 & 0.9050 & 0.8644 \\
\hline IV & 0.5749 & 0.5797 & 0.7179 & 0.8474 & 0.8488 & 0.7945 & 0.8773 & 0.8782 & 0.8342 & 0.9025 & 0.9019 & 0.8550 \\
\hline V & 0.5568 & 0.5611 & 0.6887 & 0.8011 & 0.8026 & 0.7593 & 0.8592 & 0.8591 & 0.8208 & 0.8889 & 0.8880 & 0.8410 \\
\hline VI & 0.5555 & 0.5598 & 0.6843 & 0.7974 & 0.7988 & 0.7555 & 0.8478 & 0.8481 & 0.8012 & 0.8859 & 0.8851 & 0.8280 \\
\hline VII & 0.5488 & 0.5527 & 0.6757 & 0.7816 & 0.7830 & 0.7438 & 0.8582 & 0.8580 & 0.8125 & 0.8903 & 0.8891 & 0.8471 \\
\hline VIII & 0.5435 & 0.5472 & 0.6674 & 0.7651 & 0.7671 & 0.7321 & 0.8492 & 0.8500 & 0.8075 & 0.8815 & 0.8806 & 0.8330 \\
\hline IX & 0.5208 & 0.5250 & 0.6433 & 0.8339 & 0.8357 & 0.8026 & 0.8371 & 0.8372 & 0.7956 & 0.8764 & 0.8760 & 0.8255 \\
\hline$x$ & 0.5338 & 0.5389 & 0.6536 & 0.7412 & 0.7431 & 0.7122 & 0.8346 & 0.8358 & 0.7923 & 0.8675 & 0.8687 & 0.8158 \\
\hline $\mathrm{XI}$ & 0.4820 & 0.4869 & 0.5817 & 0.7049 & 0.7069 & 0.7021 & 0.7884 & 0.7893 & 0.7481 & 0.8220 & 0.8238 & 0.7668 \\
\hline
\end{tabular}

Fonte: Elaborada pelo autor.

do filtro Wiener. É possível notar que o BM3D gerou o maior val or SSIM (Fig. 31d). Porém, conforme anteriormente di scutido, é necessária uma anál ise qual itativa dos dados, pois o método Winer+NLM (Fig. 31c) apresenta, visual mente, uma qual idade de restauração comparável ao BM3D.

A Figura 32 ilustra o resul tado da combinação das técnicas de redução de borramento $R L$ com os al goritmos de remoção de ruído. Visual mente, a qual idade da restauração da combinação do $\mathrm{RL}$ com os algoritmos NLM e BM3D é comparável aos resul tados obtidos com o filtro de Wiener (Fig. 31). O próximo experimento (6.5) descreve as mel hores combinações das técnicas de redução de borramento e ruído apl icadas a imagens LEEM reais. Será possível verificar que a combinação do RL com os filtros de ruído é, visualmente, superior ao Wiener e ao CLSF.

\subsubsection{Análise dos melhores parâmetros}

Para cada imagem deconvoluida pel os métodos Wiener, CLSF e RL, foram aplicados os filtros TV, BF, NLM e BM3D. Ainda, para cada filtro, variaram-se os parâmetros na intenção de encontrar a mel hor qualidade de filtragem. A Tabela 6 exibe os parâmetros necessários para que os resultados da Tabela 5 fossem atingidos. Nela é possível verificar que, diferentemente dos parâmetros obtidos quando as imagens sintéticas foram degradadas somente com ruído, 
Figura 31 - Combi nação do Wiener com os al goritmos TV, BF, NLM e BM3D.

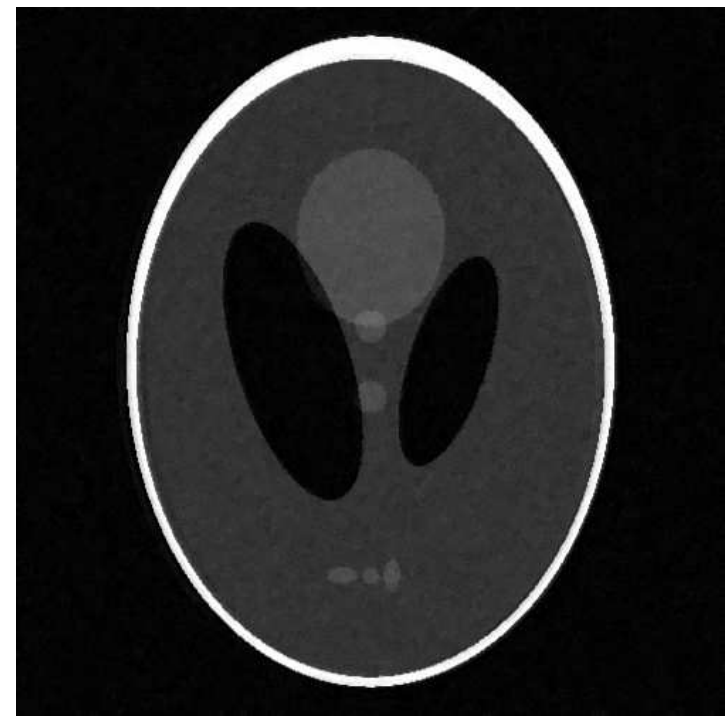

(a) TV - PSNR: 29.7123, SSIM: 0.5568

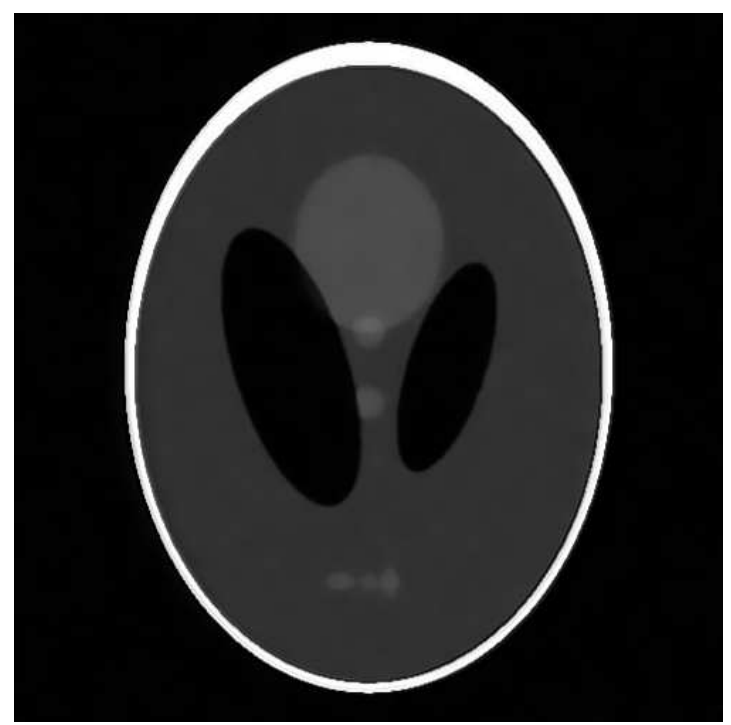

(c) NLM - PSNR: 30.2981, SSIM: 0.8592

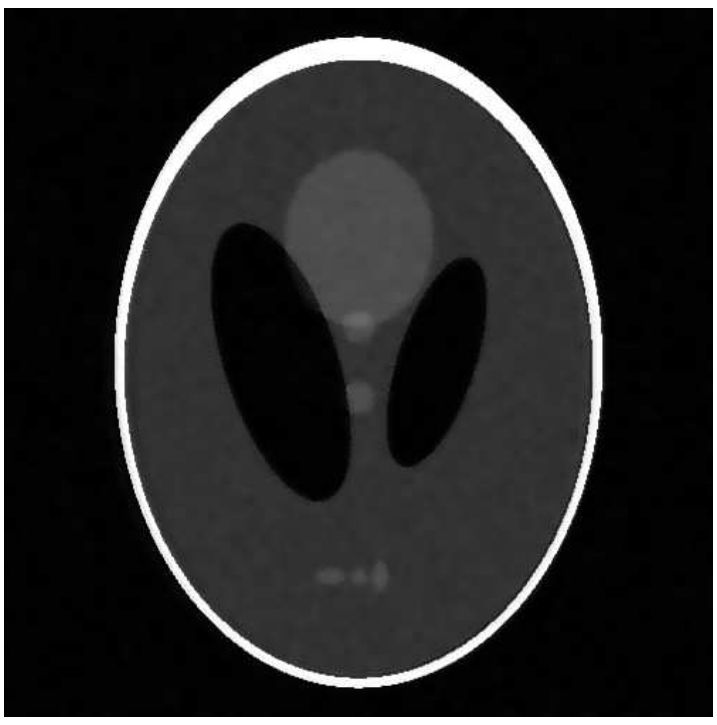

(b) BF - PSNR: 32.2442, SSIM: 0.8011

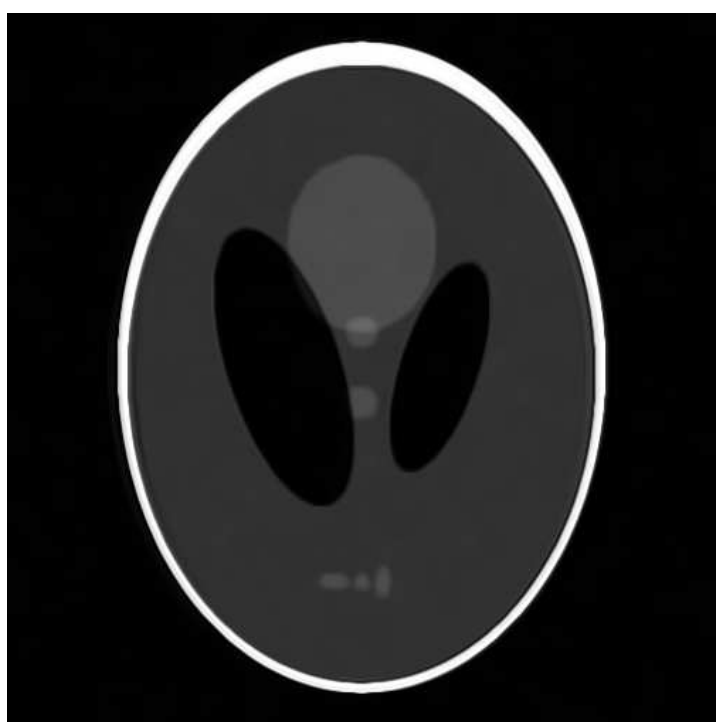

(d) BM3D - PSNR: 29.4166, SSIM: 0.8889

Fonte: Elaborada pelo autor.

devido as técnicas de deconvolução ampliar o ruído, foi necessária a utilização de parâmetros mai ores nos filtros NLM e BM3D. Entretanto, os filtros TV e BF sofreram poucas al terações nos parâmetros, com exceção da combinação do RL com o BF, onde os parâmetros foram reduzidos.

A Figura 33 ilustra a evolução do SSIM em função do parâmetro sigma (s ) do filtro BM3D. É possível verificar que, ao contrário da ocasião em que havia somente ruído nas imagens sintéticas, a introdução de borramento requereu um aumento dos parâmetros do BM3D. Além disso, após um determinado valor do sigma ( $s=41)$ o valor do SSIM estabilizou-se. 
Figura 32 - Combinação do RL com os al goritmos TV, BF, NLM e BM3D.

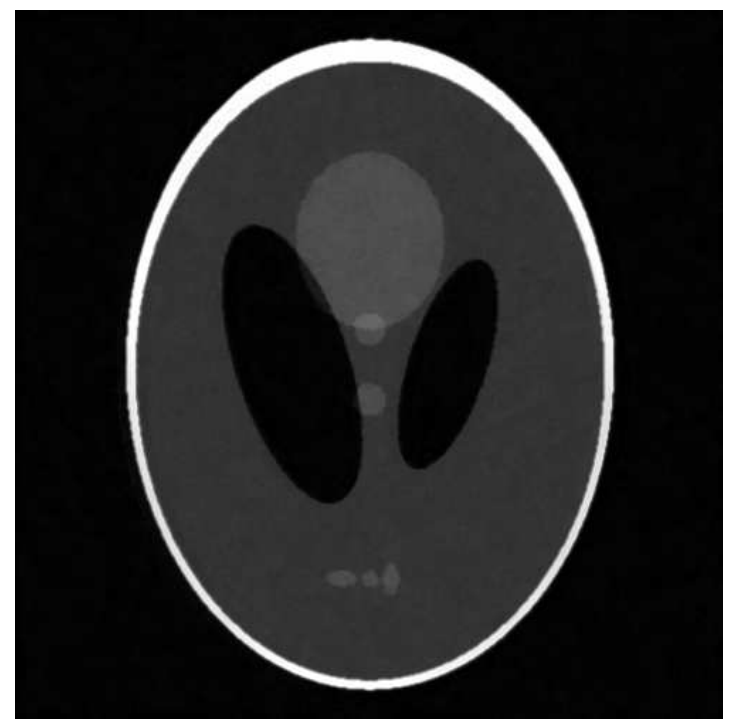

(a) TV - PSNR: 27.6836, SSIM: 0.6887

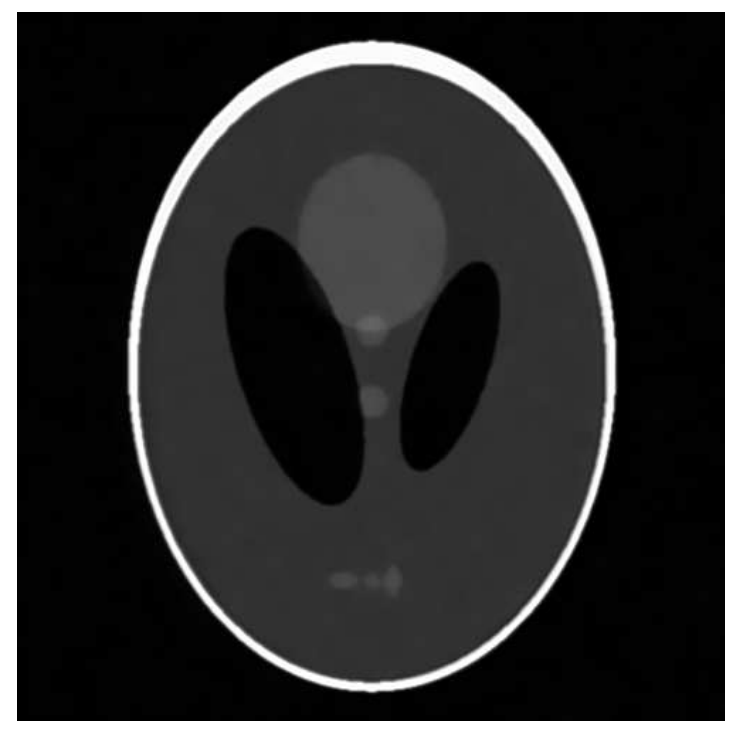

(c) NLM - PSNR: 27.7242, SSIM: 0.8208

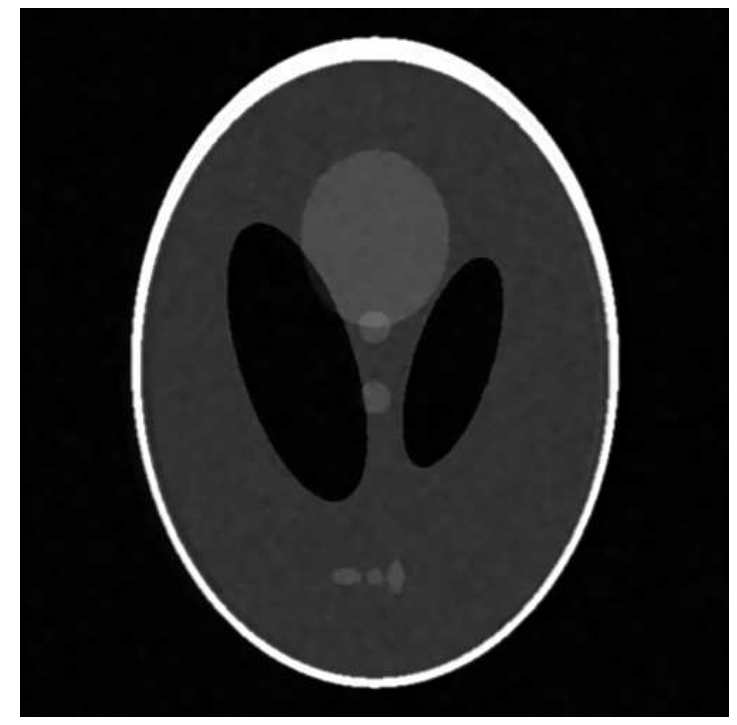

(b) BF - PSNR: 27.9814, SSIM: 0.7593

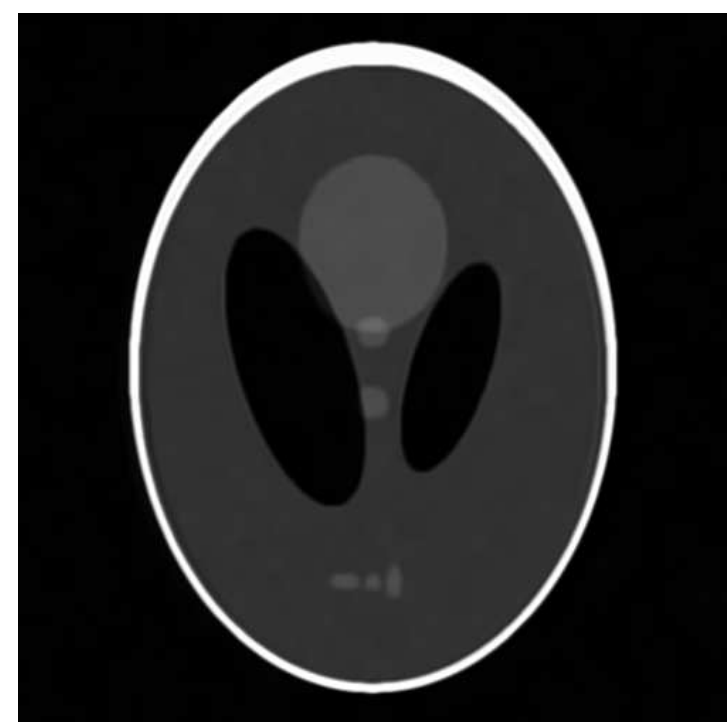

(d) BM3D - PSNR: 29.4166, SSIM: 0.8889

Fonte: El aborada pelo autor.

\subsection{Experimento 4 - Test es de texturas e pequenos detalhes}

Este experimento compara os dois métodos propostos pelo autor, NLM3D-LBP-MSB e NLM3D-LBP-Adaptive, com os seguintes al goritmos de filtragem: NLM, NLM3D, NLM-LBP e BM3D. Inicial mente são apresentadas as imagens utilizadas (imagens sintéticas, porém ao contrário das anteriores, estas contêm texturas e pequenos detal hes tornando os testes mais fiéis à proposta deste trabalho). Foi realizada uma análise exaustiva para encontrar os "mel hores parâmetros". Além disso, foi analisado o impacto do uso do MSB como pré-processamento. 
Tabela 6 - Análise da combinação de métodos de redução de borramento e ruído (Parâmetros)

\begin{tabular}{c|ccc|ccc|ccc|ccc}
\cline { 2 - 12 } & \multicolumn{3}{c}{ TV $(\mathrm{I})$} & \multicolumn{3}{c}{ BF $\left(\mathrm{S}_{\mathrm{S}}\right)$} & \multicolumn{3}{c}{ NLM $(\mathrm{H})$} & \multicolumn{3}{c}{ BM3D(S) } \\
\hline Ruído & Wiener & CLSF & RL & Wiener & CLSF & RL & Wiener & CLSF & RL & Wiener & CLSF & RL \\
\hline 0.0176 & 1.1 & 1.1 & 0.6 & 19 & 28 & 10 & 0.1 & 0.1 & 0.1 & 50 & 50 & 50 \\
0.0189 & 1.2 & 1.1 & 0.4 & 19 & 18 & 10 & 0.1 & 0.1 & 0.1 & 50 & 49 & 50 \\
0.0189 & 1.1 & 1.1 & 0.4 & 20 & 21 & 10 & 0.1 & 0.1 & 0.1 & 50 & 50 & 49 \\
0.0200 & 1.1 & 1.1 & 0.5 & 19 & 19 & 10 & 0.1 & 0.1 & 0.1 & 50 & 50 & 49 \\
0.0256 & 1.2 & 1.2 & 0.5 & 27 & 27 & 10 & 0.1 & 0.1 & 0.1 & 50 & 50 & 50 \\
0.0263 & 1.2 & 1.1 & 0.5 & 27 & 27 & 10 & 0.1 & 0.1 & 0.1 & 50 & 50 & 50 \\
0.0286 & 1.2 & 1.1 & 0.5 & 26 & 27 & 10 & 0.1 & 0.1 & 0.1 & 50 & 50 & 50 \\
0.0305 & 1.2 & 1.2 & 0.5 & 27 & 28 & 10 & 0.1 & 0.1 & 0.1 & 50 & 50 & 50 \\
0.0340 & 1.2 & 1.1 & 0.6 & 29 & 29 & 20 & 0.1 & 0.1 & 0.1 & 50 & 49 & 50 \\
0.0347 & 1.2 & 1.1 & 0.5 & 31 & 31 & 12 & 0.1 & 0.1 & 0.1 & 50 & 50 & 50 \\
0.0523 & 1.1 & 1.1 & 0.5 & 41 & 41 & 15 & 0.1 & 0.1 & 0.1 & 50 & 50 & 50 \\
\hline
\end{tabular}

Fonte: Elaborada pelo autor.

Figura 33 - Variação do parâmetro s do al goritmo BM3D.

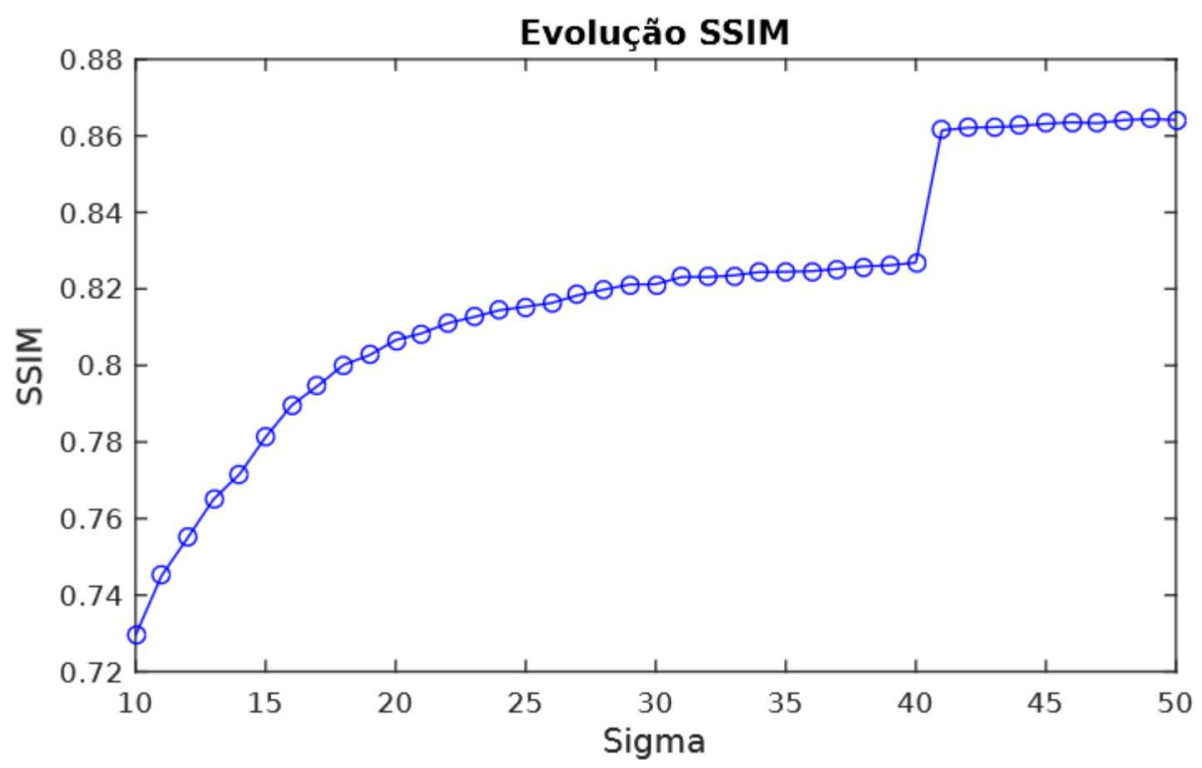

Fonte: Elaborada pelo autor.

Final mente, é real izada uma aval iação quantitativa de ambos os métodos com medidas PSNR e SSIM, al ém de uma aval iação qual itativa visual.

\subsubsection{Imagens sintéticas}

Seis sequências de vídeos sem ruído de dimensão $320 \times 180$ foram extraídas do vídeo "The Big Buck Bunny" 1 e então convertidas para escal a de cinza. Os quadros centrais de cada sequências são ilustrados na Figura 34.

Foram aplicados, à cada sequência gerada, 4 diferentes níveis de ruído branco Gaussiano ( $s=\{10 ; 15 ; 20 ; 25\}$ ), produzindo 24 sequências de vídeos ruidosas. A Figura 35 ilustra estes 4

1 Este vídeo possui licença under the Creative Commons Attribution 3.0 license. O vídeo original (colorido) $320 \times 180$ pode ser baixado em: <http://download.blender.org/peach/bigbuckbunny_movies/BigBuckBunny_ $320 \times 180 . \mathrm{mp} 4>$ 
Figura 34 - Quadros centrais de cada sequência: quadros de (a) a (f) referem-se às sequências 1 a 6, respectivamente.

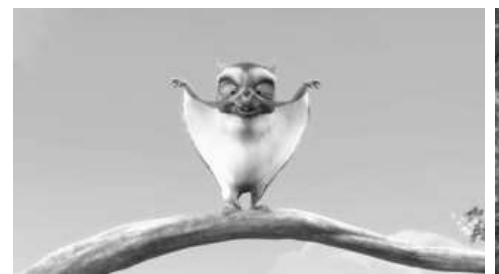

(a)

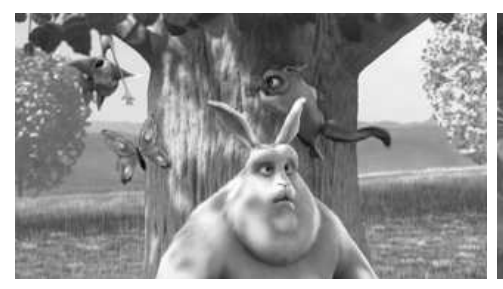

(d)

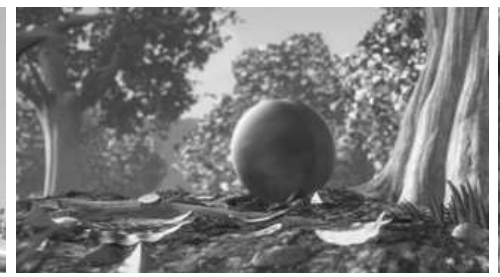

(b)

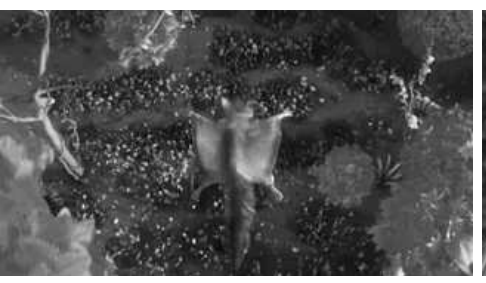

(e)

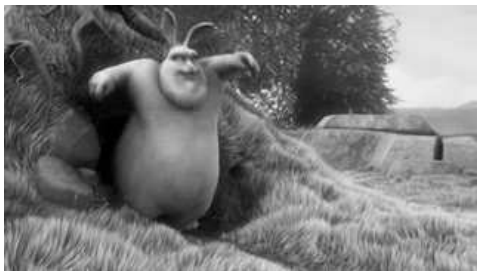

(c)

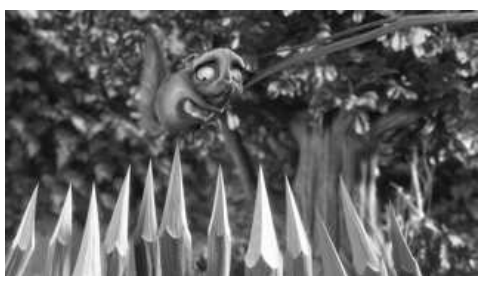

(f)

Fonte: Elaborada pelo autor.

níveis de ruídos aplicados à sequência (d) da Figura 34.

Figura 35 - Diferentes níveis de ruído aplicados na sequência 4 (Figura. 34d).

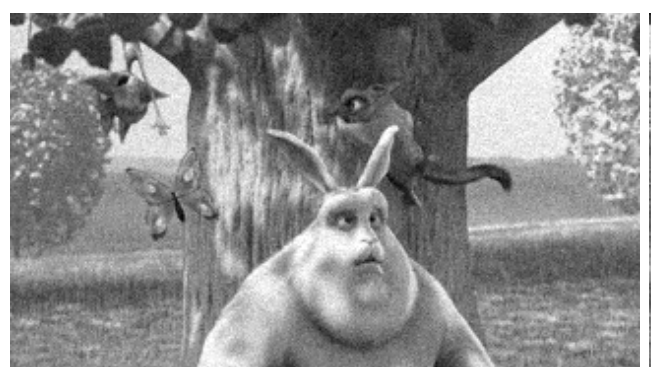

(a)

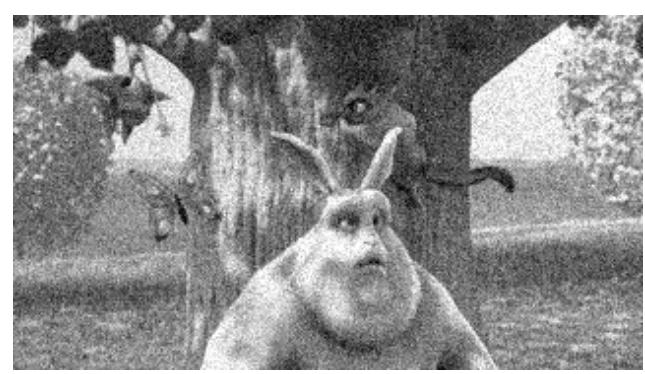

(c)

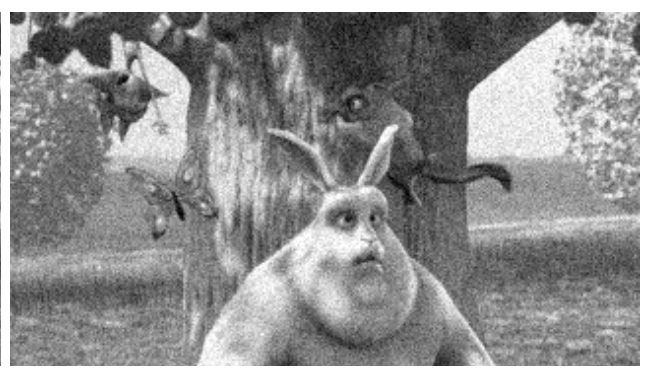

(b)

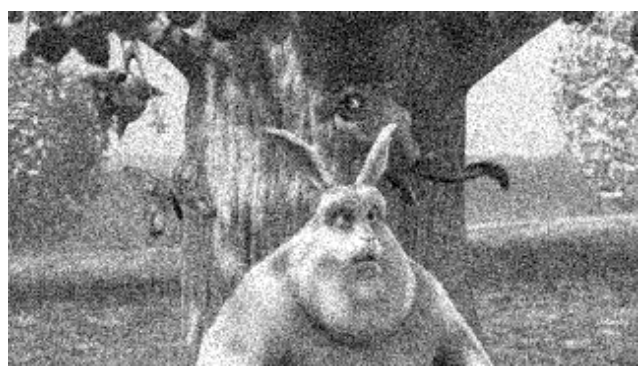

(d)

Fonte: Elaborada pelo autor.

\subsubsection{Análise de parâmetros}

A fim de permitir uma comparação justa, ambos os métodos foram testados com parâmetros variados. Os parâmetros foram definidos da seguinte forma: tamanho da janela de busca $s=\{7 ; 9 ; 11 ; 13\}$, tamanho da vizinhança $p=5$ e grau de filtragem $h=\{10 ; 15 ; 20 ; 25\}$. 
Adicional mente, todos os val ores de $\mathrm{h}$ foram combinados com os val ores $s=5$ e $p=3$. Quanto aos métodos 3D, os parâmetros $s_{t}$ (o comprimento temporal da janela de pesquisa) e $p_{t}$ (o comprimento temporal das vizinhanças) foram atribuídos os val ores s e $p$, respectivamente.

Outros parâmetros foram definidos empiricamente como se segue: o número dos bits mais significativos $m=3$ (para o método proposto NLM3D-LBP-MSB), o limiar $t=0: 09$ (para o método proposto NLM3D-LBP-adaptativo), o desvio padrão para o kernel Gaussiano com $\mathrm{a}=1$. Por fim, os descritores LBP e LBP-TOP empregaram uma vizinhança quadrada de tamanho $p=8$ e raio $r=1$.

Dentre todos os parâmetros, o tamanho da janel a de pesquisa (s) foi a que apresentou o maior impacto sobre os resul tados de filtragem. As Figuras 36 e 37 exemplificam essa influência para o vídeo da sequência 4, com dois diferentes níveis de ruído. Mudanças nos outros parâmetros não alterou significativamente a qual idade da filtragem.

Figura 36 - Resultados para diferentes val ores de s para a sequência 4 com s = 20 .

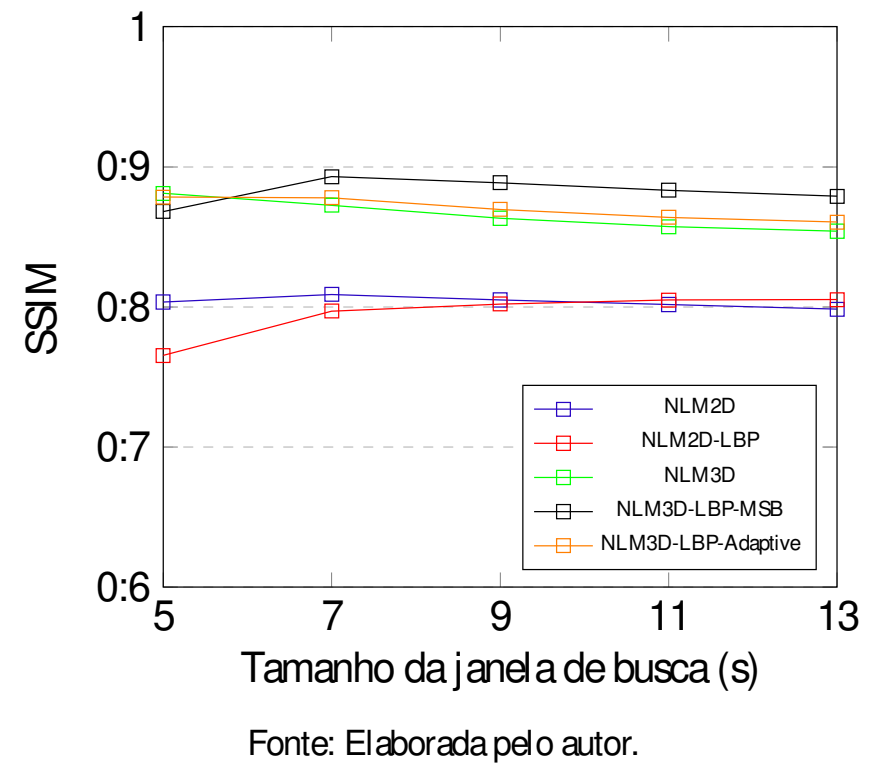

\subsubsection{Impacto da utilização do MSB}

Para avaliar o impacto do MSB no desempenho do método NLM3D-LBP-MSB testes de filtragem, com e sem MSB, foram conduzidos. Os resultados são mostrados na Tabela 7. O uso de MSB aumentou o desempenho da suavização em 22 dos 24 casos, tanto para o PSNR quanto para o SSIM.

Vale a pena mencionar que o passo de quantização MSB é computacional mente barato, especial mente se comparado com o custo do método NLM sozinho. Portanto, este não impacta na complexidade geral do processo de suavização. Por isso, apesar do aumento marginal sobre medidas PSNR e SSIM, a adição da estratégia MSB para o nosso método provou-se ser mui to vantajosa. 
Figura 37 - Resul tados para diferentes val ores de s para a sequência 4 com s = 25.

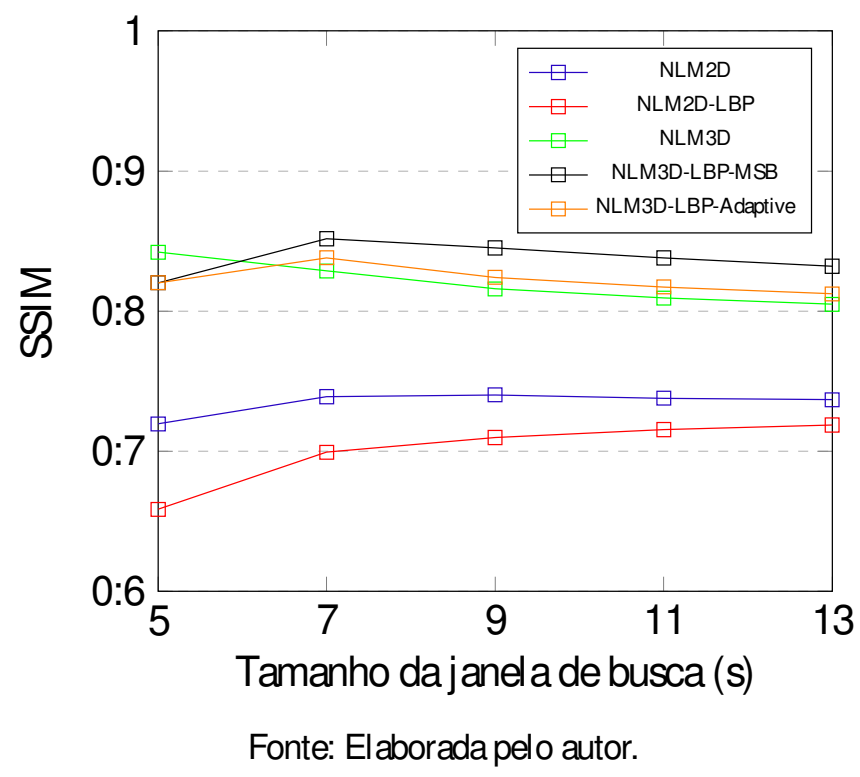

Tabela 7 - Ganho relativo a utilização do MSB.

\begin{tabular}{|c|c|c|c|c|c|c|c|}
\hline \multirow{2}{*}{\multicolumn{2}{|c|}{ Noise }} & \multicolumn{2}{|c|}{ Com MSB } & \multicolumn{2}{|c|}{ Sem MSB } & \multicolumn{2}{|c|}{ Ganho } \\
\hline & & PSNR & SSIM & PSNR & SSIM & PSNR & SSIM \\
\hline \multirow{4}{*}{$\overline{\mathscr{S}}$} & $s=10$ & 39.3453 & 0.9773 & 39.1824 & 0.9757 & 0.1629 & 0.0016 \\
\hline & $s=15$ & 35.6766 & 0.9569 & 35.4909 & 0.9551 & 0.1857 & 0.0018 \\
\hline & $s=20$ & 34.6349 & 0.9176 & 34.4995 & 0.9152 & 0.1354 & 0.0024 \\
\hline & $s=25$ & 33.1419 & 0.8195 & 32.9982 & 0.8237 & 0.1437 & -0.0042 \\
\hline \multirow{4}{*}{$\begin{array}{c}\text { N } \\
\mathscr{B}\end{array}$} & $s=10$ & 35.8919 & 0.9667 & 35.8154 & 0.9659 & 0.0765 & 0.0008 \\
\hline & $s=15$ & 32.8849 & 0.9344 & 32.8305 & 0.9328 & 0.0544 & 0.0016 \\
\hline & $s=20$ & 30.8613 & 0.897 & 30.8292 & 0.8959 & 0.0321 & 0.0011 \\
\hline & $s=25$ & 29.3623 & 0.8623 & 29.3175 & 0.8624 & 0.0448 & -0.0001 \\
\hline \multirow{4}{*}{$\begin{array}{l}m \\
\mathscr{8}\end{array}$} & $s=10$ & 34.5067 & 0.9456 & 34.4889 & 0.9452 & 0.0178 & 0.0004 \\
\hline & $S=15$ & 32.1897 & 0.9065 & 32.1495 & 0.9042 & 0.0402 & 0.0023 \\
\hline & $s=20$ & 30.213 & 0.8604 & 30.1866 & 0.8584 & 0.0264 & 0.002 \\
\hline & $s=25$ & 28.8755 & 0.817 & 28.8803 & 0.8159 & -0.0048 & 0.0011 \\
\hline \multirow{4}{*}{$\stackrel{+}{\stackrel{্}{8}}$} & $s=10$ & 35.9273 & 0.9592 & 35.8471 & 0.9581 & 0.0802 & 0.0011 \\
\hline & $s=15$ & 33.2705 & 0.9266 & 33.2385 & 0.9247 & 0.032 & 0.0019 \\
\hline & $s=20$ & 31.2472 & 0.893 & 31.2223 & 0.8913 & 0.0249 & 0.0017 \\
\hline & $s=25$ & 29.6398 & 0.8517 & 29.6388 & 0.8509 & 0.001 & 0.0008 \\
\hline \multirow{4}{*}{$\begin{array}{l}10 \\
\mathbb{8}\end{array}$} & $s=10$ & 32.3515 & 0.9116 & 32.3551 & 0.9114 & -0.0036 & 0.0002 \\
\hline & $s=15$ & 30.056 & 0.8503 & 30.0098 & 0.8492 & 0.0462 & 0.0011 \\
\hline & $s=20$ & 28.2856 & 0.7916 & 28.2468 & 0.7908 & 0.0388 & 0.0008 \\
\hline & $s=25$ & 27.0759 & 0.7377 & 27.0529 & 0.7369 & 0.023 & 0.0008 \\
\hline \multirow{4}{*}{$\begin{array}{l}0 \\
\stackrel{8}{\mathscr{S}}\end{array}$} & $s=10$ & 36.7086 & 0.9789 & 36.5899 & 0.9782 & 0.1187 & 0.0007 \\
\hline & $s=15$ & 33.8042 & 0.9598 & 33.7611 & 0.9583 & 0.0431 & 0.0015 \\
\hline & $s=20$ & 31.7354 & 0.9369 & 31.6173 & 0.9342 & 0.1181 & 0.0027 \\
\hline & $s=25$ & 30.2572 & 0.9155 & 30.173 & 0.9118 & 0.0842 & 0.0037 \\
\hline
\end{tabular}

Fonte: El aborada pelo autor.

\subsubsection{Avaliação quantit ativa}

Utilizando o PSNR e o SSIM, foi realizada uma comparação das técnicas propostas com os filtros NLM, NLM3D, NLM-LBP e BM3D para cada uma das 24 sequências de vídeo ruidosos. A Tabela 8 apresenta os mel hores resultados obtidos de cada al goritmo, para cada sequência e nível de ruído. 
Tabela 8 - Resultados quantitativos dos métodos de filtragem de ruído em imagens com texturas.

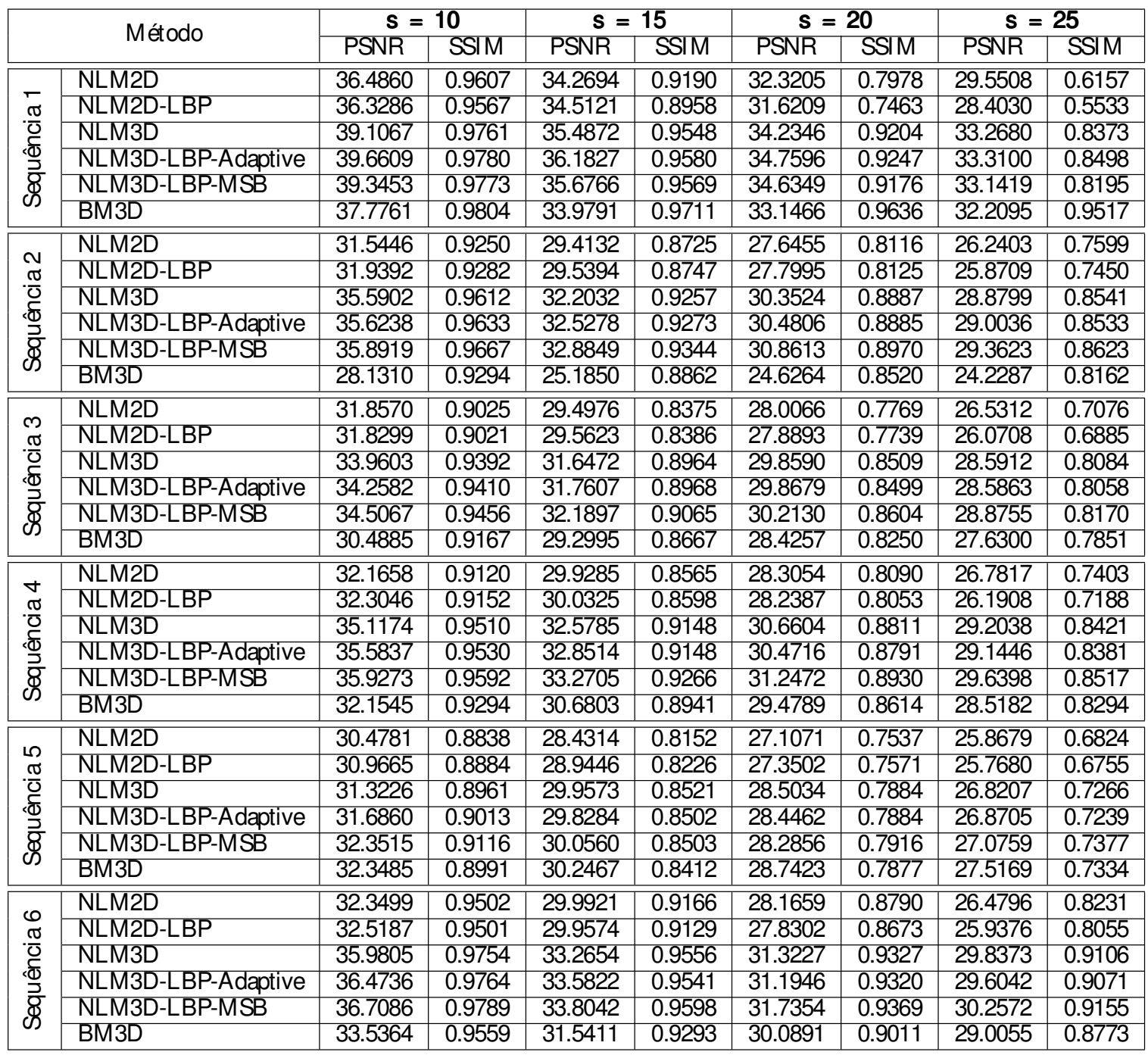

Fonte: Elaborada pelo autor.

O método proposto, NLM3D-LBP-MSB, produziu melhores resultados (ambos SSIM e PSNR) na mai oria dos casos, para as sequências de vídeo de 2 a 6. Quanto à sequência 1, o método adaptativo proposto foi mel hor em todos os casos, de acordo com PSNR, enquanto o BM3D produziu os melhores resultados, segundo a medida SSIM.

Observe que a imagem da sequência 1 (Figura 35a) é composta de regiões bastante homogêneas, possuindo muito menos texturas e pequenos detal hes se comparada às de 2-6. Esta é uma indicação da capaci dade do método NLM3D-LBP-MSB em lidar com textura e pequenos detal hes. Quando a informação é predomi nantemente homogênea (regiões com pouca variação de intensidade), o método adaptativo proposto, bem como o al goritmo BM3D, são os mais adequados. 


\subsubsection{Avaliação Qualitativa}

A Figura 38 ilustra regiões de zoom de quadros processados com todos os métodos de filtragem. Percebe-se que regi ões texturizadas (tronco) e estruturas detal hadas (asas de borboleta) são particularmente bem preservadas quando filtrados com o al goritmo NLM3D-LBP-MSB. No entanto, para regiões planas (fundo do céu e da grama) o filtro BM3D (Figura 38f), NLM3D (Figura 38e) e o NLM3D-LBP-Adaptive (Figura 38g) são melhores. No entanto, a análise quantitativa fornecida na Tabela 8 revela também que a versão adaptativa só é ultrapassada pela sua contraparte (não-adaptativa), para a maioria das sequências de vídeo texturizados (sequências 2, 3, 4 e 6). Assim, a versão adaptativa fornece um bom trade-off para filtrar vídeos que combinam textura e regiões homogêneas.

Figura 38 - Anál ise qual itativa do resultado da filtragem das imagens com textura.

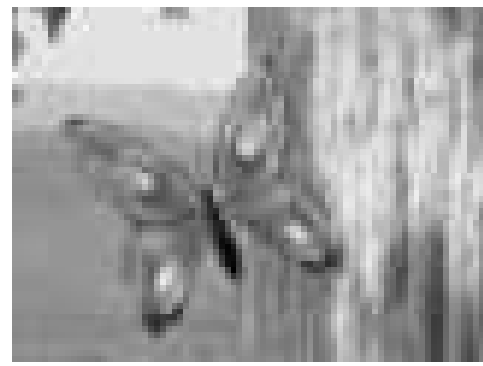

(a) Imagem original

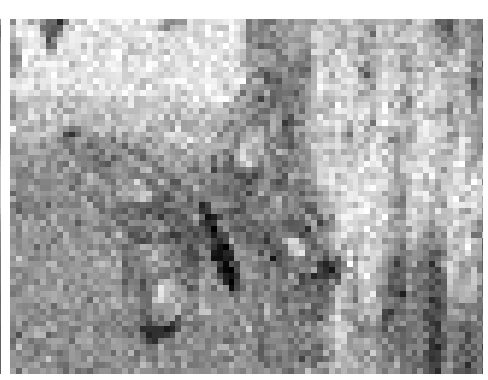

(b) Imagem ruidosa

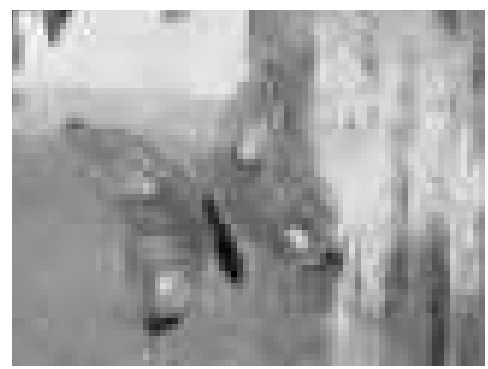

(c) NLM

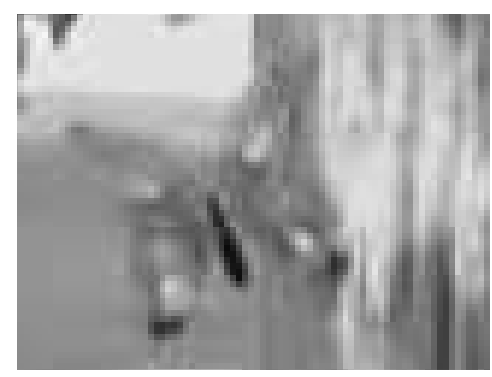

(f) BM3D

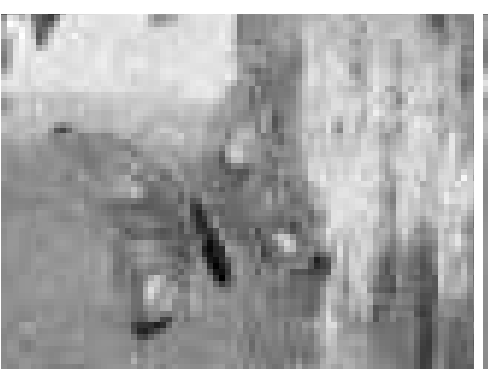

(d) NLM-LBP

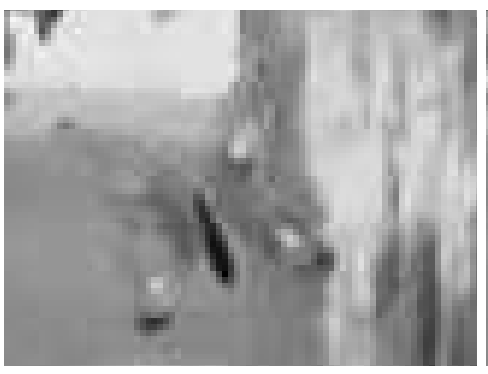

(g) NLM3D-LBP-Adaptive

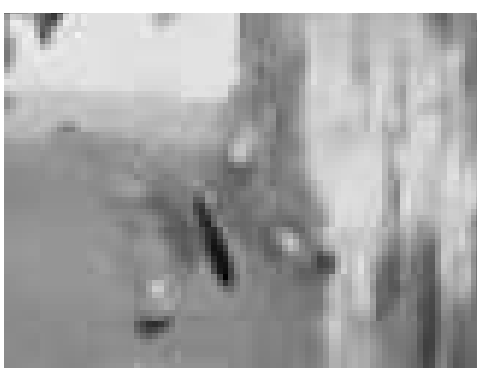

(e) NLM3D

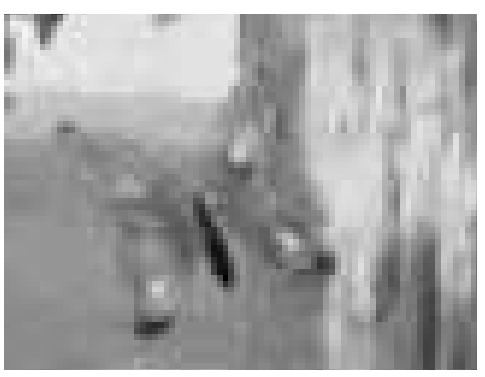

(h) NLM3D-LBP-MSB

Fonte: Elaborada pelo autor. 


\subsection{Experimento 5 - Aplicação das melhores combina- ções de algoritmos em imagens LEEM}

Este experimento avalia os métodos de redução de borramento e ruído para as imagens LEEM reais. Os parâmetros foram determi nados por meio das anál ises em imagens si ntéticas mostradas nos experimentos anteriores. Apesar da grande quantidade de imagens testadas, este experimento se limita a apresentar o resultado para 6 imagens, já que estas traduzem o desempenho global observado.

Todas as imagens foram restauradas por meio do método de deconvolução $R L$, seguido da filtragem com os métodos TV, BF, NLM, BM3D, NLM3D-LBP-MSB e NLM3D-LBP-Adaptive. Os parâmetros utilizados foram únicos para todas as imagens, sendo eles: TV ( $(=0: 92)$, BF (kernel size $\left.=11, \mathrm{~s}_{\mathrm{r}}=10, \mathrm{~s}_{\mathrm{s}}=22\right)$, NLM (H=0:1), BM3D ( $\left.\mathrm{s}=49\right)$, NLM3D-LBP-MSB $(H=20, m s b=3)$ e NLM3D-LBP-Adaptive $(H=20, t=0: 09)$. No Apêndice A é mostrada a restauração das imagens com Wiener e CLSF. Além da combi nação do processo de filtragem com os métodos de redução de borramento, a filtragem também foi aplicada diretamente às imagens LEEM, a fim de anal isar a qual idade das imagens quando aplicados somente métodos de filtragem. Para não estender demasiadamente o texto, os resul tados foram disponi bilizados em <https://goo.gl/2uKMvF> e <https://goo.gl/oCJYPB>.

As Figuras 39 - 44 revel am um comportamento esperado: a combinação dos métodos de redução de borramento com os métodos de filtragem não locais (propostos e existentes) são superiores aos métodos locais (TV e BF). Porém, esse comportamento se limita a utilização do métodos de redução de borramento RL. Os métodos Wiener e CLSF na presença de ruído degradam ai nda mais as imagens, prejudicando assim a etapa de filtragem e, consequentemente, a qual idade da imagem final.

Tanto os métodos de filtragem quanto os métodos locais TV e BF filtram os ruídos presentes. Entretanto, os métodos locais TV e BF tendem a borrar e suprimir detal hes pequenos presentes nas imagens. Já os métodos não locais, NLM e BM3D, possuem a capacidade de filtrar de forma superior aos métodos locais grande parte dos ruídos e preservar bordas e al guns detal hes menores. Contudo, os métodos propostos NLM3D-LBP-MSB e NLM3D-LBP-Adaptive filtram uma quantidade menor de ruído se comparados aos métodos NLM e BM3D, mas preservam uma quantidade superior de detal hes como bordas, texturas e pequenos objetos. 
Figura 39 - A plicação da combinação do método RL com os filtros de ruído na imagem LEEM GaAsFringe.

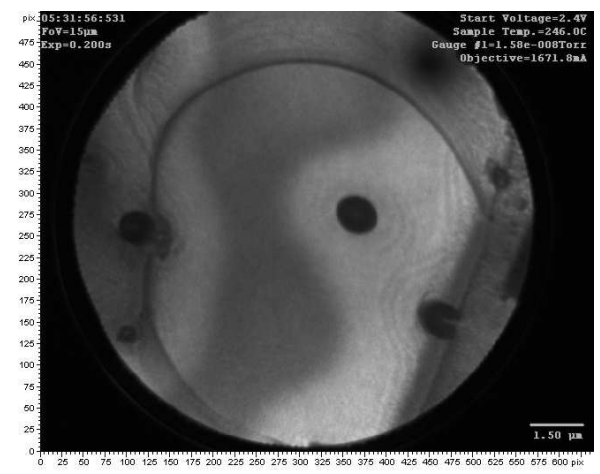

(a) GaAsFringe (Original)

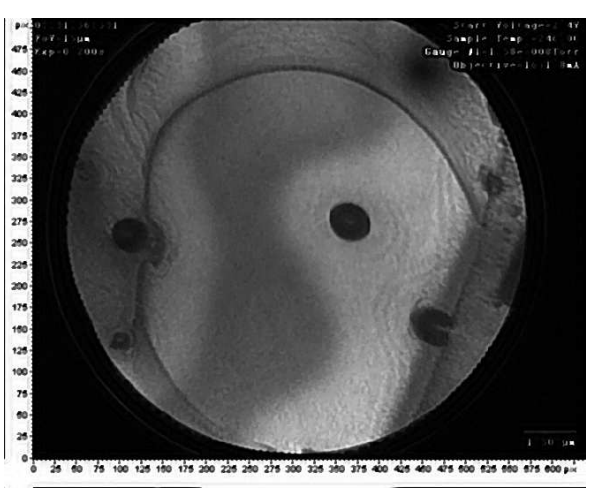

(b) $R L+T V$

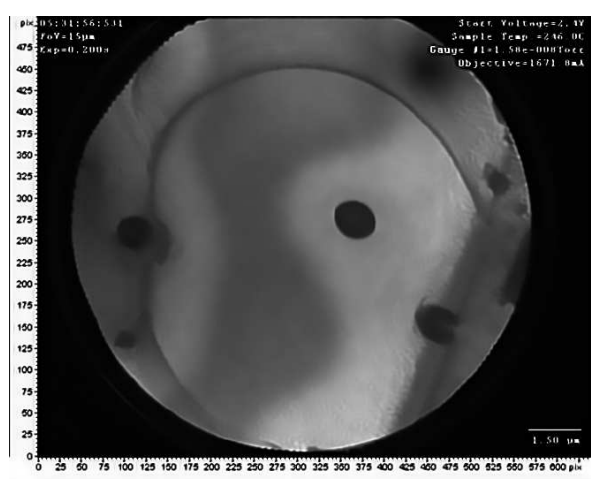

(d) $R L+N L M$

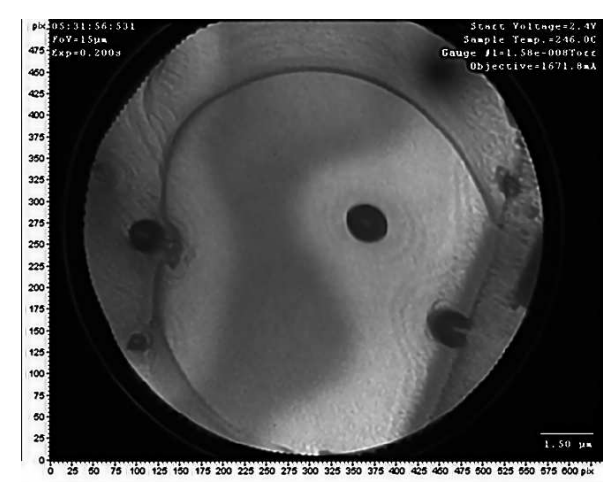

(f) $R L+N L M 3 D-L B P-A d a p t i v e$

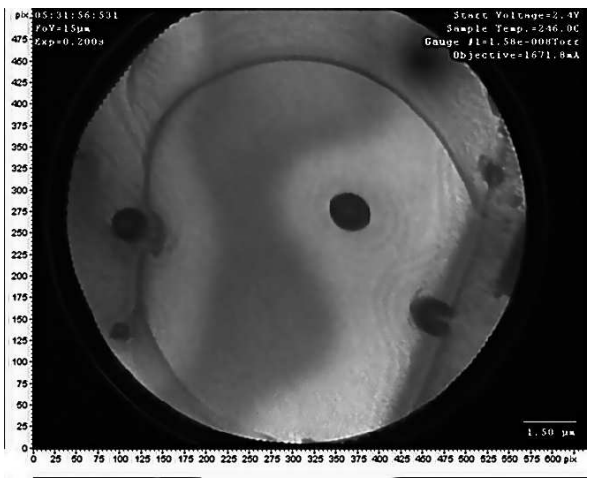

(c) $R L+B F$

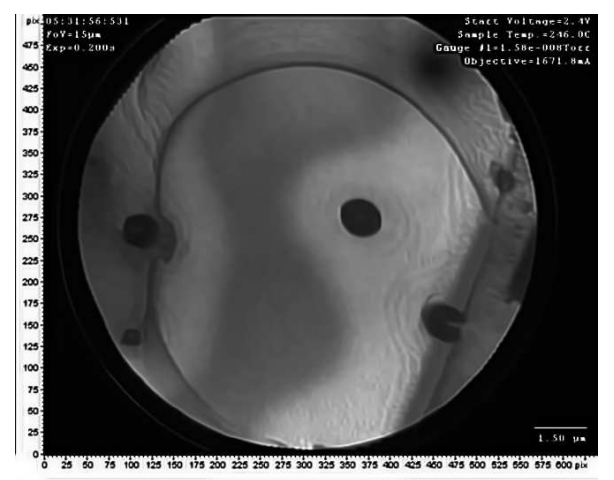

(e) $R L+B M 3 D$

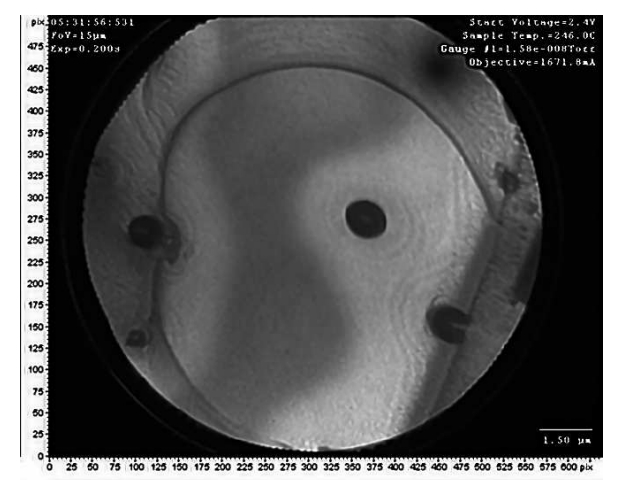

(g) RL + NLM3D-LBP-MSB

Fonte: Adaptado das imagens cedidas pelo professor Dr. Wen-Xin Tang. 
Figura 40 - A plicação da combinação do método RL com os filtros de ruído na imagem LEEM MoviewGa.

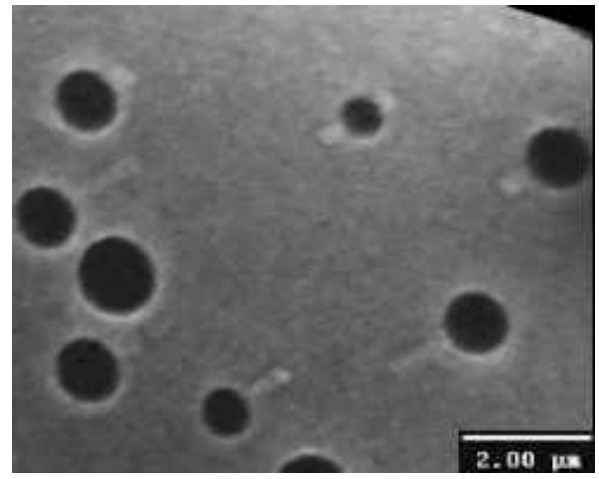

(a) MoviewGa (Original)

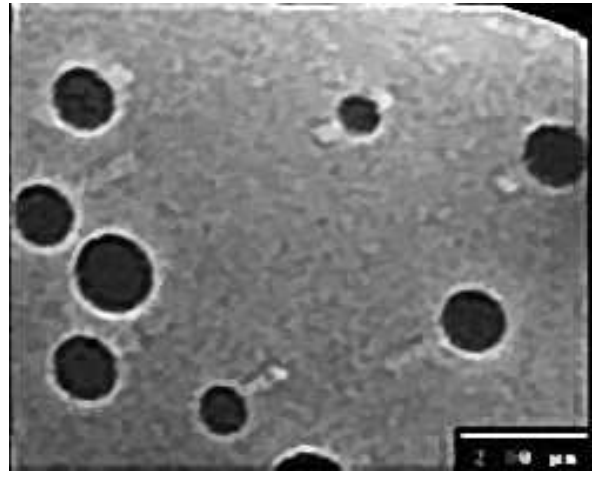

(b) $R L+T V$

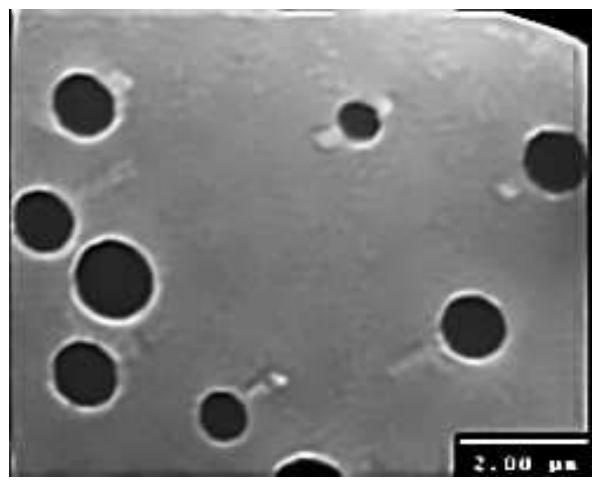

(d) $R L+N L M$

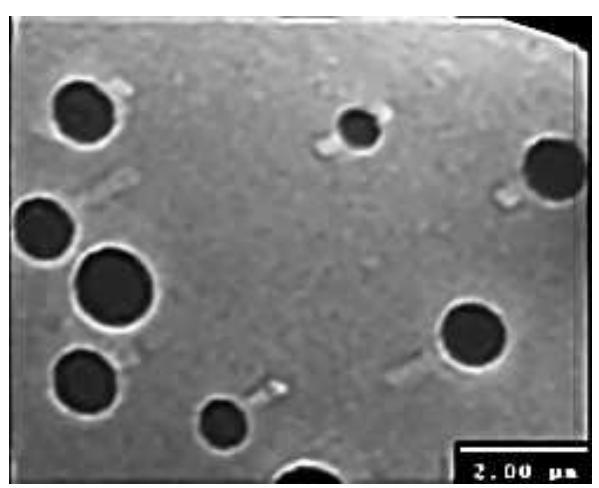

(f) $R L+N L M 3 D-L B P-A d a p t i v e$

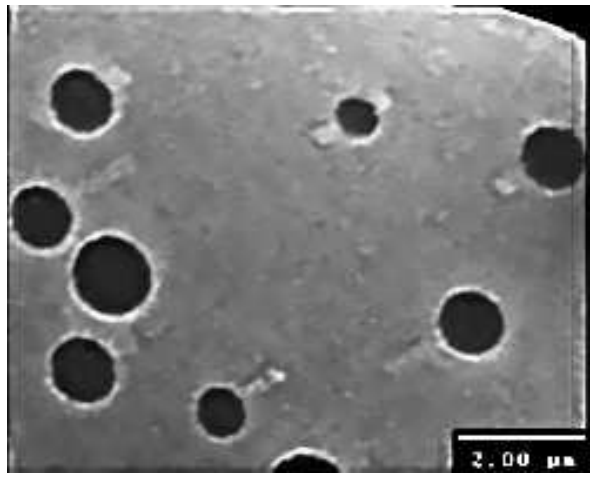

(c) $R L+B F$

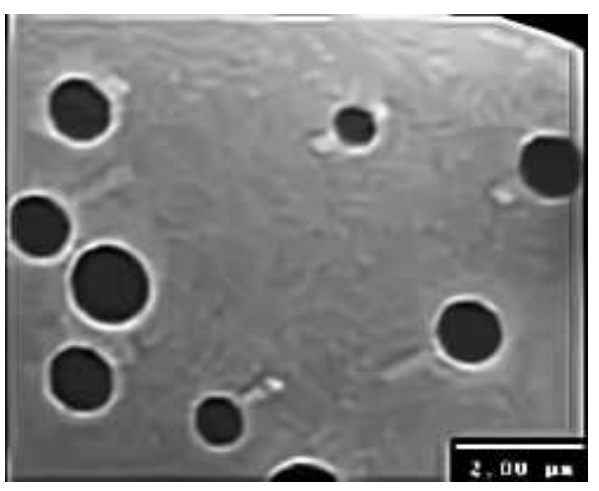

(e) $R L+B M 3 D$

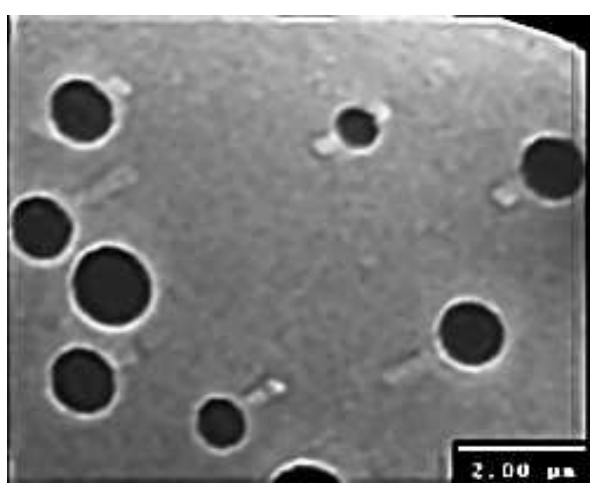

(g) $R L+N L M 3 D-L B P-M S B$

Fonte: Adaptado das imagens cedidas pelo professor Dr. Wen-Xin Tang. 
Figura 41 - Aplicação da combinação do método RL com os filtros de ruído na imagem LEEM PbCu.

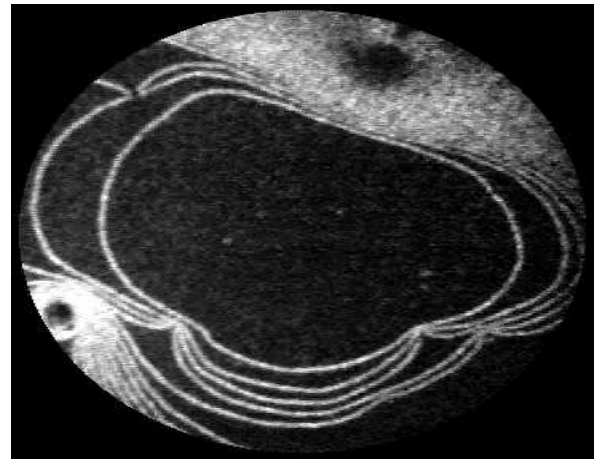

(a) $\mathrm{PbCu}$ (Original)

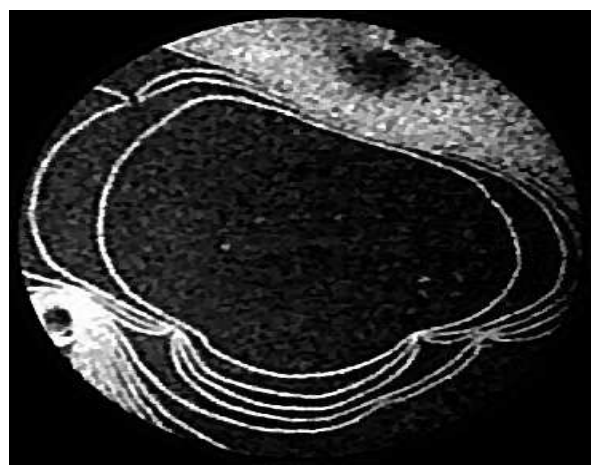

(b) $R L+T V$

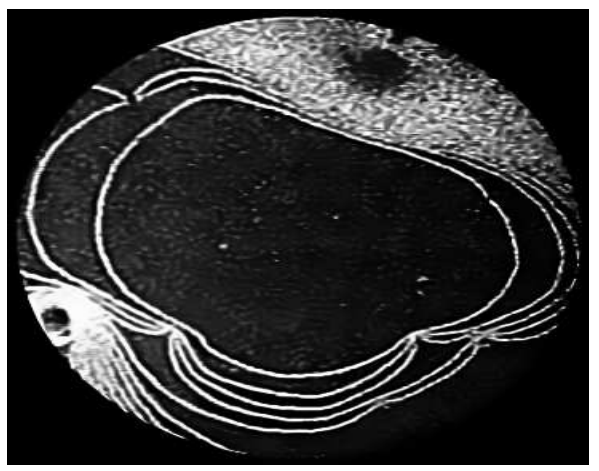

(d) $\mathrm{RL}+\mathrm{NLM}$

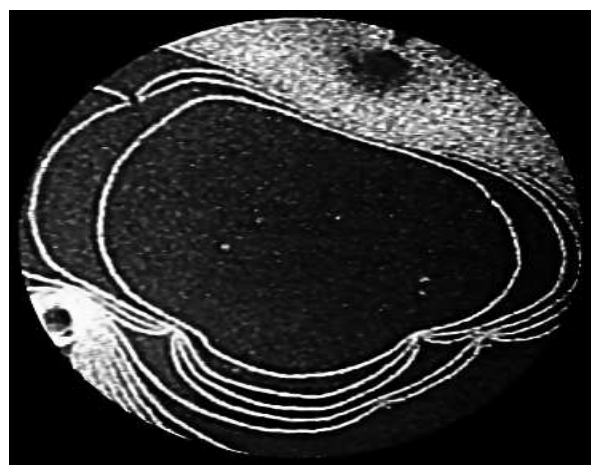

(f) $R L+N L M 3 D-L B P-A d a p t i v e$

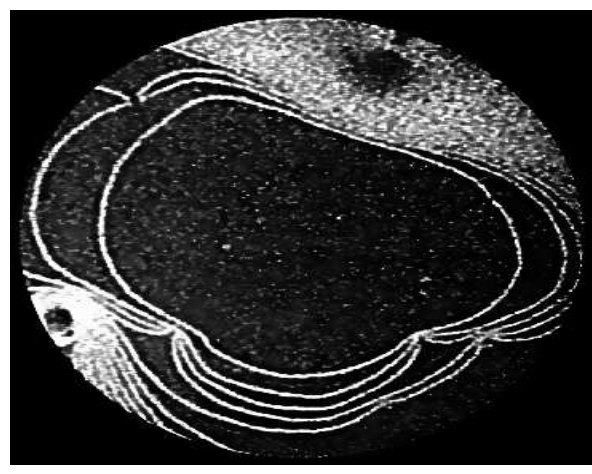

(c) $R L+B F$

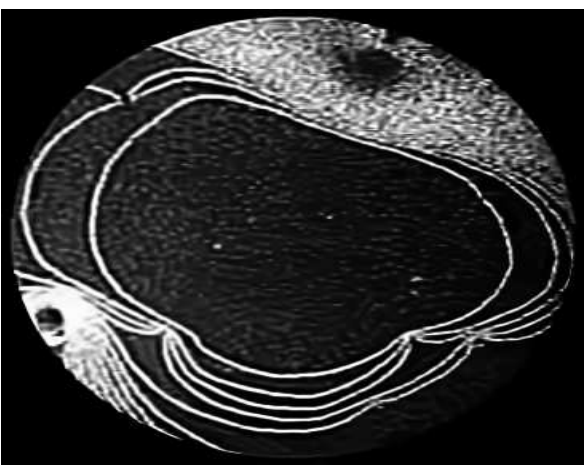

(e) $R L+B M 3 D$

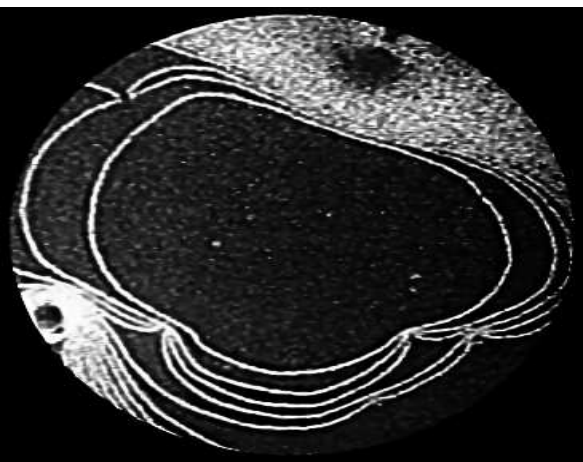

(g) $R L+N L M 3 D-L B P-M S B$

Fonte: Adaptado das imagens cedidas pelo professor Dr. Wen-Xin Tang. 
Figura 42 - Aplicação da combinação do método RL com os filtros de ruído na imagem LEEM Graphene.

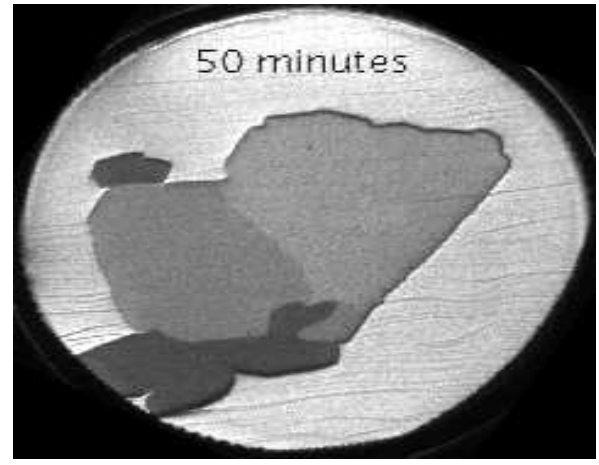

(a) Graphene (Original)

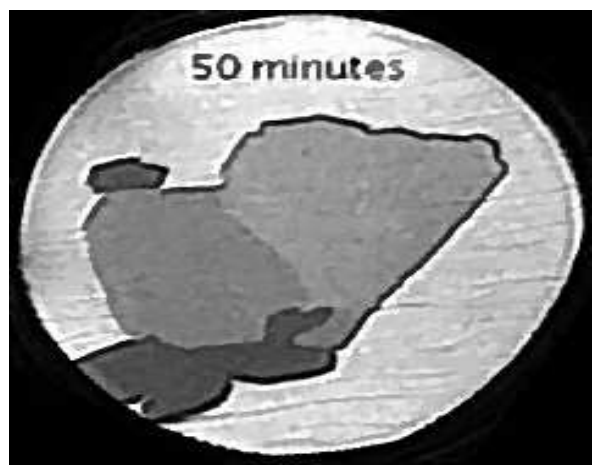

(b) $R L+T V$

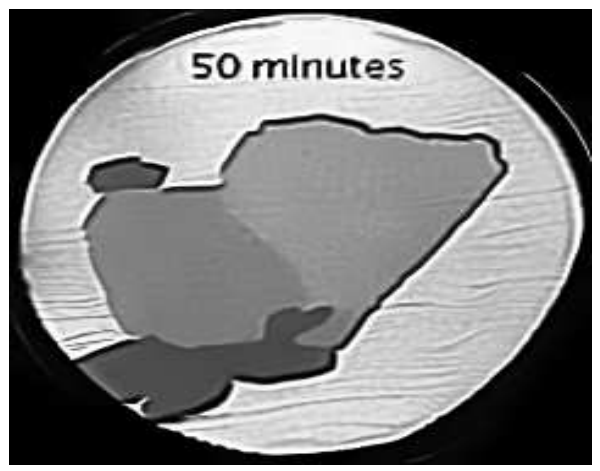

(d) $R L+N L M$

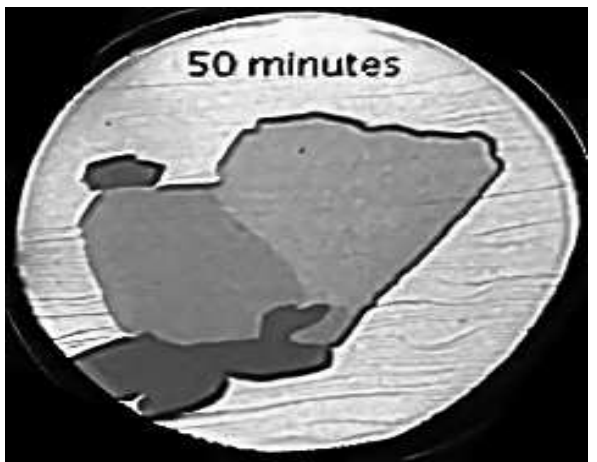

(f) $R L+N L M 3 D-L B P-A d a p t i v e$

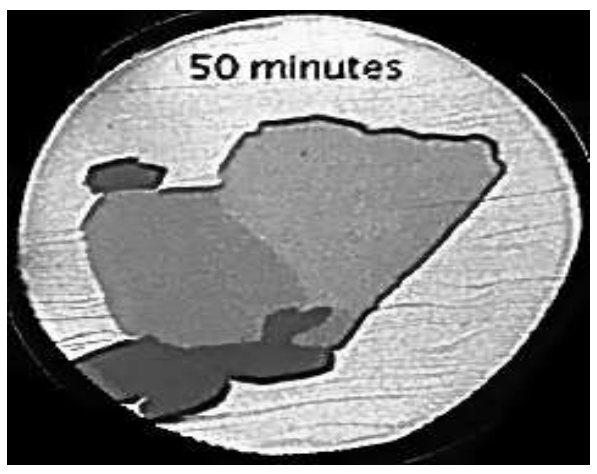

(c) $R L+B F$

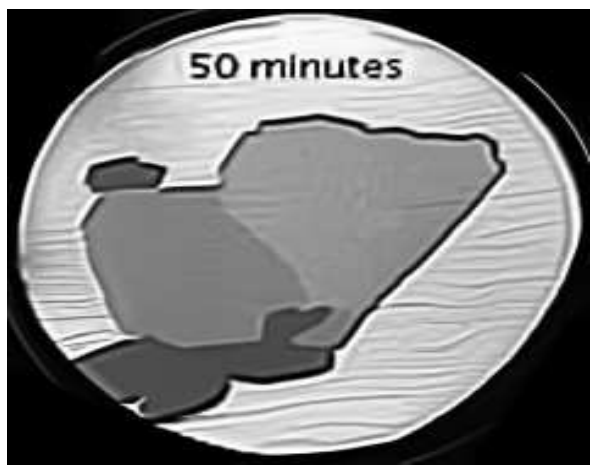

(e) $R L+B M 3 D$

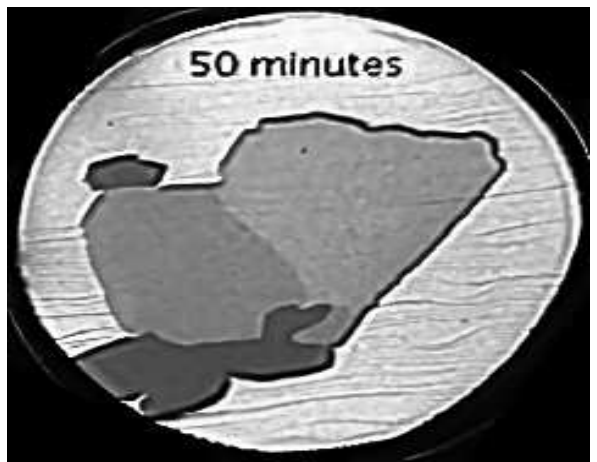

(g) $R L+N L M 3 D-L B P-M S B$

Fonte: Adaptada de Rogge et al. (2015). 
Figura 43 - Aplicação da combinação do método RL com os filtros de ruído na imagem LEEM NiAl2.

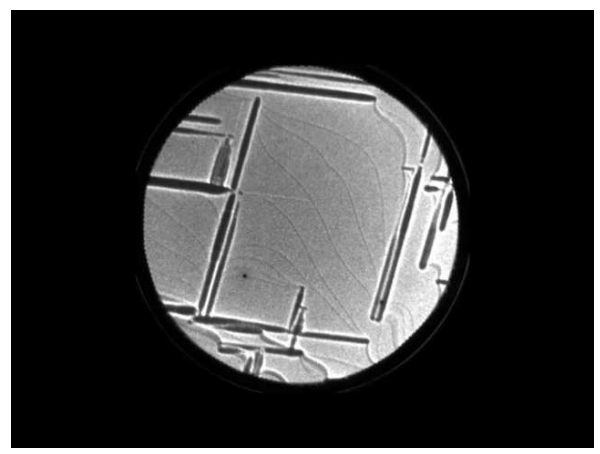

(a) $\mathrm{NiAl2} \mathrm{(Original)}$

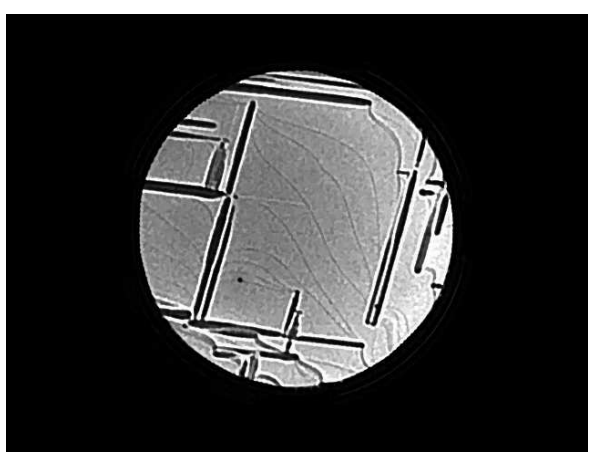

(b) $R L+T V$

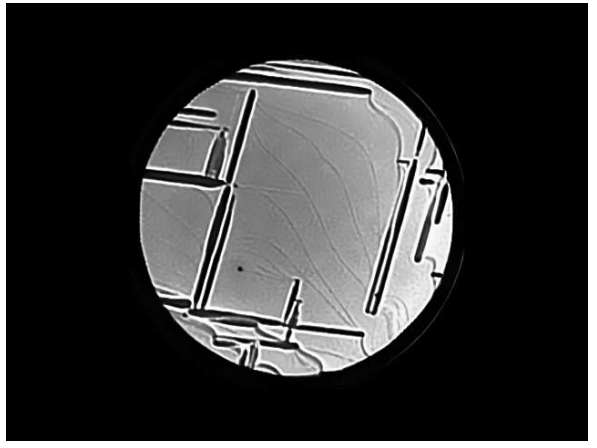

(d) $\mathrm{RL}+\mathrm{NLM}$

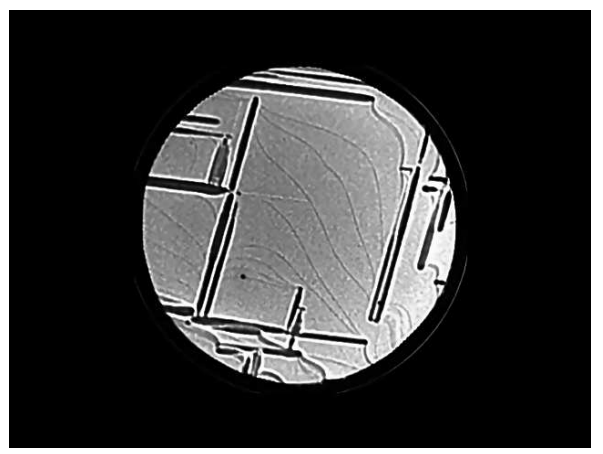

(f) $R L+N L M 3 D-L B P-A d a p t i v e$

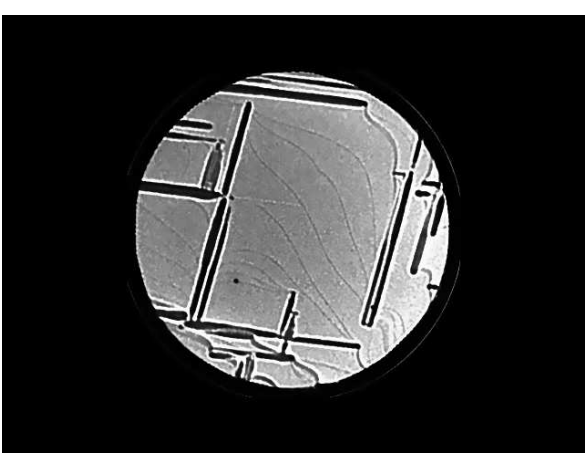

(c) $R L+B F$

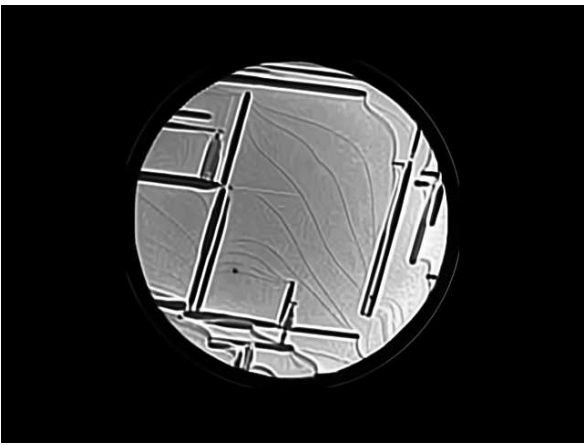

(e) $R L+B M 3 D$

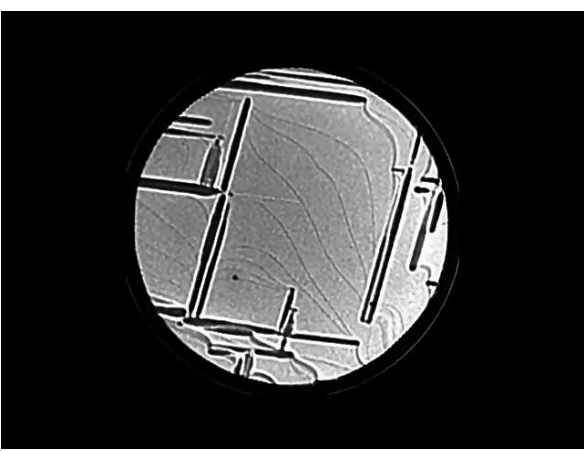

(g) $R L+N L M 3 D-L B P-M S B$

Fonte: Adaptada de Qin et al. (2015). 
Figura 44 - A plicação da combinação do método RL com os filtros de ruído na imagem LEEM Nell_Z.

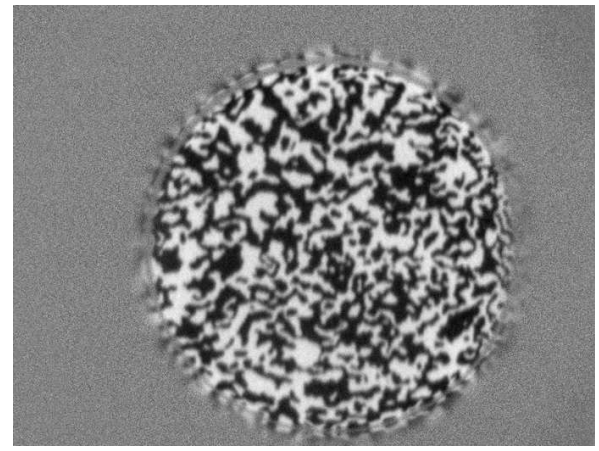

(a) Nell_Z (Original)

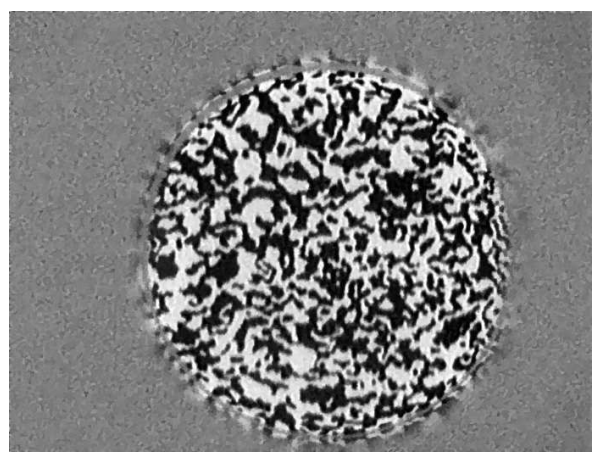

(b) $R L+T V$

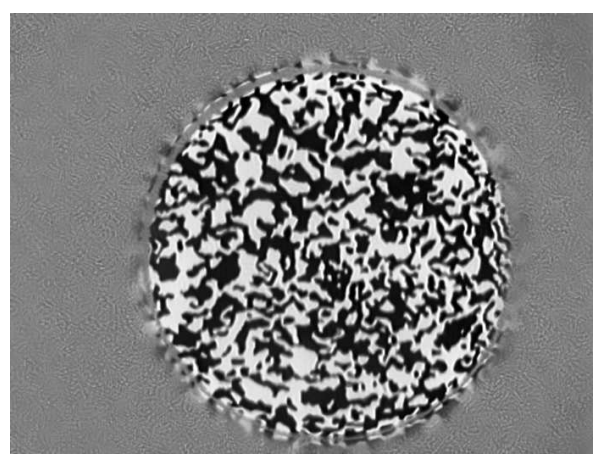

(d) $\mathrm{RL}+\mathrm{NLM}$

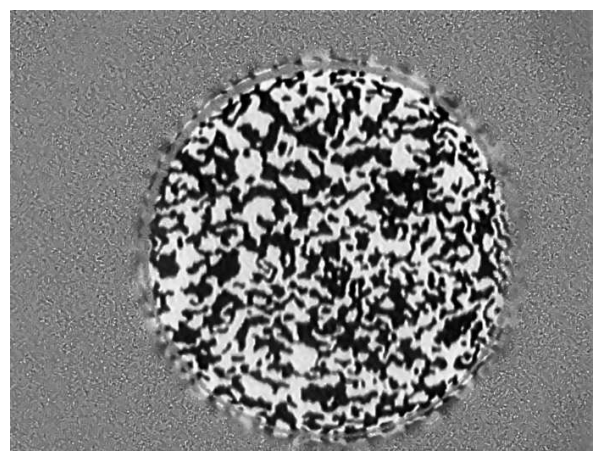

(f) $\mathrm{RL}+$ NLM3D-LBP-Adaptive

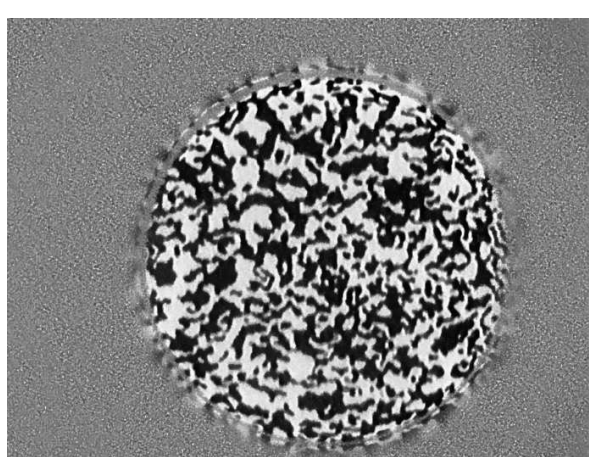

(c) $R L+B F$

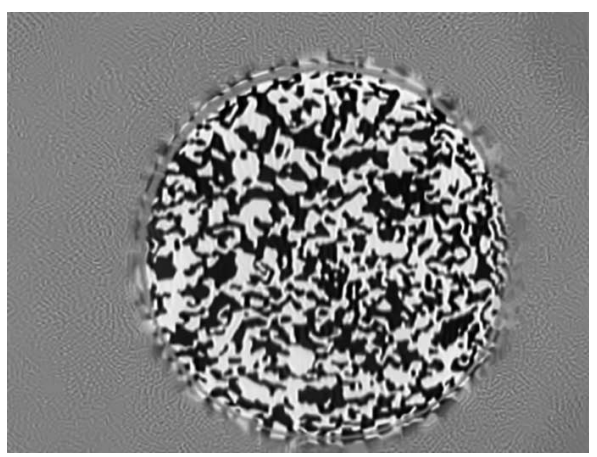

(e) $R L+B M 3 D$

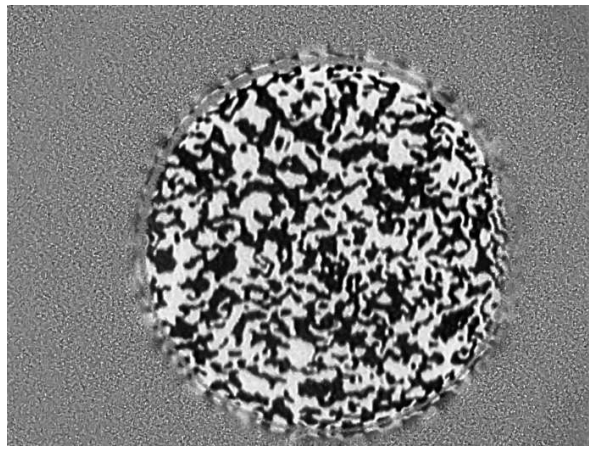

(g) $R L+N L M 3 D-L B P-M S B$

Fonte: Adaptado da imagem cedida pelo professor Dr. Gong Chen. 


\subsection{Experimento 6 - Análise qualitativa}

Para um ser humano, a definição de qual idade de uma imagem (grau de ruído, ilumi nação, etc) é um processo bastante subjetivo. Isso explica porque imagens nos parecem diferentes, embora al gumas medi das quantitativas que af erem tais diferenças indiquem serem as mesmas.

O objetivo deste experimento é o de anal isar a qual idade dos métodos de restauração de forma qual itativa, segundo a percepção do observador. Foi desenvolvido um si stema web que apresenta 10 imagens LEEM, cada qual restaurada por meio de uma combinação de métodos de filtragem e redução de borramento apresentados nas seções anteriores. Para cada imagem, foram geradas 24 imagens resul tantes das combinações. Além disso, foi adicionado ao grupo a imagem original. Com isso, para cada imagem LEEM um conjunto de 25 imagens resultantes é apresentado ao respondente.

Estas 25 imagens foram então al eatoriamente distribuídas em 5 grupos, cada qual composto por 5 imagens. Para cada um destes 5 conjuntos, o respondente é convidado a escol her a "melhor" imagem. Ao final das 5 escol has, uma nova consulta é apresentada ao observador, contendo as imagens selecionadas anteriormente e solicita-se a escol ha da "mel hor entre as melhores". Este processo é feito para todas as 10 imagens originais. É importante lembrar que al gumas das imagens podem representar resul tados de filtragens não ideais, já que o teste inclui todos os resultados, bons ou ruins. Porém, todas foram inseridas no teste para torná-lo justo.

No total, 60 testes foram apresentados para cada respondente e, ao final, para cada imagem LEEM este escolhe a melhor restauração. As Tabel as 9 e 10 apresentam os resultados obtidos com 10 respondentes, todos especial istas na área de processamento de imagens e/ou microscopia A Tabela 9 mostra a quantidade e a porcentagem das escol has quando utilizado, ou não, métodos de redução de borramento. Nesta etapa fica claro que os métodos Wiener e CLSF apresentaram os piores resultados. Além disso, também é possível verificar que utilizar as imagens originais, sem aplicar quai squer métodos de restauração, não gera bons resultados. Nesse contexto, o mel hor resul tado, corroborando o que foi mostrado nos testes quantitativos, se deu com a utilização do método RL, que foi escol hido em mais de 50\% dos casos.

Tabel a 9 - Teste de usuário - utilização dos métodos de remoção de ruídos

\begin{tabular}{l|c|c}
\cline { 2 - 3 } & Quantidade de escolhas & \% em relação ao total \\
\hline Original & 4 & 4.65 \\
\hline Somente Filtragem & 33 & 38.37 \\
\hline Wiener & 4 & 4.65 \\
\hline CLSF & 1 & 1.16 \\
\hline RL & 44 & 51.16
\end{tabular}

Fonte: Elaborada pelo autor.

A tabela 10 espande os resultados da tabel a anterior, detalhando as combinações de métodos de filtragem e redução de borramento. É possível verificar que os métodos TV e BF não 
produziram bons resultados, diferentemente dos resul tados quantitativos apresentados na Seção 6.2, em que, na presença de al tos níveis de ruído, o método TV apresenta os val ores mais al tos.

Tabela 10 - Teste de usuário detalhado

\begin{tabular}{l|c|c}
\cline { 2 - 3 } & Quantidade de escolhas & \% em relação ao total \\
\hline Original & 4 & 4.65 \\
\hline TV & 2 & 2.33 \\
\hline BF & 1 & 1.16 \\
\hline NLM & 5 & 12.79 \\
\hline BM3D & 6 & 5.81 \\
\hline NLM3D-LBP-MSB & 8 & 6.98 \\
\hline NLM3D-LBP-Adaptive & 0 & 9.30 \\
\hline Wiener + TV & 0 & 0.00 \\
\hline Wiener + BF & 2 & 0.00 \\
\hline Wiener + NLM & 1 & 2.33 \\
\hline Wiener + BM3D & 0 & 1.16 \\
\hline Wiener + NLM3D-LBP-MSB & 1 & 0.00 \\
\hline Wiener + NLM3D-LBP-Adaptive & 0 & 1.16 \\
\hline CLSF + TV & 0 & 0.00 \\
\hline CLSF + BF & 0 & 0.00 \\
\hline CLSF + NLM & 1 & 0.00 \\
\hline CLSF + BM3D & 0 & 1.16 \\
\hline CLSF + NLM3D-LBP-MSB & 0 & 0.00 \\
\hline CLSF + NLM3D-LBP-Adaptive & 1 & 0.00 \\
\hline RL + TV & 1 & 1.16 \\
\hline RL + BF & 15 & 1.16 \\
\hline RL + NLM & 6 & 17.44 \\
\hline RL + BM3D & 17 & 19.77 \\
\hline RL + NLM3D-LBP-MSB & 0.65 \\
\hline RL + NLM3D-LBP-Adaptive & 0.98 \\
\hline
\end{tabular}

Fonte: Elaborada pelo autor.

Os métodos NLM e BM3D foram escol hidos na mai oria dos casos, principal mente na combinação com o RL. Contudo, vale ressal tar que os métodos propostos produziram bons resultados, tanto com ou sem a utilização do método RL. No geral, as imagens LEEM testadas possuem mui tas áreas homogêneas e poucas áreas com pequenos detal hes. Devido a isso, é esperado que os métodos NLM e BM3D tragam resul tados mel hores e o métodos propostos fiquem em desvantagem. Contudo, nas imagens LEEM que possuem detal hes pequenos como as Figuras 45a e 45b os métodos tiveram mais de 80\% de escol ha, devido a característica da imagem. E como citado anteriormente, em imagens como as Figura 45c e 45d os métodos NLM e BM3D foram melhores. 
Figura 45 - Exemplo imagens LEEM.

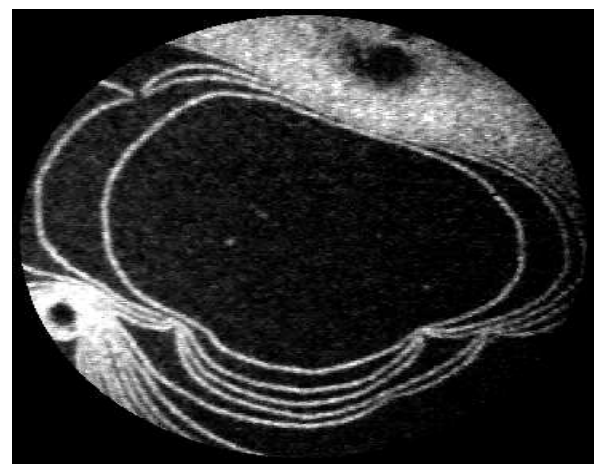

(a) $\mathrm{PbCu}$

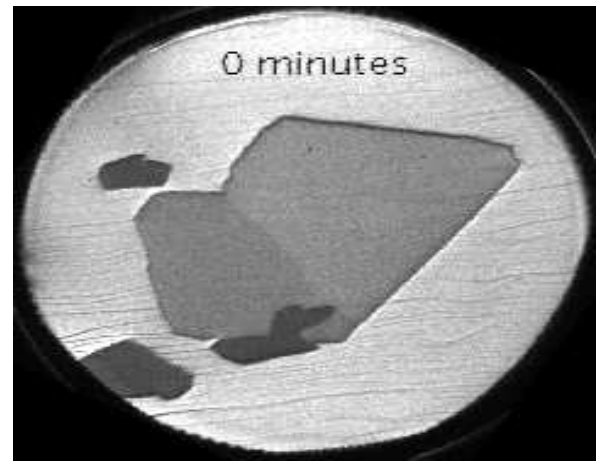

(c) Graphenelr

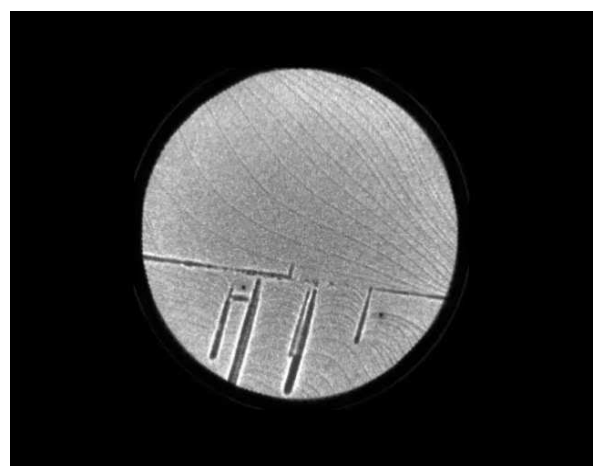

(b) $\mathrm{NiAl3}$

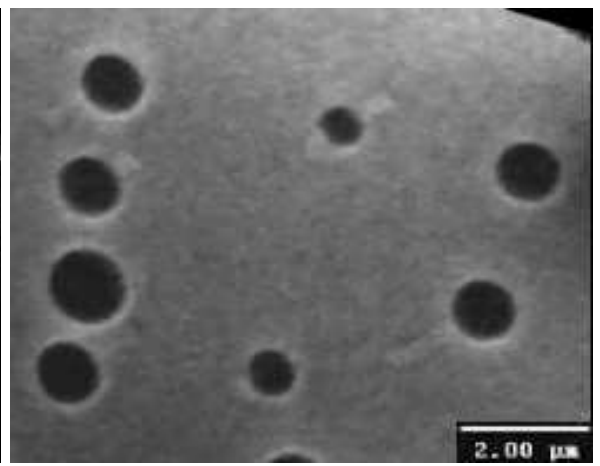

(d) MoviewGa

Fonte: El aborada pelo autor. 


\section{CONCLUSÃO}

Este trabal ho de mestrado teve início com a anál ise das imagens/vídeos de Microscopia El etrônica de Baixa Energia (LEEM), técnica essa que consegue imagear com al tos níveis de resolução estruturas em superfícies, em formato de vídeo, até mesmo durante transições de fases. Foi constatado que diversos tipos de degradação estão presentes nas imagens. Contudo, as imagens LEEM são predominantemente degradadas com ruído Gaussiano em diferentes níveis. Isso foi comprovado com a análise dos histogramas das imagens e com a utilização de técnicas de Goodness-of-Fit (GOF).

Além da análise do ruído presente nas imagens LEEM, foi real izada a estimativa da Função de Espal hamento de Ponto (PSF) dos equi pamentos. Esta estimativa foi feita por meio da utilização do método Fast Motion Deblurring (CHO; LEE, 2009) que apresentou o mel hor desempenho. Entretanto, foi também realizada a estimativa através da utilização do feixe de elétrons. Porém, não produziu-se uma boa estimativa, devido à grande quantidade de ruído presente.

Após estas anál ises, foram realizados experimentos com combi nações de métodos de filtragem de ruído e métodos de redução de borramento aplicados a imagens sintéticas, geradas com base nas características das imagens de mi croscopia el etrôni ca de bai xa energia (LEEM). Esta anál ise englobou a utilização de métodos de filtragens locais (Total Variation (TV) e Bilateral (BF)) e métodos de filtragem não locais (Non-Local Means (NLM) e Block-Matching 3-D (BM3D)). Verificou-se que a utilização de métodos não locais geraram mel hores resul tados de filtragem se comparados aos métodos locais. Entretanto, estes resultados estão diretamente associados à escol ha do método de redução de borramento. Os métodos de redução de borramento utilizados foram: Wener, Constrained Least Squares Filtering e Richardson-Lucy (RL). Vale ressal tar que todos os métodos de redução de borramento utilizados neste trabal ho são consi derados clássicos. Porém, possuem baixa complexidade computacional e são amplamente utilizados em imagens de várias modal idades de microscopia. Dentre estes métodos, foi verificado que, 
especificamente para as imagens LEEM com altos níveis de ruídos, os métodos Wiener e CLSF degradam ainda mais as imagens na maioria dos casos. $\mathrm{O}$ método $\mathrm{RL}$ produziu bons resultados com praticamente todos métodos de filtragem anal isados.

Além destas análises, foram propostos dois novos métodos de filtragem de vídeos: NLM3D-LBP-MSB e NLM3D-LBP-Adaptive. Estes métodos utilizam o descritor de texturas Local Binary Pattern (LBP) para alterar a função de pesos do NLM tradicional. Estes métodos mostraram-se eficientes na filtragem de imagens com texturas e pequenos detal hes, superando o método de filtragem BM3D. Contudo, em imagens que possuem poucas texturas e muitas regiões homogêneas estes métodos se mostraram menos eficazes.

Como último experimento, foram real izados testes com as combinações de al goritmos sendo aplicadas a imagens LEEM reais. Neste teste, os métodos propostos também foram combinados com os métodos de redução de borramento. Na impossibilidade de gerar testes quantitativos para as imagens reais, foi desenvol vido um sistema web para a real ização de um teste com usuários de forma qual itativa. Esta anál ise foi real izada com especialistas das área de processamento de imagens e microscopia. O experimento constatou que os métodos de filtragem TV e BF, por mel hores que tenham sido os resultado para as imagens sintéticas, não foram ef etivos em imagens LEEM reais. Os métodos NLM e BM3D foram os que apresentaram os melhores resul tados, seguidos dos métodos propostos. Outro ponto importante para se destacar foi o uso das técnicas de redução de borramento, onde os métodos Wiener e CLSF apresentaram os piores resultados e o método $\mathrm{RL}$ foi o escol hido em mais de $50 \%$ dos casos.

Todos estes experimentos comprovaram que a utilização de técnicas de filtragem não locais com métodos de redução de borramento são ef etivas para restauração das imagens LEEM e suas variantes. Os métodos de filtragem TV e BF, assim como os métodos de redução de borramento Wiener e CLSF não apresentaram resultados satisfatórios.

\subsection{Publicações}

Foi publicado e apresentado um artigo no SIBGRAPI - Conference on Graphics, Patterns and Images, referente aos resultados dos métodos de filtragem de vídeos desta pesquisa (CONTATO et al., 2016).

Foi aceito um artigo para o XII Workshop de Visão Computacional, com o título "An empirical study on the effects of di fferent types of noise in image cl assi fication tasks". Embora não diretamente relacionado à filtragem de imagens LEEM, este emprega boa parte do embasamento teórico estudado e aplicado neste trabal ho (PARANHOS da COSTA et al., 2016). 


\subsection{Trabalhos Futuros}

Como trabalhos futuros, propõe-se utilizar esse conjunto de combinações de técnicas em imagens geradas a partir de outras modal idades de microscopia e até mesmo imagens médicas, como tomografia Além disso, em continuação a este trabal ho, é interessante utilizar técni cas de segmentação a fim de agilizar o trabal ho dos especial istas da área. Existem diversas estruturas de interesse que são anal isadas visual mente onde, uma única análise manual pode durar até dois meses. Sendo assi m, a utilização de técnicas de segmentação pode agilizar este processo.

Outro ponto importante é a utilização de mais bases de dados LEEM. Com mais dados podemos verificar se o comportamento visto neste trabal ho se mantém. Os métodos de filtragem propostos foram ligeiramente inferiores em comparação ao NLM e BM3D. Porém, em al gumas imagens eles foram mel hores em mais de $80 \%$ dos casos. Sendo assi m, novos dados poderiam confirmar que estes métodos podem ser uma al ternativa, caso nos vídeos existam objetos de interesse que são pequenos em comparação com a resol ução dos quadros ou em relação a outros objetos presentes.

Real izar a análise e estimativa do ruído considerando não somente uma única distribuição, mas anal isando-o como um ruído misto. Esta análise pode mel horar a quali dade final das imagens após a aplicação dos métodos de filtragem e redução de borramento.

Além disso, ainda se faz necessária uma anál ise qual itativa com os especial istas LEEM. Os testes qual itativos foram real izados com especial istas em processamento de imagens e/ou microscopia. Este teste pode reforçar os resultados obtidos, ou até mesmo revelar resultados diferentes em al guns casos, pois, a percepção de especialistas em imagens LEEM acerca da qual idade pode ser diferente daquel a demonstrada pel os respondentes neste trabal ho. 

AGARWAL, V. Total variation regularization and I-curve method for the selection of regularization parameter. ECE599, 2003. Citado na página 23.

AGUERREBERE, C.; DELON, J.; GOUSSEAU, Y.; MUSÉ, P. Study of the digital camera acquisition process and statistical modeling of the sensor raw data. HAL, 2012. Citado na página 20.

ALTMAN, M. S. Trends in low energy electron microscopy. Journal of Physics: Condensed Matter, v. 22, n. 8, p. 084017, 2010. Citado 2 vezes nas páginas 1 e 10.

ANDERS, S.; PADMORE, H. A.; DUARTE, R. M.; RENNER, T.; STAMMLER, T.; SCHOLL, A.; SCHEINFEIN, M. R.; STÖHR, J.; SÉVE, L.; SINKOVIC, B. Photoemi ssion electron microscope for the study of magnetic materials. Review of Scientific Instruments, AIP Publishing, v. 70, n. 10, p. 3973-3981, 1999. Citado 2 vezes nas páginas 14 e 15.

BAUER, E. Low energy electron microscopy. Rep. Prog. Phys., v. 9, n. 57, p. 895-938, 1994. Citado na página 1.

Leem basics. Surface Review and Letters, v. 5, p. 1275-1286, 1998. Citado na página 10.

Surface Microscopy with Low Energy Electrons. New York: Springer, 2014. C Citado 2 vezes nas páginas 10 e 11 .

BIGGS, D. S.; ANDREWS, M. Accel eration of iterative image restoration al gorithms. Applied optics, v. 36, n. 8, p. 1766-75, 1997. ISSN 0003-6935. Disponível em: <http://www.ncbi.nlm. nih.gov/pubmed/18250863>. Citado 2 vezes nas páginas 33 e 34.

BIGNAMI, G. F. The microscope's coat of arms. Nature, Nature Publishing Group, v. 405, n. 6790, p. 999-999, 2000. Citado na página 5.

BRUNO, O. M.; NONATO, L. G.; PAZOTI, M. A.; NETO, J. B. Topological multi-contour decomposition for image anal ysis and image retrieval. Pattern Recognition Letters, El sevier, v. 29, n. 11, p. 1675-1683, 2008. Citado na página 18.

BUADES, A.; COLL, B.; MOREL, J. Denoising image sequences does not require motion estimation. In: IEEE. Advanced Video and Signal Based Surveillance, 2005. AVSS 2005. IEEE Conference on. [S.I.], 2005. p. 70-74. Citado na página 36.

Non-Local Means Denoising. I mage Processing On Line, v. 1, 2011. Citado na página 28.

BUADES, A.; COLL, B.; MOREL, J.-M. A non-local al gorithm for image denoising. In: IEEE. Computer Vision and Pattern Recognition, 2005. CVPR 2005. IEEE Computer Society Confer ence on. [S.I.], 2005. v. 2, p. 60-65. Citado 3 vezes nas páginas 26, 27 e 28. 
CASTILHO, C. M. C. de; NASCIMENTO, V. B.; SOARES, E. A.; ESPERIDIAO, A. S. C.; MOTA, F. B.; CARVALHO, V. E. de. Difração de elétrons de bai xa energia (LEED) e a determinação da estrutura atômica de superfícies ordenadas. Revista Brasileir a de Ensino de Fısica, SciELO Brasil, v. 27, n. 4, p. 527-543, 2005. Citado 4 vezes nas páginas 8, 9, 10 e 11.

CHO, S.; LEE, S. Fast motion deblurring. In: ACM. ACM Transactions on Graphics (TOG). [S.I.], 2009. v. 28, n. 5, p. 145. Citado 3 vezes nas páginas 48, 57 e 83.

CONTATO, W. A.; NAZARE, T. S.; Paranhos da Costa, G. B.; PONTI, M.; Batista Neto, J. E. S. Improving non-local video denoising with local binary patterns and image quantization. In: IEEE. 2016 29th SI BGRAPI Confer ence on Graphics, Patterns and Images. [S.I.], 2016. Citado 2 vezes nas páginas 41 e 84.

DABOV, K.; FOI, A.; KATKOVNIK, V.; EGIAZARIAN, K. Image denoising by sparse 3-d transform-domain collaborative filtering. I mage Processing, IEEE Transactions on, IEEE, v. 16, n. 8, p. 2080-2095, 2007. Citado 2 vezes nas páginas 29 e 30.

Image Denoising With Shape-Adaptive Principal Component Analysis. SPARS' 09-Signal Processing with Adaptive Spar se Str uctured Repr esentations, 2009. Citado na página 31.

DEDAVID, B. A.; GOMES, C. I.; MACHADO, G. Microscopia eletrônica de var redura: aplicações e pr epar ação de amostr as: materiais polimér icos, metálicos e semicondutor es. Porto Alegre: EDIPUCRS, 2007. Citado 2 vezes nas páginas 6 e 8.

FIGUERA, J.; MCCARTY, K. F. Surface science techniques. In: [S.I.]: Springer Science \& Business Media, 2013. cap. Low-Energy Electron Microscopy, p. 531-561. Citado na página 14.

FILHO, O. M.; NETO, H. V. Processamento digital de imagens. [S.I.]: Brasport, 1999. Citado 2 vezes nas páginas 52 e 61 .

FLEGE, J. I. Oxide Flatlands. 2013. <http://www.cost-redox.nano.cnr.it/esr/wg2-esr/ jan-ingo-flege/>. Online; Acessado em: 02 Jul 2015. Citado na página 12.

GOLDSTEIN, T.; OSHER, S. The split bregman method for I1-regularized problems. SI AM Journal on I maging Sciences, SIAM, v. 2, n. 2, p. 323-343, 2009. Citado na página 23.

GONZALEZ, R. C.; WOODS, R. E. Digital Image Processing (3rd Edition). Upper Saddle River, NJ, USA: Prentice Hall, Inc., 2006. ISBN 013168728X. Citado 7 vezes nas páginas 17, 19, 20, 21, 31, 33 e 51.

GOYAL, A.; BIJALWAN, A.; CHOWDHURY, M. K. A comprehensive review of image smoothing techniques. International Journal of Advanced Research in Computer Engineering \& Technology (IJARCET), v. 1, n. 4, p. pp-315, 2012. Citado na página 18.

HELD, G. Low-energy electron diffraction: Crystallography of surfaces and interfaces. BunsenMagazin 12 (12), Wiley Online Library, p. 124-131, 2010. Citado 2 vezes nas páginas 9 e 10.

HORÉ, A.; ZIOU, D. Image quality metrics: PSNR vs. SSIM. Proceedings - Inter national Confer ence on Pattern Recognition, p. 2366-2369, 2010. ISSN 10514651. Citado na página 50 . 
JESSON, D.; TANG, W.-X. Surface electron microscopy of ga droplet dynamics on gaas (001). Microscopy: Science, Technology, Applications and Education, Formatex, Badajoz, p. 16081619, 2010. Citado na página 12.

JIANG, W.; BAKER, M. L.; WU, Q.; BAJAJ, C.; CHIU, W. Applications of abilateral denoising filter in biological electron microscopy. Jour nal of structur al biology, Elsevier, v. 144, n. 1, p. 114-122, 2003. Citado na página 24.

KHELLAH, F. M. Application of local binary pattern to windowed nonlocal means image denoising. In: 17th International Confer ence on Image Analysis and Processing - ICI AP 2013. Naples, Italy: [s.n.], 2013. p. 21-30. Citado 3 vezes nas páginas 35, 36 e 40.

KNAUS, C.; ZWICKER, M. Dual-domain image denoising. 2013 IEEE International Confer ence on I mage Processing, ICIP 2013 - Proceedings, n. 4, p. 440-444, 2013. Citado na página 31.

LEBRUN, M. An analysis and implementation of the bm3d image denoising method. I mage Processing On Line, n. 2012, 2012. Citado 2 vezes nas páginas 29 e 30.

LFF-IF-USP. Microscópio Eletrônicos de Varredura (MEV). 2013. <http://fap01.if.usp.br/ lff/mev.html>. Online; Acessado em: 15 Jun 2015. Citado na página 7.

LI, B.; QUE, D. Medical images denoising based on total variation al gorithm. Procedia Environmental Sciences, Elsevier, v. 8, p. 227-234, 2011. Citado na página 23.

MAYDEU-OLIVARES, A.; GARCIA-FORERO, C. Goodness-of-fit testing. International Encyclopedia of Education, v. 7, p. 190-196, 2010. Citado na página 48.

MITTAL, A.; MOORTHY, A. K.; BOVIK, A. C. No-reference image quality assessment in the spatial domain. IEEE transactions on image processing: a publication of the IEEE Signal Processing Society, v. 21, n. 12, p. 4695-708, 2012. ISSN 1941-0042. Disponível em: <http://www.ncbi.nlm.nih.gov/pubmed/22910118>. Citado 2 vezes nas páginas 52 e 58.

MITTAL, A.; SOUNDARARAJAN, R.; BOVIK, A. C. Making a' completely blind' image quality analyzer. IEEE Signal Processing Letters, v. 20, n. 3, p. 209-212, 2013. ISSN 10709908. Citado 2 vezes nas páginas 52 e 58.

MOORTHY, A. K.; BOVIK, A. C. A two-step framework for constructing blind image quality indices. IEEE Signal Processing Letters, v. 17, n. 5, p. 513-516, 2010. ISSN 10709908. Citado 2 vezes nas páginas 52 e 58 .

NANNI, L.; LUMINI, A.; BRAHNAM, S. Survey on LBP based texture descriptors for image classification. Expert Systems with Applications, Pergamon Press, Inc., Tarrytown, NY, USA, v. 39, n. 3, p. 3634-3641, fev. 2012. ISSN 0957-4174. Citado na página 36.

N'DIAYE, A. T.; QUESADA, A. Spin-Polarized Low-Energy Electron Microscopy (SPLEEM). In: Char acterization of Materials. Hoboken, NJ, USA: John Wiley \& Sons, Inc., 2012. p. 1827-1840. Disponível em: <http://doi.wiley.com/10.1002/0471266965.com135>. Citado na página 15.

OJALA, T.; PIETIKAINEN, M.; HARWOOD, D. Performance evaluation of texture measures with classification based on kullback discrimination of distributions. In: ICPR94. [S.I.: s.n.], 1994. p. A:582-585. Citado 2 vezes nas páginas 35 e 36. 
OJALA, T.; PIETIKälNEN, M.; MäENPää, T. Multiresolution gray-scale and rotation invariant texture classification with local binary patterns. IEEE Transactions on Pattern Analysis and Machine Intelligence, IEEE Computer Society, Washington, DC, USA, v. 24, n. 7, p. 971-987, jul. 2002. ISSN 0162-8828. Citado 2 vezes nas páginas 36 e 39.

OUARTI, N.; SAUVET, B.; RÉGNIER, S. High quality real-time video with scanning electron microscope using total variation al gorithm on a graphics processing unit. Inter national Journal of Optomechatronics, Taylor \& Francis, v. 6, n. 2, p. 163-178, 2012. C Citado na página 23.

PARANHOS da COSTA, G. B.; CONTATO, W. A.; NAZARE, T. S.; Batista Neto, J. E. S.; PONTI, M. An empirical study on the effects of different types of noise in image classification tasks. arXiv preprint arXiv:1609.02781, 2016. Citado na página 84.

PARIS, S.; KORNPROBST, P.; TUMBLIN, J.; DURAND, F. Bilater al filtering: Theory and applications. [S.I.]: Now Publishers Inc, 2009. Citado 2 vezes nas páginas 23 e 24.

PIETIKäl NEN, M.; OJALA, T.; XU, Z. Rotation-invariant texture classification using feature distributions. Pattern Recognition, v. 33, p. 43-52, 2000. Citado na página 38.

PONTI, M. Extrapolação Espectral na Restauração de Imagens Tridimensionais de Micr oscopia Ótica de Fluor escência. Tese (Doutorado) — Universidade Federal de São Carlos, São Carlos, 8 2008. Citado 2 vezes nas páginas 5 e 31.

PONTI, M.; NAZARé, T. S.; THUMé, G. S. Image quantization as a dimensionality reduction procedure in color and texture feature extraction. Neur ocomputing, v. 173, p. 385-396, 2016. Citado na página 39.

PONTI, M. P. Microscope volume segmentation improved through non-linear restoration. Int. J. Natural Computing Research, v. 1, n. 4, p. 37-47, 2010. Citado na página 18.

QIN, H.; CHEN, X.; LI, L.; SUTTER, P. W.; ZHOU, G. Oxidation-driven surface dynamics on nial (100). Proceedings of the National Academy of Sciences, National Acad Sciences, v. 112, n. 2, p. E103-E109, 2015. Citado 5 vezes nas páginas 45, 55, 78, 102 e 103.

ROCHE, A.; RIBES, D.; BACH-CUADRA, M.; KRÜGER, G. On the convergence of emlike al gorithms for image segmentation using markov random fields. M edical image analysis, Elsevier, v. 15, n. 6, p. 830-839, 2011. Citado na página 17.

ROGGE, P. C.; THÜRMER, K.; FOSTER, M. E.; MCCARTY, K. F.; DUBON, O. D.; BARTELT, N. C. Real-time observation of epitaxial graphene domain reorientation. Nature communications, Nature Publishing Group, v. 6, 2015. Citado 5 vezes nas páginas 45, 54, 77, 100 e 101.

RUDIN, L. I.; OSHER, S.; FATEMI, E. Nonlinear total variation based noise removal al gorithms. Physica D: Nonlinear Phenomena, Elsevier, v. 60, n. 1, p. 259-268, 1992. Citado na página 22.

SANTOS, D. P.; NETO, J. B. Feature sel ection with equal ized salience measures and its application to segmentation. In: IEEE. Computer Graphics and I mage Processing, 2007. SI BGRAPI 2007. XX Brazilian Symposium on. [S.I.], 2007. p. 253-262. Citado na página 18.

SOLOMON, C.; BRECKON, T. Fundamentals of Digital Image Processing: A Practical Approach with Examplesin Matlab. 1st. ed. [S.I.]: Wiley Publishing, 2011. ISBN 0470844736, 9780470844731. Citado na página 34. 
TERSOFF, J.; JESSON, D. E.; TANG, W. X. Running droplets of gallium from evaporation of gallium arsenide. Science, v. 324, n. 5924, p. 236-238, 2009. Disponível em: <http://www. sciencemag.org/content/324/5924/236.abstract>. Citado na página 14.

TOMASI, C.; MANDUCHI, R. Bilateral filtering for gray and color images. In: IEEE. Computer Vision, 1998. Sixth International Conference on. [S.I.], 1998. p. 839-846. Citado na página 23.

TROMP, R. M. Low-energy electron microscopy. MRS Bulletin, Cambridge Univ Press, v. 19, n. 06, p. 44-46, 1994. Citado 2 vezes nas páginas 11 e 13.

WANG, Z.; BOVIK, A. C. A universal image quality index. Signal Processing Letters, IEEE, IEEE, v. 9, n. 3, p. 81-84, 2002. Citado na página 51.

WANG, Z.; BOVIK, A. C.; SHEIKH, H. R.; SIMONCELLI, E. P. Image quality assessment: from error visibility to structural similarity. I mage Processing, IEEE Transactions on, IEEE, v. 13, n. 4, p. 600-612, 2004. Citado 2 vezes nas páginas 51 e 58.

WEN, C.-Y.; LEE, C.-H. Point spread functions and their applications to forensic image restoration. For ensic Science Journal, v. 1, n. 1, p. 15-26, 2002. Citado na página 21.

ZHANG, B.; ALLEBACH, J. P. Adaptive bilateral filter for sharpness enhancement and noise removal. Image Processing, IEEE Transactions on, IEEE, v. 17, n. 5, p. 664-678, 2008. Citado 2 vezes nas páginas 25 e 26.

ZHAO, G.; PIETIKAINEN, M. Dynamic texture recognition using local binary patterns with an application to facial expressions. IEEE Transactions on Pattern Analysis and Machine Intelligence, IEEE Computer Society, Washington, DC, USA, v. 29, n. 6, p. 915-928, jun. 2007. ISSN 0162-8828. Citado 2 vezes nas páginas 35 e 38. 

APÊNDICE

A

\section{COMBINAÇÃO DOS MÉTODOS WIENER E CLSF COM OS MÉTODOS DE REMOÇÃO DE RUÍDO}

Neste apêndice estão contidos os testes combinando os métodos Wiener e CLSF com os filtros TV, BF, NLM, BM3D, NLM3D-LBP-MSB e NLM3D-LBP-Adaptive. Os mesmos parâmetros da Seção 6.5 foram utilizados para estes testes. Nestas imagens fica evidente que o método de deconvolução RL é superior ao Wiener e ao CLSF. Como citado anteriormente, outros testes foram realizados com outras imagens LEEM. Porém, devido a não extender demasiadamente o texto estes testes não foram inseridos nesta dissertação, sendo di sponíveis em $<$ https://goo.gl/2uKMvF> e <https://goo.gl/oCJYPB>. Além disso, as imagens contidas abaixo também estão di sponíveis nos mesmos links melhor resol ução. 
Figura 46 - Aplicação da combinação do método Wiener com os filtros de ruído na imagem LEEM GaAsFringe.

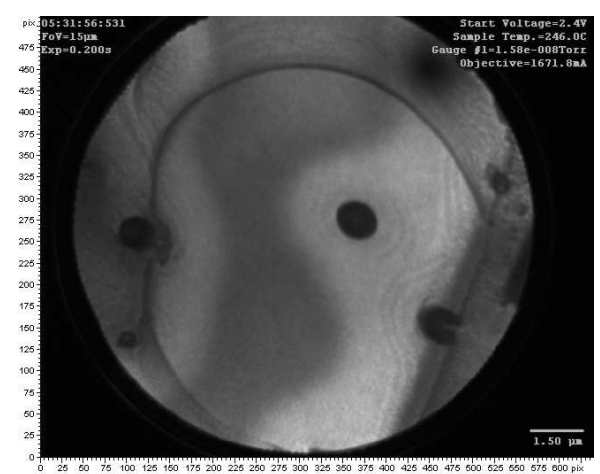

(a) GaAsFringe (Original)

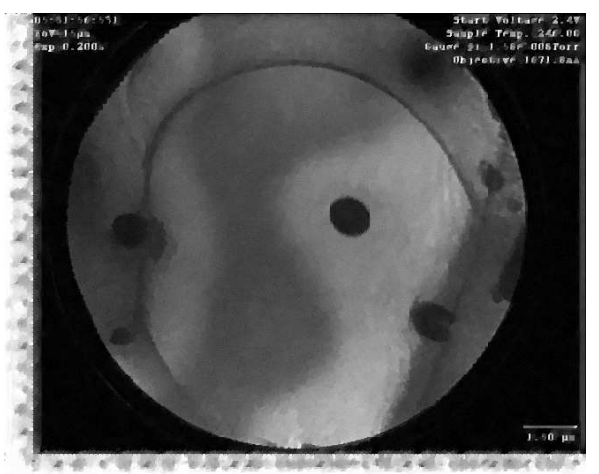

(b) Wiener + TV

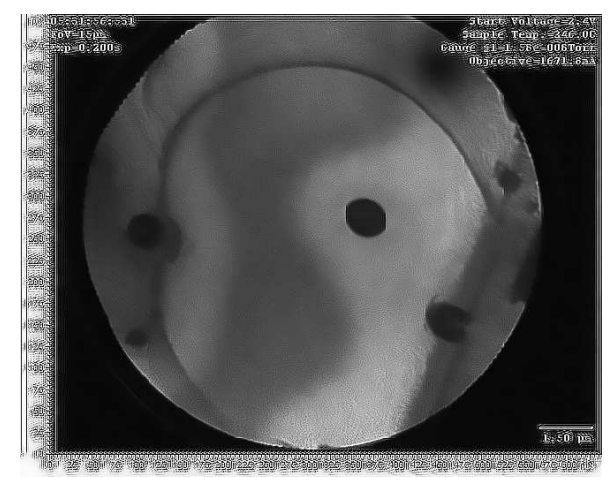

(d) Wiener + NLM

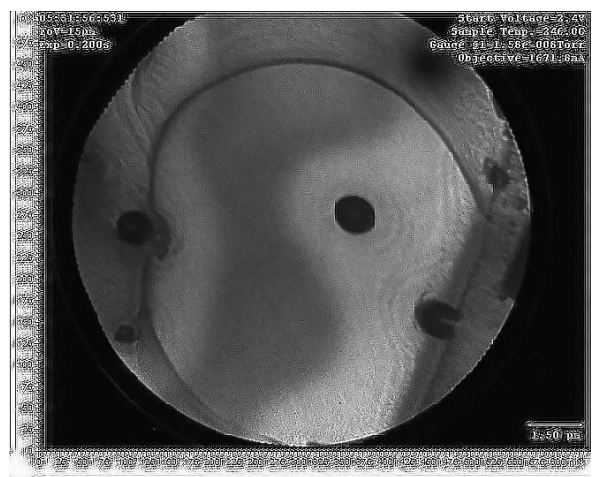

(f) Wiener + NLM3D-LBP-Adaptive

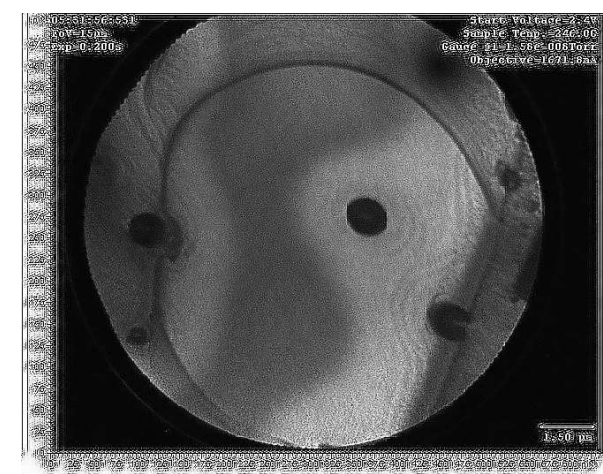

(c) Wiener + BF

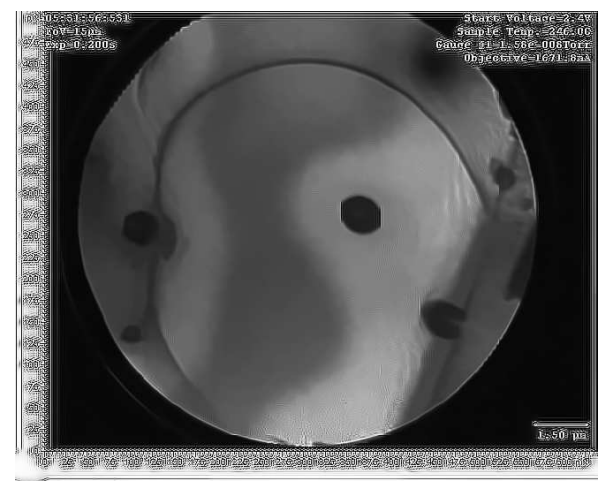

(e) Wiener + BM3D

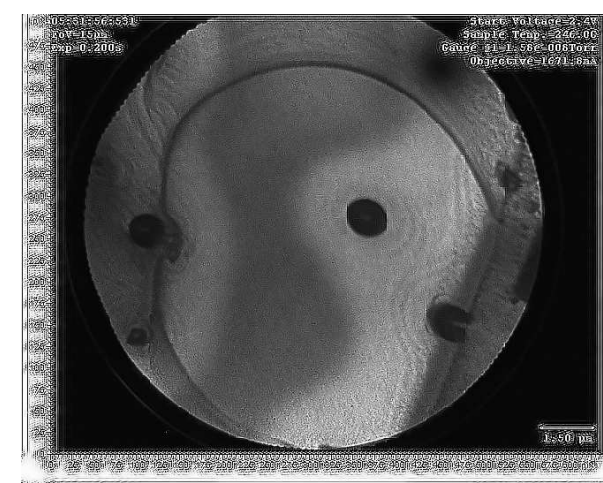

(g) Wiener + NLM3D-LBP-MSB

Fonte: Adaptado das imagens cedidas pelo professor Dr. Wen-Xin Tang. 
Figura 47 - Aplicação da combinação do método CLSF com os filtros de ruído na imagem LEEM GaAsFringe.

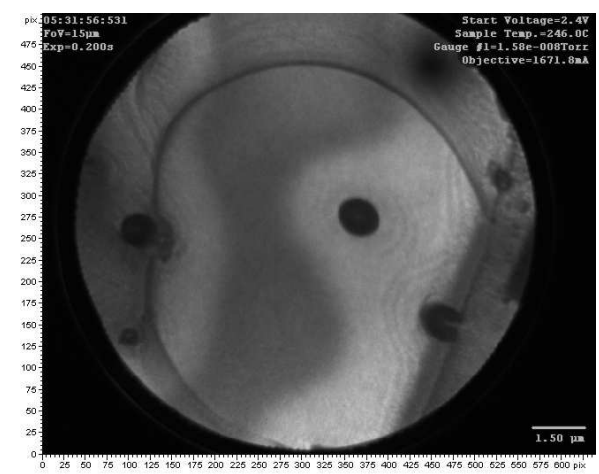

(a) GaAsFringe (Original)

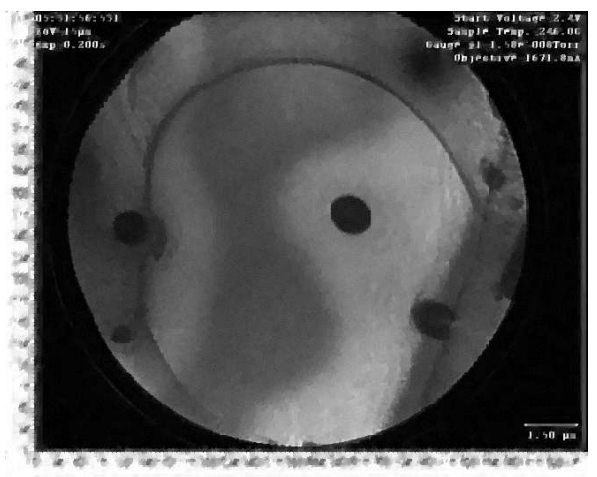

(b) CLSF + TV

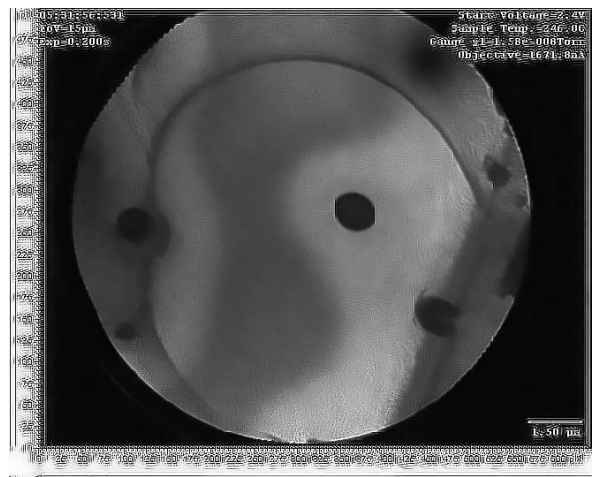

(d) $\mathrm{CLSF}+\mathrm{NLM}$

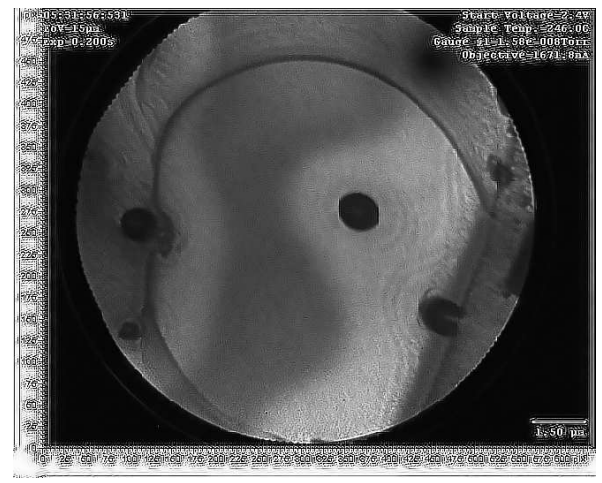

(f) CLSF + NLM3D-LBP-Adaptive

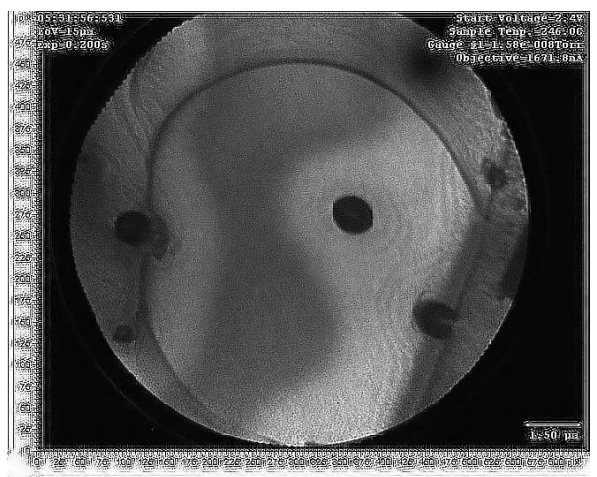

(c) $\mathrm{CLSF}+\mathrm{BF}$

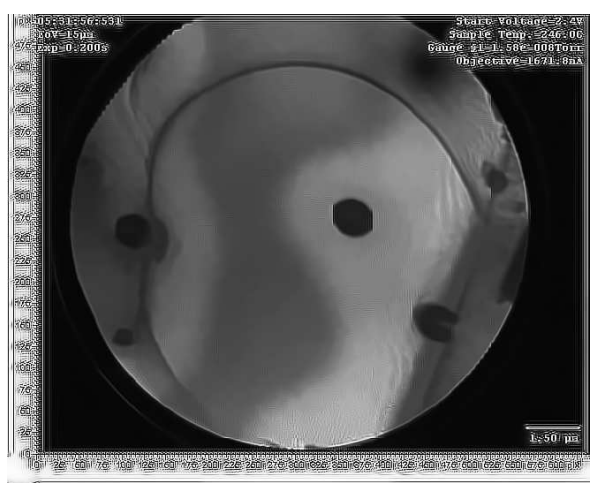

(e) $\mathrm{CLSF}+\mathrm{BM} 3 \mathrm{D}$

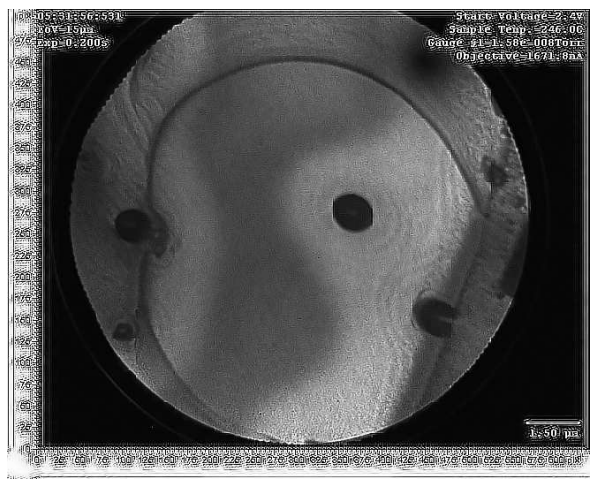

(g) CLSF + NLM3D-LBP-MSB

Fonte: Adaptado das imagens cedidas pelo professor Dr. Wen-Xin Tang. 
Figura 48 - A plicação da combinação do método Wiener com os filtros de ruído na imagem LEEM MoviewGa.

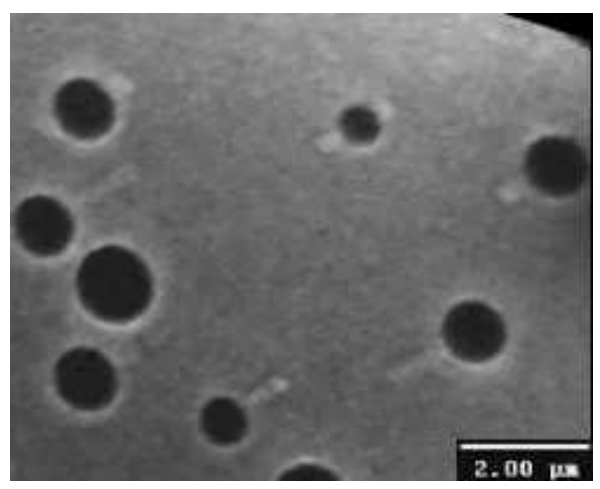

(a) MoviewGa (Original)

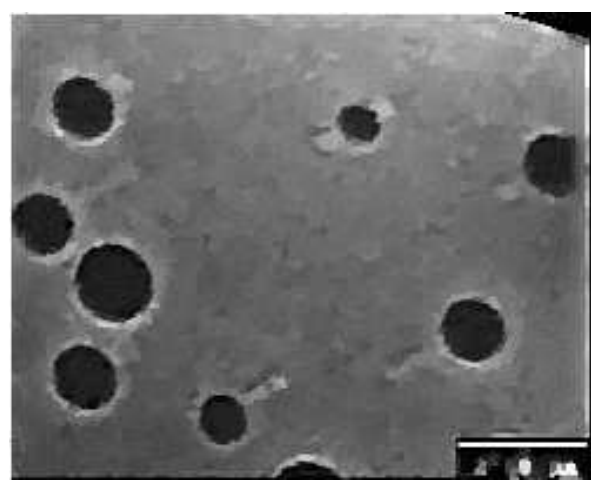

(b) Wiener + TV

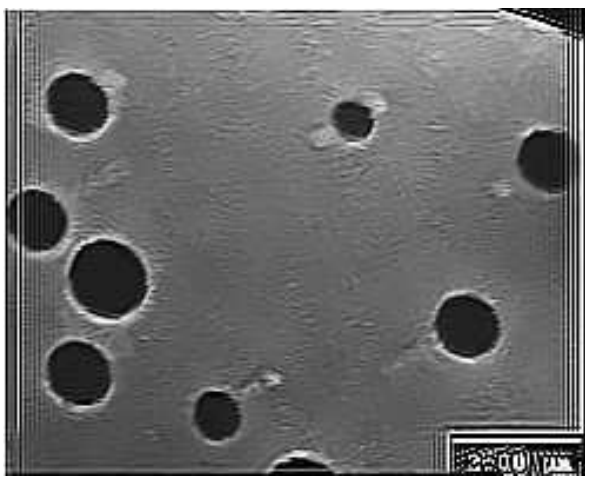

(d) Wiener + NLM

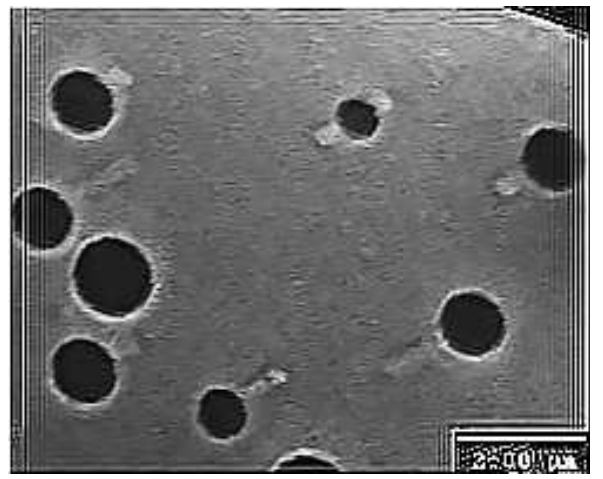

(f) Wiener + NLM3D-LBP-Adaptive

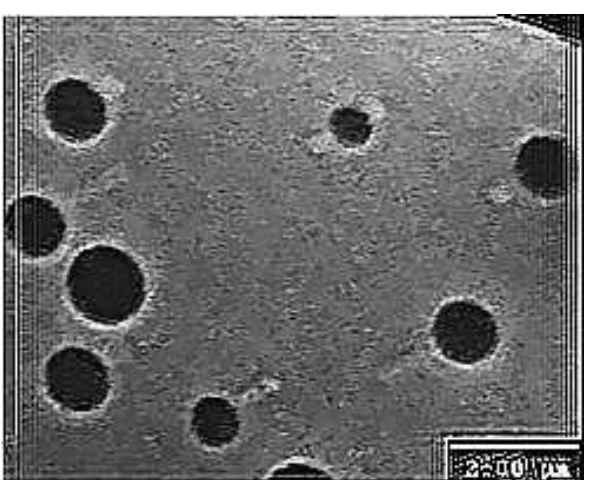

(c) Wiener + BF

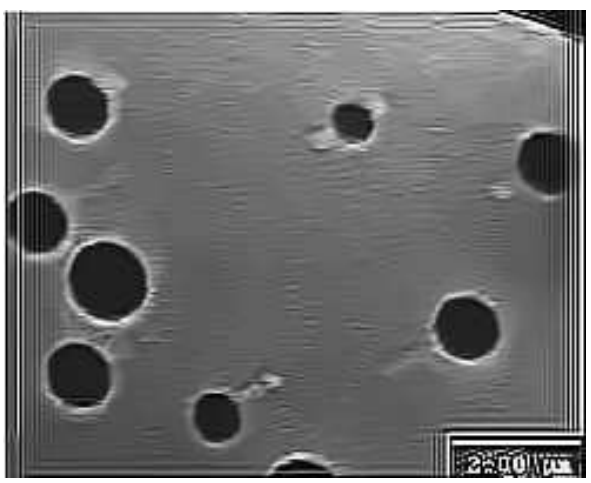

(e) Wiener + BM3D

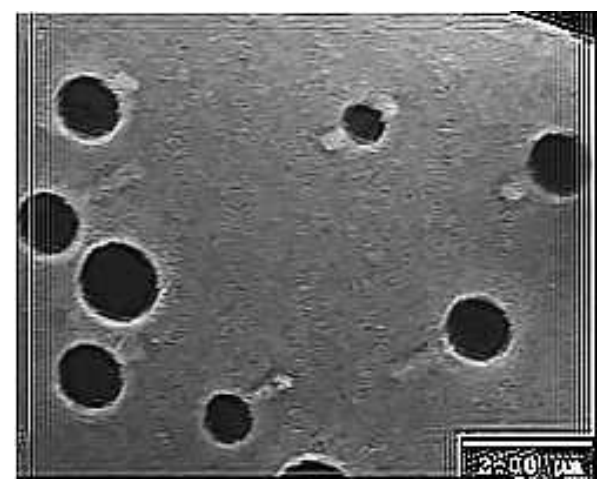

(g) Wiener + NLM3D-LBP-MSB

Fonte: Adaptado das imagens cedidas pelo professor Dr. Wen-Xin Tang. 
Figura 49 - Aplicação da combinação do método CLSF com os filtros de ruído na imagem LEEM MoviewGa.

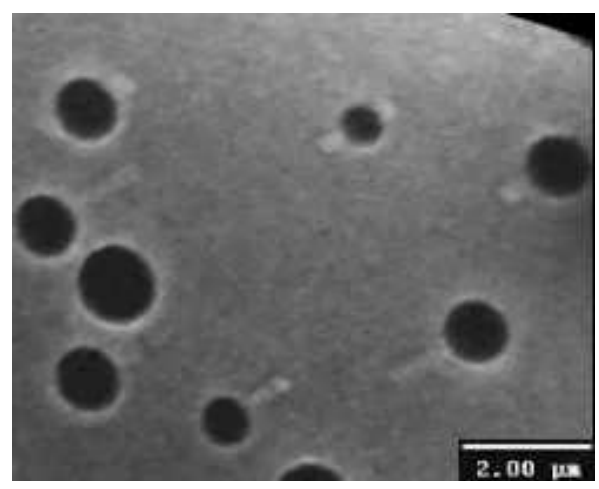

(a) MoviewGa (Original)

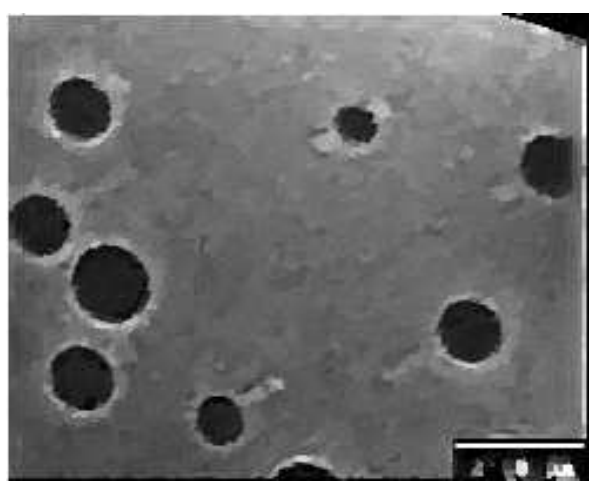

(b) CLSF + TV

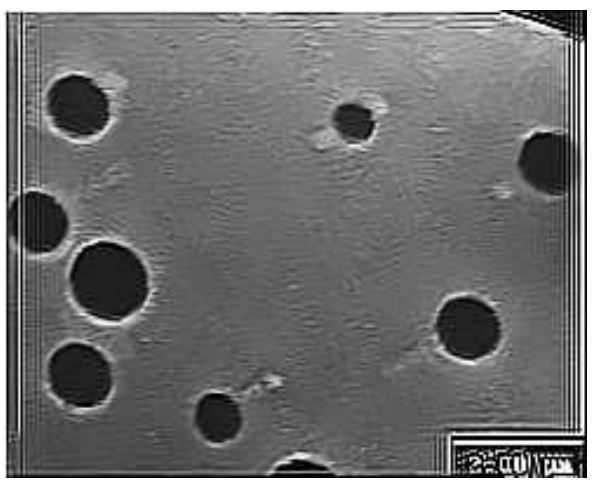

(d) $\mathrm{CLSF}+\mathrm{NLM}$

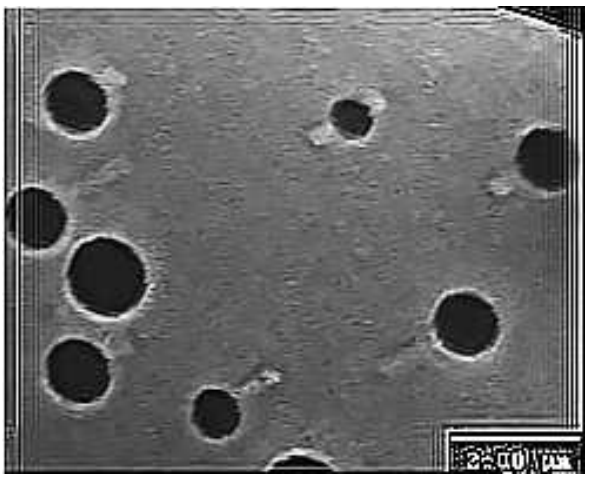

(f) CLSF + NLM3D-LBP-Adaptive

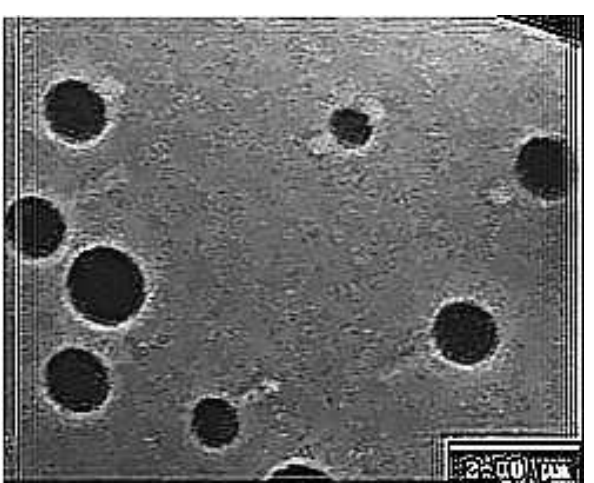

(c) $\mathrm{CLSF}+\mathrm{BF}$

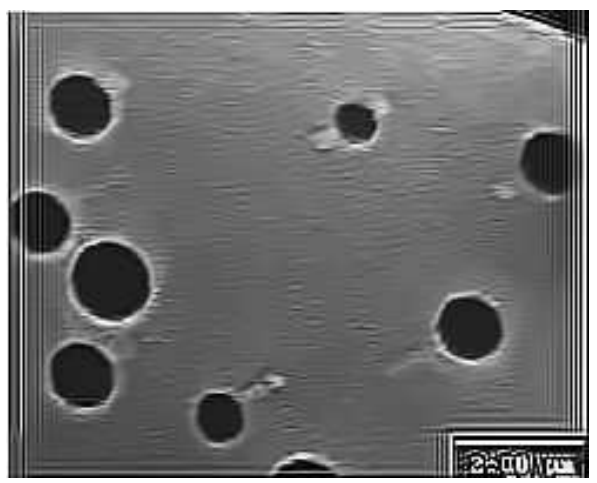

(e) $\mathrm{CLSF}+\mathrm{BM} 3 \mathrm{D}$

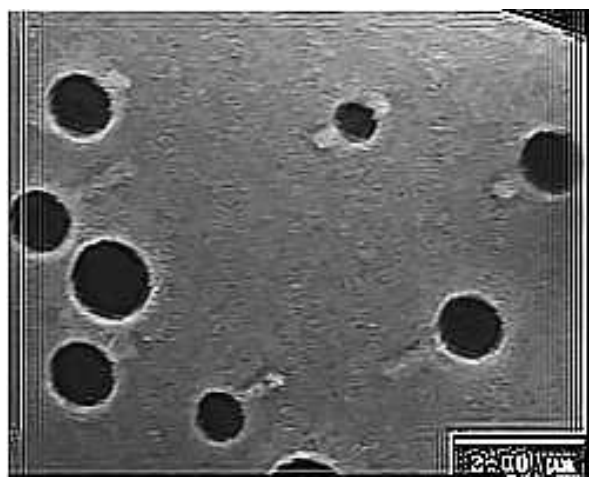

(g) CLSF + NLM3D-LBP-MSB

Fonte: Adaptado das imagens cedidas pelo professor Dr. Wen-Xin Tang. 
Figura 50 - Aplicação da combinação do método Wiener com os filtros de ruído na imagem LEEM PbCu.

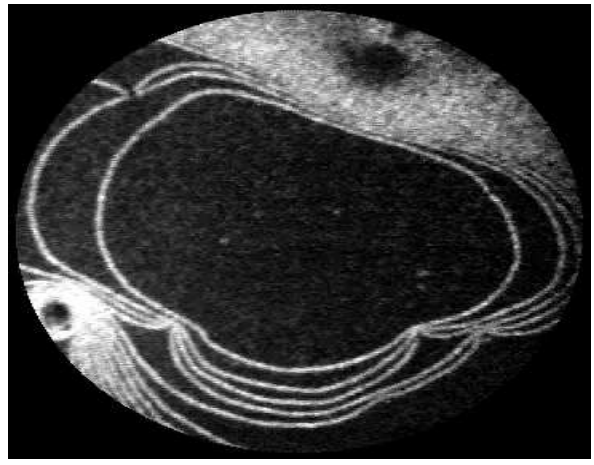

(a) $\mathrm{PbCu}$ (Original)

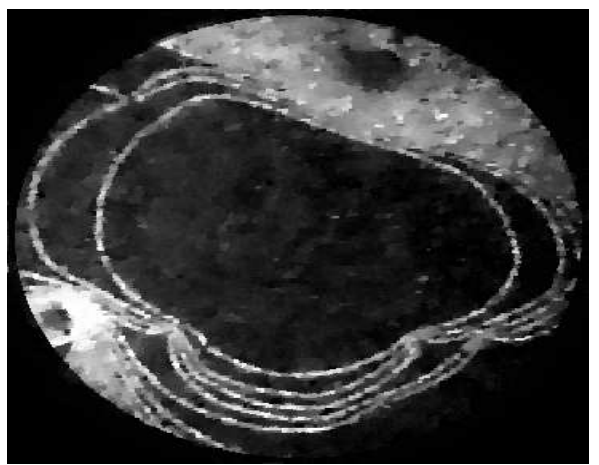

(b) Wiener + TV

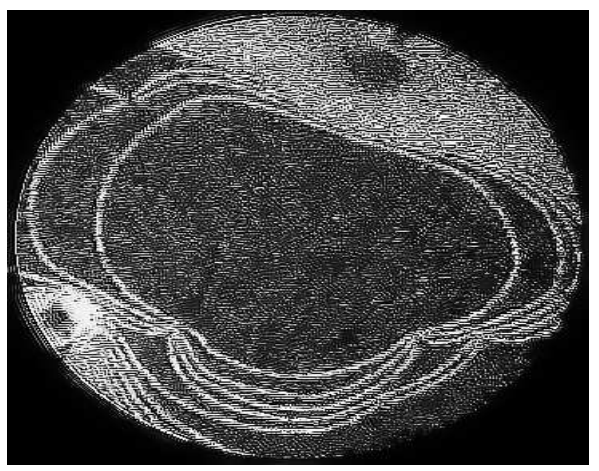

(d) Wiener + NLM

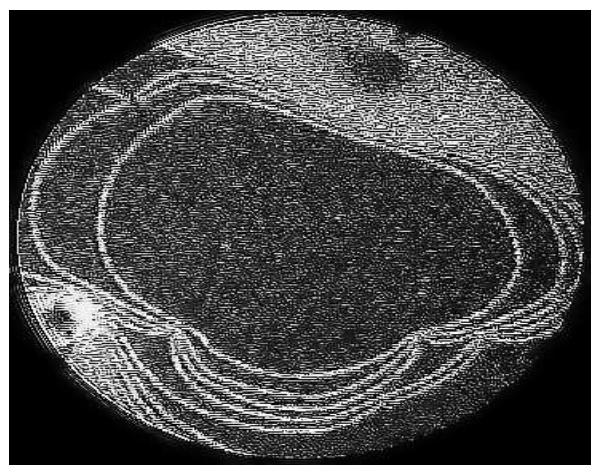

(f) Wiener + NLM3D-LBP-Adaptive

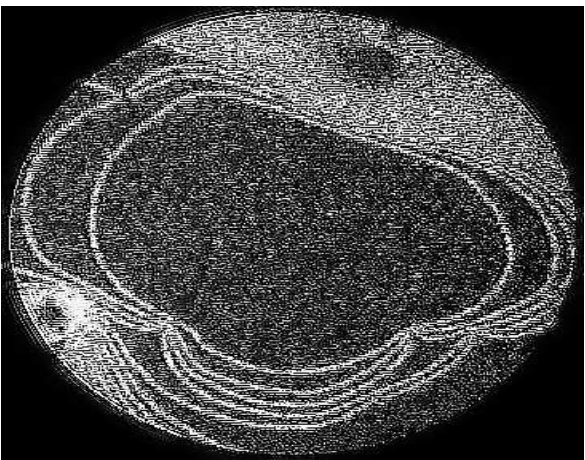

(c) Wiener + BF

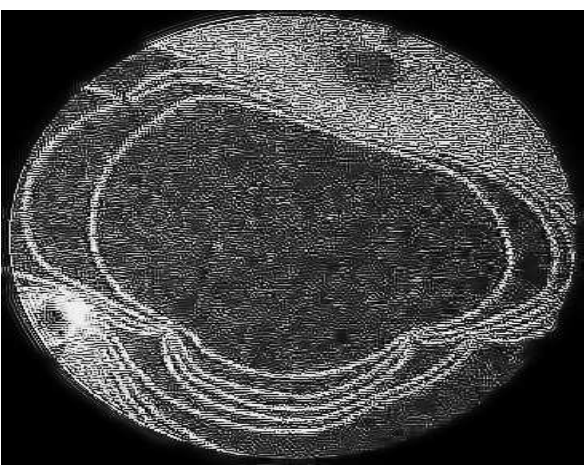

(e) Wiener + BM3D

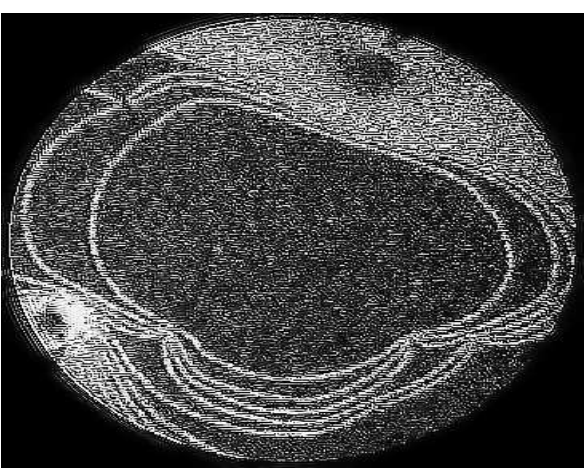

(g) Wiener + NLM3D-LBP-MSB

Fonte: Adaptado das imagens cedidas pelo professor Dr. Wen-Xin Tang. 
Figura 51 - A plicação da combinação do método CLSF com os filtros de ruído na imagem LEEM PbCu.

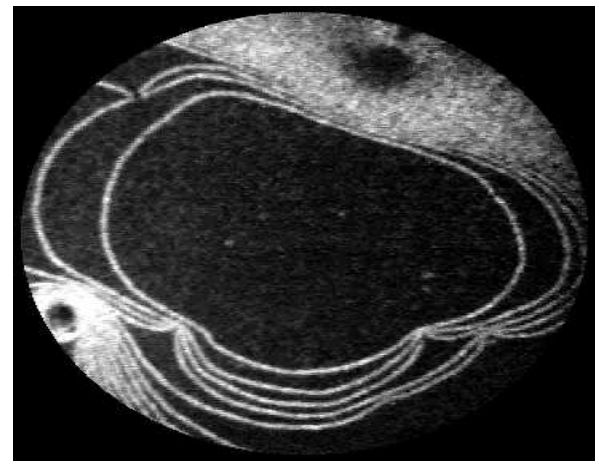

(a) $\mathrm{PbCu}$ (Original)

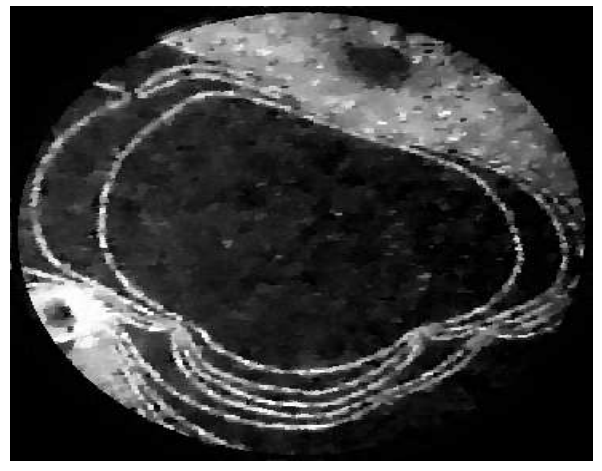

(b) CLSF + TV

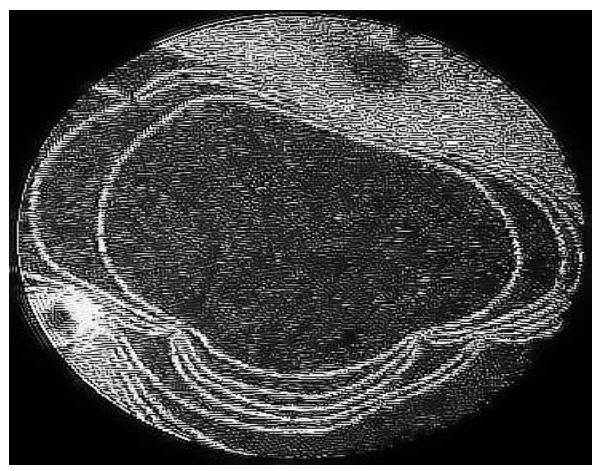

(d) $\mathrm{CLSF}+\mathrm{NLM}$

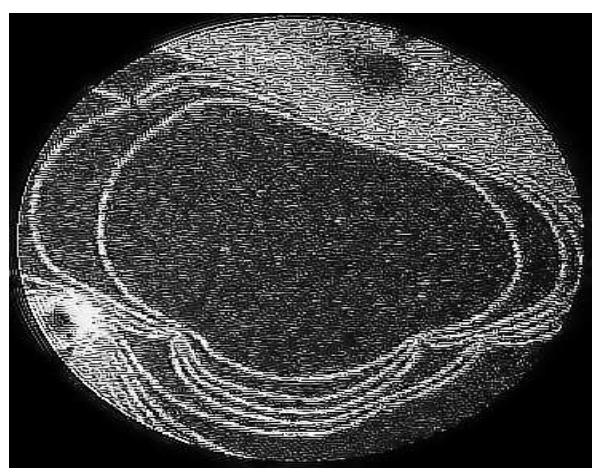

(f) CLSF + NLM3D-LBP-Adaptive

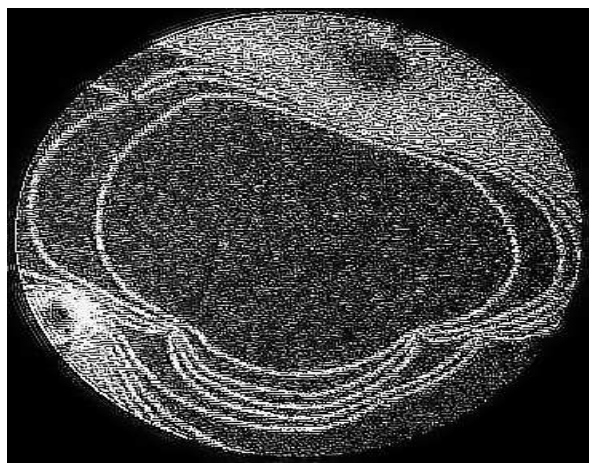

(c) $\mathrm{CLSF}+\mathrm{BF}$

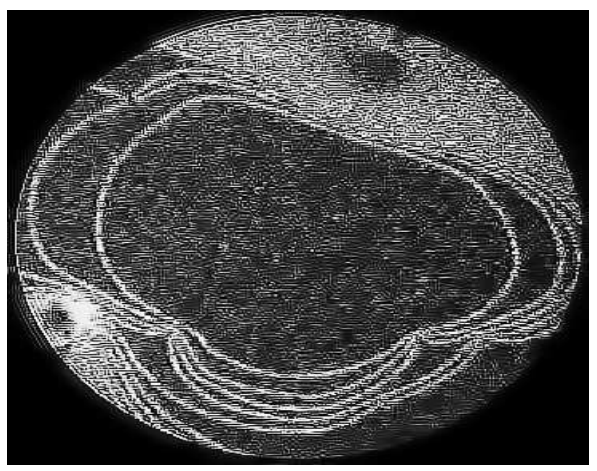

(e) $\mathrm{CLSF}+\mathrm{BM} 3 \mathrm{D}$

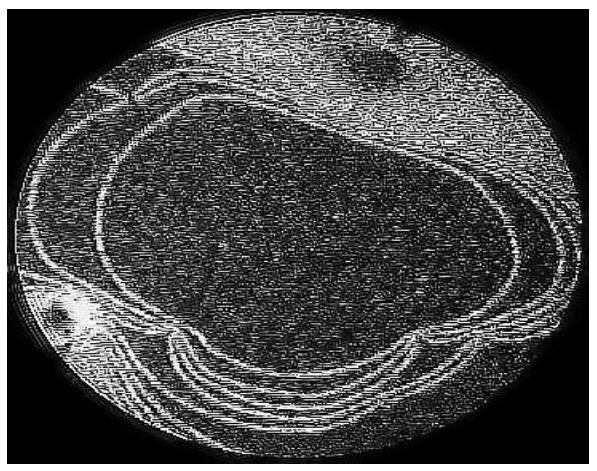

(g) CLSF + NLM3D-LBP-MSB

Fonte: Adaptado das imagens cedidas pelo professor Dr. Wen-Xin Tang. 
Figura 52 - Aplicação da combinação do método Wiener com os filtros de ruído na imagem LEEM Graphene.

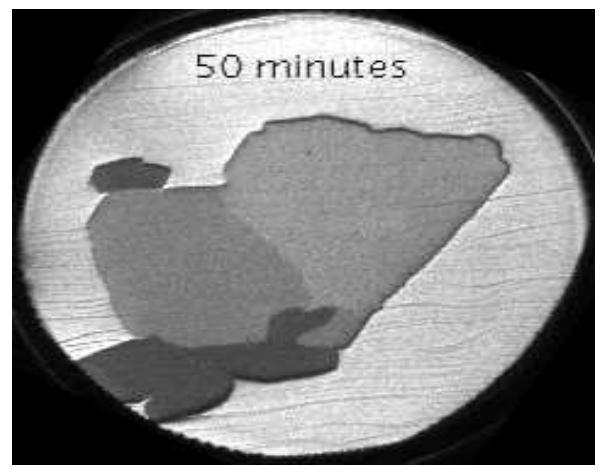

(a) Graphene (Original)

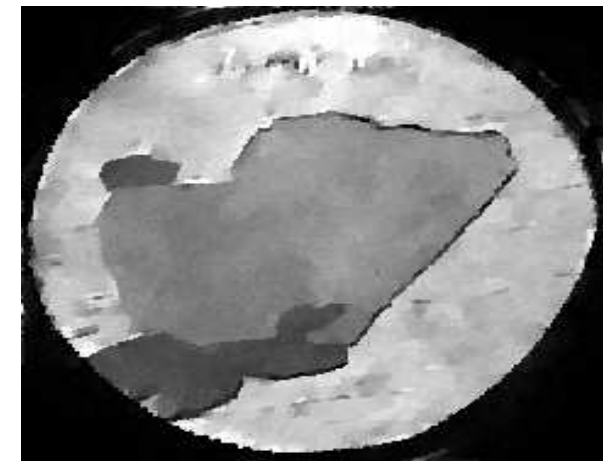

(b) Wiener + TV

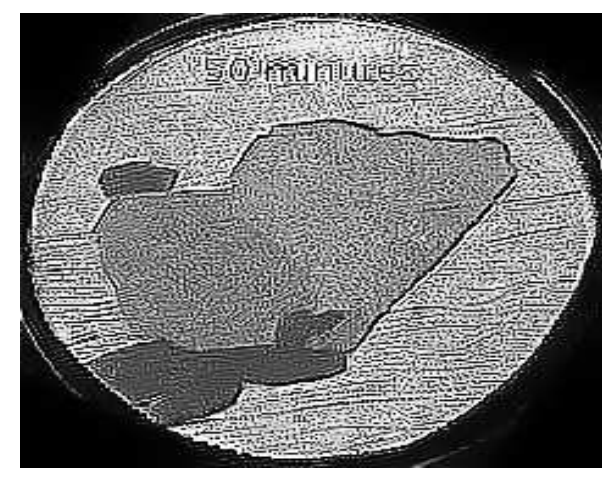

(d) Wiener + NLM

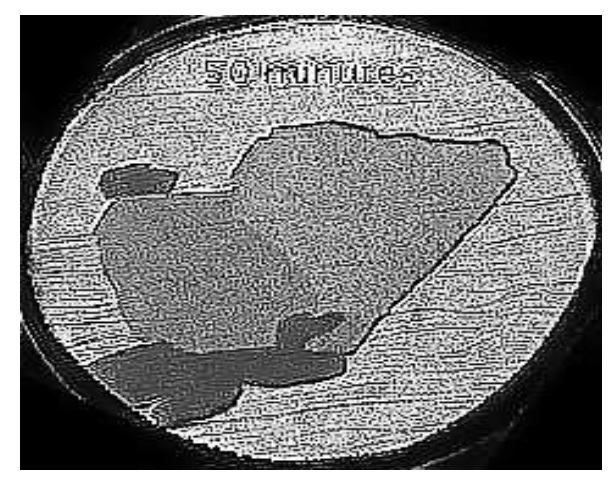

(f) Wiener + NLM3D-LBP-Adaptive

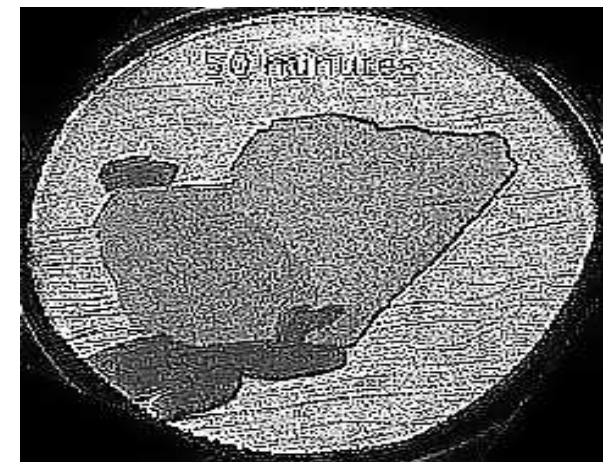

(c) Wiener + BF

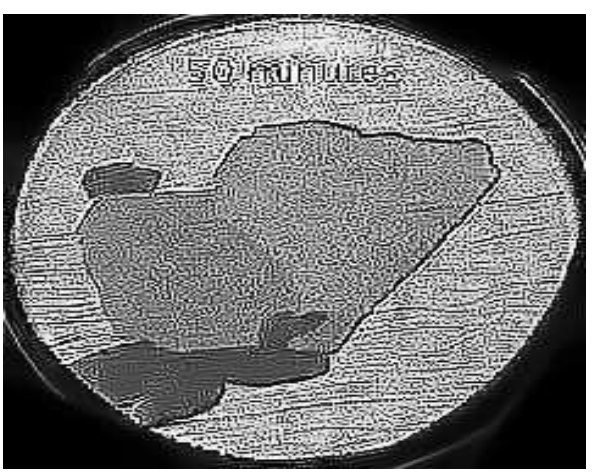

(e) Wiener + BM3D

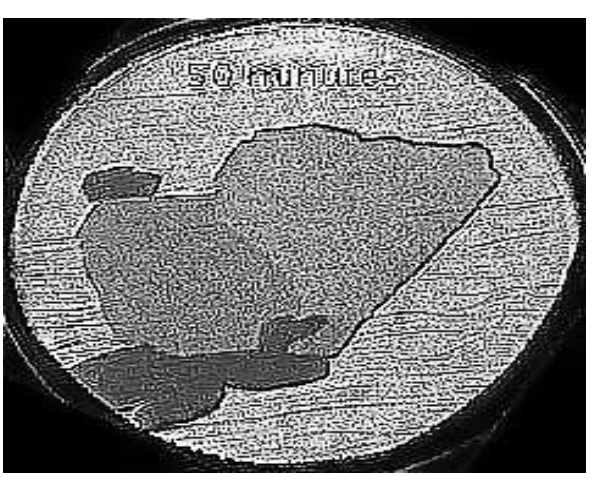

(g) Wiener + NLM3D-LBP-MSB

Fonte: Adaptada de Rogge et al. (2015). 
Figura 53 - A plicação da combinação do método CLSF com os filtros de ruído na imagem LEEM Graphene.

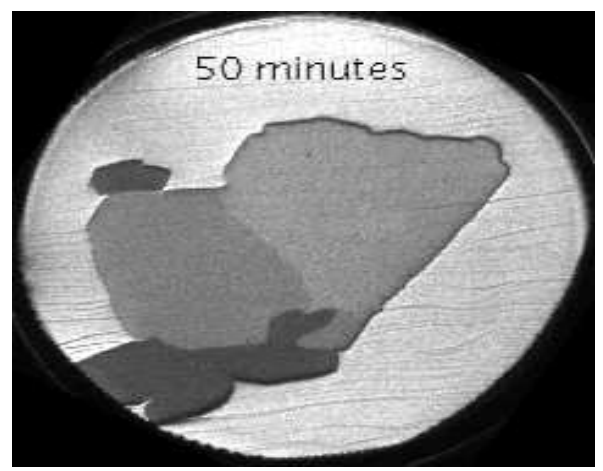

(a) Graphene (Original)

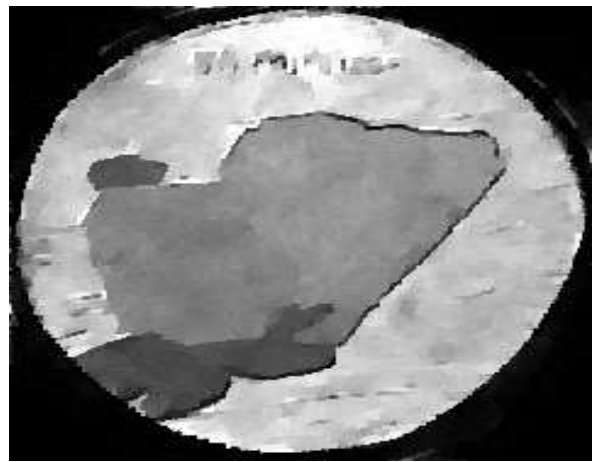

(b) $\mathrm{CLSF}+\mathrm{TV}$

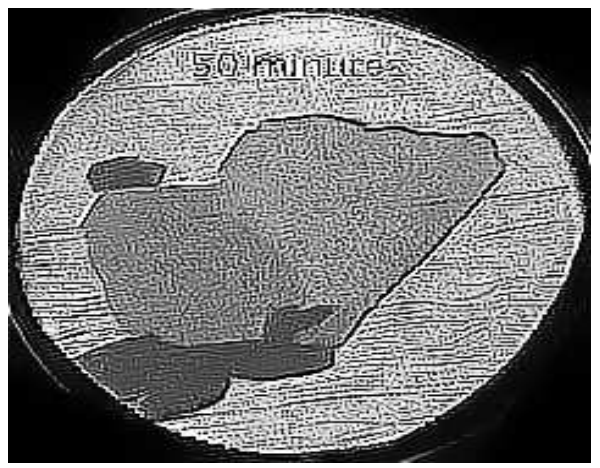

(d) $\mathrm{CLSF}+\mathrm{NLM}$

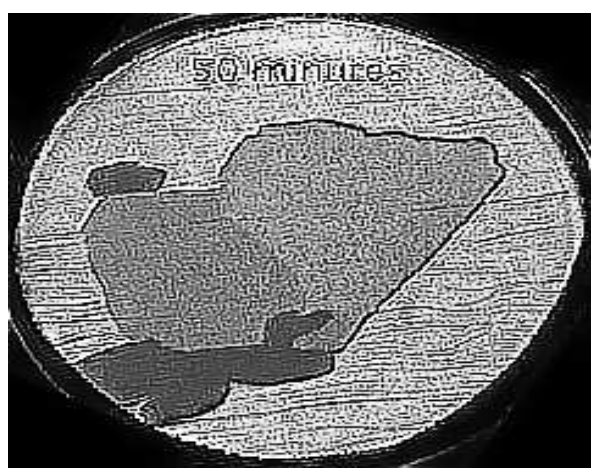

(f) CLSF + NLM3D-LBP-Adaptive

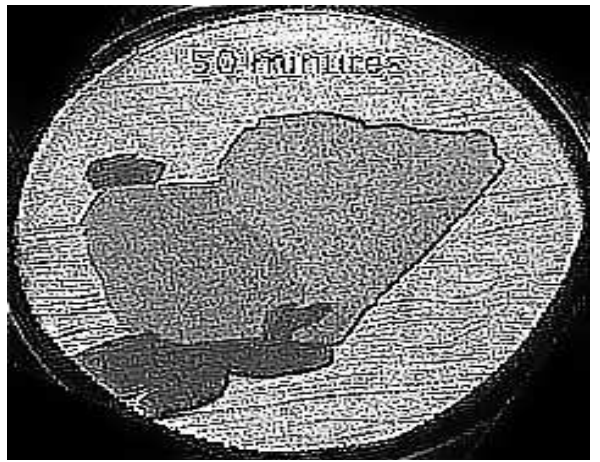

(c) $\mathrm{CLSF}+\mathrm{BF}$

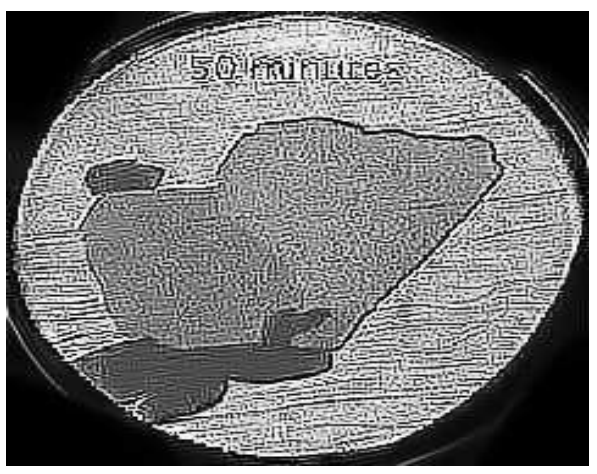

(e) CLSF + BM3D

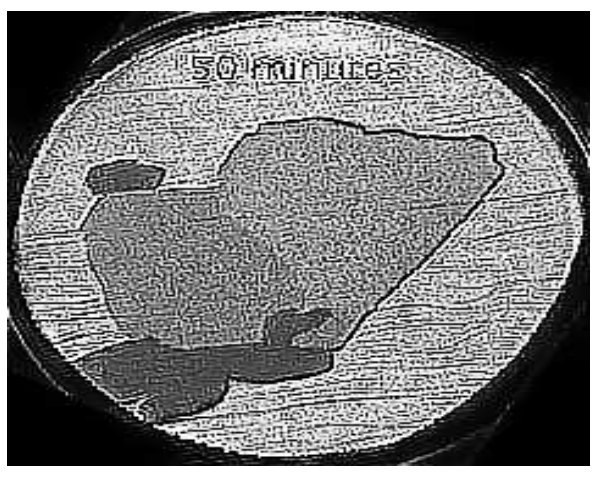

(g) $\mathrm{CLSF}+$ NLM3D-LBP-MSB

Fonte: Adaptada de Rogge et al. (2015). 
Figura 54 - A plicação da combinação do método Wiener com os filtros de ruído na imagem LEEM NiAl2.

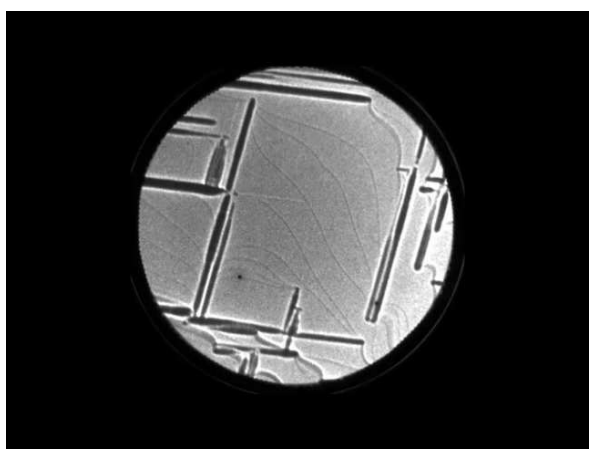

(a) NiAl2 (Original)

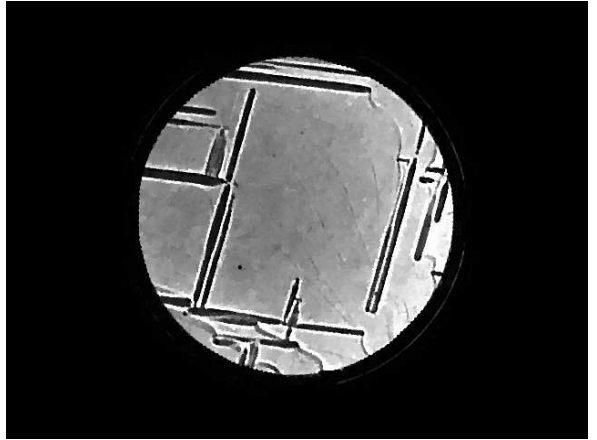

(b) Wiener + TV

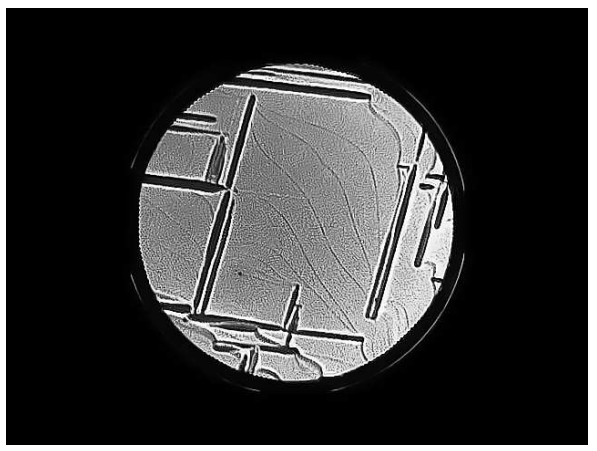

(d) Wiener + NLM

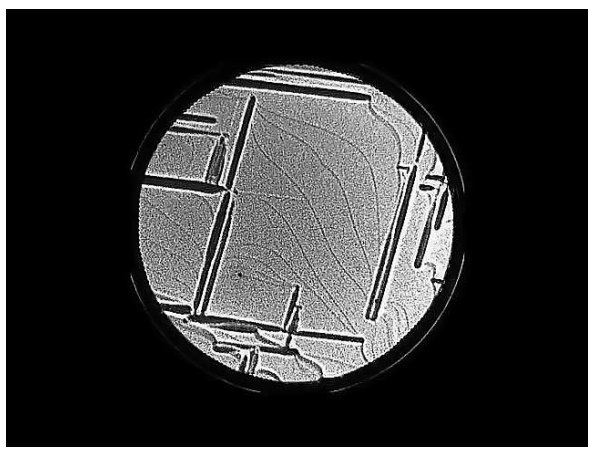

(f) Wiener + NLM3D-LBP-Adaptive

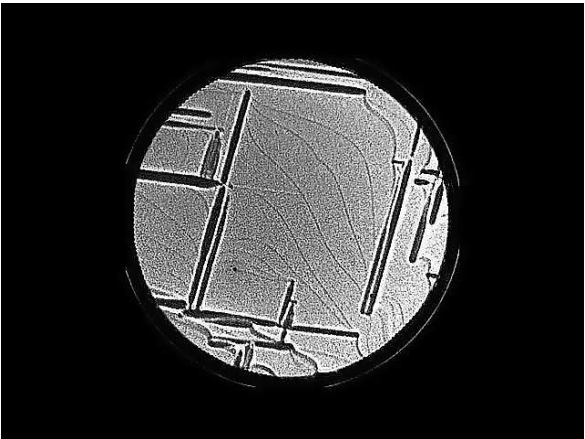

(c) Wiener + BF

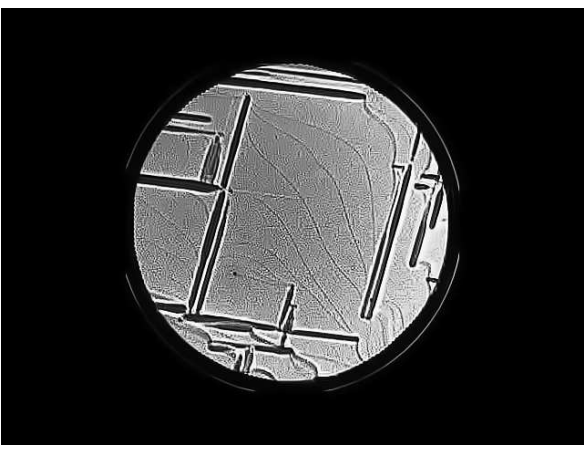

(e) Wiener + BM3D

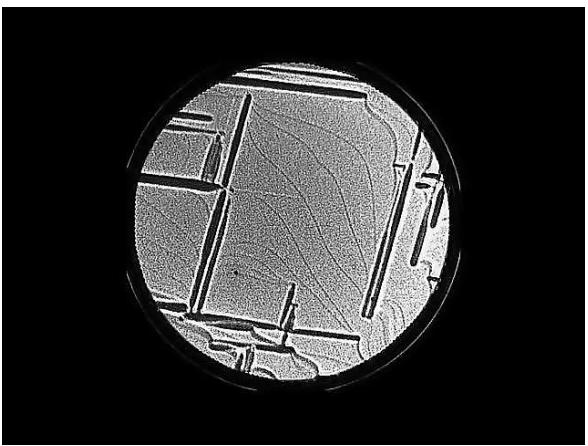

(g) Wiener + NLM3D-LBP-MSB

Fonte: Adaptada de Qin et al. (2015). 
Figura 55 - Aplicação da combinação do método CLSF com os filtros de ruído na imagem LEEM NiAl2.

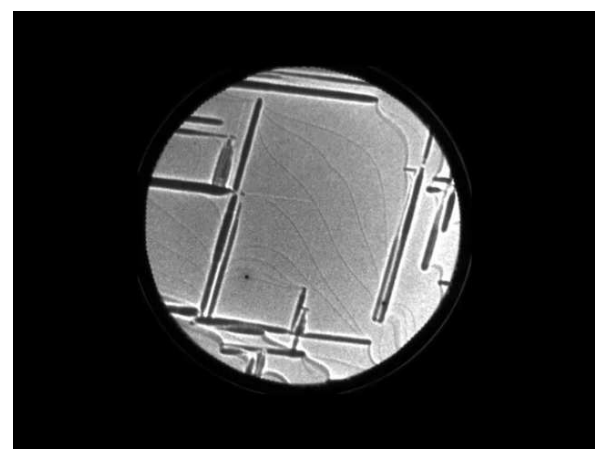

(a) NiAl2 (Original)

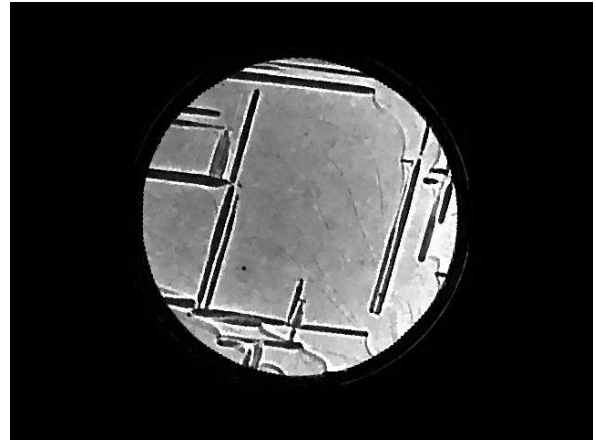

(b) $\mathrm{CLSF}+\mathrm{TV}$

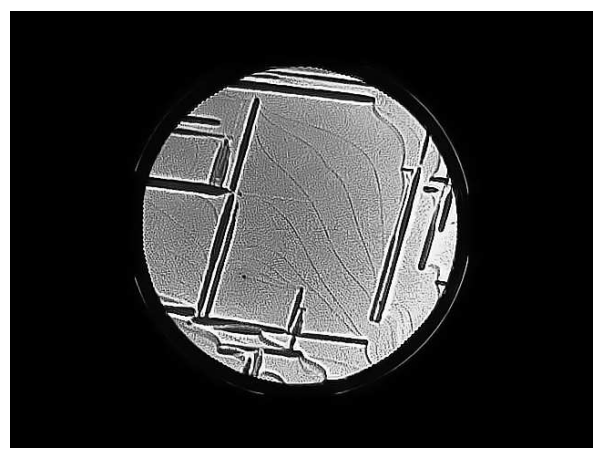

(d) $\mathrm{CLSF}+\mathrm{NLM}$

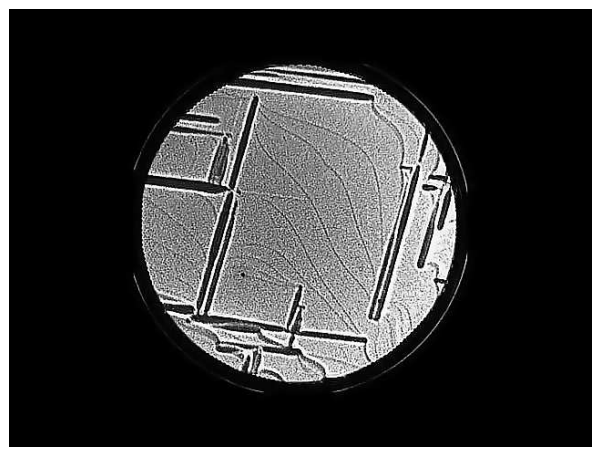

(f) CLSF + NLM3D-LBP-Adaptive

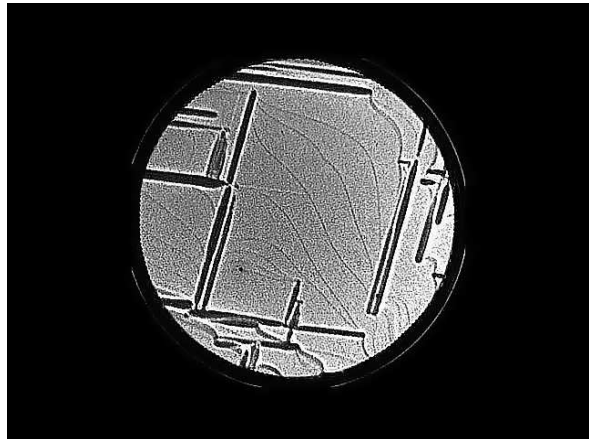

(c) $\mathrm{CLSF}+\mathrm{BF}$

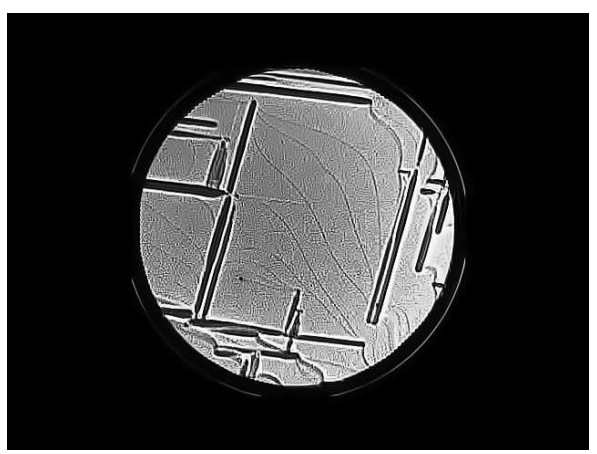

(e) $\mathrm{CLSF}+\mathrm{BM} 3 \mathrm{D}$

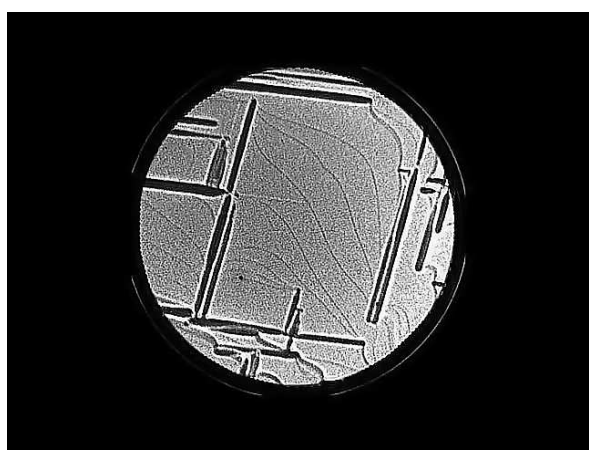

(g) CLSF + NLM3D-LBP-MSB

Fonte: Adaptada de Qin et al. (2015). 
Figura 56 - Aplicação da combinação do método Wiener com os filtros de ruído na imagem LEEM Neel_Z.

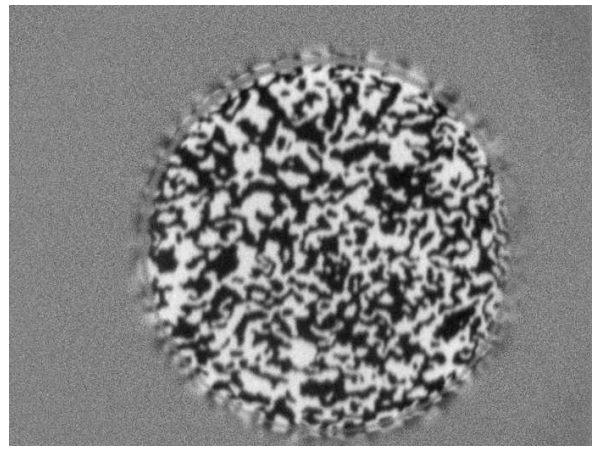

(a) Neel_Z (Original)

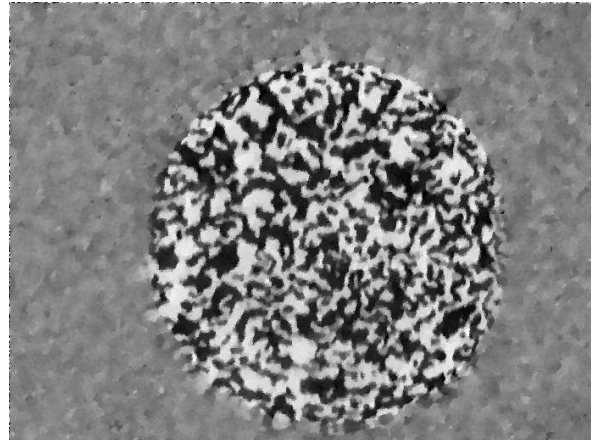

(b) Wiener + TV

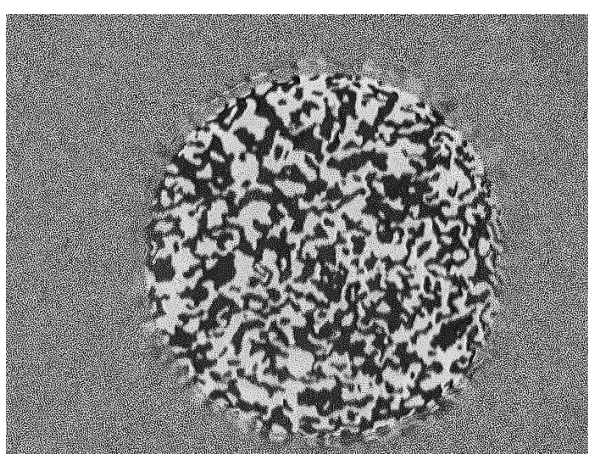

(d) Wiener + NLM

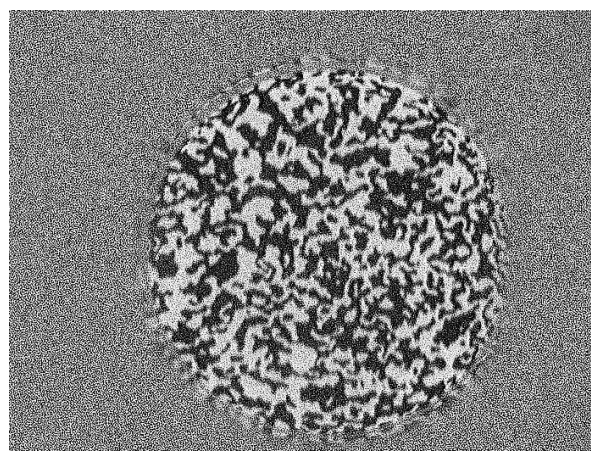

(f) Wiener + NLM3D-LBP-Adaptive

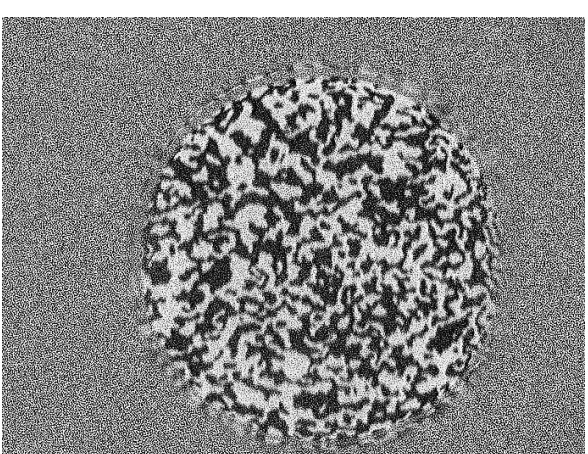

(c) Wiener + BF

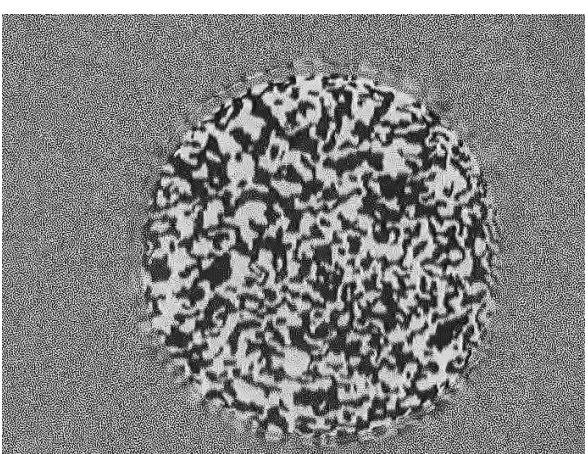

(e) Wiener + BM3D

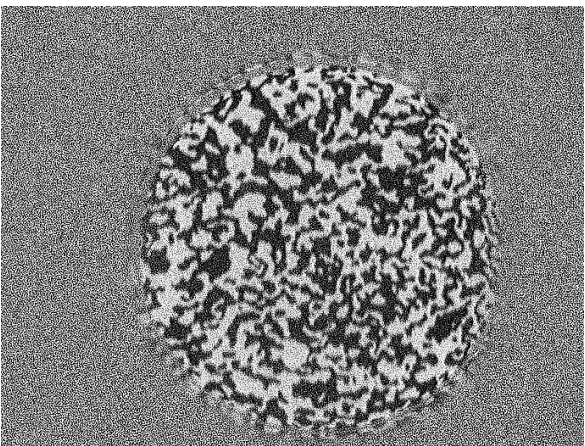

(g) Wiener + NLM3D-LBP-MSB

Fonte: Adaptado das imagens cedidas pelo professor Dr. Gong Chen. 
Figura 57 - Aplicação da combinação do método CLSF com os filtros de ruído na imagem LEEM Neel_Z.

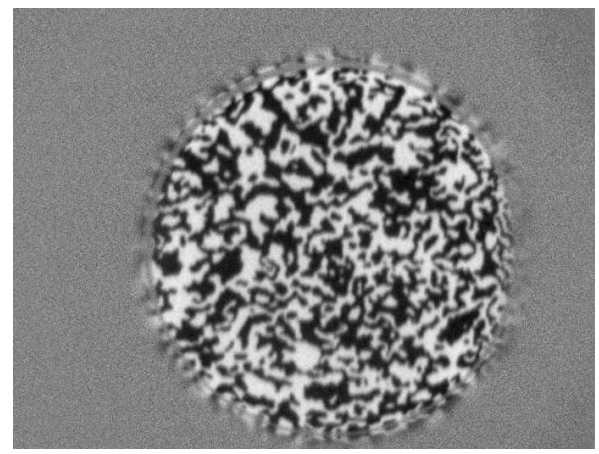

(a) Neel_Z (Original)

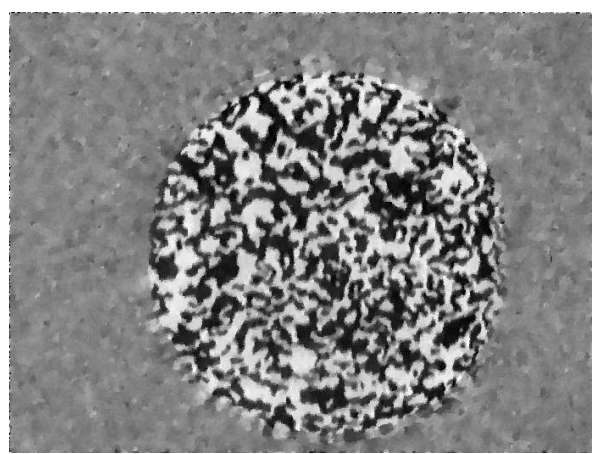

(b) CLSF + TV

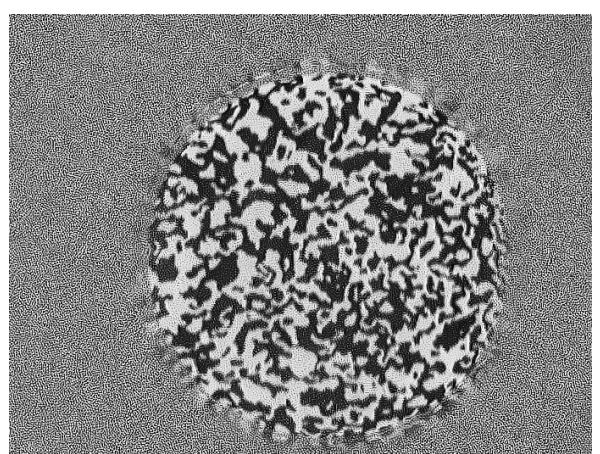

(d) $\mathrm{CLSF}+\mathrm{NLM}$

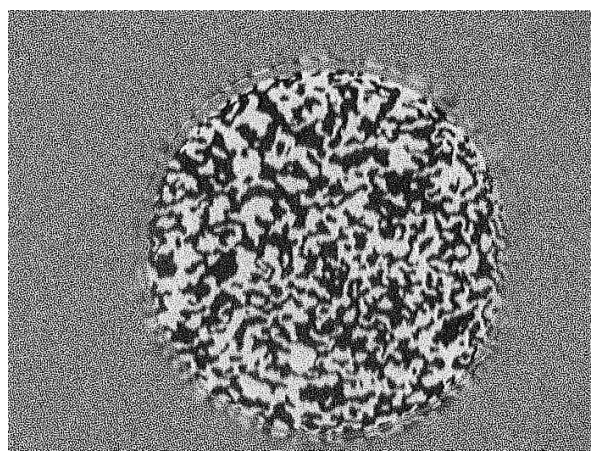

(f) CLSF + NLM3D-LBP-Adaptive

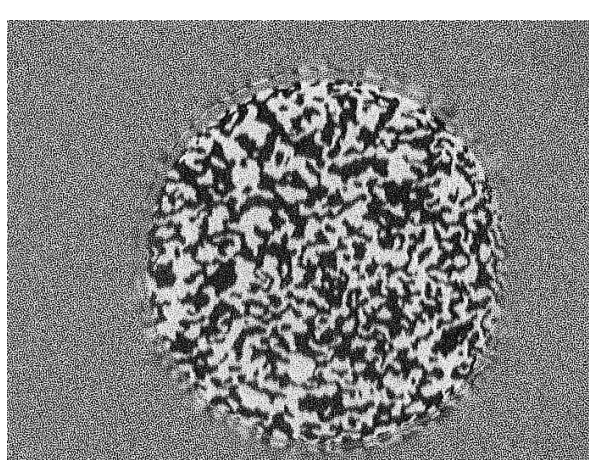

(c) $\mathrm{CLSF}+\mathrm{BF}$

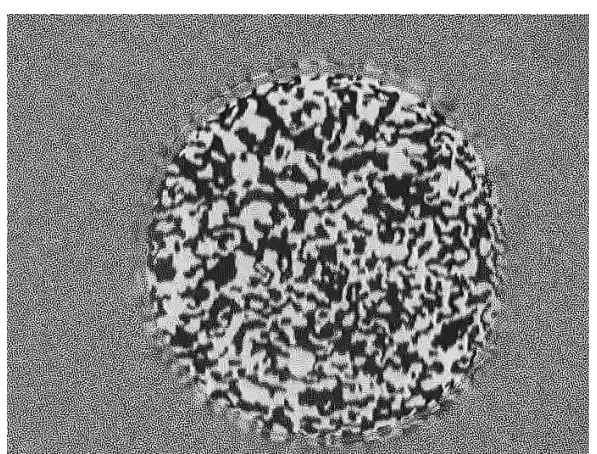

(e) $\mathrm{CLSF}+\mathrm{BM} 3 \mathrm{D}$

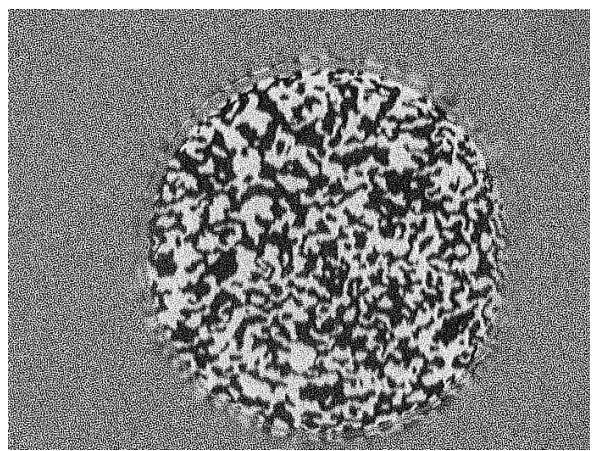

(g) CLSF + NLM3D-LBP-MSB

Fonte: Adaptado das imagens cedidas pelo professor Dr. Gong Chen. 